DOE/ID--10301

DE91 004710

\title{
ENERGY MINIMIZATION OF SEPARATION PROCESSES USING CONVENTIONAL/MEMBRANE \\ HYBRID SYSTEMS
}

\section{Final Report}

Douglas E. Gottschlich

Daryl L. Roberts

September 28, 1990

\author{
SRI International \\ 333 Ravenswood Avenue \\ Men lo Park, CA 94025-3493 \\ SRI Project 6519
}

Prepared for EG\&G Idaho, Inc. Under Subcontract No. C88-101848 and the U.S. Department of Energy Under Contract No. DE-ACO7-76ID01570 


\section{EXECUTIVE SUMMARY}

The purpose of this study was to identify the general principles governing the choice of hybrid separation systems over straight membrane or straight nonmembrane systems and to do so by examining practical applications (process design and economics). Our focus was to examine the energy consumption characteristics and overall cost factors of the membrane and nonmembrane technologies that cause hybrid systems to be preferred over nonhybrid systems. From this basis, we have recommended to DOE areas for further research that, if explored, would enhance the likelihood of commercially realizing the energy savings that are possible with hybrid membrane systems.

We evaluated four case studies, chosen on the basis of likelihood of commercial viability of a hybrid system and magnitude of energy savings: (1) propane/propylene separation; (2) removal of nitrogen from natural gas; (3) concentration of Kraft black liquor; and (4) solvent deasphalting. For propane/propylene splitting, the membrane proved to be superior to distillation in both thermodynamic efficiency and processing cost (PC) when the product was $95 \%$ pure propylene. Iowever, to produce higher purity products, the membrane alone could not perform the separation, and a membrane/distillation hybrid was required. In these cases, there is an optimum amount of separation to be accomplished by the membrane (expressed as the fraction of the total availability change of the membrane/distillation hybrid that takes place in the membrane and defined as $\phi_{\mathrm{m}}$, the thermodynamic extent of separation).

For nitrogen-methane separation, we considered membranes and pressure swing adsorption (PSA). We found that membrane technology alone gave the best economic performarce for many conditions of interest. Because the feed gas is at pressure, only a single-membrane stage was needed for the base case $\left(\mathrm{N}_{2} / \mathrm{CH}_{4}\right.$ selectivity $\left.=5\right)$. For high nitrogen contents $\left(>40 \% \mathrm{~N}_{2}\right)$ or low feed pressures ( $<600$ psia), a hybrid system had the best economic performance.

In our study of Kraft black liquor (KBL), we compared concentration by reverse osmosis (RO) with concentration by freeze drying and/or evaporation. Evaporation alore was the process of choice because of its low capital cost and economical energy source. Its energy consumption was, however, the highest of any of the three technologies or of any hybrid. A hybrid of RO with evaporation would be the least expensive process if membrane costs could be reduced below $\$ 1 / \mathrm{ft}^{2}$ of if steam costs exceeded $\$ 5$ per million Btu. 
In the fourth, we examined evaporation (EV) and ultrafiltration (UF) as a means for removing solvent from light oils in a solvent deasphalting process. We found that the least costly system is a hybrid UF/EV system wherein $35 \%$ of the separation work is done in the UF portion of the process. Energy recovery schemes are possible for the evaporation system that would make it more efficient and shift the optimum amount of separative work to be done by the membrane.

From these four case studies and intuitive reasoning, we developed qualitative and quantitative guidelines that answer the question "Is there a good chance that a hybrid process would be the process of choice at practical operating conditions?" Of these guidelines (Table ES-1), perhaps the most surprising, yet simple, result is given as quantitative guideline number (1). It is unlikely that the membrane hybrid would be preferred over either the mermbrane or nonmembrane technology alone unless the membrane (accomplishing the entire separation by itself) would use one-third or less of the energy used by the nonmembrane technology (accomplishing the entire separation by itself).

By looking for large-energy-consuming processes that are likely to be served by membrane hybrid systems, we identified 10 systems worth further studies (Table ES-2). The olefin applications topping this list are well known to be difficult separations and large energy consumers. Commercialization of a hybrid technology for propylene/propane or ethylene/ethane separation would result in measurable national energy savings. 


\section{Table ES-1 \\ GUIDELINES FOR ASSESSING \\ LIKELIHOOD OF SUCCESS OF HYBRID SYSTEMS}

\section{Qualitative Guldellnes}

(1) A hybrid is likely to be successful when there are driving force limitations in one or both membrane/nonmembrane technologies.

(2) A hybrid is likely to be successful when there is a point-wise variation in the separation factor (e.g., relative volatility, distribution coefficient, membrane selectivity).

(3) A hybrid is likely to be successful when a reversal of the minor component is possible and the two technologies act on different components.

(4) A hybrid is likely to be successful when the membrane fails to produce the required product purity on its own but has some of the following advantages:

(a) The membrane better utilizes energy contained in the feed.

(b) The membrane transfers less material.

(c) The membrane accomplishes its portion of the separation in a single stage.

(d) The membrane avoids a phase change associated with the nonmembrane technology.

(e) The traditional technology does not involve energy recovery schemes.

(f) The membrane reduces the total residence time of the process.

(g) The membrane allows process streams to exist as liquids.

(h) The membrane decreases capital investment needed to supply the driving force for the separation process.

(i) The membrane reduces the size of downstream equipment.

(5) A hybrid is not likely' to be successful when the membrane does not make the desired final purity in at least one of its outlet streams.

\section{Quantltative Guidelines}

(1) A hybrid is favored when

$A_{s e p}(m e m b)<1 / 3^{*} A_{s e p}$ (nonmemb) and $C C_{\text {sep }}$ (memb) $>C C_{\text {sep }}$ (nonmemb).

(2) A hybrid is favored when

$G>1$. 
Table ES-2

SYSTEMS RECOMMENDED FOR EXPERIMENTAL STUDY

\section{System}

1) Propane/propylene separation

2) Ethane/ethylene separation

3) Sour water stripping

4) Inorganic acid dehydration

5) Natural gas dehydration

6) Deasphalting of oil

7) Acetic acid dehydration

8) Ammonia manufacturing

9) Methyl tertiary-butyl ether manufacture

10) Urea manufacture

\section{Potentlal Energy Saving} $\left(10^{12}\right.$ Btu/yr)

13

6

6

5

$10-20$

10

3

2

1-2

1- 2 


\section{CONTENTS}

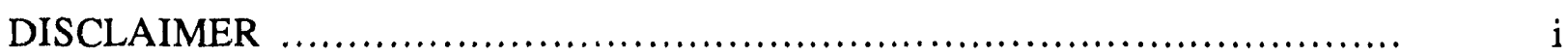

EXECUTIVE SUMMARY ...................................................

CONTENTS ....................................................................... vii

CHAPTER I: INTRODUCTION AND OBJECTIVES .......................... I-1

CHAPTER II: SELECTION OF CASE STUDIES ............................. II-1

Industrial Applications ...................................................... II 1

Case Siudy Selection Criteria .................................................... II-2

Case Study Candidates ......................................................... II 4

Removal of $\mathrm{N}_{2}$ from Natural Gas ..................................... II-5

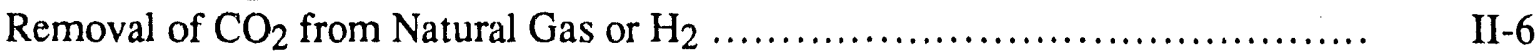

Removal of Solvent Vapors from Air ....................................... II-7

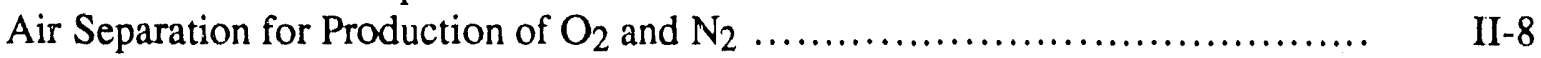

Separation of Propane/Propylene Mixtures ............................... II-8

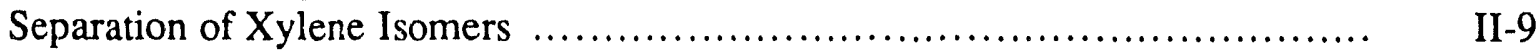

Ethannl Dehydration ................................................... II 9

Kraft Black Liquor Concentration ........................................ II-10

Concentration of Thin Beet Juice ......................................... II-10

Refining of Edible Oils .............................................. II-11

Solvent Recovery in Deasphalting ............................................... II-11

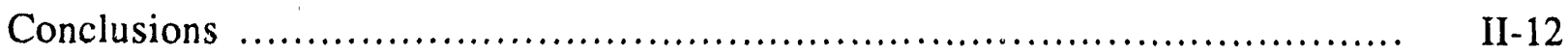

CHAPTER III: EVALUATION PROCEDURES ................................. III-1

Identification and Selection of Candidate Hybrid Systems ........................... III-1

Process Simulation .............................................................. III-1

Thermodynamic Evaluation ............................................................. III-2

Economic Evaluation .................................................................. III-4

Simulation Procedure ......................................................... III-4

CHAPTER IV: CASE STUDY 1 - PROPYLENE/PROPANE SEPARATION ....... IV-1

Process Description and Modeling ................................................. IV-1

Membrane Process Description .......................................................... IV

Membrane Process Model ..................................................... IV-8

Distillation Process Description ........................................................... IV-9

Distillation Process Model ................................................................... IV 9

Hybrid Process Description ............................................................. IV -12

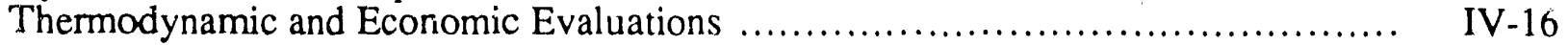




\section{CONTENTS - (Continued)}

Base Case Evaluations …............................................... IV-16

Sensitivity Analysis

IV-21

Production of $99.5 \%$ and $99.9 \%$ Propylene ........................... IV-21

Membrane Properties ............................................. IV-21

Conclusions

IV-28

CHAPTER V: CASE STUDY 2 - REMOVAL OF NITROGEN

FROM NATURAL GAS

Process Description and Modeling ..................................................... V-2

Membrane Process .................................................... V-2

Pressure Swing Adsorption ............................................ V-5

Hybrid Processes ......................................................... V-6

Thermodynamic Evaluation ................................................... V-8

Economic Evaluation ............................................................... V-8

Base Case Evaluations ....................................................... V-9

Membrane System ................................................... V-9

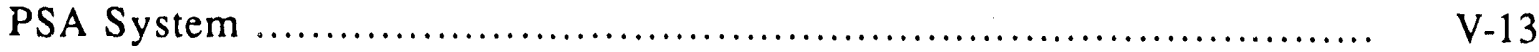

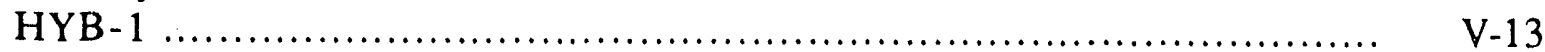

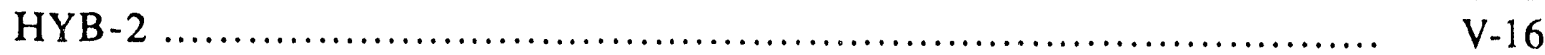

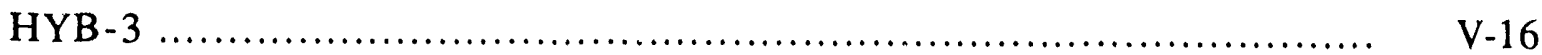

Comparison of Base Case Systems ...................................... V-18

Effect of Key Process Parameters .............................................. V-20

Feed Composition .................................................... V-20

Feed/Product Pressure ................................................ V-22

Membrane Selectivity ................................................... V-23

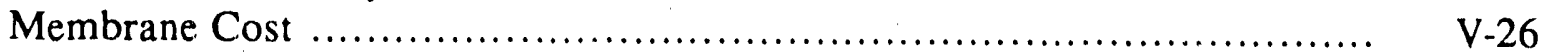

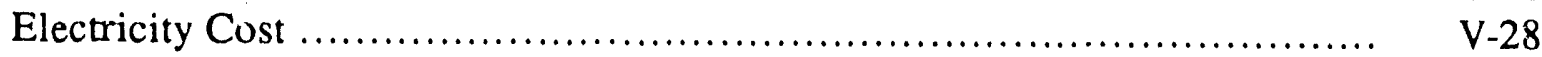

Product Recovery ...................................................... V-28

Summary of Process Parameter Results .................................... V-31

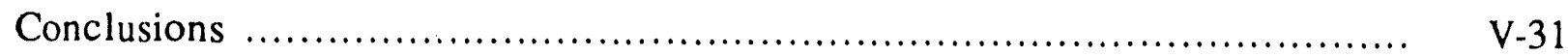

CHAPTER VI: CASE STUDY 3 - CONCENTRATION OF KRAFT

BLACK LIQUOR

VI-1

Process Description and Modeling .............................................. VI-5

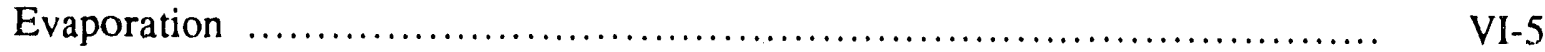

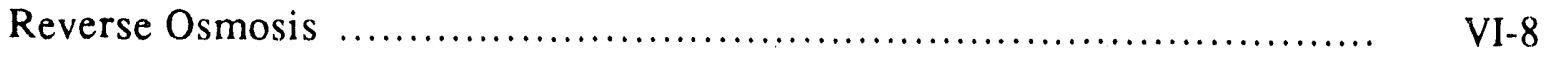

Freeze Concentration ....................................................... VI-11

Hybrid Processes ......................................................... VI-14 


\section{CONTENTS - (Continued)}

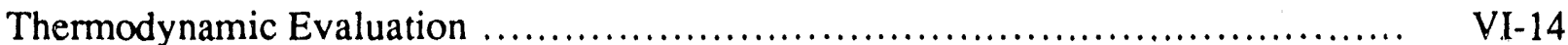

Economic Evaluation ............................................................ VI-16

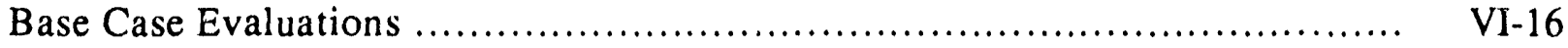

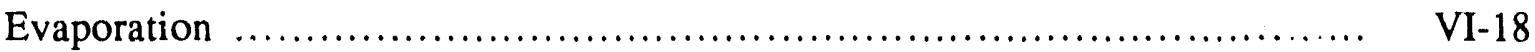

Reverse Osmosis/Evaporation ......................................... VI-22

Freeze Concentration/Evaporation ...................................... VI-22

Reverse Osmosis/Freeze Concentration/Evaporation ....................... VI-24

Comparison of Base Case Systems ..................................... VI-26

Effect of Thermodynamic Extent of Separation .................................. VI-26

Effect of Key Process Parameters .......................................... VI-30

Solids Rejection ...................................................... VI-30

Membrane Cost ...................................................... VI-35

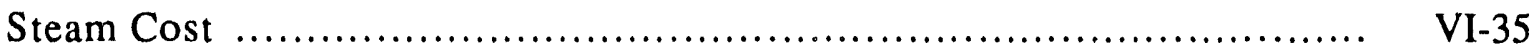

Electricity Cost ................................................... VI-38

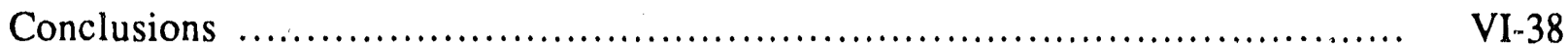

CHAPTER VII: CASE STUDY 4 - SOLVENT DEASPHALTING ................ VII-1

Process Description and Modeling ........................................ VII-3

Evaporation Process ................................................... VII-4

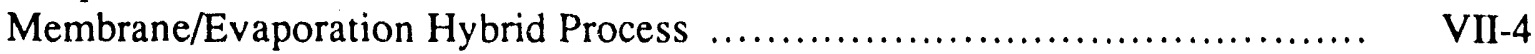

Thermodynamic Evaluation ............................................... VII-10

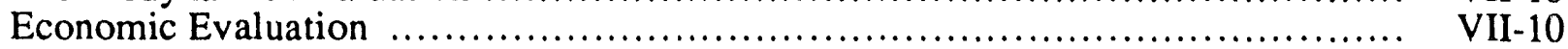

Base Case Evaluations ............................................................. VII-10

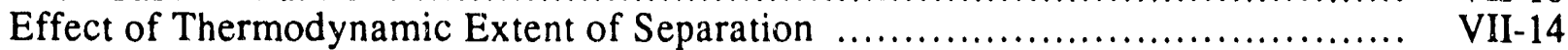

Effect of Heat Recovery ........................................................ VII-17

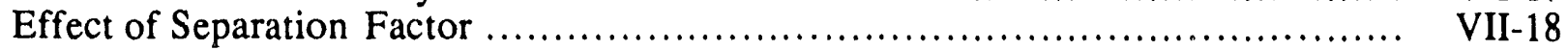

Effect of Solvent Composition ................................................. VII-21

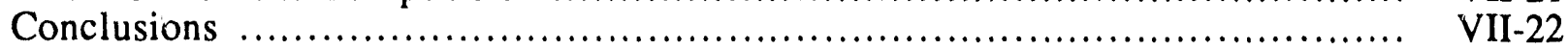

CHAPTER VIII: GUIDELINES FOR ASSESSING LIKELIHOOD OF

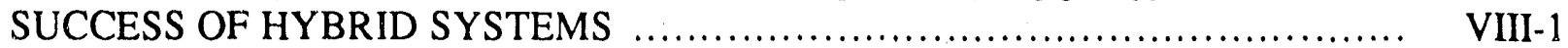

Statement of Guidelines .................................................. VIII-1

Rationale of Qualitative Guidelines ............................................ VIII-3

Direct Strength/Weakness Guidelines ............................................ VIII-3

Implicit Strength/Weakness Guidelines ....................................... VIII-5

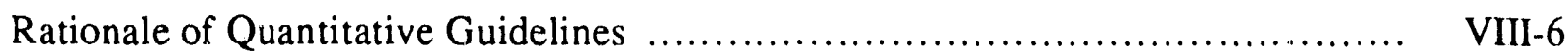


CONTENTS - (Concluded)

CHAPTER IX: RECOMENDATIONS FOR EXPERIMENTAL STUDIES ............. IX-1

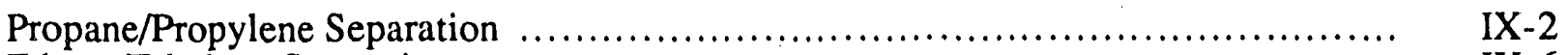

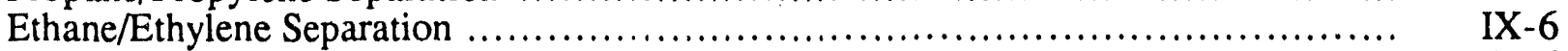

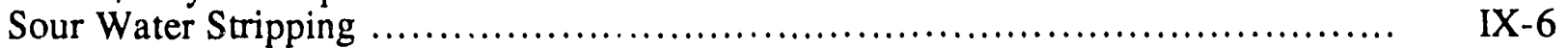

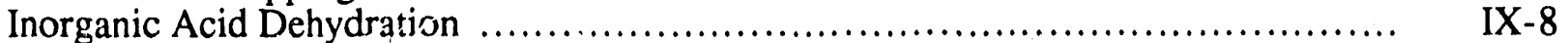

Natural Gas Dehydration ........................................................... IX-9

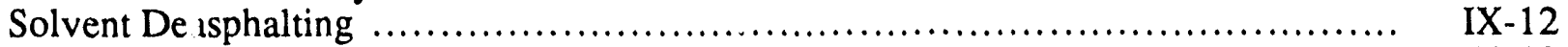

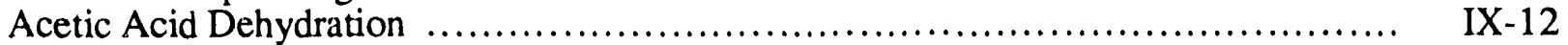

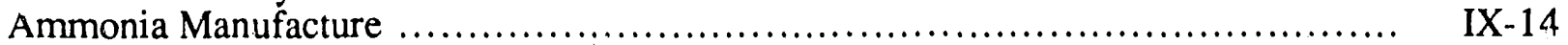

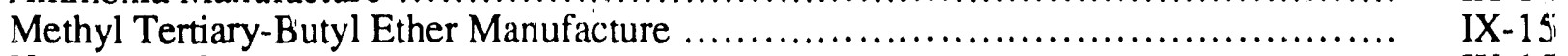

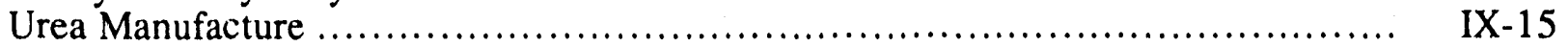

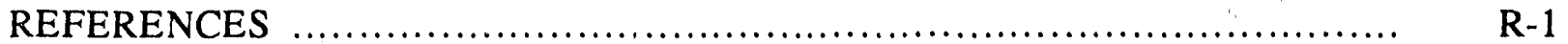

APPENDIX A - DETAILED PROCESS FLOW CONDITIONS AND COST

BREAKDOWNS FOR CASE STUDY 1 - PROPYLENE/PROPANE SPLITTING ... A A-1

APPENDIX B - UTILITY KEQUIREMENTS AND COST BREAKDOWNS

FOR CASE STUDY 2 - NITROGEN REMOVAL FROM NATURAL GAS .......... B-1

APPENDIX C: UTILITY REQUIREMENTS AND COST BREAKDOWNS

FOR CASE STUDY 3 - CONCENTRATION OF KBL ........................... C C

APPENDIX D: DISTILLATION DATA, UTILITY REQIJIREMENTS, AND

COST BREAKDOWNS FOR CASE STUDY 4 -SOLVENT DEASPHALTING ..... D -1 


\section{FIGURES}

III-1 Flow diagram showing procedure for calculating the processing cost ....... III-5

IV-1 Propylene from propane by catalytic dehydrogenation ....................... IV-2

IV-2 Inlet and outlet conditions for propylene/propane separation system .......... IV-4

IV-3 Transport mechanisms for propylene/propane separation in a facilitated transport membrane

IV-4 Membrane system for production of 95\% pure propylene ..................... IV-7

IV-5 Distillation system for production of $95 \%$ pure propylene $\ldots \ldots \ldots \ldots \ldots \ldots . \quad$ IV -11

IV-6 Hybrid configurations for propylene separation ......................... IV 13

IV-7 Hybrid system for production of 95\% pure propylene ........................ IV-15

IV-8 Overall, membrane, and distillation section thermodynamic efficiency and processing cost for stand-alone and hybrid propylene/propane separation systems

IV-9 Overall EFFs and PCs for separation systems producing 95\%, 99.5\%, and $99.9 \%$ propylene

IV-22

IV-10 Selectivity of FT membrane versus feed-side composition for propylene/propane separation

IV-24

IV-11 Relative volatilities of propylene over propane versus position

Selectivity of FT membranes with various silver concentrations for propylene/propane separation

IV-13 Overall, membrane, and distillation section EFFs for production of $95 \%$ propylene, using a membrane containing $1 \mathrm{~mol} / \mathrm{L}$ silver

IV-27

IV-14 Overall EFFs and PCs for separation of propylene and propane with silver concentrations of 1 and $2 \mathrm{~mol} / \mathrm{L}$

$\mathrm{V}-1 \quad$ Membrane configurations used for gas separation

V-4

V-2 Hybrid and nonhybrid separation systems for upgradıng subquality natural gas

V-3 Effect of feed composition on $\mathrm{PC}$ and $\mathrm{A}_{\mathrm{util}}$ for $\mathrm{N}_{2}$ recovery

$\mathrm{V}-21$

V-4 Effect of feed/product pressure on $\mathrm{PC}$ and $\mathrm{A}_{\text {util }}$ for $\mathrm{N}_{2}$ recovery

$\mathrm{V}-24$

V-5 Effect of membrane selectivity on $P C$ and $A_{u u l}$ for $\mathrm{N}_{2}$ recovery

$\mathrm{V}-25$

V-6 Effect of membrane cost on $\mathrm{PC}$ and $\mathrm{A}_{\mathrm{util}}$ for $\mathrm{N}_{2}$ recovery

V-27

$\mathrm{V}-7$ Effect of electricity cost on $\mathrm{PC}$ for $\mathrm{N}_{2}$ recovery

V-29

V-8 Effect of unrecovered methane value on $P C$ and $A_{u t i l}$ for $\mathrm{N}_{2}$ recovery .....

$\mathrm{V}-30$

VI-1 Kraft pulping process

$\mathrm{VI}-2$ 


\section{FIGURES - (Continued)}

VI-2 Steam balance for an integrated palp and paper plant ................ VI-4

VI-3 Six-effect evaporator for KBL concentration .............................. VI-7

VI-4 Two-stage reverse osmosis system for KBL concentration ............... VI-12

VI-5 Freeze concentration system for concentration of KBL ............... VI-13

VI-6 Hybrid processes for concentration of KBL ............................ VI-15

VI-7 Relationship between percent solids in the concentrated KBL stream and thermodynamic extent of separation

VI-17

VI-8 Processing cost for KBL concentration using various hybrid systems ...... VI-27

VI-9 Triangular diagram for display of thernodynamic and economic results .... VI-29

VI-10 Processing cost for KBL concentration systems ................................ VI-31

VI-11 Availability consumption by utilities for KBL concentration systems ......... VI-32

VI-12 Effect of solute rejection on PC for KBL concentration (RO/EV) ........ VI-33

VI-13 Effect of solute rejection on $A_{u t i l}$ for KBL concentration (RO/EV) ........ VI-34

VI-14 Effect of membrane cost on PC for KBL concentration (RO/EV) ........ VI-36

VI-15 Effect of steam cost on PC for KBL concentration .................... VI-37

VI-16 Effect of electricity cost on PC for KBL concentration ...................... VI-39

VII-1 Solvent deasphalting process ..................................... VII-2

VII-2 Conventional process for primary solvent recovery ..................... VII-5

VII-3 Membrane/evaporation hybrid process for primary solvent recovery ........ VII-7

VII-4 Relationship between DAO mass fraction in membrane residue and $\phi_{\mathrm{m}}$ for propane

VII-11

VII-5 Effect of $\phi_{m}$ on PC and utility availability consumption for solvent deasphalting

VII-15

VII-6 Capital cost and solvent vapor flow as a function of $\phi_{m}$ for solvent deasphalting

VII-16

Vil-7 Effect of $\phi_{\mathrm{m}}$ on PC and availability consumption with various heat recoveries, $\mathrm{Q}$, for solvent deasphalting

VII-19

VII-8 Effect of $\phi_{\mathrm{m}}$ and separation factor $(\alpha)$ on PC and availability consumption for solvent deasphalting

VII-20

VII-9 Effect of $\phi_{m}$ on PC and availability consumption with and without heat recovery using pentane as solvent for solvent deasphalting

VII-23

VII-10 Relationship between DAO mass fraction and $\phi_{\mathrm{m}}$ for propane and pentane 


\section{FIGURES - (Concluded)}

VII-11 Comparison of propane and pentane based solvent deasphalting systems

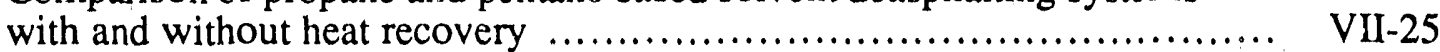

VIII-1 Differences in thermodynamic efficiency between the membrane and distillation sections of a hybrid separation systam .................... VIII-9

IX-1 Hybrid configuration for propylene separation ........................ IX-5

IX-2 Membrane-assisted recovery of $\mathrm{NH}_{3}$ and $\mathrm{H}_{2} \mathrm{~S}$ from sour water .............. IX-7

IX-3 Membrane process for dehydration of natural gas ....................... IX-10

IX-4 Membrane-assisted glycol dehydration plant ......................... IX-11

IX-5 Hybrid process for dehydration of acetic acid ............................. IX-13

IX-6 Pervaporation/distillation hybrid in the MTBE manufacturing process ..... IX-16 


\section{TABLES}

ES-1 Guidelines for Assessing Likelihood of Success of Hybrid Systems .......... v v

ES-2 Systems Recommended for Experimental Study ................................... vi

II-1 Total Purchased Fuels and Electricity in 1981 .................................. II-2

II-2 Case Study Candidates ........................................... II -5

II-3 Evaluation of Wanc: idate Applications for Use as Hybrid System Case Studies . II-13

III-1 General Parameters for Economic Evaluations ............................ III-6

IV-1 Assumptions Used in Development of Mudel of Membrane Module for Propylene/Propane Separation ........................................ IV-10

IV-2 Membrane Properties Used in Thermodynamic and Economic Evaluations for Propylene/Propane Separation ....................................... IV 10

IV-3 Assurnptions Used in Distillation Column Simulation of Propylene/Propane Separation ........................................ IV-12

IV-4 Parameters $f_{1} \cdot$ Economic Evaluation of Propylene/Propane Hybrid Systems ... IV-16

IV-5 Energy Re . direments for Propylene/Propane Separation ..................... IV-18

IV-6 Economic Results for Propylene/Propane Separation ....................... IV-18

V-1 Membrane Properties Used in Economic and Thermodynamic Evaluations of $\mathrm{N}_{2}$ Removal .......................................... V-3

V-2 Operating Conditions Used in Economic and Thermodynamic Evaluations of $\mathrm{N}_{2}$ Removal ...................................... V-10

$\mathrm{V}-3 \quad$ Stream Conditions for $\mathrm{N}_{2}$ Removal with Membrane Technology .............. V-11

$\mathrm{V}-4 \quad$ Economic Results for $\mathrm{N}_{2}$ Removal ................................ $\mathrm{V}-12$

$\mathrm{V}-5$ Thermodynamic Results for $\mathrm{N}_{2}$ Removal ...................................... $\mathrm{V}-12$

V-6 Stream Conditions for $\mathrm{N}_{2}$ Removal with PSA Technology Alone ................ V-14

V-7 Stream Conditions for $\mathrm{N}_{2}$ Removal with HYB-1 Technology ................ V-15

$\mathrm{V}-8$ Stream Conditions for $\mathrm{N}_{2}$ Removal with HYB-2 Technology ................ V-17

V-9 Stream Conditions for $\mathrm{N}_{2}$ Removal with HYB-3 Technology ................ V-17

VI-1 Major Components of Kraft Black Liquor ............................... VI-6

VI-2 Assumptions Used in Economic Evaluations for KBL Concentration ........ VI-18

VI-3 Stream Conditions for KBL Concentration with Evaporation Technology Alone ........................................ VI-19

VI-4 Energy Requirements for KBL Concentration with Hybrid Processes .... VI-20

VI-5 Economic Results for KBL Concentration with Hybrid Processes ............. VI-21 


\section{TABLES - (Continued)}

VI-6 Stream Conditions for KBL Concentration with Reverse Osmosis and

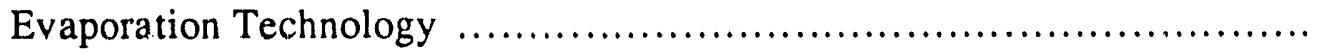

VI-7 Stream Conditions for KBL Consentration with Freeze Concentration and Evaporation Technology

VI-24

VI-8 Stream Conditions for KBL Concentration with Reverse Osmosis, Freeze Concentration, and Evaporation Technology

VII-1 Stream Conditions for Solvent Recovery in Solvent Deasphalting with Evaporation Technology Alone

VII-6

VII-2 Stream Conditions for Solvent Recovery in Solvent Deasphalting with Membrane/Evaporation Hybrid Technology

VII-3 Assumptions Used in Economic Evaluations for Solvent Deasphalting ....... VII-12

VIr-4 Energy Requirements for Solvent Recovery in Solvent Deasphalting ........... VII-13

VII-5 Economic Results for Solvent Recovery in Solvent Deasphalting .............. VII-13

VIII-1 Guidelines for Assessing Likelihood of Success of Hybrid Systems ........... VIII-2

VIIII-2 Energy Consumption and Capital Costs for Membrane and Traditional Unit Operations

VIII-8

IX-1 Top 50 Chemicals Produced in the United States in $1989 \ldots \ldots \ldots \ldots \ldots \ldots \ldots \ldots$ IX-3

IX-2 Systems Recommended for Experimental Study ................................ IX-4

A-1 Stream Conditions for Propylene/Propane Separation with Membrane Technology Alone

A-2 Utiiity Requirements for Propylene/Propane Separation with Membrane Technology Alone

A-3 Capital Investment for Propylene/Propane Separation with Memtr. ane Technology Alone

A-4 Propylene/Propane Separation with Membrane Technology Alone: Estimated Annual Operating Costs and Revenue Requirements

A-5 Stream Conditions for Propylene/Propane Separation with Distillation Technology Alone

A-6 Utility Requirements for Propylene/Propane Separation with Distillation Technology Alone

A-7 Capital Investment for Propylene/Propane Separation with Distillation Technology Alone

A-8 Propylene/Propane Separation with Distillation Technology Alone: Estimated Annual Operating Costs and Revenue Requirements 


\section{TABLES - (Continued)}

A-9 Stream Conditions for Propylene/Propane Separation with

Membrane/Distillation Hybrid Technology

A-11

A-10 Utility Requirements for Propylene/Propane Separation with

Membrane Technology Alone

A-12

A-11 Capital Investment for Propylene/Propane Separation with Membrane/Distillation Hybrid Technology Alone

A-13

A-12 Propylene/Propane Separation with Membrane/Distillation Hybria Technology: Estimated Annual Operating Costs and Revenue Requirements ..

A-14

B-1 Utility Requirements for $\mathrm{N}_{2}$ Removal with Membrane Technology Alone ...... B-3

B-2 Capital Investment for $\mathrm{N}_{2}$ Removal with Membrane Technology Alone .......... B-3

B-3 $\quad \mathrm{N}_{2}$ Removal with Membrane Technology: Estimated Annual Operating Costs and Processing Cost

B-4

B-4 Utility Requirements for $\mathrm{N}_{2}$ Removal with PSA Technology Alone ........... B-6

B-5 Capital Investment for $\mathrm{N}_{2}$ Removal with PSA Technology Alone

B-6

B-6 $\quad \mathrm{N}_{2}$ Removal with PSA Technology: Estimated Annual Operating Costs and Processing Cost

B-7

B-7 Utility Requirements for $\mathrm{N}_{2}$ Removal with HYB-1 ...................... B-9

B-8 Capital Investment for $\mathrm{N}_{2}$ Removal with HYB-1 ........................ B-9

B-9 $\quad \mathrm{N}_{2}$ Removal with HYB-1: Estimated Annual Operating Costs and Processing Cost

B-10

B-10 Utility Requirements for $\mathrm{N}_{2}$ Removal with HYB-2 …................... B-12

B-11 Capital Investment for $\mathrm{N}_{2}$ Removal with HYB-2 …................... B-12

B-12 $\mathrm{N}_{2}$ Removal with HYB-2: Estimated Annual Operating Costs and Processing Cost

B-13

B-13 Utility Requirements for $\mathrm{N}_{2}$ Removal with HYB-3 .......................

B-15

B-14 Capital Investment for $\mathrm{N}_{2}$ Removal with HYB-3

B-15

B-15 $\mathrm{N}_{2}$ Removal with HYB-3: Estimated Annual Operating Costs and Processing Cost

C-1 Utility Requirements for KBL Concentration with Evaporation Technology Alone

C-2 Capital Investment for KBL Concentration with Evaporation Technology Alone

C-3 KBL Concentration with Evaporation Technology: Estimated Annual Operating Costs and Processing Cost 


\section{TABLES - (Concluded)}

C-4 Utility Requirements for KBL Concentration with RO/EV Hybrid Technology ................................................... C-6

C-5 Capital Investment for KBL Concentration with RO/EV Hybrid Technology .................................................... C-6

C-6 Solvent Deasphalting with RO/EV Hybrid Technology: Estimated Annual Operating Costs and Processing Cost ............................ C-7

C-7 Utility Requirements for KBL Concentration with FC/EV

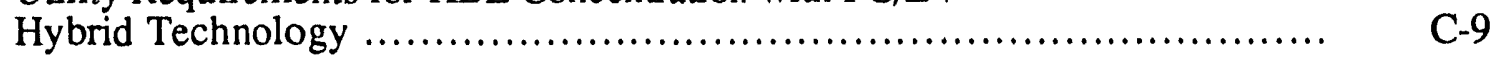

C-8 Capital Investment for KBL Concentration with FC/EV Hybrid Technology

C-9 KBL Concentration with FC/EV Hybrid Technology: Estimated Annual Operating Costs and Processing Cost ........................... C-10

C-10 Utility Requirements for KBL Concentration with RO/FC/EV Hybrid Technology .................................................. C-12

C-11 Capital Investment for KBL Concentration with RO/FC/EV Hybrid Technoiogy

C-12 KBL Concentration with RO/FC/EV Hybrid Technology: Estimated Annual Operating Costs and Processing Cost

D-1 Distillation Data for Deasphalted Oil Fraction Used in DAO Property Estimation....

D-2 Utility Requirements for Solvent Recovery in Solvent Deasphalting with Evaporation Technology Alone

D-3 Capital Investment for Solvent Recovery in Solvent Deasphalting with Evaporation Technnlogy Alone

D-4 Solvent Deasphalting with Evaporation Technology: Estimated Annual Operating Costs and Processing Cost

D-5 Utility Requirements for Solvent Recovery in Solvent Deasphalting with Membrane/Evaporation Hybrid Technology

D-6 Capital Investment for Solvent Recovery in Solvent Deasphalting with Membrane/Evaporation Hybrid Technology

D-7 Solvent Deasphalting with Membrane/Evaporation Hybrid Technology: Estimated Annual Operating Costs and Revenue Requirements 


\section{CHAPTER I \\ INTRODUCTION AND OBJECTIVES}

The development and commercialization of membrane separation technologies have given process design engineers a significant new tool for performing traditional and novel separations. However, the growing consensus is that membrane unit operations are often more economical when used in conjunction with conventional separation processes. These hybrid processes can be more effective than membranes alone for many reasons, including (1) membranes alone have a difficult time achieving high purity products, (2) membranes are very sensitive to phase changes that may occur as a separation is performed (e.g., as in the precipitation of salts in reverse osmosis), and (3) most membranes function in only a limited temperature range $\left(25^{\circ}\right.$ to $\left.150^{\circ} \mathrm{C}\right)$.

The purpose of this study was to identify the general principles governing the choice of hybrid systems over straight membrane or straight nonmembrane systems and to do so by examining practical applications (process design and economics). Our focus was to examine the energy consumption and overall costs of the membrane and nonmembrane technologies that cause hybrid systems to be preferred over nonhybrid systems. From this basis, we have recommended to DOE areas for further research that, if explored, would enhance the likelihood of commercially realizing the energy savings that are possible with hybrid membrane systems.

The project consisted of three parts: (1) identification and evaluation of case studies; (2) identification of general rules governing design and selection of hybrid membrane separation systems; and (3) identification of systems for experimental investigation. In the first part, four case studies were examined representing processes that have a high potential for energy savings if implemented commercially. We believe this approach is more useful than exploring abstract general principles about process design. For each case study, we performed economic and thermodynamic evaluations comparing the membrane alone, the nonmembrane alone, and one or more hybrid systems. These results not only indicated whether each of the case studies is worthy of further investigation by the DOE but also provided us with the experience and examples needed to complete the remaining parts of the project.

The second part of the project entailed using the thermodynamic and economic information obtained from the case studies to develop general rules that can be used to indicate whether a hybrid is likely to have superior peiformance than membrane or nonmembrane technologies alone 
for a given application. These rules can be used by design engineers in deciding which hybrid technologies are worthy of detailed evaluation for a particular separation problem. These rules were used in the third part of the project to identify applications where hybrids are likely to have better economic performance than stand-alone technologies and are likely to save a significant amount of energy over technologies currently used. A number of applications were evaluated, resulting in the recommendation to DOE of 10 specific hybrid systems for experimental research. 


\section{CHAPTER II}

\section{SELECTION OF CASE STUDIES}

Membrane hybrid processes could be used to perform separations in a great many applications. In choosing the four applications to be used as case studies, we had three concerns in mind. First, the hybrid process must have a reasonable chance of being accepted by industry. Second, the hybrid must save a significant amount of energy nver current technologies. Third, the case studies must provide us with the information needed to complete the remaining parts of the project (identification of governing rules and recommendation of experimental projects).

\section{INDUS'TRIAL APPLICATIONS}

In 1981, the total fuel and electricity purchased in the United States for industrial use was over 11,500 trillion Btu. This total is broken down by industry in Table II-1. Although 20 different industries are listed, $80 \%$ of the total fuel and electricity are purchased by six industries: food, pulp and paper, chemicals, petroleum refining, stone/clay/glass, and primary metals. All these major energy-consuming industries employ some separation processes, and we attempted to choose case studies from a variety of these industries.

Many technologies are used for separating mixtures of solids, liquids, and gases, as well as mixtures comprised of only one phase. The major separation technologies include distillation, absorption/stripping, adsorption, ion exchange, extraction, precipitation and crystallization, filtration, and membranes. The most expensive and energy-intensive separations are usually those where only one phase is present. The single phase is usually split into two phases (having different compositions) which can then be separated by gravity or filtration. The heat required for the phase change is often large (e.g., $1000 \mathrm{Btu}$ are needed to vaporize one pound of water) and can never be completely recovered.

In general, membrane processes cannot produce very high purity products; however, membranes do not require a phase change (except in pervaporation) and can perform bulk separation economically. Thus, combining membranes with a technology having less favorable economics (but one that can produce high purity products) should result in an overall process having high 


\section{Table II-1 \\ TOTAL PURCHASED FUELS AND ELECTRICITY IN 1981* \\ (trillion Btu)}

\begin{tabular}{|c|c|c|}
\hline $\begin{array}{c}\text { Standard } \\
\text { Industrial } \\
\text { Code }\end{array}$ & Description & $\begin{array}{c}\text { Energy } \\
\text { Purchased }\end{array}$ \\
\hline $\begin{array}{l}20 \\
21 \\
22 \\
23 \\
24 \\
25 \\
26 \\
27 \\
28 \\
29 \\
30 \\
31 \\
32 \\
33 \\
34 \\
35 \\
36 \\
37 \\
38 \\
39\end{array}$ & $\begin{array}{l}\text { Food } \\
\text { Tobacco } \\
\text { Textile mills } \\
\text { Apparel } \\
\text { Lumber } \\
\text { Furniture } \\
\text { Pulp and paper } \\
\text { Printing/publishing } \\
\text { Chemicals } \\
\text { Petroleum refining } \\
\text { Rubber } \\
\text { Leather } \\
\text { Stone/clay/glass } \\
\text { Primary metals } \\
\text { Fabricated metal products } \\
\text { Machinery } \\
\text { Electric/electronics } \\
\text { Transportation equipment } \\
\text { Instruments } \\
\text { Miscellaneous manufacturing industries }\end{array}$ & $\begin{array}{r}913 \\
23 \\
292 \\
61 \\
185 \\
46 \\
1,262 \\
92 \\
2,630 \\
1,137 \\
223 \\
18 \\
1,078 \\
2,241 \\
352 \\
325 \\
235 \\
329 \\
78 \\
43\end{array}$ \\
\hline $\begin{array}{l}38 \\
39\end{array}$ & TOTAL & 11,564 \\
\hline
\end{tabular}

ॠU.S. Department of Commerce, 1982 Census of Manufacturers.

product purities and favorable economics. Distillation, adsorption, absorption/stripping, extraction, and crystallization are technologies that can produce high purity products on their own, but might benefit economically by using membranes as an initial, bulk purification step.

\section{CASE STUDY SELECTION CRITERIA}

To help us quantify our reconmendations for the four case studies, we graded each potential hybrid application on the basis of four criteria. 


\section{Will hybrid systems result in significant energy savings on a national scale?}

For each application, we have obtained an estimate of the yearly U.S. energy use. Scores were assigned according to the following:

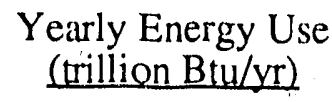

$$
\begin{gathered}
<1 \\
1-10 \\
11-20 \\
21-49 \\
>50
\end{gathered}
$$

\section{$\underline{\text { Score }}$}

1

2

3

4

5

\section{Is this a novel application of a hybrid system?}

Although the main goal of this projest was to determine the conditions where hybrid systerns are most applicable, we believed this project would have increased value if our hybrid system evaluations were based on applications not previously studied. Scores for this criterion were given according to the following:

State of Technologies for this Application

Hybrid system currently used in industry

Both conventional and membrane technologies are used individually in industry

Either conventional or membrane technologies are used in industry

Hybrid system or membrane technology has been studied on paper or in laboratory

Neither hybrid system or membrane technology have been studied

\section{Score}

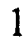

2

3

4

5

\section{Are process data known and available?}

We based our evaluations on real processes. Therefore, it was necessary that physical properties (such as membrane permeability and selectivity, capacities of absorbents and adsorbents, and relative volatilities) inherent to the hybrid system be available. Scores were assigned as follows: 
Availability of Pror ess Data for the Application

Score

Not known or estimable

Not known, but reasonable estimates are possible

Only conventional technology data are known

Only membrane technology data are known

Both conventional and membrane technology data are known

IV. What is the likelihood of commercial acceptance of the hybrid system?

We based the grading system for this criterion on two factors: industry's desire for a new technology and whether the separation application has any characteristics that favor membrane technology. Examples of favorable characteristics include availability of high-pressure feed, a relative volatility close to 1.0 (makes distillation difficult), and mild product purity requirements (Roberts, 1986). Scores were assigned as follows:

Process Desirability

No desire for new technology/no favorable characteristics

No desire for new technology/one or two favorable characteristics

Industry desires new technology/no favorable characteristics

Industry desires new technology/one or two favorable characteristics

Industry actively seeking new technology/greater than two favorable characteristics
Score

1

2

3

4

5

Each possible application was graded in the four criteria on a scale from 1 (worst) to 5 (best). Criteria I and IV were felt to be of primary importance and were given a weighting factor of 2 . This grading system was used to rank the applications and determine which applications were the best case studies.

\section{CASE STUDY CANDIDATES}

We chose 11 separation applications for review as possible case studies (Table II-2). These 11 applications were from a variety of industries and include a number of separation technologies. The following sections give a brief description of each of the 11 candidates. 


\section{Table II-2 \\ CASE STUDY CANDIDATES}

\begin{tabular}{|c|c|c|c|}
\hline Ne. & Candidate & Membrane Technology & $\begin{array}{c}\text { Conventional } \\
\text { Technology }\end{array}$ \\
\hline 1. & Removal of $\mathrm{N}_{2}$ from natural gas & Gas separation membranes & $\begin{array}{l}\text { Pressure swing } \\
\text { adsorption }\end{array}$ \\
\hline 2. & $\begin{array}{l}\text { Removal of } \mathrm{CO}_{2} \text { from natural gas or } \\
\text { hydrogen }\end{array}$ & Gas separation membranes & Amine scrubbing \\
\hline 3. & Removal of solvent vapors from air & Gas separation membranes & Carbon adsorption \\
\hline 4. & Air separation for production of $\mathrm{O}_{2}$ and $\mathrm{N}_{2}$ & Gas separation membranes & Cryogenic distillation \\
\hline 5. & Separation of propane/propylene mixtures & Pervaporation & Distillation \\
\hline 6. & Separation of xylene isomers & Pervaporation & Distillation \\
\hline 7. & Dehydration of ethanol & Pervaporation & Distillation \\
\hline 8. & Concentration of kraft black liquor & Reverse osmosis & Freeze concentration \\
\hline 9 . & Concentration of thin sugar beet juice & Reverse osmosis & Evaporation \\
\hline 10. & Refining of edible oils & Ultrafiltration & Steam stripping \\
\hline 11. & Solvent recovery in deasphalting & Ultrafiltration & Flash expansion \\
\hline
\end{tabular}

\section{Removal of $\mathbf{N}_{2}$ from Natural Gas}

Removal of $\mathrm{N}_{2}$ from natural gas is currently or potentially important in three industrial applications. The first application is in enhanced oil recovery (EOR) where $\mathrm{N}_{2}$ is injected into oil reservoirs to increase the recovery of oil. Along with the oil, some natural gas is recovered. This gas contains $\mathrm{N}_{2}$ impurities (from EOR injection) that must be separated for two reasons: (1) the natural gas can be sold only if the $\mathrm{N}_{2}$ level is below $3 \%$ (pipeline standard) and (2) the $\mathrm{N}_{2}$ can then be reinjected, saving the expense of purchasing fresh $\mathrm{N}_{2}$.

The second application is the purification of natural gas from reservoirs that naturally contain $\mathrm{N}_{2}$ impurities at levels above pipeline standard. If the $\mathrm{N}_{2}$ cannot be economically removed, the reservoir is abandoned; if an economical separation technology were available, the quantity of useful gas contained in U.S. reservoirs could be significantly increased. 
The final application is the purification of natural gas removed from a storage reservoir in which a portion of the base gas has been replaced by $\mathrm{N}_{2}$. The base gas is the quantity of gas contained in the storage reservoir needed to maintain the reservnir pressure above a minimum working value. The base gas is not part of the storage capacity and represents a large capital investment. To reduce this investment, the gas industry is considering replacing a portion of the base gas with $\mathrm{N}_{2}$ which is less expensive than the natural gas currently used for the base gas. Although it is hoped that, with proper reservoir management, the mixing of natural gas and nitrogen can be held to insignificant levels, there must be separation technologies available in the event that mixing does occur.

The current technology for separating $\mathrm{N}_{2}$ from natural gas is economically feasible only for the EOR application where the separated $\mathrm{N}_{2}$, as well as the purified natural gas, is of value. We have estimated the current U.S. energy use for $\mathrm{N}_{2}$ /natural gas s?paration in EOR applications to be approximately 0.15 trillion Btu/yr; this quantity, however, may increase tenfold over the next 20 years if predicted increases in EOR use are realized (National Petroleum Council, 1984). If technologies are developed that make the natural gas purification and storage reservoir applications economically feasible, the energy requirements for these applications could easily match those of the EOR application.

The current technology for separation of $\mathrm{N}_{2}$ and natural gas is cryogenic distillation; however, pressure swing adsorption (PSA) is emerging as a commercial technology. We believe a hybrid system utilizing membranes for the initial separation, followed by PSA, has potential for reducing the energy requirements of this separation.

Currently, there is significant interest in developing membranes, as well as PSA technology, for this application; thus, a reasonable amount of process data should be available for our analysis. Membrane/PSA hybrids are not a new idea; however, there is little information about their use for this application. Both membrane and PSA systems are currently used in the natural gas industry, and we believe an economical hybrid system would be quickly accepted.

\section{Removai of $\mathrm{CO}_{2}$ from Natural Gas or $\mathrm{H}_{2}$}

Many natural gas reservoirs contain $\mathrm{CO}_{2}$ impurities at levels that limit the use of the gas. The $\mathrm{CO}_{2}$ dilutes the natural gas, lowering its heating value, and can cause severe corrosion problems in pipelines and related equipment. To bring the gas up to pipeline standards, the $\mathrm{CO}_{2}$ must be removed to less than 100 parts per million (ppm). 
A related application is removal of $\mathrm{CO}_{2}$ produced during $\mathrm{H}_{2}$ synthesis by steam reforming of methane. Most $\mathrm{H}_{2}$ is produced for use in petroleum refining, ammonia production, or methanol production. With the exception of methanol production, the $\mathrm{CO}_{2}$ must be reduced to low levels before use.

In the United States, only a small fraction $(\sim 2 \%)$ of the total produced natural gas contains a high enough $\mathrm{CO}_{2}$ content that a hybrid system might be used $\left(>10 \% \mathrm{CO}_{2}\right)$. We have estimated the energy required to remove this $\mathrm{CO}_{2}$ to be between 5 and 10 trillion $\mathrm{Btu} / \mathrm{yr}$; the energy use in $\mathrm{H}_{2}$ purification is about the same.

The current separation technologies for these applications are absorption/stripping processes such as Selexol ${ }^{\circledR}$, diethanolamine, and hot potassium carbonate. Yressure swing adsorption, however, has a significant share of the $\mathrm{H}_{2}$ purification market and membranes have a small portion of the natural gas purification market. Combining membrares and an amine scrubbing system (diethanolamine) could result in significant energy savings by reducing the steam required for amine regeneration.

Because both membranes and amine scrubbing systems are currently in use for these applications, substantial process data are available, and a number of studies of hybrid systems have been reported; hence, an economical hybrid system would likely find acceptance.

\section{Removal of Solvent Vapors from Air}

Increased regulation governing the emission of solvent vapors to the atmosphere has caused much interest in technologies for solvent vapor removal and, if possible, recovery. Vapor emissions come from a variety of industrial sources ranging in size from small dry cleaning operations to large printing operations. Other sources include stored petroleum liquids, coating operations (i.e., pressure-sensitive adhesives), and painting operations.

In 1975, over 30 million tons of solvent vapor were released into the atmosphere (Baker et al., 1987). It is difficult to estimate what faction of these vapors is now being treated; however, if only $5 \%$ of the total vapor emitted in 1975 is now recovered, we estimate 10 trillion Btu in process energy would be required to recover the solvent. The main technology used for solvent removal is adsroption by activated carbon. As with most membrane applications, membranes have trouble with removing the solvent vapor to very low levels. A membrane/carbon adsorption hybrid system, however, would remove the solvent vapor to adequate levels and could reduce energy use over carbon adsorption alone. Currently, there is active research in the area of membrane technology for solvent 
vapor recovery and commercial membrane systems are available. There have also been several studies of hybrid systems; thus, process data are available for use in evaluations. The fact that commercial membrane systems are now being offered suggests that a hybrid technology would be readily accepted if it were economically attractive.

\section{Air Separation for Production of $\mathrm{O}_{2}$ and $\mathrm{N}_{2}$}

Many industries require pure oxygen (for combustion or reaction processes) or nitrogen (for refrigeration or inerting). The energy required for this separation was 10 trillion Btu/yr in 1981 in the United States (Bravo et al., 1984). Currently, cryogenic distillation is the major technology, with small amounts of nitrogen being produced by membranes and PSA.

Air separation is one of the largest areas of membrane research at present, and a great deal of process data is available. However, studies of membrane/cryugenic hybrids have not shown favor-able economics. Because many of the industrial laboratories performing this research are involved in the sale of air gases, we believe a hybrid system would be quickly implemented if membrane improvements resulted in an economically feasible systemi.

\section{Separation of Propane/Propylene Mixtures}

Propylene and ethylene are produced in greater quantities than any other organic chemicals in the United States; their main use is in the production of plastics. The purification of clefins (such as in propane/propylene, $C_{3}$, and ethane/ethylene, $C_{2}$, separations) is currently performed by distillation. The relative volatilities, however, are very low $(<1.5)$, making the distillation difficult and expensive. Columns are typically 200 - to 300 - $\mathrm{ft}$ tall and can contain over 100 trays; the reflux ratios are large, requiring a high energy input. Olefin purifications are the largest user of energy for distillation in the chemical industry, using 50 trillion Btu/yr (Earron et al., 1987).

We have chosen to examine propane/propylene separation because the $\mathrm{C}_{2}$ distillation is conducted at subambient temperatures. To achieve these temperatures, a complex integrated refrigeration system is used; the integrated nature makes the energy analysis more difficult and less obvious than with the $\mathrm{C}_{3}$ applications. For this application, we envision using a pervaporation membrane initially, followed by distillation to complete the separation. Such hybrid systems have been evaluated primarily for azeotropic distillations; their use for difficult but nonazeotropic distillations has not been studied to the same extent. Some data on membrane separation of olefins are available, but not as much as for other applications, such as air separation or ethanol dehydration. Membrane hybrids 
have a good chance of having favorable economics compared with straight distillation; however, the large amount of capital already invested in distillation equipment may make plant expansion a more likely application than a complete retrofit.

\section{Separation of Xylene Isomers}

Benzene, toluene, and xylene ( $\mathrm{B}^{\prime} \mathrm{TX}$ ) are primary petrochemicals used in manufacturing a wide range of products. Separation of these components is done primarily by distillation and is one of the largest users of energy in the chemical industry (24 trillion Btu/yr; Barron et al., 1987). Since an individual distillation column is generally used to remove only one component, several distillation columns are required. The separation of xylene isomers, however, is not effectively performed by distillation, and freeze crystallization or adsorption processes are used. For the separation of xylene isomers, a hybrid system consisting of pervaporation followed by freeze crystallization might result in reduced energy consumption. Approximately 7 trillion Btu/yr are used for xylene isomer separation.

Some studies of membrane performance have been reported, providing process data for our evaluations. The use of membrane/freeze crystallization hybrids has received little attention in general, and none for this application. This hybrid system is a departure from the traditional technology for this separation application, and industry might be reluctant to accept it.

\section{Ethanol Dehydration}

Ethanol is a common chemical used as a solvent, as a raw material, and for fuel (gasohol). Two primary grades of ethanol are produced in the Uinted States: technical grade ( $95 \%$ vol) and anhydrous. Ethanol used for fuel and some used as a raw material or solvent is anhydrous, and the remainder (approximately $25 \%$ of the total 800 million gallons of ethanol produced un the United States during 1984) is technical grade. It is predicted that the use of ethanol for fuel ( 600 million gallons in 1984) will fall sharply to less than 100 million gallons by 1995 due to the changing economic and regulatory atmosphere surrounding transportation fuels. In 1984, approximately 15 trillion Btu were used in the production of anhydrous ethanol; this figure may drop to less than 2 trillion Btu by 1995 (SRI International, 1985).

Commercial dehydration of ethanol is done by distillation. However, an azeotrope forms at $95 \%$ (vol) ethanol, requiring use of an entrainer (such as benzene) to make higher ethanol purities. Azeotropic distillation normally requires the use of a second distillation column to separate the 
ethanol from the entrainer, resulting in increased capital and operating costs. Only anhydrous ethanol requires azeotropic distillation; technical grade ethanol can be produced by conventional single-column distillation.

Pervaporation of ethanol/water mixtures has been the subject of considerable research, including studies of distillation/pervaporation hybrids. Currently, there are a number of commercial hybrid plants for production of $99 \%$ ethanol. These plants use distillation to reach $70 \%$ ethanol and then use pervaporation to get to $99 \%$ ethanol.

\section{Kraft Black Liquor (KBL) Concentration}

The pulp and paper industry is third among all industries for energy consumption, using 1260 trillion Btu in 1981. Of this total, we estimate 160 trillion Btu are used for the concentration of $\mathrm{KBL}$, a waste from the pulping process. The concentrated liquor is burned for its fuel and to recover inorganic chemicals that are reused. Currently, multieffect evaporation is used to concentrate $\mathrm{KBL}$; however, several studies have shown that freeze concentration may be practical.

A hybrid system consisting of reverse osmosis (RO) membranes to initially concentrate $\mathrm{KBL}$ followed by freeze concentration (FC) to remove the final quantity of water could reduce energy requirements by reducing the amount of water that must be frozen. There is research activity in using RU/FC hybrids to clean up other pulp and paper waste streams, and some research has been done on KBL concentration by RO. Ultrafiltration (UF) membranes have also been used to treat $\mathrm{KBL}$, but only to remove certain high viscosity components, not to concentrate the KBL.

\section{Concentration of Thin Beet Juice}

Sugar is produced from beets by extracting the sugar with water, followed by clarification with milk of lime. The resulting liquid contains 10 to $12 \%$ sucrose and is called thin beet juice (TBJ). The TBJ is concentrated to about $60 \%$ sugar by multiple-effect evaporation (MEE), purified by carbon adsorption, and then crystalized in vacuum pans. In 1985, 25 trillion Btu were used in evaporation of TBJ in the United States (Mohr et al., 1988).

In place of using MEE to concentrate the TBJ, a hybrid system using RO for the initial concentration followed by MEE to concentrate the juice to 6()$\%$ could be used. Several studies of this hybrid system have been reported, and one European sugar beet factory is claiming a $65 \%$ net energy saving for the factory by using RO to concentrate the TBJ to $18 \%$ sugar. 
The use of sugar has been declining in the United States (between 1980 and 1986, total sugar production dropped by over $15 \%$ ); thus, it is unlikely that new plants will be built soon. Because of this decline, we expect only a moderate chance of commercial acceptance of the hybrid system, despite any demonstrated economic advantages.

\section{Refining of Edible Oils}

Edible oils are produced from crude edible oils by several steps: degumming, refining, and bleaching. In degumming, the oil is heated and treated with water to precipitate phosphatides. The refining step can be by chemical means (alkali is used to convert free fatty acids, FFA, to watersoluble soaps which are separated by centrifugation) or physical means (steam stripping is used to remove FFA). Bleaching removes pigments, decomposes peroxides, and removes the remaining traces of water-soluble soaps.

Currently, most refining is done chemically because some oils contain components not successfully removed by physical refining. Chemical refining is more energy intensive than physica' refining, and methods are sought to allow more widespread use of physical refining. Using UF in the degumming step has been shown to remove the problem components. Thus, a hybrid process of UF followed by physical refining (steam stripping) could result in significant reductions in the 60 trillion Btu used each year in conventional chemical refining (Mohr et al., 1988).

\section{Solvent Recovery in Deasphalting}

In crude oil refining, the vacuum still bottoms (reduced crude) is often further fractionated into an asphalt fraction and a deasphalted oil (DAO) fraction by a process known as solvent deasphalting. The U.S. solvent deasphalting capacity in 1985 was 283,000 barrels of reduced crude per day. We estimate the total energy used in solvent deasphalting to be 50 trillion Btu/yr.

In solvent deasphalting, the lower molecular weight oils are separated from the asphalt components by dissolution into a solvent (such as propane). Solvent is recovered from the solvent/oil mixture by evaporation; steam stripping is used to remove any remaining solvent from the DAO. Ultrafiltration membranes are capable of separating mixtures of solvents and DAO (Kulkarni et al., 1985) and could preceed evaporators in a hybrid separation process.

Although laboratory studies have given promising results toward membrane use in this application, the current low value of energy is hindering industrial interest in residual oil recovery operations such as solvent deasphalting. However, as energy prices increase, industrial interest should also increase. 


\section{CONCLUSIONS}

Table II-3 shows that propane/propylene (28 points) and $\mathrm{N}_{2} /$ natural gas (23 points) applications received the highest total scores and, therefore, were chosen for the case studies. Four applications $\left(\mathrm{CO}_{2}\right.$ /natural gas, $\mathrm{KBL}$ concentration, $\mathrm{N}_{2} / \mathrm{O}_{2}$ separation, and solvent deasphalting) tied for the next highest score with 21 points each. We chose KBL concentration and solvent deasphalting as the two remaining case studies. KBL concentration was chosen because, of the top five applications, it is the only one that uses RO technology, and we wished to use as many membrane technologies as possible. Solvent deasphalting was our final choice, ensuring that all four different types of membrane technology were included in the case studies. By covering a range of conventional and membrane technologies, we were able to increase our ability to identify the general principles involved in the choice of hybrid systems versus individual technologies. 


\section{Table II-3 \\ EVALUATION OF CANDIDATE APPLICATIONS \\ FOR USE AS HYBRID SYSTEM CASE STUDIES}

\begin{tabular}{|c|c|c|c|c|c|c|c|}
\hline \multirow{2}{*}{$\begin{array}{l}\text { Separation } \\
\text { Applleatlon }\end{array}$} & & \multirow[b]{2}{*}{1} & \multirow[b]{2}{*}{11} & \multirow[b]{2}{*}{111} & \multirow[b]{2}{*}{ IV } & \multirow[b]{2}{*}{ Total } \\
\hline & Membrane & Conventional & & & & & \\
\hline Propane/propylenet & Pervaporation & Distillation & 5 & 5 & 3 & 5 & 28 \\
\hline $\mathrm{N}_{2} /$ natural gas ${ }^{\dagger}$ & Gas separatic & $\begin{array}{l}\text { Pressure swing } \\
\text { adsorption }\end{array}$ & 2 & 4 & 5 & 5 & 23 \\
\hline $\mathrm{KBL}$ concentration ${ }^{\dagger}$ & Reverse osmosis & $\begin{array}{l}\text { Freeze } \\
\text { concentration }\end{array}$ & 5 & 4 & 3 & 2 & 21 \\
\hline $\begin{array}{l}\text { Solvent } \\
\text { deasphalting }{ }^{t}\end{array}$ & Ultrafiltration & Flash expansion & 4 & 4 & 5 & 2 & 21 \\
\hline $\begin{array}{c}\mathrm{CO}_{2} \text { /natural gas or } \\
\mathrm{H}_{2}\end{array}$ & Gas separation & Amine scrubbing & 3 & 2 & 5 & 4 & 21 \\
\hline $\mathrm{N}_{2} / \mathrm{O}_{2}$ & Gas separation & $\begin{array}{l}\text { Cryogenic } \\
\text { distillation }\end{array}$ & 3 & 2 & 5 & 4 & 21 \\
\hline $\begin{array}{l}\text { Beet juice } \\
\text { concentration }\end{array}$ & Reverse osmosis & Evaporation & 4 & 3 & 5 & 2 & 20 \\
\hline $\begin{array}{l}\text { Refining of edible } \\
\text { oils }\end{array}$ & Uttrafiltration & Steam stripping & 5 & 3 & 3 & 2 & 20 \\
\hline Xylene isomers & Pervaporation & $\begin{array}{l}\text { Freeze } \\
\text { concentration }\end{array}$ & 2 & 5 & 3 & 4 & 20 \\
\hline Ethanol dehydration & Pervaporation & Distillation & 3 & 1 & 5 & 2 & 16 \\
\hline Solvent vapor/air & Gas separation & Carbon adsorption & 2 & 2 & 5 & 2 & 15 \\
\hline
\end{tabular}

Hybrid System Technologles

Criteria Score* 


\section{CHAPTER III}

\section{EVALUATION PROCEDURES}

Evaluation of each case study included simulation of the membrane and nonmembrane technologies and of the hybrids determined to have the greatest potential for successful performance. Then, the economic and thermodynamic results were compared to determine whether a hybrid system resulted in better overall performance (economic evaluations) and whether any hybrid system has potential for reducing energy consumption (thermodynamic evaluations). A simulation entails calculation of steady-state mass and energy balances of all streams and unit operations included in the separations system and sizing of process equipment and utility requirements. Thermodynamic evaluations were conducted by reducing the thermodynamic results (from mass and energy balances) into a form concise enough to be understood easily (i.e., several parameters to be defined later). Similarly, the economic results were reduced to several parameters that allow easy comparison of the different separation systems.

\section{IDENTIFICATION AND SELECTION OF CANDIDATE HYBKID SYSTEMS}

Once the membrane and nonmembrane technologies to be considered were chosen, it was necessary to determine the hybrid configurations that result from combining the two stand-alone technologies. The most likely of these configurations were then chosen as the hybrid systems to be included in the evaluation. Although the number of hybrid configurations that can result from any two technologies is large, only a few make sense; the others are obviously too complicated or outlandish. After this selection process, only one or two hybrid configurations were included in each case study.

\section{PROCESS SIMULATION}

The first step in simulating a separation system is to develop a detailed flowsheet for the system to include any auxiliary equipment not included in deterrnining the hybrid and nonhybrid system configurations. Next, models must be developed to predict the performance of any unit operation (membrane and nonmembrane) included in the separation system. These models can be based on empirical curves obtained from literature and vendor quotes, or they may be based on phy'sical and chemical fundamentals. 
These models were then incorporated in a commercial process simulator (ASPEN/SP; Simulation Sciences, Denver, $\mathrm{CO}$ ) which performed the actual mass and energy balances. The simulator determined thermodynamic and transport properties of the species included in the simulation and incorporated many unit operation models used in the simulations. Using the process simulator allowed generation and management of many different results and allowed sensitivity analyses on feed and process variables to be performed quickly.

\section{THERMODYNAMIC EVALUATION}

To simplify ine large amount of data generated in each simulation, we reduced the thermodynamic data to give four results: process stream availability change $\left(A_{p r o c}\right)$, utility :tream availability consumed $\left(\mathrm{A}_{\mathrm{util}}\right)$, thermodynamic extent of separation $(\phi)$, and the thermodynamic efficiency (EFF). These parameters are defined in the following paragraphs.

There are many thermodynamic quantities that could be used as the basis for the evaluations; however, the availability (or exergy) is the quantity that we expect to provide the most insight into the conditions that lead to advantages in using a hybrid separation system over a nonhybrid system. The definition of availabilty is the free energy referenced to the temperature of the ultimate heat sink (usually the ambient environment temperature):

$$
A=H-T_{0} S
$$

where $A$ is the availability (Btu/lb), $\mathrm{H}$ is the enthalpy (Btu/lb), $T_{0}$ is the temperature of the ultimate heat sink $\left({ }^{\circ} \mathrm{R}\right)$, and $\mathrm{S}$ is the entropy $\left(\mathrm{Btu} / \mathrm{lb} /{ }^{\circ} \mathrm{R}\right)$. A complete discussion of availability is beyond the scope of this report but can be found in most thermodynamic texts (e.g., Gaggioli, 1980).

We have defined $A_{\text {proc }}$ to be the change in availability of the process streams entering and exiting the separation system, or specified section of $\ldots . \dot{s}$ separation system, at a reference temperature and pressure. By process streams, we mean feed and purified product streams, not utility and thermal flows. Thus, $A_{p r o c}$ is the availability change required to separate a mixed feed stream into two or more purified outlet streams, exclusive of any change in temperature or pressure that occurs as a result of the specific separation process. The concept of a reference temperature and pressure was necessary for the definition of $A_{\text {proc }}$ so that meaningful comparisons could be made: between processes that resulted in outlet streams with different temperatures and pressures. Thus, Aproc is given by 


$$
\begin{array}{cc}
A_{\text {proc }}=\Sigma\left[A^{*}(i)\right] & -\Sigma\left[A^{*}(j)\right] \\
\text { products } & \text { feeds }
\end{array}
$$

where $A^{*}(i)$ and $A^{*}(j)$ are the availabilities of product and feed process streams at a reference temperature and pressure, usually equal to the feed temperature and pressure. The sum of the availabilities of two relatively pure streams is always greater than the availability of a single stream resulting from mixing the two pure streams (availability, unlike enthalpy, is not conserved) and, therefore, A proc is always positive.

The availability consumed between the utility stream inlets and outlets, $A_{u t i l}$, is given by

$$
\begin{array}{cc}
A_{\text {util }}=\Sigma\left[A^{*}(i)\right] & -\Sigma\left[A^{*}(j)\right] \\
\text { inlets } & \text { outlets }
\end{array}
$$

where $A^{*}(i)$ and $A^{*}(j)$ are the availabilities of inlet and outlet utility streams at their actual temperatures and pressures. Utility streams are generally the source of energy required to separate the feed and, thus, $A_{u t i l}$ is always greater than or equal to zero.

In a hybrid system, the membrane may perform most of the separation, or by a change in the operating conditions, the membrane may perform a minor part of a separation. An intuitive and fundamental way to quantify the "amount" of the separation performed by each technology is the fraction of the total process availability change that occurs in one process section. This quantity is defined to be $\phi_{i}$ and is given by

$$
\phi_{i}=\frac{A_{\text {proc }}}{A_{\text {proc }}} \frac{(\text { section } \mathrm{i})}{(\text { total })}
$$

where i refers to a specified section of the process (e.g., the membrane section or distillation section). Technically, $\phi_{i}$ is the fraction of the total separative work performed by section $i$. Values for $\phi_{\mathrm{i}}$ of 0.0 and 1.0 imply that all the work is performed by one technology (in other words, the system is not a hybrid system), and fractional values imply the separation is performed by more than one technology (a hybrid system).

One other useful parameter is the thermodynamic efficiency, EFF, defined as

$$
\mathrm{EFF}=\frac{A_{\text {proc }}}{A_{\text {util }}}
$$


This quantity can be applied to the entire separation system or to a specific section. We reported our results in Case Study 1 with the EFF parameter. In Case Studies 2, 3. and 4, it was more meaningful to report $A_{u t i l}$ instead of EFF since $A_{\text {proc }}$ may differ if two systems do not result in identical outlet stream compositions.

Aside from these availability measures, steam and electricity consumption are reported in terms of enthalpy and thermal energy equivalent*

\section{ECONOMIC EVALUATION}

To evaluate the economic performance of different separation systems, we used a single parameter, the processing cost (PC), which is the cost required to transform the feed into the product streams. The PC includes charges for capital expenses (such as plant facilities investment, PFI, working capital, interest, and loan repayment) and operating expenses (such as utilities, labor, sup-

plies, property tax, and insurance). These capital and operating expenses are included in a discounted cash flow analysis along with other parameters (such as on-stream factor, return on investment, depreciation rates) to give the PC in terms of dollars per unit of product (or per unit of feed processed). Figure III-1 illustrates the procedure used to determine the PC.

Membrane capital costs were calculated using the membrane area determined by the appropriate membrane model and an estimated membrane cost per unit area. An installation factor of 2.4 was used for the initial installation only; the membrane lifetime varied depending on the case study. Related equipment (pumps, heat exchanges, flash vessels) costs were calculated using the ASPEN/SP cost routines. The discounted cash flow analysis assumed a plant life of 20 years and a return on investment of $15 \%$. Table III-1 lists the major parameters used in the economic evaluations.

\section{SIMULATION PROCEDURE}

Once the simulation program was developed (including calculation of thermodynamic and economic parameters), it was used to simulate the performance of the stand-alone membrane system, stand-alone nonmembrane system, and hybrid systems. When appropriate, the hybrid system was simulated for a range of $\phi_{\mathrm{m}}$ values. Thus, all systems, membrane, nonmembrane, and hybrids, can be represented on a single graph with $\phi$ as the independent variable; at $\phi_{\mathrm{m}}$ equal to

Thermal energy equivalents are based on an electric power generation efficiency of $33 \%$ and a steam generation efficiency of $85 \%$. 


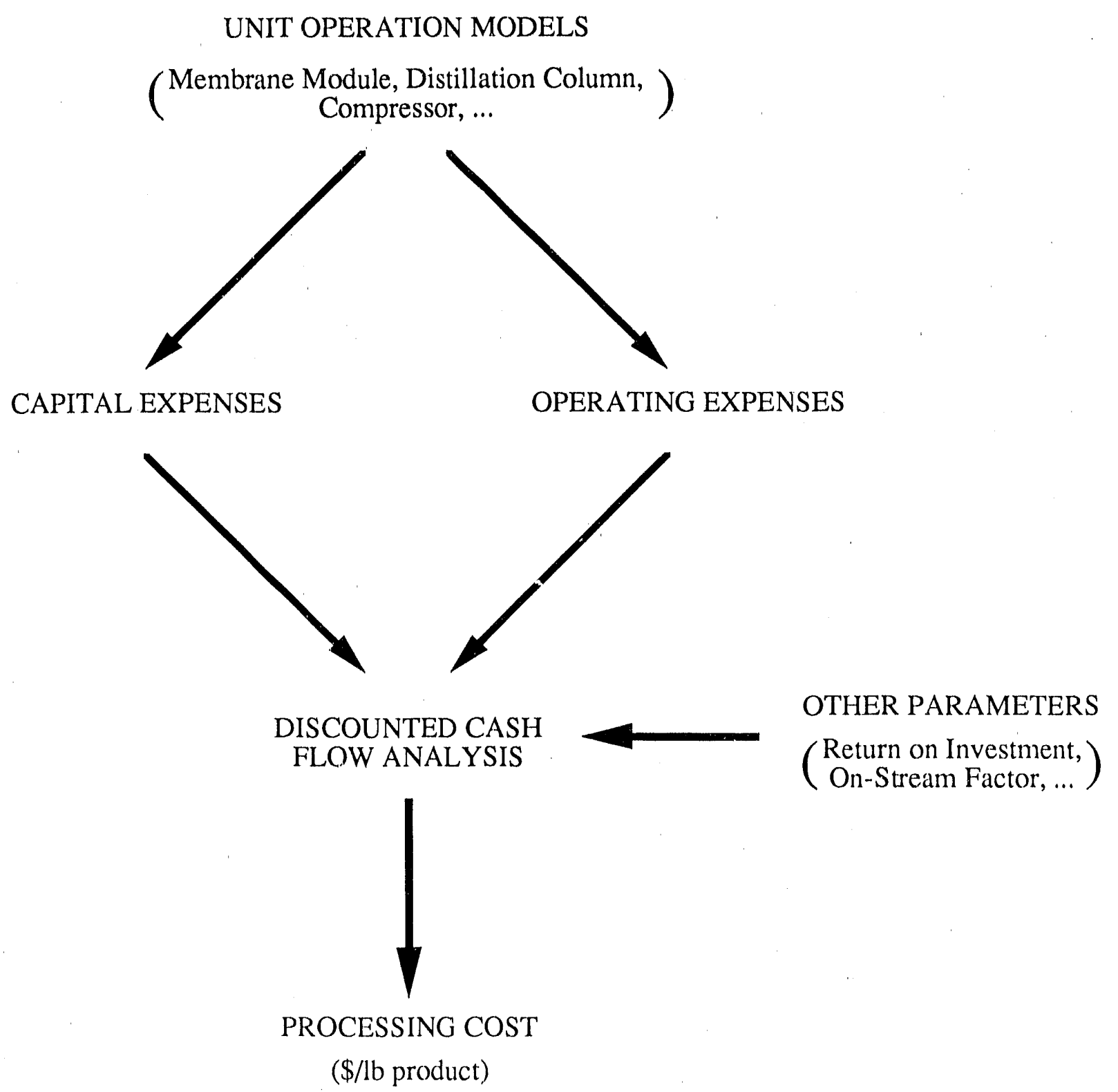

RAM-6519-14

Figure III-1. Flow diagram showing procedure for calculating the processing cost. 
Table III-1 GENERAL PARAMETERS FOR ECONOMIC EVALUATIONS

\begin{tabular}{ll} 
Utillty and Operating Costs & \\
Steam (high pressure, 250 psia) & $\$ 5.00 / 1,000 \mathrm{lb}$ \\
Steam (low pressure, 25 psia) & $\$ 2.00 / 1,000 \mathrm{lb}$ \\
Electricity & $5.0 \mathrm{c} / \mathrm{kWh}$ \\
Cooling water & $5.7 \% / 1,000 \mathrm{gal}$ \\
Operating labor & $\$ 15 / \mathrm{hr}$ \\
Maintenance labor & $2.5 \%$ of $\mathrm{PFI}$ \\
Supervision & $15 \%$ of operating labor \\
Benefits & $35 \%$ of total labor \\
Maintenance supplies & $2.5 \%$ of $\mathrm{PFI}$ \\
General and administrative expenses & $20 \%$ of labor \\
Property taxes and insurance & $2.5 \%$ of PFI \\
& \\
Economic Parameters & \\
Plant life & 20 years \\
Rate of return on equity & $15 \%$ \\
General service facilities & $13 \%$ of PFI \\
On-stream factor & $90 \%$ \\
Inflation rate & $0 \%$ \\
Administrative costs & $2.0 \%$ of annual revenue \\
Annual tax rate & $40 \%$ \\
Dollar basis & first quarter, 1989 \\
\hline
\end{tabular}

"Plant facilities investment. 
0.0 , the corresponding results represent the stand-alone nonmembrane system; at $\phi_{\mathrm{m}}$ equal to 1.0 , the corresponding results represent the stand-alone membrane system; and for $\phi_{m}$ between 0.0 and 1.0 , the col responding results represent a hybrid system.

The simulations are reported in two parts: base case results and a sensitivity analysis on key process and economic variables. The base case simulation uses a set of variables that we consider typical. Simulation results are reported in detail using the base case conditions for the stand-alone membrane and nonmembrane systems and for the hybrid at a particular value of $\phi_{\mathrm{m}}$. In the sensitivity analyses, key process and economic variables are varied one at a time, and all other variables remain at their base case values. Typical variables included in the sensitivity analysis include feed and product composition, membrane selectivity and cost, and utility costs. The sensitivity analysis shows which variables are important in determining the best separation system and what membrane performance is required for the hybrid to be the best system. 


\section{CHAPTER IV}

\section{CASE STUDY 1 - PROPYLENE/PROPANE SEPARATION}

In this case study, we evaluate the thermodynamics (availability) and economics of several propane/propylene separation processes. Computer models using publicly available process data were used to perform the evaluations. The results show that for $95 \%$ purity propylene product the membrane technology (based on small-scale laboratory data) is superior, both economically and thermodynamically, to the distillation technology. Thus, a separation system consisting of a membrane alone results in the highest thermodynamic efficiency and lowest processing cost. However, if the required degree of separation is high (99.5\% propylene) the membranes cannot, by themselves, perform the separation. In this case, the best system consists of a membrane that accomplishes as much of the separation as it is able, along with a distillation column that performs the remainder. Distillation alone results in the lowest efficiency and highest cost. If, however, we perform the evaluations with membrane properties inferior to those reported in the literature, the best system is a combination of membrane and distillation (even if the entire separation can be done by membrane alone); both highest efficiency and lowest cost result from a system where $85 \%$ of the separation is performed by the membrane and the remainder by distillation.

\section{PROCESS DESCRIPTION AND MODELING}

Figure IV-1 diagrams a typical process for production of propylene from propane (Craig and Spence, 1988). Fresh and recycle propane are heated and fed to a catalytic reactor; the reaction is incomplete and results in a mixture of propane and propylene leaving the reactor. The hot reactor gases are cooled (preheating the feed and producing steam) and compressed and then enter the purification section. Hydrogen and methane can be removed by flashing after the compression step or by absorption using naphtha as the solvent. After a first distillation step to remove ethane (stabilizer column), acid gases and other impurities may be removed, and the remainder is sent to the propylene splitter. Propylene product leaves the top of the column, and propane plus heavier components leave at the bottom. The propane stream is sent to the deoiler where $\mathrm{C}_{4}+$ compounds are removed. The remaining propane is recycled to the reactor feed. 


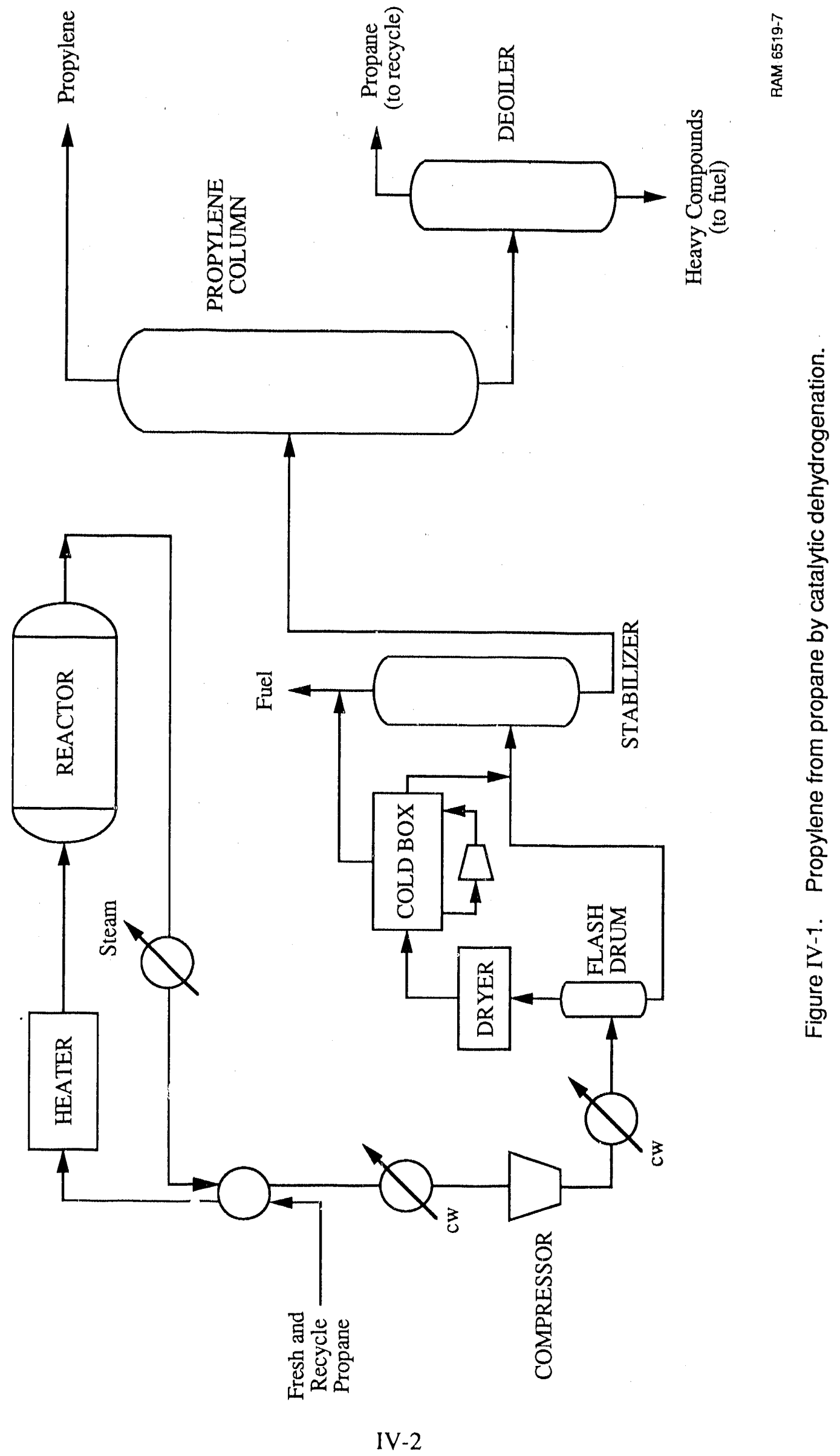


This study will deal only with the propylene splitter section of the flowsheet as shown in Figure IV-2. The feed stream, a saturated liquid, contains $44 \mathrm{~mol} \%$ propylene, $54 \%$ propane, and $2 \%$ heavier compounds. Three propylene purities will be examined, $95 \%, 99.5 \%$, and $99.9 \%$, with corresponding propane streams containing $3.8 \%, 2.5 \%$, and $1.3 \%$ propylene. The exact temperatures and pressures of the exit streams depend on the outlet purities and the process used (membrane, distillation, or hybrid), but were kept within the ranges shown in Figure IV-2. All streams exit the system as saturated liquids.

\section{MEMBRANE PROCLCS DESCRIPTION}

Conventional polymer membranes studied for similar separations have not shown good performance because of the similar molecular size, solubility behavior, and vapor pressures of propane and propylene. However, another class of membranes, facilitated transport (FT) membranes, have been shown in laboratory studies to give good performance in this separation (Hughes et al., 1982; Teramoto et al., 1986; Koval and Spontarelli, 1988; Peinemann and Shukla, 1989). An FT membrane contains a compound that acts as a carrier by reversibly binding to the species of interest. In this case, silver ions reversibly bind to the double bond portion of propylene and facilitate its transport across the membrane. Propane, which does not contain a double bond, is unaffected by the silver.

The mechanism by which separation takes place in an FT membrane is shown in Figure IV-3. The first step is the dissolution of propane and propylene into the membrane from the high pressure side (feed-side). Although the solubility of both compounds in most membrane materials is similar, some of the propylene reacts with the silver so that the total quantity of propylene contained in the membrane can be much greater than that of propane. The three species (propane, propylene, and propylene/silver complex) diffuse across the membrane, and propane and propylene are desorbed from the membrane at the low pressure side. Desorption of propylene at the low pressure side results in dissociation of the propylene/silver complex. The facilitated portion of the total propylene transport will be significant only if tie ratio of bound propylene to unbound propylene is large; the more significant the facilitated portion, the more selective the membrane for propylene over propane. The ratio of bound to unbound propylene is a function of the concentration of silver and of the equilibrium constant for the reaction between silver and propylene.

Typically, FT membranes have been studied in the form of an immobilized liquid membrane (ILM; Teramotc et al., 1986), a microporous membrane whose pores are filled with a solution containing the dissolved carrier. Transport takes place only in the solution-filled pores. Modules with 


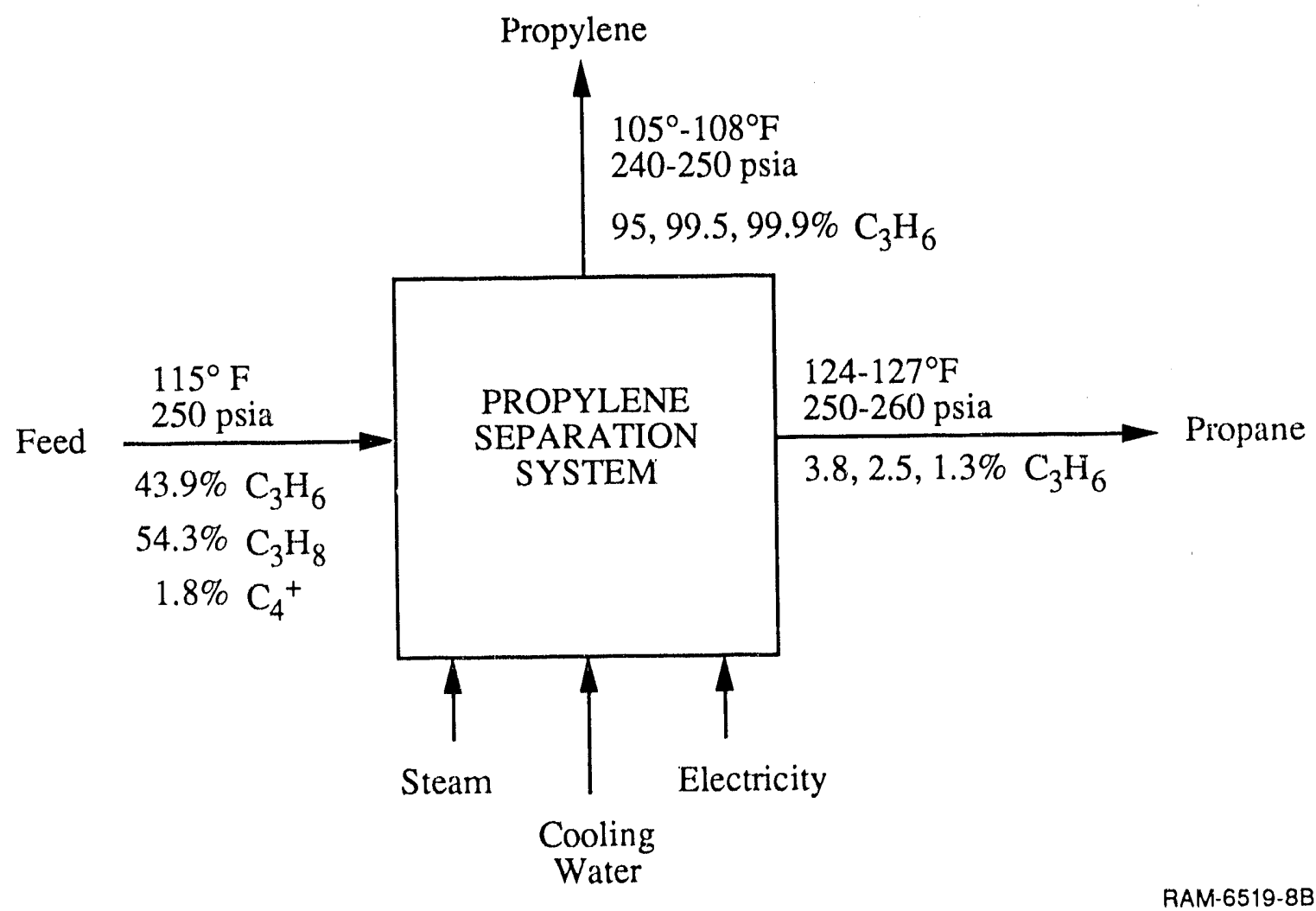

Figure IV-2. Inlet and outlet conditions for propylene/propane separation system. 


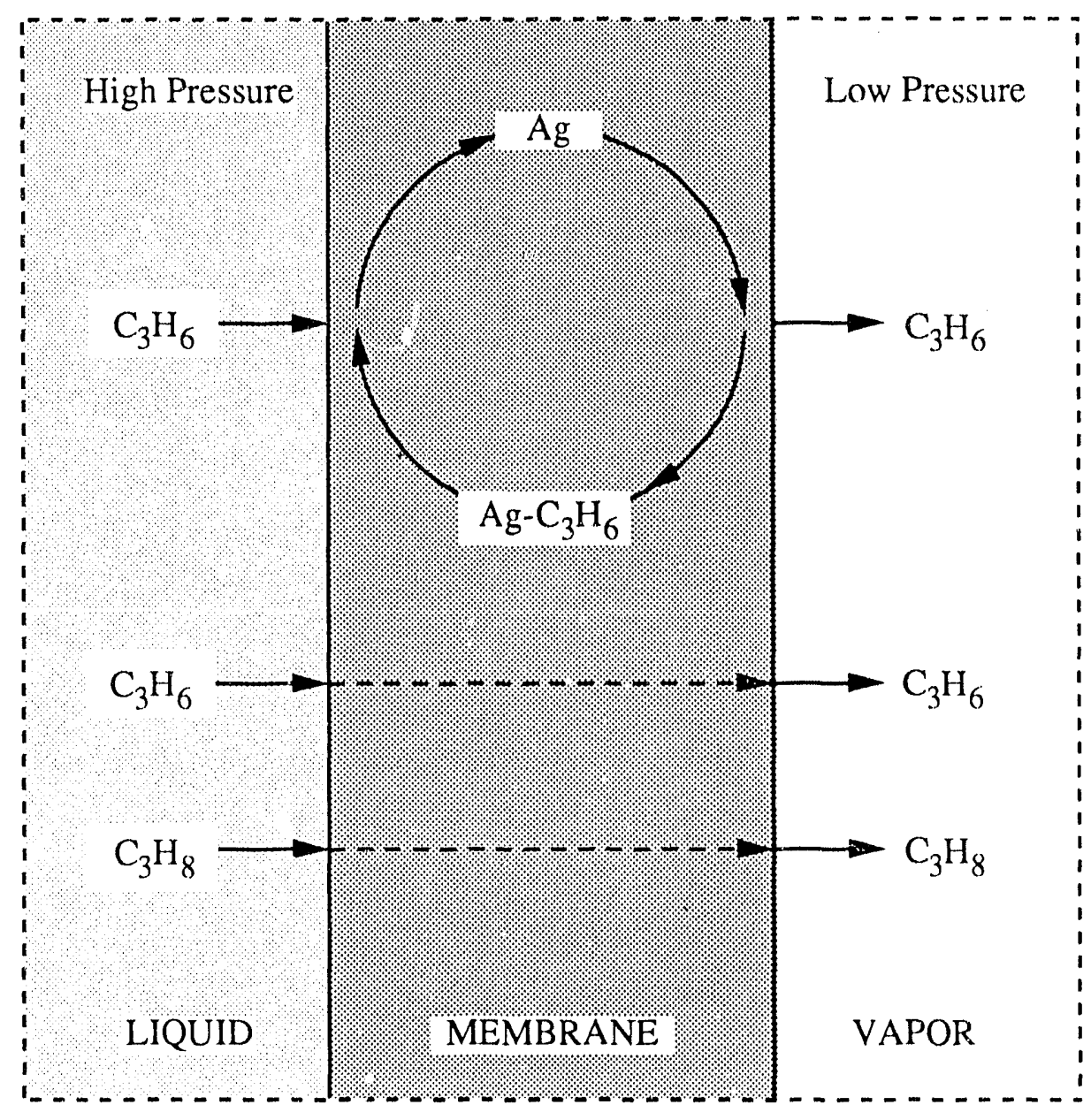

Facilitated

Transport

Solution-Diffusion

Transport

RAM-6519-9

Figure IV-3. Transport mechanisms for propylene/propane separation in a facilitated transport membrane. 
these membranes have not been produced commercially, primarily because of instability. If the pressure drop across the membrane is too high, the solution will be blown out of the membrane pores, and the membrane will be ruined. Another problem is the evaporation of the solvent from the membrane pores; some means of replenishing this solvent or preventing the solvent evaporation must be used if the membranes are to remain active.

Another form of FT membrane, the fixed carrier membrane (FCM), has also been studied for a variety applications including olefin/paraffin separation (Koval and Spontarelli, 1988). An FCM consists of an ion exchange membrane into which the carrier species has been ionically exchanged. Because the carrier is ionically bonded to the membrane, it is more stable than an ILM.

In our membrane system, the feed will be a saturated liquid, and the propylene permeate will be a vapor. Membrane separations where the feed is liquid and the permeate is vapor are called pervaporation systems to differentiate them from systems where no phase change occurs. The heat of vaporization required to effect this phase change must be supplied by preheating the feed, by heating the membrane module, or by using a series of small membrane modules with heaters between them.

In our membrane process for propylene splitting (Figure IV-4), the feed-side is maintained at a constant temperature by heating with steam. The residue stream is heated slightly after leaving the membrane so that liquid leaving the separation system is saturated as we specified earlier. The permeate stream is drawn off at atmospheric pressure, compressed to the feed pressure, and condensed to a saturated liquid.

The membrane module configuration for this application could be either spiral wound or hollow fiber. To maintain a constant temperature on the feed side of the membrane, the modules could be designed to include internal heating elements; however, a simpler approach would be to arrange the modules in series with heat exchangers between each stage.

In a real-world installation, the possibility of poisoning the silver in the membrane (rendering it inactive) must be considered. Impurities that may poison the silver include reducing species such $\mathrm{H}_{2} \mathrm{~S}, \mathrm{H}_{2}$, or acetylenes (which can irreversibly bind to the silver and may form explosive compounds). These silver poisons are likely to be found in the mixture entering the membrane in trace quantities; if trace quantities are enough to shorten the life of the membrane, they must either be removed prior to the membrane or a method for regenerating the membrane must be developed. There are many technologies for removal of impurities; however, we have not included their cost in our analysis because we do not expect their cost to be great. 


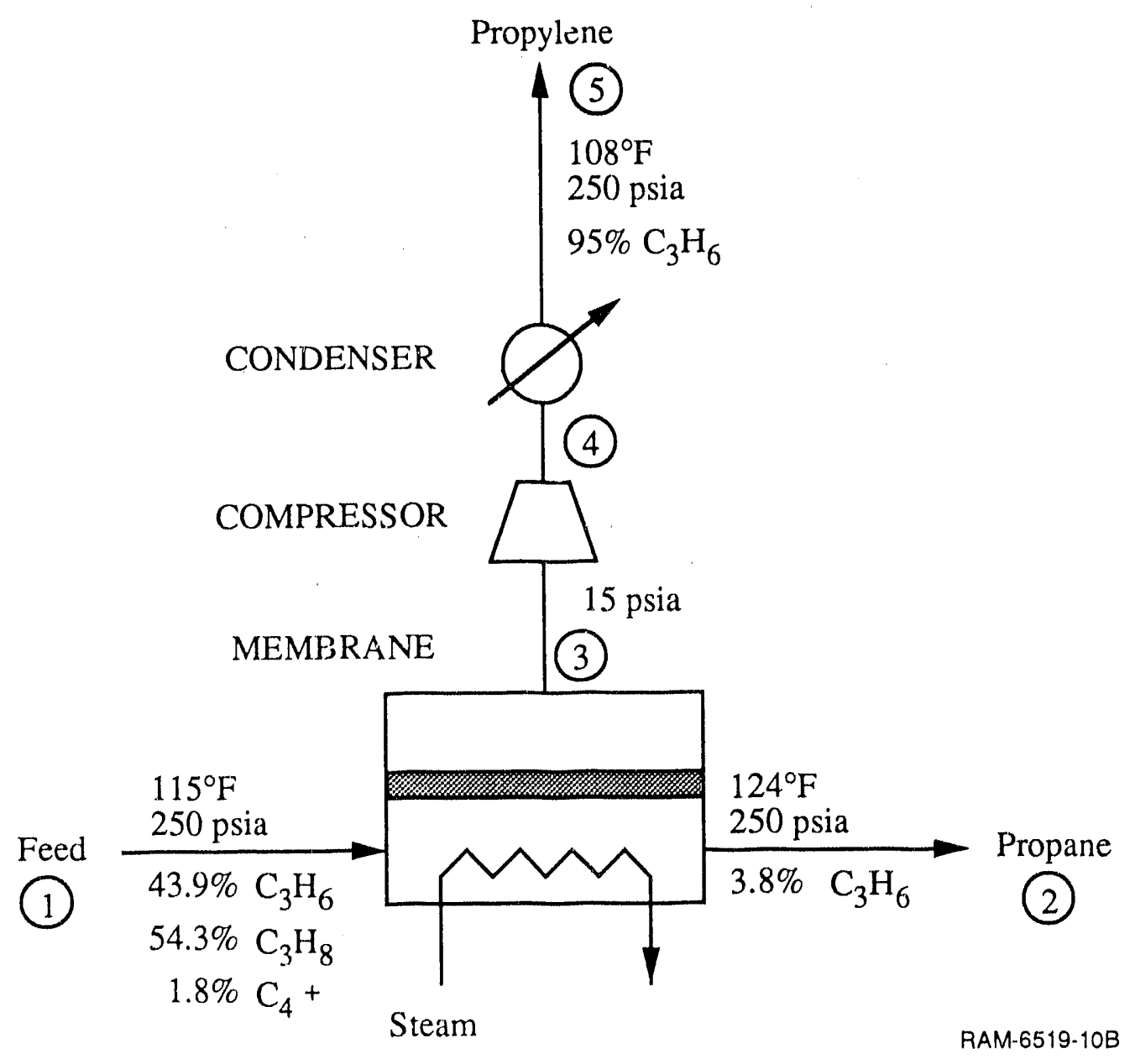

Figure IV-4. Membrane system for production of $95 \%$ pure propylene. 


\section{MEMBRANE PROCESS MODEL}

To simulate the performance of the FT membrane separation process, a computer model was developed based on the mechanism described above. The fluxes of paraffin (propane) and olefin (propylene) across the membrane are given by

$$
\begin{gathered}
N_{p}=\frac{1}{L} D_{p}\left[C_{p}(0)-C_{p}(L)\right] \\
N_{o}=\frac{1}{L} D_{0}\left(C_{o}(0)-C_{o}(L)\right)+\frac{1}{L} D_{c}\left(C_{c}(0)-C_{c}(L)\right)
\end{gathered}
$$

and

$$
\begin{gathered}
C_{p}(0)=H_{p} P_{p}(0) ; C_{p}(L)=H_{p} P_{p}(L) \\
C_{o}(0)=H_{o} P_{o}(0) ; C_{-}(L)=H_{o} P_{o}(L) \\
C_{c}(0)=\frac{K C_{o}(0) C_{T}}{1+K C_{0}(0)} \\
C_{c}(L)=\frac{K C_{i}(L) C_{T}}{1+K C_{o}(L)}
\end{gathered}
$$

where

$N_{p}$ and $N_{0}=$ the fluxes of the paraffin and the olefin across the membrane $\mathrm{L}=$ the membrane thickness

$D_{p}$ and $D_{0}=$ the diffusivities of the paraffin and the olefin in the membrane $C_{p}(0)$ and $C_{o}(0)=$ the concentrations of the paraffin and the olefin in the membrane at the feed-side

$C_{p}(L)$ and $C_{o}(L)=$ the concentrations of the paraffin and the olefin in the membrane on the permeate-side

$\mathrm{D}_{\mathrm{C}}=$ the diffusivity of complex in the membrane

$\mathrm{C}_{\mathrm{C}}(\mathrm{L})=$ the concentration of complex in the membrane at the permeate-side

$\mathrm{H}_{\mathrm{p}}$ and $\mathrm{H}_{\mathrm{O}}=$ the Henry solubility coefficients of the paraffin and the olefin in the membrane $P_{p}(0)$ and $P_{0}(0)=$ the feed-side partial pressures of the paraffin and the olefin 
$P_{p}(L)$ and $P_{o}(L)=$ the permeate-side partial pressures of the paraffin and the olefin

$\mathrm{C}_{\mathrm{c}}(0)=$ the concentration of complex in the membrane at the feed-side

$\mathrm{K}=$ the reaction equilibrium constant

$\mathrm{C}_{\mathrm{T}}=$ the total concentration of silver in the membrane

The assumptio is used in developing the membrane model are given in Table IV-1; full details of the model development are beyond the scope of this report. (Details of a gas phase FT membrane module model can be found in Gottschlich et al., 1988). Membrane properties required by the model were taken from laboratory studies of similar systems reported in the literature. The membrane properties used in the simulations (Table IV-2) are based on the results of Teramoto et al. (1986) for an ILM. The membrane model was interfaced with a commercial process simulation package (ASPEN/ SP by JSD Simulation Service Company, Denver, CO; now part of Simulation Sciences, Irvine, $\mathrm{CA}$ ) which performed material and energy balances and economic calculations.

The membrane model assumption of isothermal operation requires that energy be put into the system to supply the heat of vaporization for the pervaporation step. This energy requirement was calculated by performing an enthalpy balance around the membrane module with the assumption that the permeate and residue streams leave the module at the same temperature.

\section{DISTILLATION PROCESS DESCRIPTION}

Distillation is the process currently used commercially for propylene splitting. For propane/ propylene separation, distillation requires large columns and high energy inputs because of the low relative volatility $(<1.2)$. The distillation system we have used for propylene splitting is shown in Figure IV-5. Reboiler energy is supplied by low pressure steam, and cooling water is used in the condenser. A process option, not shown in Figure IV-5, is to include a heat exchanger between the reboiler and the condenser. Our base case does not include such a heat exchanger, although any energy savings from such a heat exchanger are easily calculated from our base case results.

\section{DISTILLATION PROCESS MODEL}

The desiggn of a distillation column is a complex optimization problem because of the many process variables that can be manipulated. The most important of these variables are the reflux and boilup ratios, the number of trays, and the location of the feed. In this example, two of these variables, the reflux and boilup ratios, are manipulated to obtain the specified values for the propylene concentration leaving at the top and the bottom of the column. Of the two remaining variables, we have chosen to fix the number of trays used in all calculations (152 equilibrium trays). The feed 


\section{Table IV-1 \\ ASSUMPTIONS USED IN DEVELOPMENT OF MODEL OF MEMBRANE MODULE FOR PROPYLENE/PROPANE SEPARATION}

1. Cross-flow module configuration.

2. Negligible pressure drop on feed-side and permeate-side streams

3. Instantaneous propylene/silver reaction.

4. Concentration-independent reaction equilibrium constant, solubilities, and diffusivities.

5. No gas or liquid phase mass transfer resistances.

6. Steady state.

7. Plug flow in gas and liquid phases.

8. Isothermal operation.

Table IV-2

MEMBRANE PROPERTIES USED IN THERMODYNAMIC AND ECONOMIC EVALUATIONS FOR PROPYLENE/PROPANE SEPARATION

\begin{tabular}{|c|c|}
\hline $\begin{array}{l}\text { Propylene } \\
\text { Solubility } \\
\text { Diffusivity }\end{array}$ & $\begin{array}{l}209 \mathrm{~atm}-\mathrm{L} / \mathrm{mol} \\
1.63 \times 10^{-5} \mathrm{~cm}^{2} / \mathrm{s}\end{array}$ \\
\hline $\begin{array}{l}\text { Propane } \\
\text { Solubility } \\
\text { Diffusivity }\end{array}$ & $\begin{array}{l}662 \mathrm{~atm}-\mathrm{L} / \mathrm{mol} \\
1.61 \times 10^{-5} \mathrm{~cm}^{2} / \mathrm{s}\end{array}$ \\
\hline $\begin{array}{l}\text { Propylene-SIlver Complex } \\
\text { Diffusivity } \\
\text { Equilibrium constant }\end{array}$ & $\begin{array}{l}1.06 \times 10^{-5} \mathrm{~cm}^{2} / \mathrm{s} \\
100 \mathrm{~L} / \mathrm{mol}\end{array}$ \\
\hline Silver Concentration & 2 molar (aqueous) \\
\hline $\begin{array}{l}\text { Membrane } \\
\text { Porosity/tortuosity ratio } \\
\text { Thickness }\end{array}$ & $\begin{array}{l}0.25 \\
1 \mu \mathrm{m}\end{array}$ \\
\hline Thermodynamlc Propertles & $\begin{array}{l}\text { Calculated using the Peng-Robinson equation- } \\
\text { of-state with binary interaction parameters }\end{array}$ \\
\hline
\end{tabular}




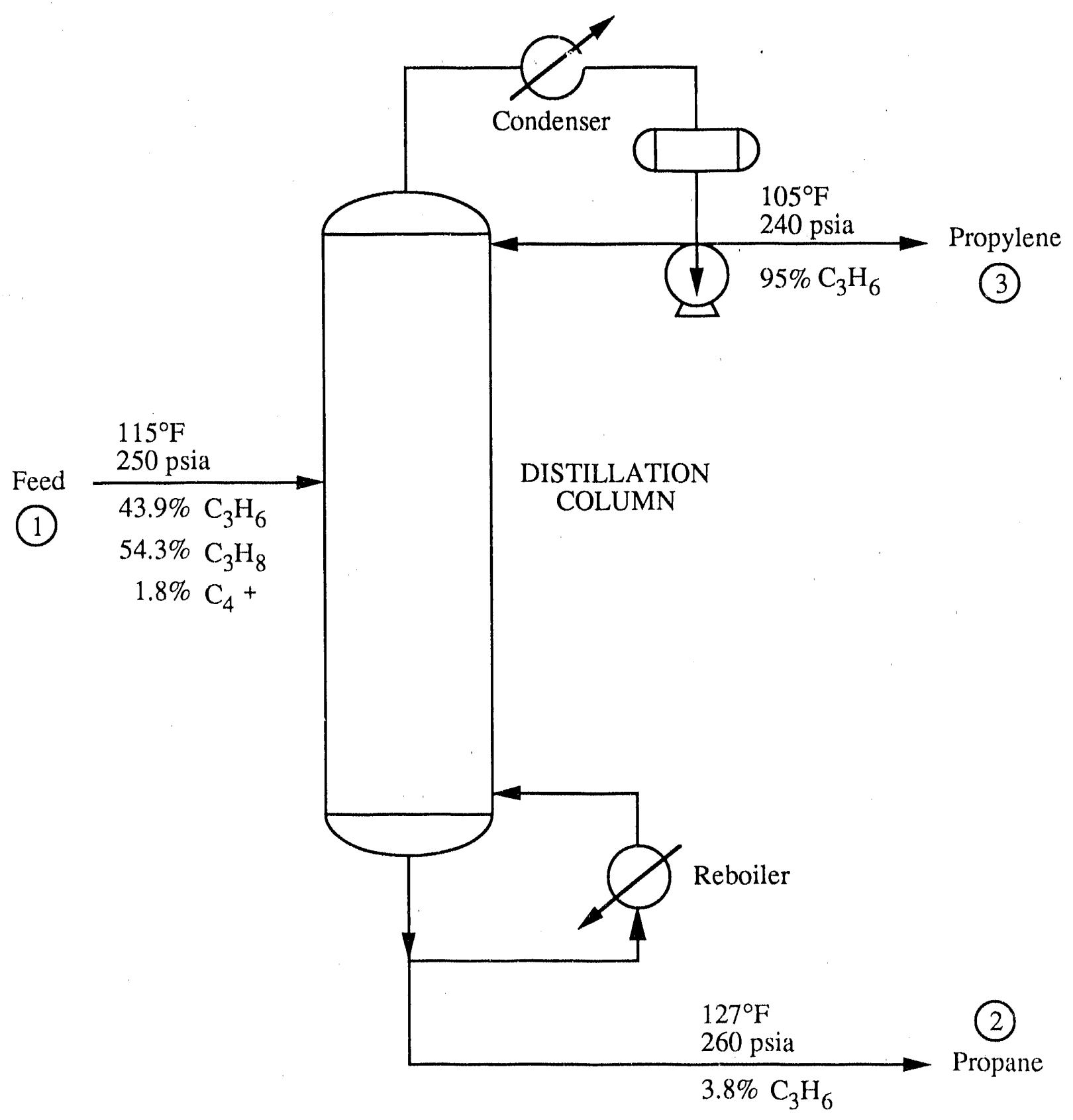

RAM-6519-11B

Figure IV-5. Distillation system for production of $95 \%$ p!!re propylene. 
location will be optimized to give the lowest overall processing cost. We have simulated the column using the ASPE V/SP distillation model. The model performs phase equilibria calculations at each tray using the Peng-Robertson equation of state (with binary interaction parameters). The assumptions used in the distillation simulation are listed in Table IV-3.

\section{Table IV-3 \\ ASSUMPTIONS USED IN DISTILLATION COLUMN SIMULATION OF PROPYLENE/PROPANE SEPARATION}

1. Top and bcttom streams leave as saturated liquids.

2. 152 equilibrium stages are used in all calculations (plus reboiler and condenser).

3. Feed enters at the tray that results in the lowest overall processing cost.

4. Reflux and boilup ratios are manipulated to give the desired top and bottom cornpositions.

5. Phases are in equilibrium at each stage.

6. 20 psi pressure drop across the column.

7. Thermodynamic properties are calculated using the Peng-Robinson equation of state with binary interaction parameters.

\section{HYBRID PROCESS DESCRIPTION}

Figure IV-6 shows three possible distillation/membrane hybrid configurations. In the first configuration (top of figure), the feed first enters the membrane; the residue stream leaves the membrane at the desired propane stream composition, and the permeate stream becomes the feed to the distillation column. The propylene product stream leaves the top of the column, and the bottom stream is recycled to the membrane feed. (To reduce thermodynamic inefficiencies resulting from mixing, the composition of the column bottom would probably be specified to equal the membrane feed composition.) In the second configuration, the feed stream first enters the distillation column. The propane stream leaves at the bottom, and the column top is fed to the membrane. The membrane residue, enriched in propane, is recycled to the column, and the propylene product exits as 

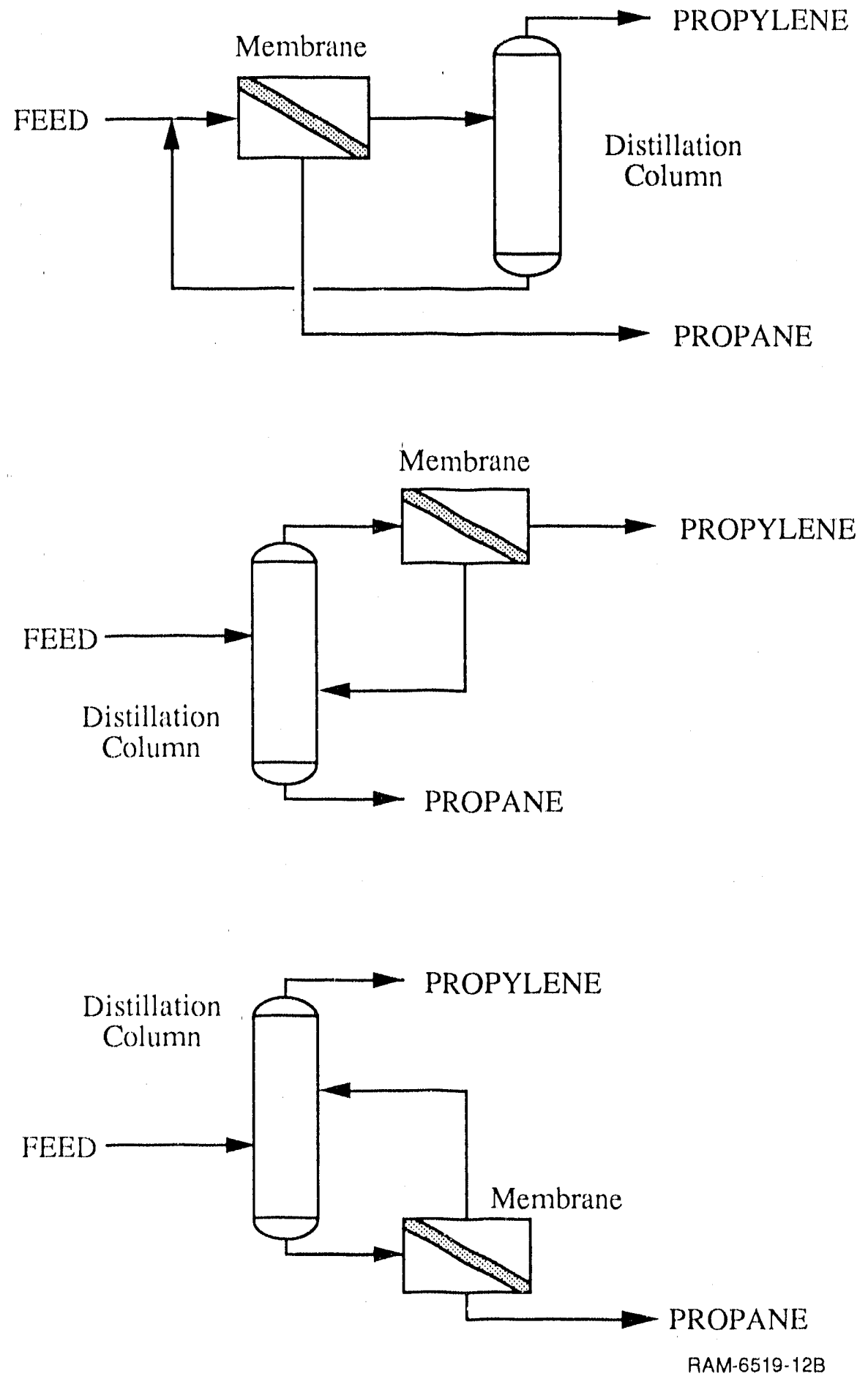

Figure IV-6. Hybrid configurations for propylene separation. 
the permeate stream. The third configuration is similar to the second except that the membrane is located at the bottom of the column. The membrane permeate is recycled $\mathrm{s}$ the column, and the propane stream exits as the residue stream.

We chose to use the third configuration for several reasons. As in all separation processes, there is a trade-off between product purity and product recovery; to recover a high purity product, the fractional recovery is usually small and vice versa. In the first configuration, the membrane must produce high purity propane starting from dilute feed and therefore is likely to have a low propane recovery. A low propane recovery requires a high recycle rate between the distillation column and the membrane to meet the propylene purity specification; high recycle rates necessitate large and expensive process equipment. Therefore, the first configuration, which would probably require high recycle rates, was eliminated as a potential system for this application.

The two remaining configurations do not have the same problem that caused elimination of the first; their feeds are preconcentrated by the distillation column, and thus the membrane system product recoveries should be acceptable. To choose between these two, we followed a rule-ofthumb for membrane systems: to minimize the membrane area requirement, choose a membrane system that causes the minor component of the membrane feed to be concentrated in the permeate stream. Thus, the third configuration was chosen for evaluation in this study.

Figure IV-7 shows the complete flowsheet for the hybrid process. The propylene concentration in the stream that leaves the column and enters the membrane (referred to as the intermediate mole fraction of propylene, IMFP) can be varied by adjusting the operating conditions in the distillation column. If the IMFP is close to the final propylene product value, then the distillation column is doing most of the separation; conversely, if the IMFP is close to the feed value, then the membrane is doing most of the separation. By manipulation of the IMFP, the thermodynamic extent of separation due to the membrane section, $\phi_{\mathrm{m}}$, can be varied from 0.0 (distillation only) to 1.0 (membrane alone). By varying $\phi_{\mathrm{m}}$, we can evaluate the performance of not just a single hybrid system bui the complete range of hybrids from those that are primarily membrane processes to those that are primarily distillation processes.

In Figure IV-7, the two sections of the hybrid process, membrane and distillation, are shown in dashed boxes. Thermodynamic and economic results are reported both for the overall process and for the individual sections. The models used to describe the hybrid process are the same as those used for the membrane module and distillation column. 


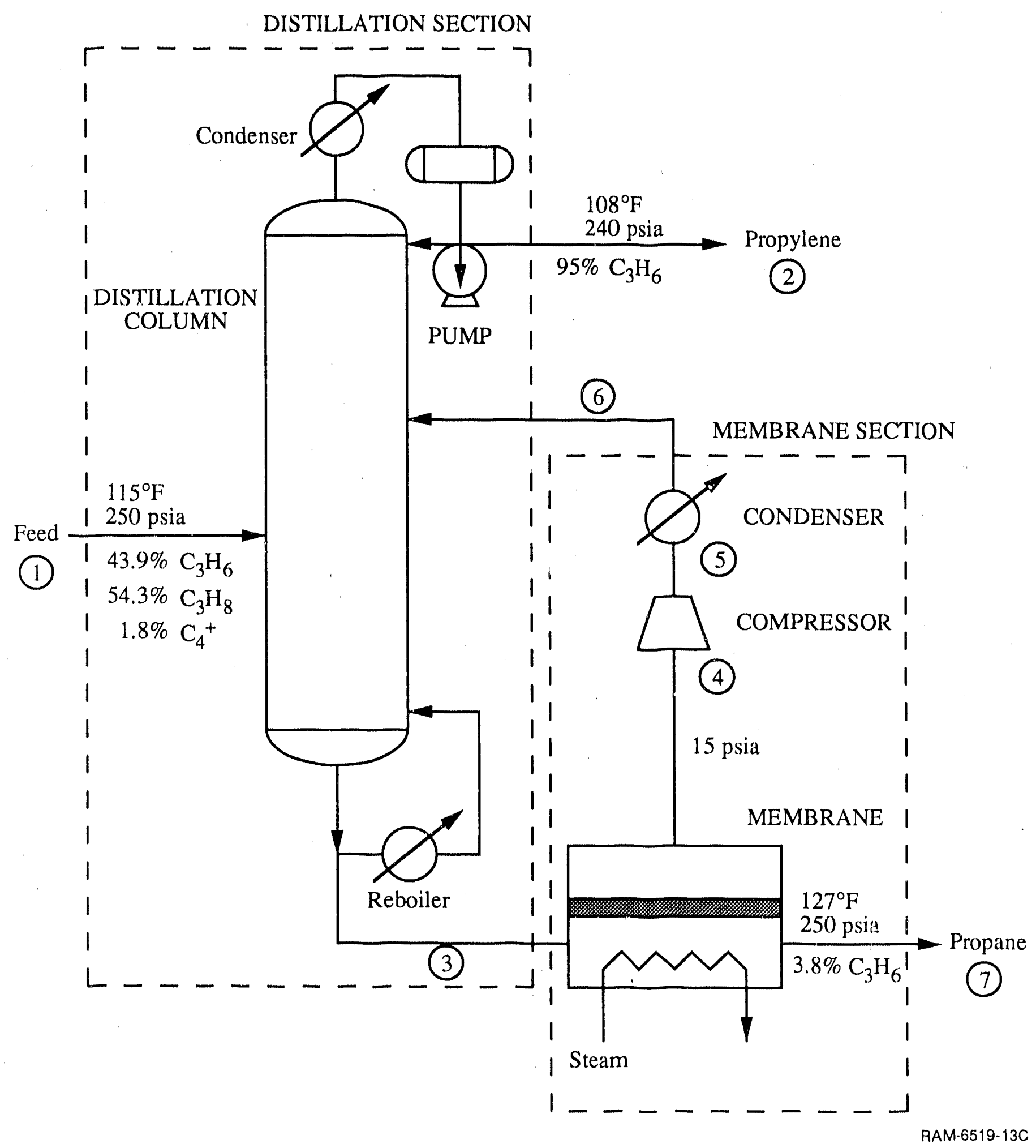

Figure IV-7. Hybrid system for production of $95 \%$ pure propylene. 


\section{THERMODYNAMIC AND ECONOMIC EVALUATIONS}

Thermodynamic and economic evaluations were performed as discussed Chapter III. The processing cost, $\mathrm{PC}$, is reported as dollars per pound of propylene product (not on pure propylene basis). Table IV-4 gives economic parameters specific to this case study.

\section{Table IV-4 \\ PARAMETERS FOR ECONOMIC EVALUATION OF PROPANE/PROPYLENE HYBRID SYSTEMS (Basis: 500 Million Pounds Propylene Per Year)}

Installed membrane system cost
Replacement membrane cost
Membrane life
Distillation tray efficiency
Distillation tray spacing
Distillation column material
General service facilities

Installed membrane system cost

Replacement membrane cost
$\$ 22.30 / \mathrm{ft}^{2}$

$\$ 9.29 / \mathrm{ft}^{2}$

5 years

0.80

$1.5 \mathrm{ft}$

Carbon steel

$13 \%$ of total PFI

A separation system producing propylene and propane streams containing $95 \%$ and $3.8 \%$ propylene, respectively, was considered the base case system, although two other product purities were also examined $(99.5 \%$ and $99.9 \%$ pure propylene product with corresponding propane streams containing $2.5 \%$ and $1.3 \%$ propylene, respectively). Because the systems with membranes alone or distillation alone aie really just extreme cases of the hybrid system, extremes wherein all the separation is performed by one technology, there is no need to give separate evaluations for the stand-alone technologies. Results for all systems, membrane alone, distillation alone, and the entire range of possible hybrid systems can be displayed on a single graph.

\section{Base Case Evaluations}

The systems shown in Figures IV-4 (membrane), IV-5 (distillation alone), and IV-7 (hybrid) were evaluated for production of $95 \%$ propylene. We discuss here a particular hybrid with extent of separation, $\phi_{\mathrm{m}}$, equal to 0.69 simply to have a concrete example of a hybrid. 
Table IV-5 shows the energy consumption of the three separation systems. The membrane system uses equal amounts of electricity and steam (based on heat content) with a thermal energy equivalent" consumption of $460 \mathrm{Btu} / \mathrm{lb}$ propylene product stream. The distillation system uses very little electricity. However, its steam consumption is more than ten times greater than that of the membrane system, and the resulting thermal energy equivalent consumption is more than five times greater than thäi of the membrane system. The hybrid process (based on $\phi_{\mathrm{m}}=0.69$ ) gives energy consumption results between that of the membrane and distillation processes. (Complete details of simulation for the three systems are given in Appendix A.)

Table IV-6 shows the economic results for the three systems. The membrane system has a capital cost of $\$ 4$ million, of which only $\$ 0.3$ million is for the membrane modules; most of the system's capital cost is for the compressor. The distillation system capital cost is much greater, $\$ 20$ million, and the hybrid system capital cost is intermediate at $\$ 12$ million.

Table IV- 6 also includes a breakdown of the processing cost for the three systems. The membrarie system has a PC of 0.54 cents/lb product of which $30 \%$ is a result of electricity expense. The PC for the distillation system is approximately five :mes greater, 2.72 cents/lb product, of which steam accounts for over $40 \%$. The hybrid process results in a PC of 1.58 cents/lb product, of which steam is the major expense, accounting for over $30 \%$.

The results of these evaluations indicate that, in terms of both energy and economics, the membrane process is superior to the distillation process. The hybrid process is better than distillation alone, but is inferior to the membrane alone. Before making any further conclusions regarding these systems, we present the thurmodynamic efficiencies and processing costs for the entire range of systems $\left(0 \leq \phi_{m} \leq 1\right)$

Figure IV-8a shows EFF versus $\phi_{m}$ for the membrane section, distillation section, and the entire process for production of $95 \%$ propylene. The most obvious observation from this graph is that the membrane section is much more efficient than the distillation section for all systems; membrane efficiency is on the order of $25 \%$, and distillation efficiency is about $5 \%$. (The overall efficiency is not simply a linear combination of the distillation and membrane efficiencies and therefore may not have the shape which is initially expected.) The figure shows that the membrane alone is more efficient than distillation alone or any of the hybrid processes.

\footnotetext{
* Thermal energy equivalents include steam and electricity and are calculated based on an electric power gencration efficiency of $33 \%$ and a steam gencration efficiency of $85 \%$.
} 
Table IV-5

ENERGY REQUIREMENTS FOR PROPYLENE/PROPANE SEPARATION

(Basis: $95 \%$ propylene, 500 million lb product per year)

\begin{tabular}{|c|c|c|c|c|c|}
\hline & \multicolumn{5}{|c|}{ Process } \\
\hline & \multirow{2}{*}{$\begin{array}{c}\text { Membrane } \\
\text { Alone }\end{array}$} & \multirow{2}{*}{$\begin{array}{c}\text { Distillation } \\
\text { Alone }\end{array}$} & \multicolumn{3}{|c|}{ Hybrid $\left(\phi_{m}=0.69\right)$} \\
\hline & & & Memb. & Dist. & Iotal \\
\hline Steam (Btu/lb product) & 110 & 2,190 & 73 & 939 & 1,012 \\
\hline Electricity (Btu/lb product) & 110 & 6 & 70 & 3 & 73 \\
\hline $\begin{array}{l}\text { Thermal energy equivalent } \\
\text { (Btu/lb product) }\end{array}$ & 460 & 2,580 & 297 & 1,113 & 1,409 \\
\hline
\end{tabular}

Table IV-6

ECONOMIC RESULTS FOR PROPYLENE/PROPANE SEPARATION

(Bas!s: $95 \%$ propylene, 500 million lb product per year)

\begin{tabular}{|c|c|c|c|}
\hline \multirow[b]{2}{*}{ Cost } & \multicolumn{3}{|c|}{ Process } \\
\hline & $\begin{array}{c}\text { Membrane } \\
\text { Alene }\end{array}$ & $\begin{array}{l}\text { Distillation } \\
\text { Alone }\end{array}$ & $\begin{array}{c}\text { Hybrld } \\
(6 \mathrm{~m}=0.69)\end{array}$ \\
\hline Total capital (\$ millions) & 4.0 & 20.3 & 12.1 \\
\hline Membrane capital ( $\$$ millions) & 0.3 & -- & 0.2 \\
\hline Labor (cents/lb product) & 0.04 & 0.17 & 0.11 \\
\hline Steam (cents/lb product) & 0.06 & 1.15 & 0.54 \\
\hline Electricity (cents/lb product) & 0.16 & 0.0 & 0.11 \\
\hline Total operating cost ( $₫ /$ ib product) & 0.32 & 1.61 & 0.93 \\
\hline Processing cost (cents/lt product) & 0.54 & 2.72 & 1.58 \\
\hline
\end{tabular}




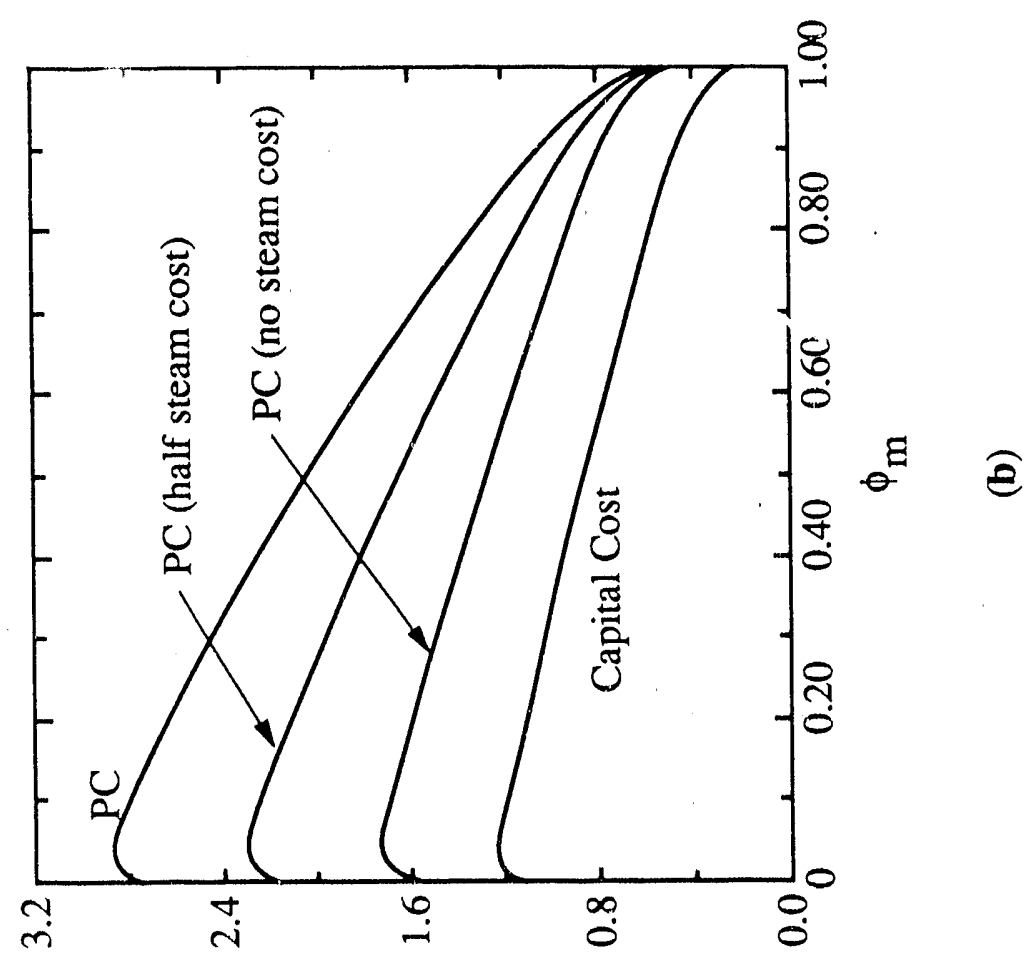

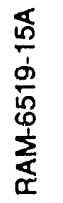
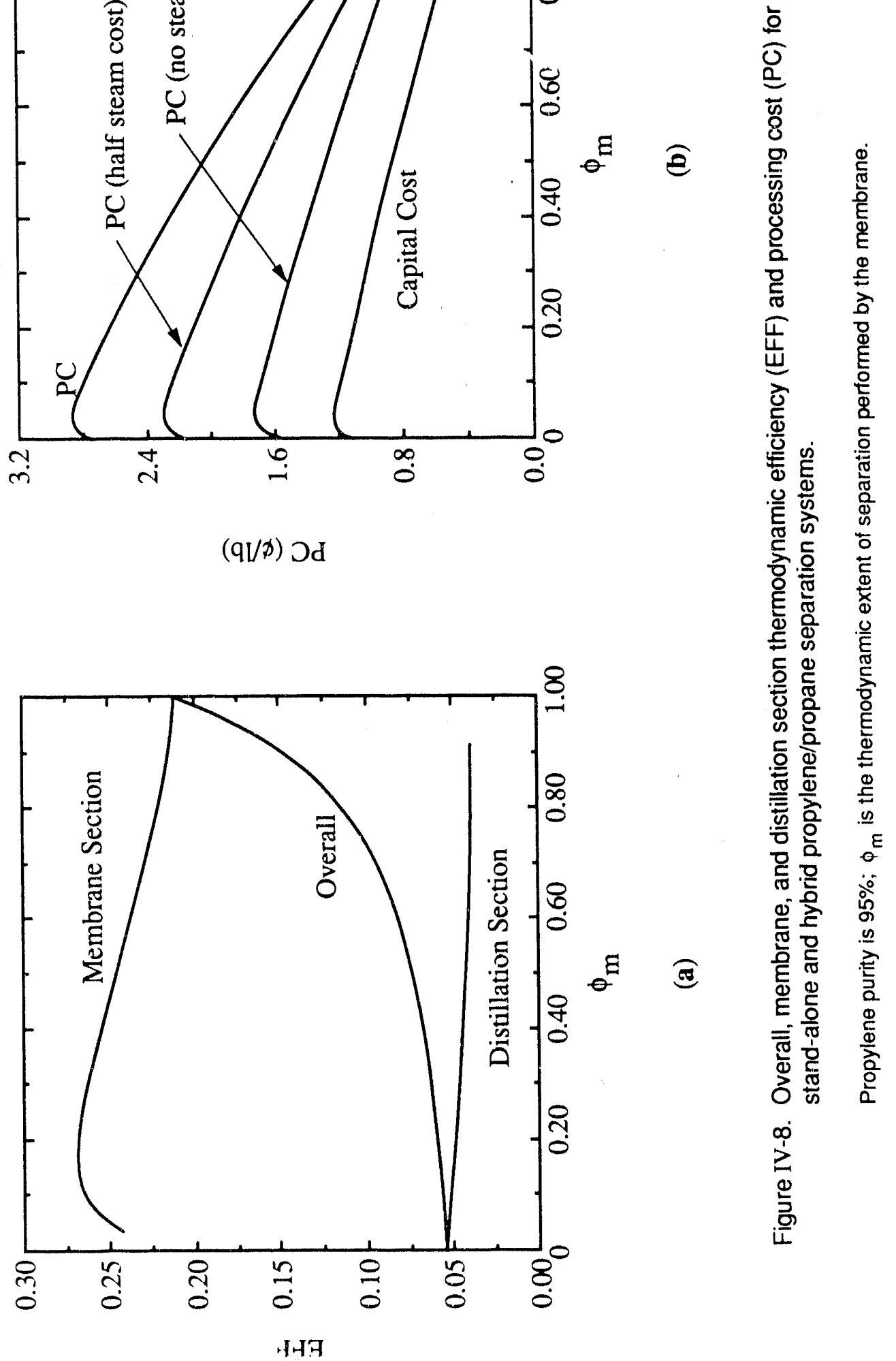

IV-19 
The membrane efficiency reaches a maximum at approximately $\phi_{\mathrm{m}}=0.20$. It has previously been recognized that the cost of a membrane unit operation reaches a minimum at a specific product purity (Gottschlich et al., 1989; the specific purity resulting in the optimurn performance is particularly sensitive to the permeate/feed pressure ratio, membrane selectivity, feed and composition, and the product recovery requirement). Therefore it is also not surprising that the availability efficiency should also show a maximum for one specific set of conditions. In this case, it is at a specific feed composition since all other variables are fixed. Although this maximum point in the membrane curve has a negligible influence on the shape of the overall efficiency curve (due to the large difference between the membrane and distillation curves), in other circumstances the maximum might be enough to cause a maximum in the overall curve.

Figure IV-8b shows PC versus $\phi_{m}$ for production of $95 \%$ propylene. In general, PC decreases steadily from a high value of 2.7 cents/lb propylene for distillation alone to a low of 0.54 cent $/ \mathrm{lb}$ for membrane alone. At the left side of the graph (distillation alone), there is a slight increase in $\mathrm{PC}$ in going from distillation alone to a hybrid containing a small membrane section. Similarly there is a greater increase in PC going from membrane alone to a hybrid using a small distillation section than is found throughout the midsection of the graph. These anomalous slopes at the sides of the graph are probably caused by the increase in capital cost resulting from addition of even an insignificantly small unit of a second technology (because of economies of scale, an insignificantly small distillation column may have a small but significant capital cost).

Also shown in Figure IV-8b are the PCs when steam is half the base case cost and when steam is free; even if steam is free, the membrane system has the lowest PC. As expected, changing the steam cost changes significantly the costs for distillation but not for the membrane system. Although not explicitly shown in Figure IV-8a, the effect of reducing the steam consumption in distillation (say, by heat exchange between the reboiler and condenser) can be estimated knowing that practically $100 \%$ of $A_{u t i l}$ in the distillation process is a result of steam use; the steam use would have to be reduced by $80 \%$ for the distillation section efficiency to be equivalent to that of the membrane section.

The portion of PC related to capital related expenses is shown in Figure IV-8b to be approximately $40 \%$. The capital costs follow the same general trend as PC; capital cost for the membrane alone is less than for that of distillation alone or any hybrid system.

Figures IV-8a,b show that the membrane process is superior to distillation or any of the hybrid processes for production of $95 \%$ propylene. Even if steam consumption by the distillation section could be reduced by $80 \%$, the membrane alone would still have the lowest capital and operating costs. 


\section{Sensitivity Analysis}

The effect of steam cost on distillation was discussed in the previous section, and although it is a major portion of the distillation cost, reducing its cost to zero still did not result in a PC with the distillation or hybrid systems lower than that with the membrine system. Other process variables which have a major affect on these separation systems are the desired product purity and the membrane properties; these will be discussed in the following sections.

Production of $\mathbf{9 9 . 5 \%}$ and $\mathbf{9 9 . 9 \%}$ Propylene. So far we have presented the results of processes for production of $95 \%$ propylene. The performance of these separation technologies can change markedly as the product purity specifications are changed. Figure IV-9 shows the overall efficiencies and PCs for production of $95 \%, 99.5 \%$ and $99.9 \%$ propylene. The most obvious difference between the high purity curves and the $95 \%$ curve is that the membrane alone is not represented by any data because it is not capable of meeting both the propylene and propane purity specifications. The maximum $\phi_{\mathrm{m}}$ for which a hybrid system will meet product specifications drops as the purity specifications become more strict. Thus as the product purity increases, the curves end further from the right side (membrane only) of the graph.

Another difference between the higher purity cases and the $95 \%$ case is that the efficiency goes down and the PC increases as the product specifications become higher. In general, PCs increase by about a factor of two for each increase in propylene purity, although the PCs for distillation alone increase much more than the PCs for the hybrid systems.

Membrane Properties. Although we performed these calculations based on membrane properties from experimental studies, it is likely that any commercial membrane developed from these laboratory efforts would not perform as well. Thus, it is worth examining the effect of varying the membrane properties on the membrane system performance. Similarly, variations in the distillation technology properties, the relative volatilities, will affect the performance of the distillation system; however, these properties are not easily varied in practice and therefore will not be examined.

The membrane properties listed in Table IV-2 are given in terms of solubilities, diffusivities, concentrations, and equilibrium constants. These quantities are not conventional properties typically used to describe membranes. Gas separation membrane properties are more commonly given in terms of selectivities and permeabilities. The permeability of a membrane to a particular species is defined by

$$
N_{i}=Q_{i}\left(P_{i}(0)-P_{i}(L)\right) / L
$$



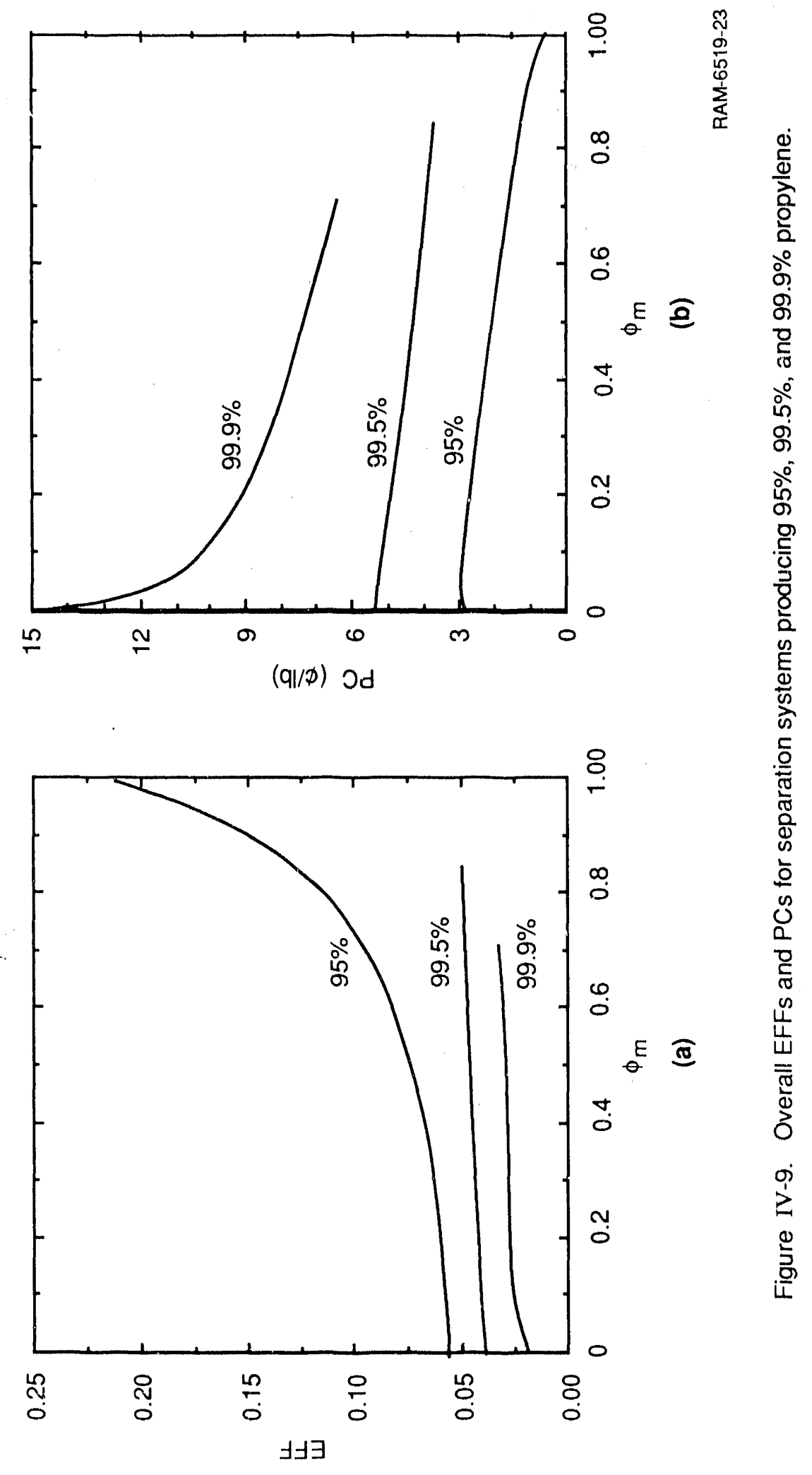
where $\mathrm{N}_{\mathrm{i}}$ is the flux of species $\mathrm{i}, \mathrm{Q}_{\mathrm{i}}$ is the permeability of species $\mathrm{i}, \mathrm{P}_{\mathrm{i}}(0)$ is the feed-side partial pressure of species $i, P_{i}(L)$ is the permeate-side partial pressure of species $i$, and $L$ is the membrane thickness. The selectivity, $\alpha_{i j}$, is the ratio of permeabilities of species $i$ to species $j$.

For the FT membrane, an effective permeability can be defined by replacing $\mathrm{Pi}_{\mathrm{i}}(0)$ with the fugacity of species $i$ (because the feed-side is a liquid in a pervaporation system), equating the flux given by Eqns. IV-1 or IV-2 with the flux given by Eqn. IV-7, and solving for Qi. The sèlectivity of an FT membrane is the ratio of the effective permeabilities. Because the flux of an FT membrane is a function of the feed-side composition, the selectivity of an FT membrane will change with position along the membrane. Figure IV-10 shows the effective selectivity of the membrane versus the feed-side propylene mole fraction. The selectivity increases as the propylene mole fraction decreases, from 60 at the feed end of the membrane to 350 at the residue end (99\% propylene product). Selectivities of 60 are usually considered quite good for gas separation or pervaporation membranes. The propane permeability, which is not facilitated, is constant throughout the membrane and has a value of 18 barrer*. This permeability is acceptable for gas separation or pervaporation membranes.

For comparison, Figure IV-11 shows the relative volatility, RV, for propylene over propane; the relative volatility determines the performance of a distillation column. The RV changes as the composition changes in the column and is reported as a function of column position. The RV varies between 1.07 and 1.17; typically distillations with RVs less than 1.5 are considered difficult. From these property values, it can be seen that we are comparing a very good membrane separation with a very difficult distillation separation.

To examine what would happen to the membrane system performance if an inferior membrane were used, we calculated selectivities for membranes with various carrier concentrations. These selectivities are shown in Figure IV-12 for carrier concentrations of 0.80, 1.0, 2.0, and 10.0 molar. The effect on selectivity is great; the change in selectivity is almost proportional to the change in carrier concentration (typical of "carrier dominated" facilitated transport).

Figure IV-13 shows the efficiency for distillation, membrane, and hybrid systems for production of $95 \%$ propylene with a carrier concentration of 1 molar. The steep drop in the membrane efficiency at the right side of the graph occurs because the membrane cannot do the separation by itself unless the permeate pressure is lowered from the value of 1 atm used in other calculations. Lowering the permeate pressure allows the membrane to perform the separation but requires a large additional utility input (electricity) for increased compression requirements on the permeate stream.

* 1 barrer $=10^{-10}\left(\mathrm{~cm}^{3}[\mathrm{STP}] / \mathrm{cm}-\mathrm{s}-\mathrm{cm} \mathrm{Hg}\right)$ 


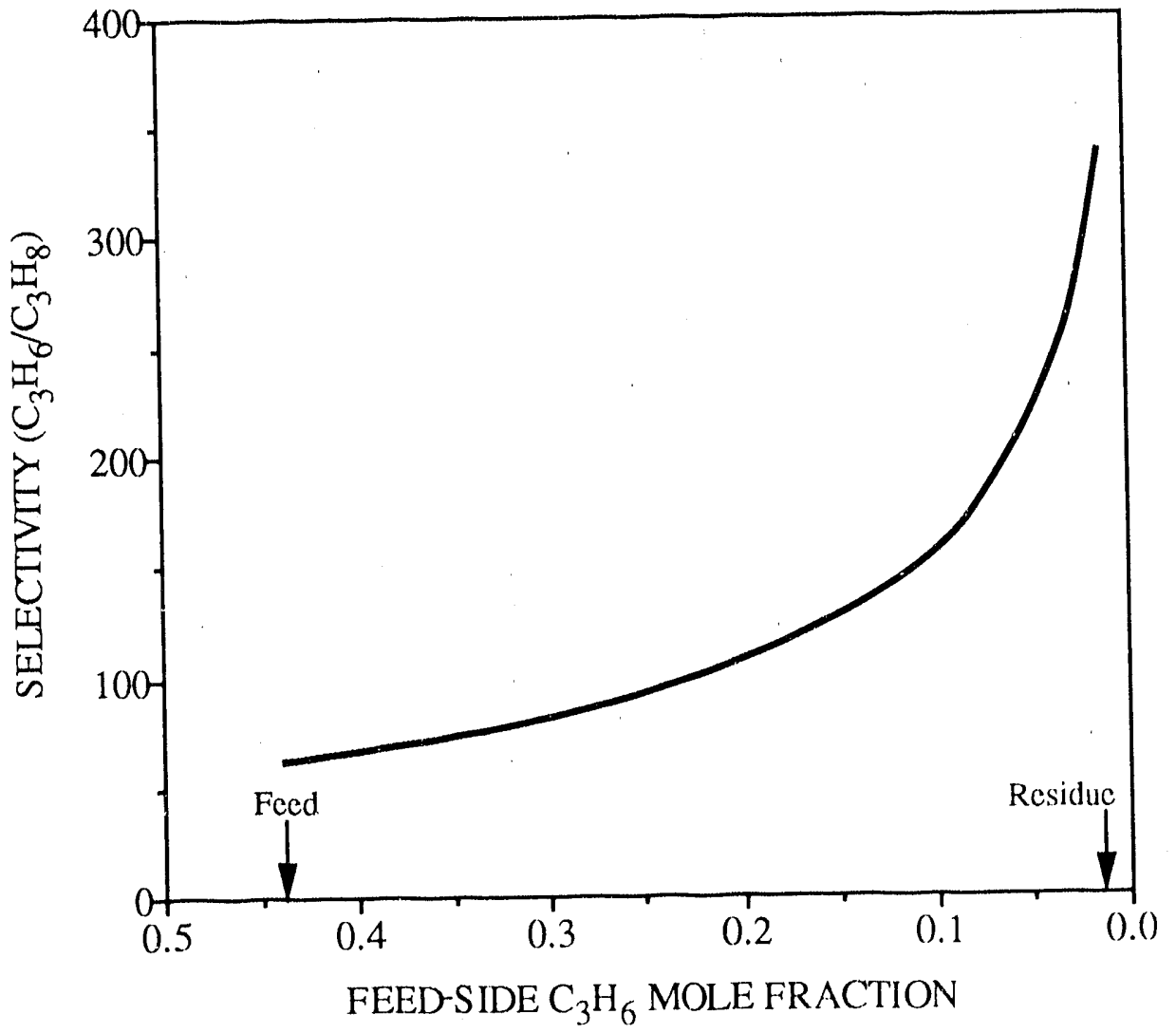

RAM-6519-17

Figure IV-10. Selectivity of FT membrane versus feed-side composition for propylene/propane separation. $(2.0 \mathrm{~mol} / \mathrm{L}$ silver concentration.)

The effective permeability of $\mathrm{C}_{3} \mathrm{H}_{8}$ has a constant value of 18 barrer. 


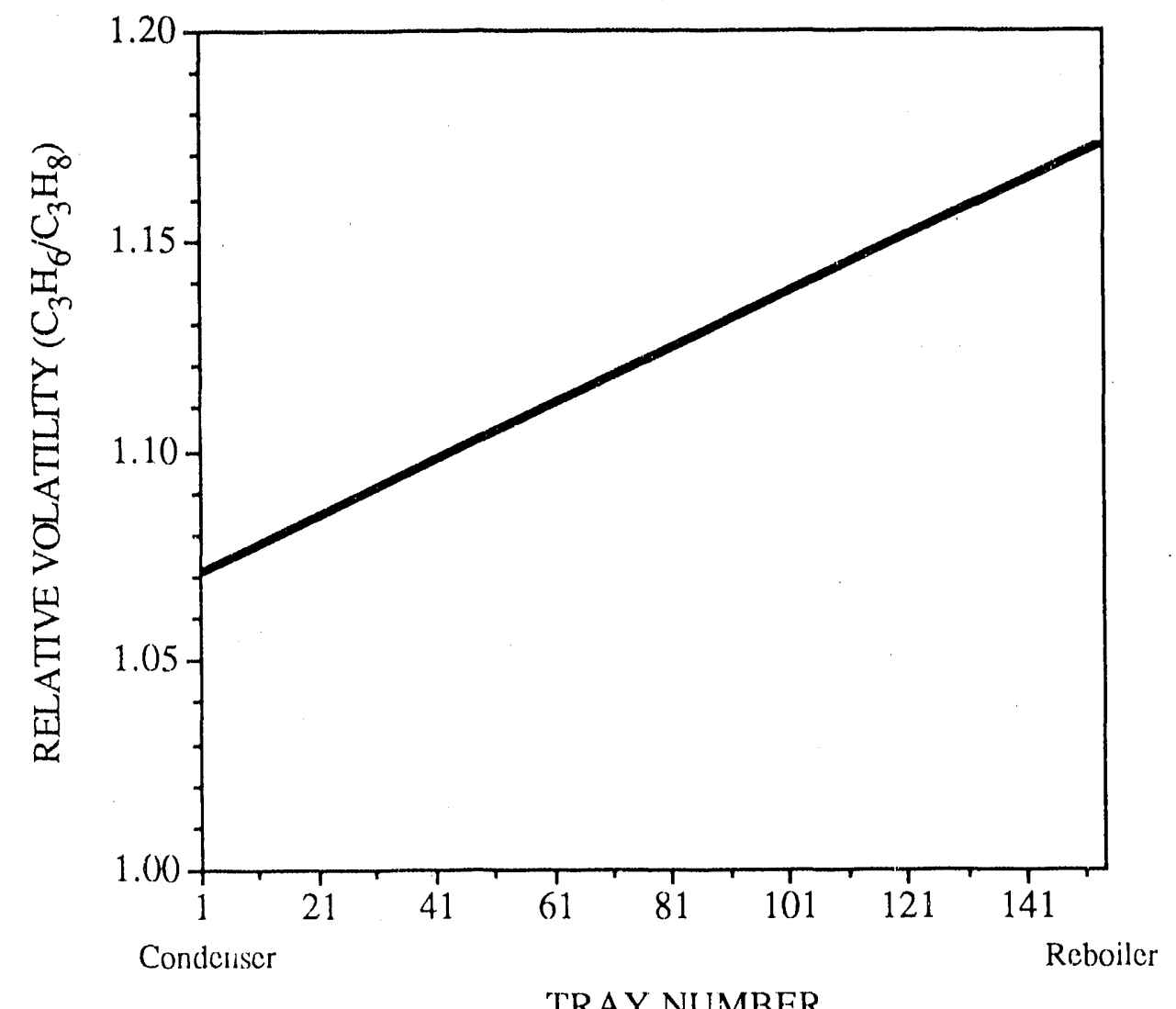

TRAY NUMBER

RAM-6519-18

Figure IV-11. Relative volatilities of propylene over propane versus position in the distillation column. 


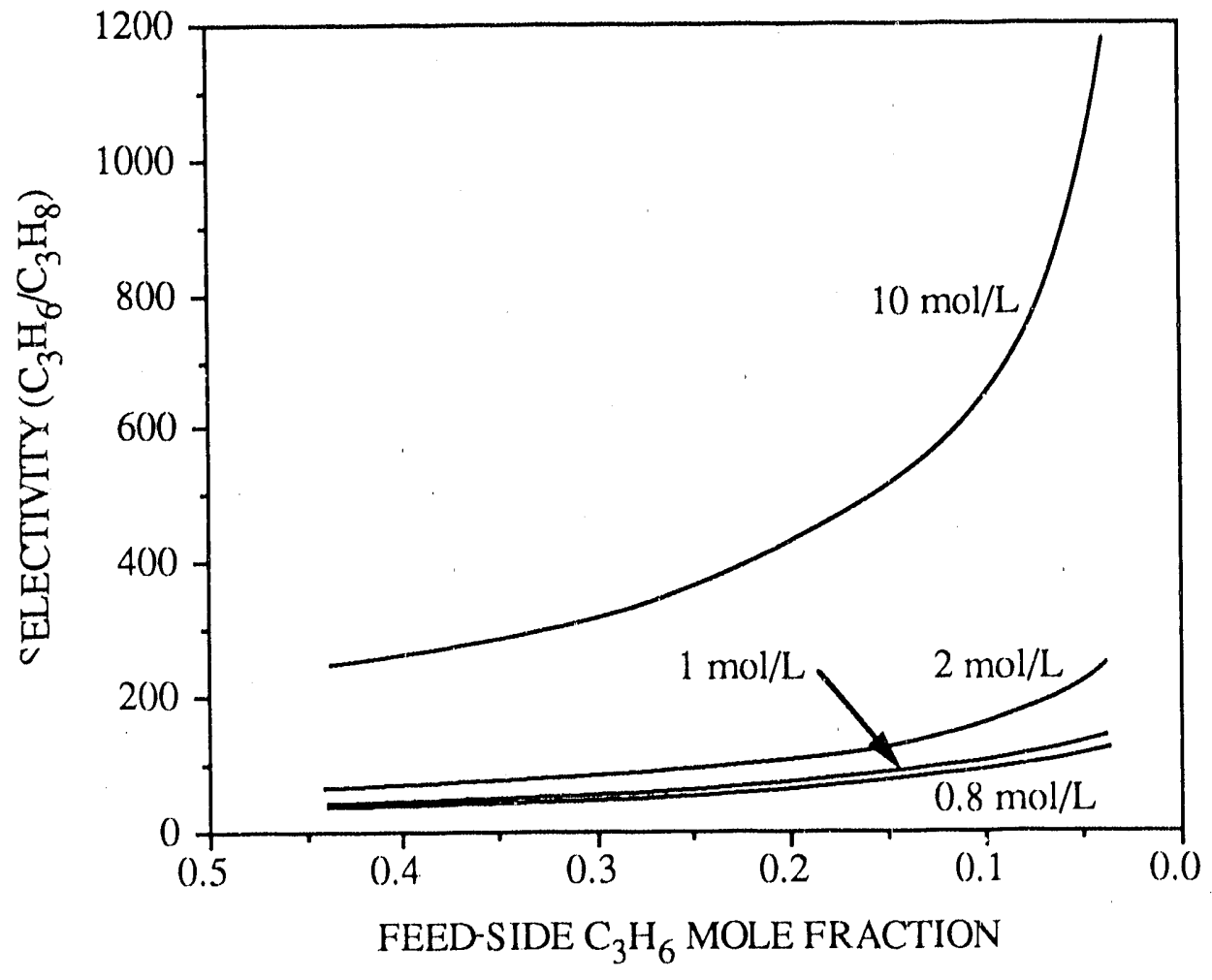

RAM-6519-19

Figure IV-12. Selectivity of FT membranes with various silver concentrations for propylene/propane separation. 


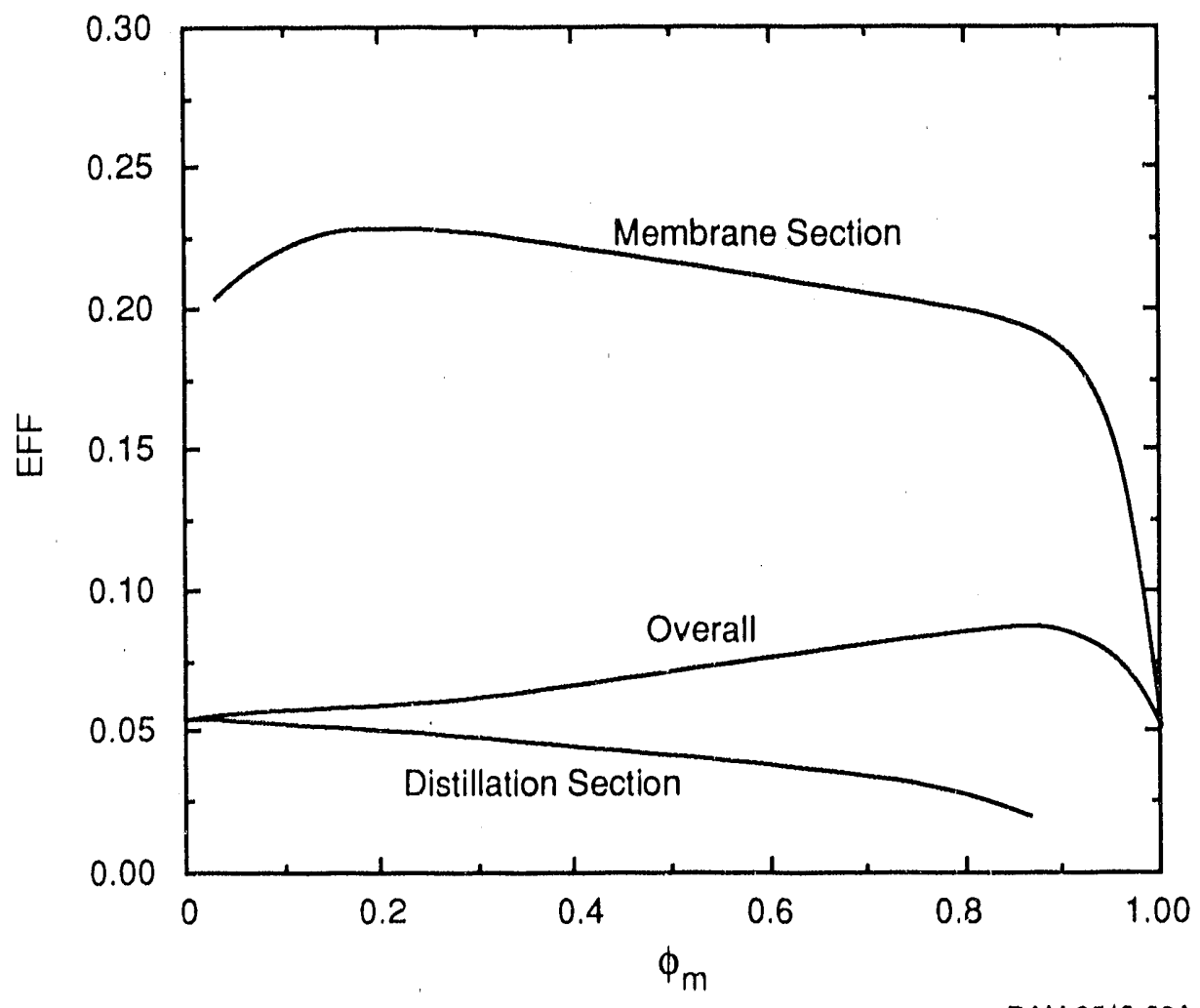

Figure IV-13. Overall, membrane, and distillation section EFFs for production of $95 \%$ propylene, using a membrane containing $1 \mathrm{~mol} / \mathrm{L}$ silver. Propylene purity is $95 \%$. 
Figure IV-14 shows the overall efficiencies and PCs for both the base case membrane (carrier concentration of 2 molar) and the membrane containing 1 molar carrier. As expected, the results for distillation alone do not change from the base case results. However, the efficiency of the membrane alone drops and the PC increases, both by a factor of 4 . Of significance is that the minimum in the PC curve occurs at the same $\phi_{\mathrm{m}}$ as the maximum in the efficiency curve. Whether this correspondence between the efficiency maximum and the PC minimum is a general rule in hybrid systems or just an artifact for this particular application cannot be determined until further case studies have been evaluated.

\section{CONCLUSIONS}

For propylene splitting with membrane properties taken from small-scale laboratory data, the membrane proved to be superior to distillation both in availability efficiency and PC; however, to produce higher purity products, the membrane alone cannot perform the separation, and a hybrid is required. Higher product purities resulted in lower efficiencies and higher PCs for all systems. Second, a key qualitative parameter of the hybrid system is the thermodynamic extent of separation in the membrane, $\phi_{\mathrm{m}}$.

In this example, we were comparing a very good membrane process with a very difficult distillation process. If development of commercial membranes results in inferior membrane properties, then the situation could be quite different. We have shown that a reduction in the carrier concentration (from 2 to 1 molar) leads to a hybrid process as the optimal system both in terms of efficiency and PC. Although this is only the first example and therefore results cannot be generalized yet, the process with the highest availability efficiency always resulted in the lowest PC. 


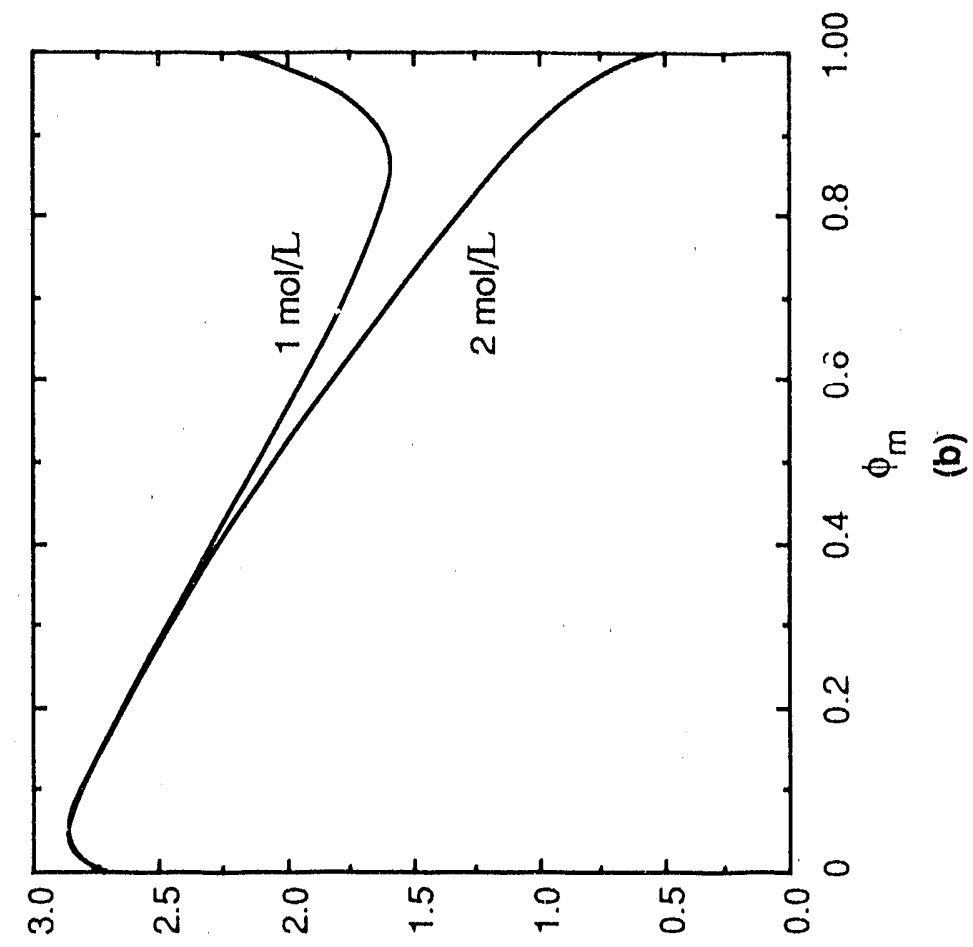

$(q / / p)$ od

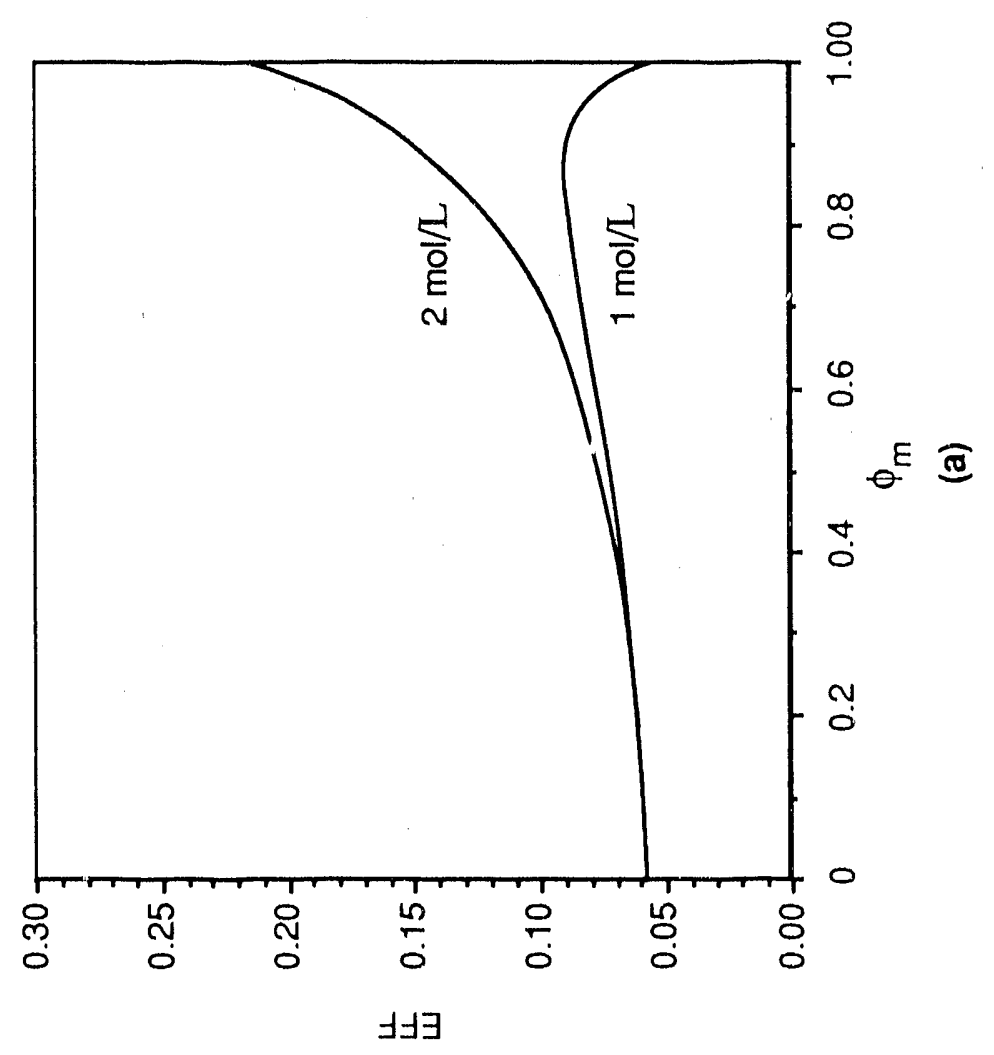

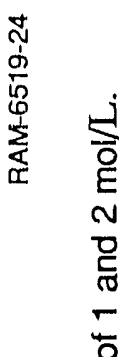

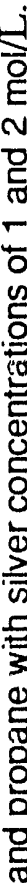

$\frac{0}{\frac{0}{2}}$

음

ర0

동

융

ᄒ

号

들

i

嵌

흐

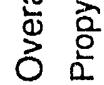

$\frac{\dot{1}}{2}$

产

IV-29 


\section{CHAPTER V}

\section{CASE STUDY 2 - REMOVAL OF NITROGEN FROM NATURAL GAS}

Natural gas is one of the major energy sources in the United States, with discovered reserves estimated to be $145 \mathrm{Tcf}^{1}$ and undiscovered reserves estimated tr be in excess of $400 \mathrm{Tcf}$ in the lower 48 states alone. Of this gas, more than one-third is subq'ality; i.e., some processing of this gas is required to remove impurities before the gas can be used. More than half of this subquality gas ( $20 \%$ of total reserves) contains nitrogen impurities greater than are generally tolerated by natural gas consumers $\left(>3-4 \% \mathrm{~N}_{2}\right.$; Meyer et al., 1990).

Currently, most of the gas that is subquality because of excessive $\mathrm{N}_{2}$ cannot be used because of the high cost of $\mathrm{N}_{2}$ removal processes and the present low value of natural gas. The exceptions to this rule occur when there is simultaneous recovery of another valuable product other than methane (helium or $\mathrm{N}_{2}$ for enhanced oil recovery) or in association with vary large reserves where economies of scale result in a viable separation process. Current separation processes are based on cryogenic distillation technology; however, two new technologies (pressure swing adsorption and membrane separation) are being developed for this application. These new technologies promise to be simpler to operate and may be economical for smaller reservoirs where cryogenic separation is not. The benefits of improved $\mathrm{N}_{2}$ removal technologies include a potential reduction in the energy required by the separation process and an increase in the marketable reserve of natural gas.

We examined the use of membrane and pressure swing adsurption (PSA) technologies for removing nitrogen from subquality natural gas. These technologies were considered by themselves and in several hybrid configurations.

The results of these evaluations indicate that there are ranges of conditions in which membrane alone, PSA alone, or a hybrid process will give the best economic performance. Conditions including high feed pressure, low $\mathrm{N}_{2}$ feed content, and high membrane selectivity favor the membrane alone. When the conditions are between these extremes, a hybrid process may result in the lowest separation costs. The energy use is always lowest with membrane alone because PSA produces methane at low pressure and, therefore, must recompress the entire product stream. However, the membrane produces methane at high pressure and does not require any recompression.

$1 \mathrm{Tcf}=$ trillion cubic feet $\left(1 \mathrm{~atm}, 60^{\circ} \mathrm{F}\right)$ 


\section{PROCESS DESCRIPTION AND MODELING}

We evaluated the thermodynamics and eccinomics of five configurations. Membrane system performance was determined using a fundamental computer model (Shindo et al., 1985); PSA system performance was obtained from a commercial supplier of PSA equipment. The membrane and PSA systems are described in detail in following sections.

To achieve the project goal of understanding where membranes will best complement other technologies in hybrid systems, we chose operating conditions, from the range of typical natural gas well conditions, where we expected membranes to have the greatest chance of favorable economic performance. These favorable conditions include low gas production rate, moderately high feed pressure, and low $\mathrm{N}_{2}$ feed content. Evaluations were also performed over a range of these conditiors, including areas that are not favorable to membranes.

\section{Membrane Process}

No commercially available membranes have favorable characteristics for $\mathrm{N}_{2} / \mathrm{CH}_{4}$ separation. Thus, for the membrane properties used in these evaluations, we used values that we believe could be attainable in the next two to three years. $\mathrm{N}_{2} / \mathrm{CH}_{4}$ selectivities as high as 8 have been reported in laboratory tests with $\mathrm{CH}_{4}$ permeabilities of $\sim 1$ Barrer (Hayes, 1988). Kim et al. (1989) reported work on a class of polyimide polymers with $\mathrm{N}_{2} / \mathrm{CH}_{4}$ selectivity of 2 and methane permeability of 0.5 Barrer. Based on this information, we believe a membrane with a $\mathrm{N}_{2} / \mathrm{CH}_{4}$ selectivity of 5 and a $\mathrm{CH}_{4}$ permeance of 10,000 Barrer/cm could be commercialized in the next two to three years, and these arc the properties used in our base case evaluations. Other membrane properties are given in Table V-1. Glassy polymers are currentiy used in natural gas applications and are not degraded by most impurities. Glassy polymers can also be expected to have a lower permeance for $\mathrm{C}_{2}+$ compounds and, thus, we will assume that essentially none of these compounds are lost in the membrane permeate stream.

To perform evaluations of membrane systems, we require not only the membrane properties, but alsc the configuration and operating conditions that result in the lowest cost membrane system. The available configuratic de single stage with and without recycle (SS and SSR), series (SER), cascade (CAS), and cascade with premembrane (CPM), as shown in Figure V-1. The transmembrane pressure ratio and membrane areas for each membrane must be optimized to give the lowest overall separation cost. Choice of the incorrect configuration and operating conditions can result in separation costs much higher than necessary. 
Table V-1

MEMBRANE PROPERTIES USED IN
ECONOMIC AND THERMODYNAMIC EVALUATIONS OF $\mathrm{N}_{2}$ REMOVAL

Membrane Property

Permeance (Barrer/cm)

$$
\begin{aligned}
& \mathrm{N}_{2} \\
& \mathrm{CH}_{4}
\end{aligned}
$$

Selectivity

Life (years)

Cost $(\$ / s q t)$
Base Case Value

50,000

10,000

5

3

1.00
Range of Values

25,000 to 150,000

2.5 to 15

$-$

0.20 to 10.00

V-3 


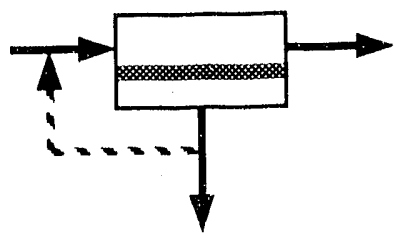

(a) Single Module (SS or SSR)

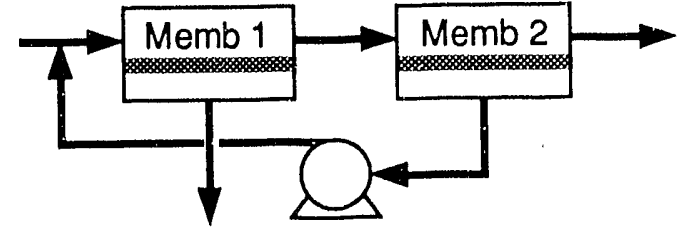

(b) Series (SER)

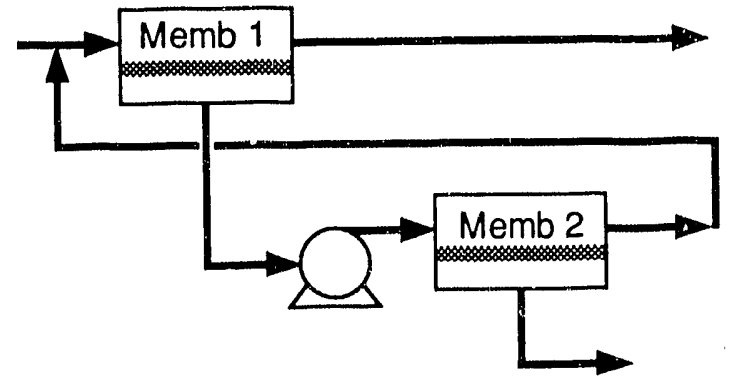

(c) Cascade (CAS)

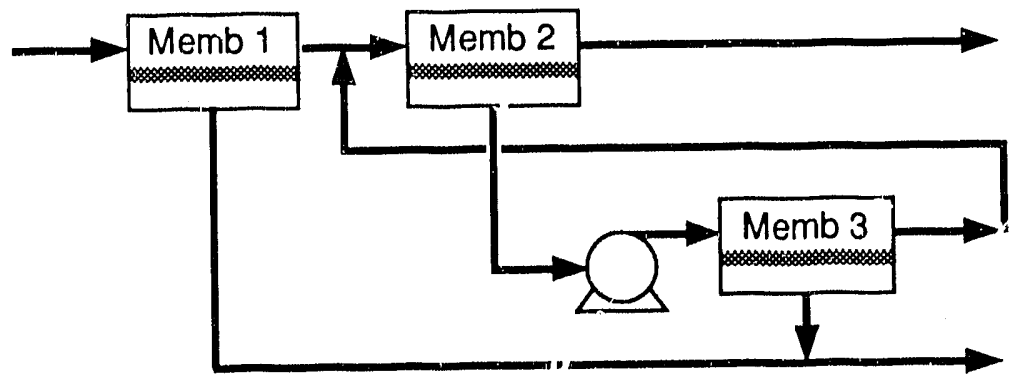

(d) Cascade With Premembrane (CPM)

RM-6519-52

Figure V-1. Membrane configurations used for gas separation. 
Based on the results for other applications, natural gas sweetening (Spillman et al., 1989) and $\mathrm{H}_{2} / \mathrm{N}_{2}$ separation (Gottschlich et al., 1989), we then chose SS or CPM as the configurations most likely to give the lowest cost. In many applications, SS results in the lowest cost because expenses associated with recycling and recompression are eliminated. However, in other cases (where the feed concentration is low, the desired product purity is high, the membrane selectivity is low, or high product recovery is required), CPM will often result in the lowest cost. Examination of CPM and SS showed that SS is a special case of CPM* and, therefore, only CPM was included in the evaluations. (In several cases, SER was also examined but never resulted in lower costs than CPM.)

The operating variables were optimized to give the lowest overall separation cost (i.e., lowest $\mathrm{PC}$ ) for all evaluations. Operating variables include the $\mathrm{N}_{2}$ content of the residue streams leaving membranes 1 and 3 and the pressure ratio in membrane 2 . The pressure ratios in membranes 1 and 3 were not variables because the permeate pressure was assumed to be atmospheric. To simplify the optimization, we specified the $\mathrm{N}_{2}$ content of the residue from membrane 3 to be equal to that in the residue of membrane 1 . This specification eliminates the loss of availability that would result if these streams were of different composition, a situation that has been shown to result in the lowest separation cost (Gottschlich and Roberts, 1990). This membrane configuration can be used as the nonhybrid membrane system (NH-MEMB) or in conjunction with PSA in a hybrid system.

\section{Pressure Swing Adsorption}

In PSA, a feed gas is passed at high pressure over an absorbent bed wherein a portion of the feed is retained by the adsorbent. The gas not retained exits the bed concentrated in the nonadsorbed gas. Once the bed has reached its capacity and will not adsorb more gas, the feed is turned off, and the bed pressure is reduced, releasing the adsorbed gas; this gas is enriched in the adsorbed component. Once the bed has been fully desorbed (sometimes under vacuum), the feed is turned on again, and the cycle is repeated. Because of the cyclic nature of this process, at least two beds are used to allow continuous separation of the feed stream. PSA can produce gas containing less than $1 \% \mathrm{~N}_{2}$, typically has methane recoveries of 80 to $90 \%$, and has essentially complete recovery of higher hydrocarbons.

* Depending on the operating conditions used, CPM will reduce to SS (by setting areas in membranes 2 and 3 to zero) or CAS (by setting the area in membrane 1 to zero). 
The two-step process described above is the simplest PSA cycle; three-, four-, and fivestep cycles are often used to improve the performance of the PSA system (Yang, 1987). The PSA system for $\mathrm{N}_{2} / \mathrm{CH}_{4}$ separation uses an adsorbent which selectively adsorbs $\mathrm{CH}_{4}$ over $\mathrm{N}_{2}$. The process uses a four-step, four-bed cycle, including a vacuum regeneration step. The feed pressure is reduced (or compressed) to 250 to 300 psia before entering the bed. While feed gas is entering the bed, methane and higher hydrocarbons are adsorbed, and a waste stream concentrated in $\mathrm{N}_{2}$ leaves the bed. After the feed is shut off, the bed pressure is lowered, and the methane-rich product stream is drawn off. The product stream is then compressed to the desired pressure. Like the membrane process, the conditions favorable to PSA include low gas production rate; in contrast to the membrane, however, low feed pressure and high $\mathrm{N}_{2}$ feed content are favorable to PSA.

The performance and cost data for the PSA system were supplied by Nitrotec Engineering (Linthicum, MD) for its currently available methane recovery system. These data were used to describe the nonhybrid PSA system (NH-PSA), as well as the PSA sections of hybrid systems. Although currently none of these units are operating solely for nitrogen removal, a similar unit is operating for the recovery of helium from natural gas. If the two to three years suggested for membrane development were used for PSA process development, we would expect to see some performance improvement over that used in this evaluation (for example, because of improved adsorbents or improved process design).

\section{Hybrid Processes}

Along with the stand-alone membrane and PSA systems, three hybrid membrane/PSA systems were evaluated; these five systems are shown in Figure V-2. The two stand-alone systems were described in the previous sections. The first hybrid system (HYB-1) is simply a combination of the membrane system followed by the PSA system. Although this combination does not have any obviously favorable characteristics, we thought it worthy of evaluation.

The two final hybrid systems (HYB-2 and HYB-3) take advantage of the differing pressure ranges favorable to each technology. In HYB-2 the feed enters the membrane first; the membrane permeate is recompressed only to 275 psia (taking advantage of the pressure reduction at the PSA feed which would otherwise be wasted) and fed to the PSA unit. The PS $A$ unit produces a methane-rich product stream and a $\mathrm{N}_{2}$-rich waste stream. The operating conditions in the membrane are such that the residue stream is pipeline quality. This configuration can be thought of as a stand-alone membrane unit with a PSA unit added to recover some methane from the membrane waste stream. 


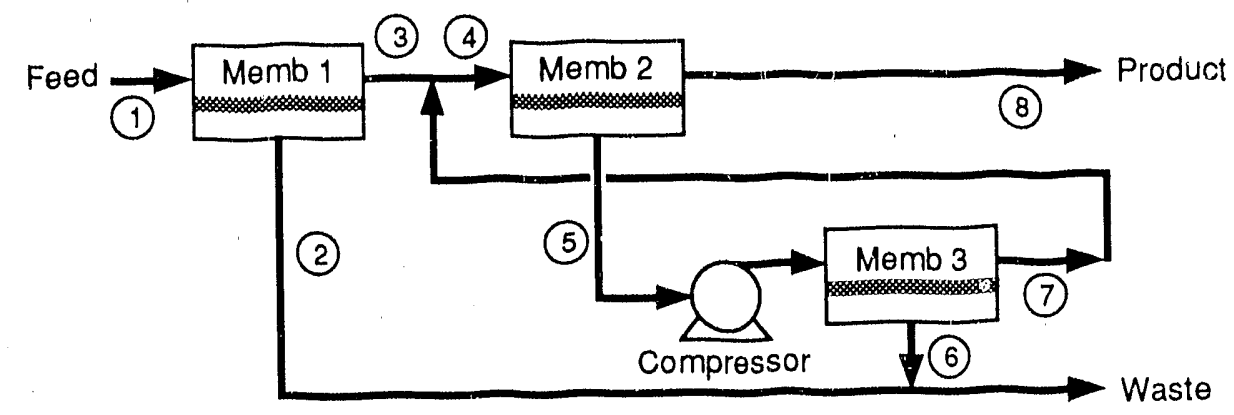

(a) NH-MEMB

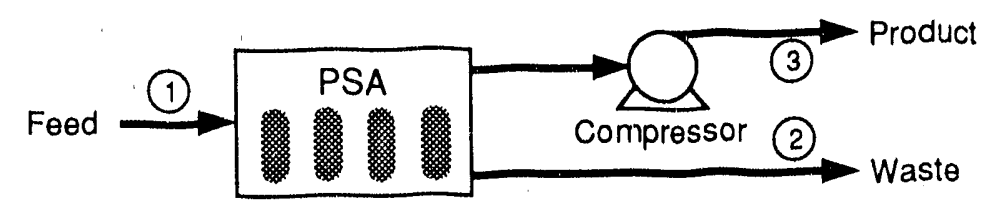

(b) NH-PSA

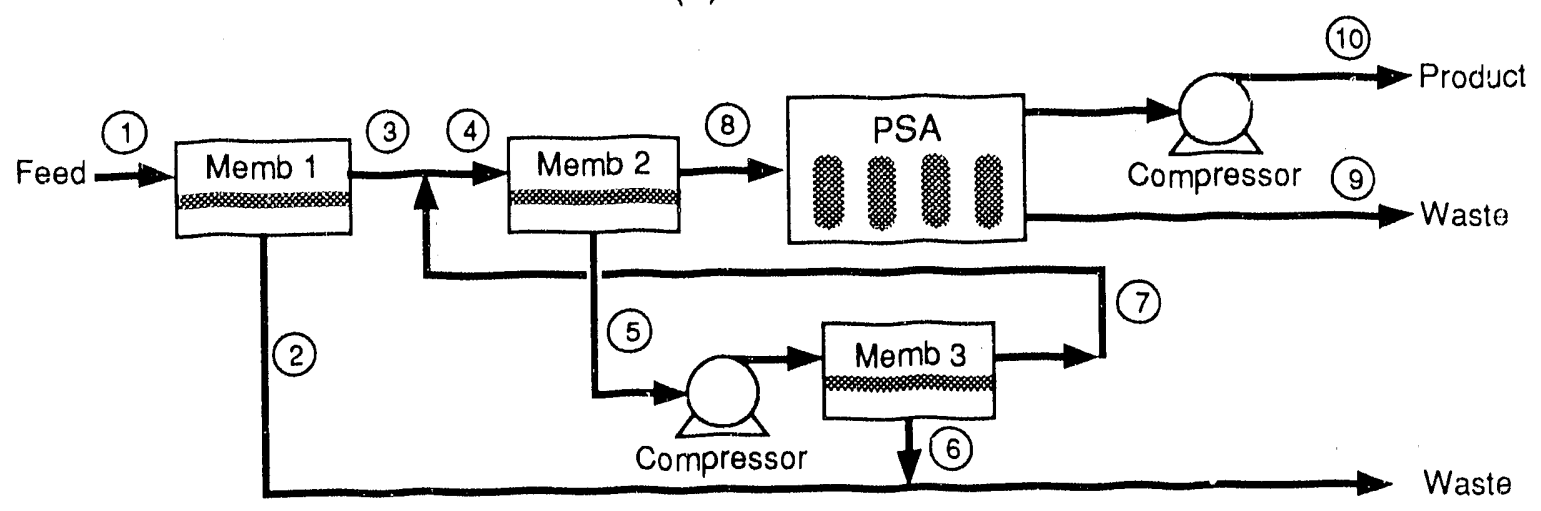

(c) HYB-1

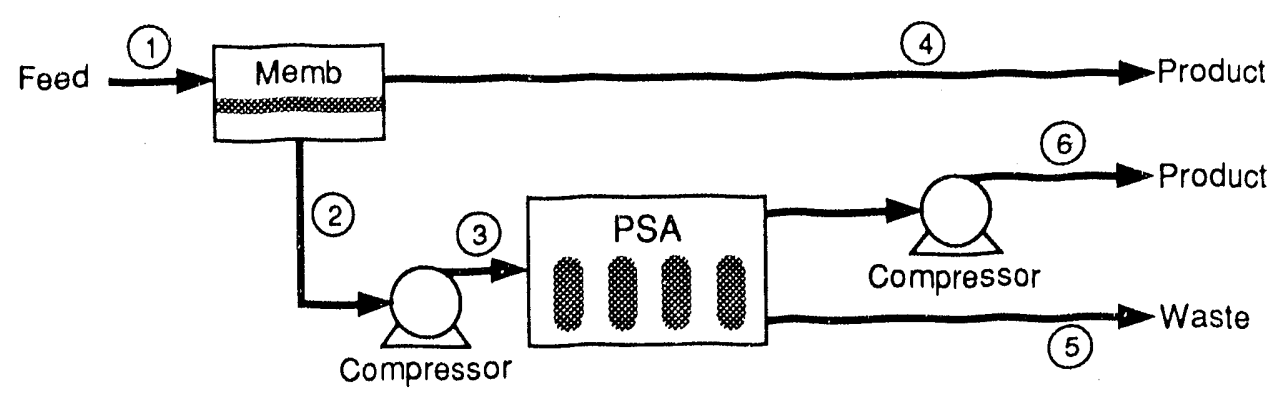

(d) HYB-2

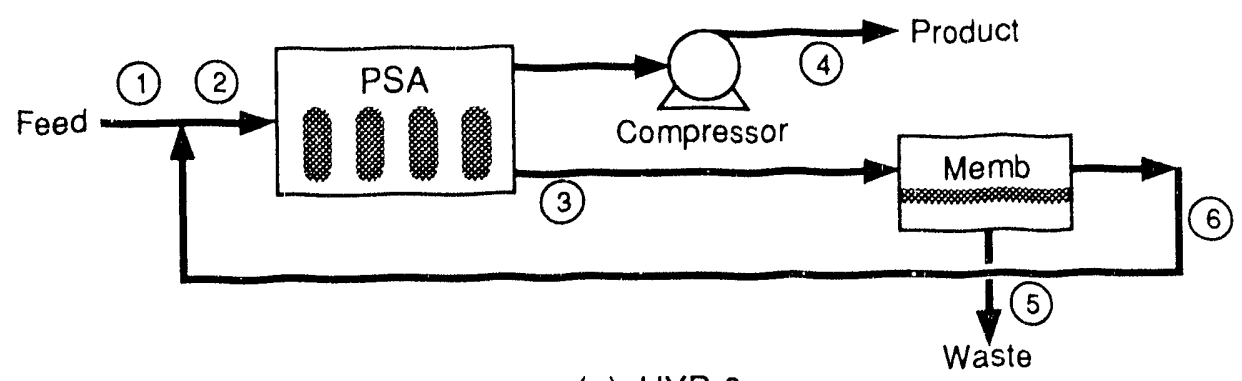

(e) HYB-3

RM-6519-53

Figure V-2. Hybrid and nonhybrid separation systems for upgrading subquality natural gas. 
In HYB-3, the feed first enters the PSA unit (after the required pressure reduction) that produces a methane-rich product stream and a $\mathrm{N}_{2}$-rich waste stream. Instead of simply venting or flaring the waste stream (which is at the PSA feed pressure of $275 \mathrm{psia}$ ), the $\mathrm{N}_{2}$-rich waste stream is fed to a membrane. The membrane permeates a waste stream even more concentrated in $\mathrm{N}_{2}$ and a residue stream that is enriched in methane. However, the membrane residue still contains too high an $\mathrm{N}_{2}$ content to be fed to the pipeline and, therefore, is recycled to the PSA unit. In this configuration, the mernbrane area is optimized to give the lowest separation cost. HYB-3 can be thought of as a stand-alone PSA unit with a membrane added to recover some methane from the PSA waste stream.

\section{THERMODYNAMIC EVALUATION}

Thermodynamic evaluations were performed in the same manner as described previously. The thermodynamic extent of separation $\left(\phi_{\mathrm{m}}\right)$ was used as the independent variable to indicate how much of the separation is performed by each technology in a hybrid process. Only one result is reported, the availability consumed in utility streams $\left(A_{u t i l}\right)$.

\section{ECONOMIC EVALUATION}

Economic evaluations were performed in a similar way as described previously. Capital and operating costs were estimated; these costs were then included in a discounted cash flow analysis which results in the processing cost (PC; in \$/Mcf total product gas). Membrane capital costs were determined by calculating the membrane area required to perform the separation and using an installed membrane cost of $\$ 2.40 / \mathrm{ft}^{2}$; the membranes must be replaced every three years at a cost of $\$ 1 / \mathrm{ft}^{2}$. These membrane costs are typical of hollow fiber membranes (see for example A/G Technology, Needham, MA, product bulletin on its AVIR air separation membrane). Costs for the PSA system were obtained from Nitrotec Engineering Company. Compressor costs were calculated using in-house cost data and an installation factor of three.

One difference between the economic calculations for this case study and the other case studies arose because the five hybrid and nonhybrid systems result in different methane recoveries. To account for this, a penalty was assessed for any unrecovered methane; an unrecovered methane cost of $\$ 1 / \mathrm{Mcf}$ was used. This cost was included in the discounted cash flow analysis in a similar manner as for any other operating cost. (Lower methane recovery increases PC in two ways: the total expense attributed to lost methane is increased, and less product gas is available to pay for the processing.) 


\section{BASE CASE EVALUATIONS}

The thermodynamic and economic results are described for each of the five process configurations. Many calculations were performed over different values of application and process parameters; however, here we describe in detail only the results for the base case application with each of the five process configurations.

The $\mathrm{N}_{2}$ removal application is based on a small natural gas well containing $\mathrm{N}_{2}$ impurities at levels too high for the natural gas to be used and, therefore, has little value unless the $\mathrm{N}_{2}$ can be removed. The base case application has a feed flowrate to the separation system of $8 \mathrm{MMcfd}^{*}$, an $\mathrm{N}_{2}$ content of $20 \%$ (mole \%), and a feed pressure of 800 psia. The product gas must be of pipeline quality $\left(<3 \% \mathrm{~N}_{2}\right)$ and at the feed pressure; unrecovered methane is valued at $\$ 1.00 / \mathrm{Mcf}$. These base case conditions, along with the range of nonbase case values, are given in Table V-2. Although subquality natural gas comes in a wide range of reservoir pressures and compositions, we chose these conditions to meet our intuitive impression of where hybrid systems would be practical.

\section{Membrane System}

The base case NH-MEMB system is shown in Figure V-2. Optimization of process variables resulted in elimination of all but the first membrane. Elimination of the second and third membranes resulted in elimination of the compressor; hence, no electricity is required by the process (except for control equipment). Stream conditions and compositions are shown for the base case NH-MEMB system in Table V-3. This table shows that the waste stream consists of $65 \%$ methane; thus the methane recovery (fraction of feed methane in residue stream) is low, only $57 \%$. A higher methane recovery could be achieved by using the full three-membrane configuration, but this would have resulted in a higher PC due to the added capital and operating expenses.

Table V-4 summarizes the economic evaluation for this configuration (and for the other four configurations to be discussed in following sections). The PC for the base case membrane system is $\$ 1.07 / \mathrm{Mcf}$ product gas. Almost $70 \%$ of this expense is a result of lost methane; the installed capital cost is $\$ 730,000$ or $25 \%$ of the PC. The thermodynamic results are given in Table V-5; since no electricity is used the utilities availability consumption, $A_{u t i l}$ is zero. Complete details of this evaluation are given in Appendix B.

* $\mathrm{MMcfd}=$ million cubic feet per day $\left(1 \mathrm{~atm}, 60^{\circ} \mathrm{F}\right)$ 
Table V-2

OPERATING CONDITIONS USED IN ECONOMIC AND THERMODYNAMIC EVALUATIONS OF $\mathrm{N}_{2}$ REMOVAL.

\begin{tabular}{|c|c|c|}
\hline $\begin{array}{c}\text { Operating } \\
\text { Variable }\end{array}$ & $\begin{array}{c}\text { Base Case } \\
\text { Value } \\
\end{array}$ & $\begin{array}{l}\text { Range of } \\
\text { values }\end{array}$ \\
\hline \multicolumn{3}{|l|}{ Feed stream } \\
\hline Flowrate (MMcfd) & 8 & $\ldots$ \\
\hline Temperature $\left({ }^{\circ} \mathrm{F}\right)$ & 60 & - \\
\hline Pressure (psia) & 800 & 275 to 800 \\
\hline \multicolumn{3}{|l|}{ Composition } \\
\hline$\% \mathrm{~N}_{2}$ & 20 & 10 to 40 \\
\hline$\% \mathrm{CH}_{4}$ & 75 & 55 to 85 \\
\hline$\% \mathrm{C}_{2}+$ & 5 & $\ldots$ \\
\hline \multicolumn{3}{|l|}{ Product stream } \\
\hline Temperature $\left({ }^{\circ} \mathrm{F}\right)$ & $<100$ & .-. \\
\hline Pressure (psia) & 800 & Same as feed \\
\hline \multicolumn{3}{|l|}{ Composition } \\
\hline$\% \mathrm{~N}_{2}$ & 3 & $\ldots$ \\
\hline $\mathrm{CH}_{4}$ recovery & \multicolumn{2}{|c|}{ Determined by economics } \\
\hline $\mathrm{C}_{2}+$ recovery $(\%)$ & $>95$ & $\ldots$ \\
\hline
\end{tabular}




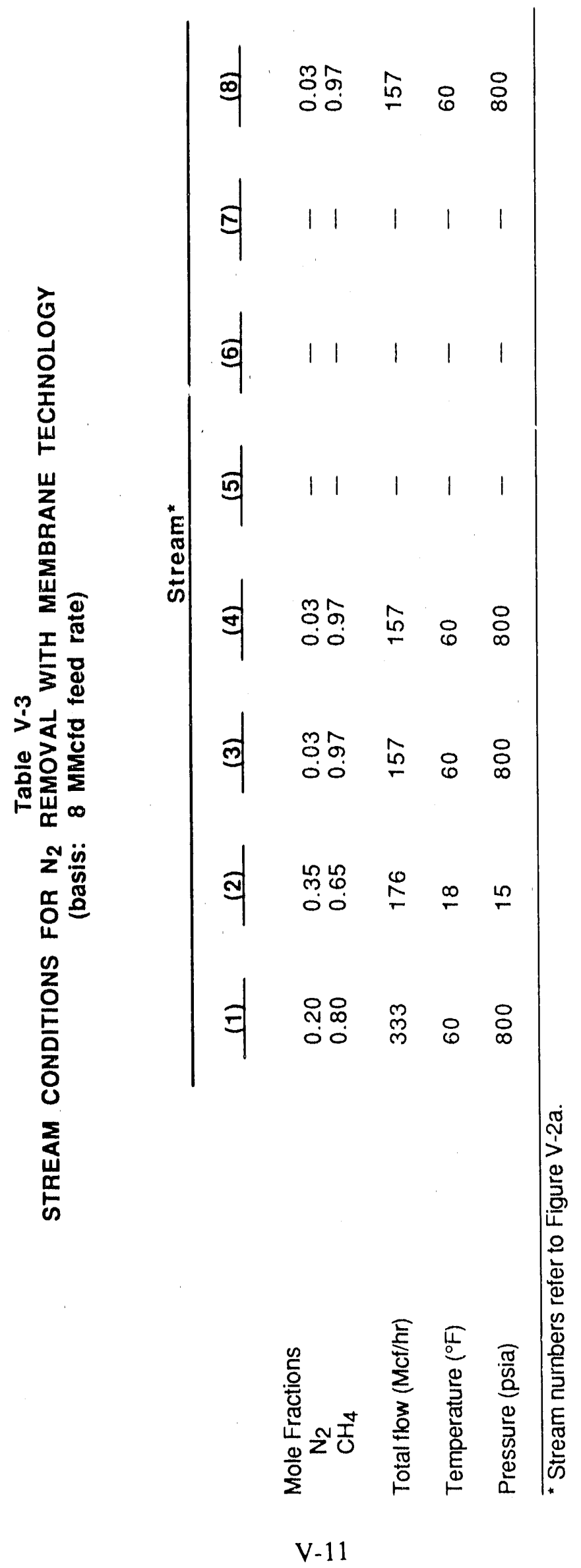




\section{Table $\quad V-4$ \\ ECONOMIC RESULTS FOR N2 REMOVAL \\ (basis: 8 MMcfd feed rate)}

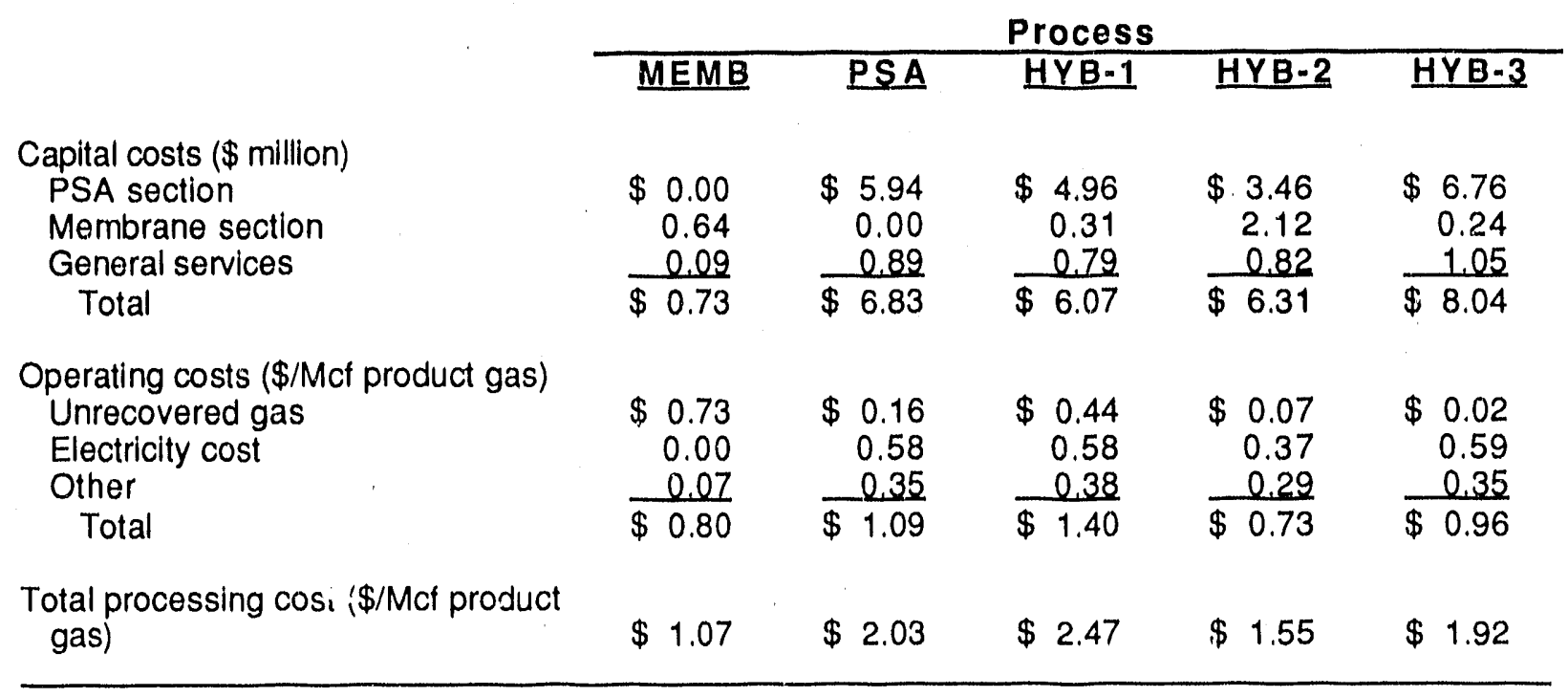

Table V.5

THERMODYNAMIC RESULTS FOR N2 REMOVAL

(basis: 8 MMcfd feed rate)

\begin{tabular}{lccccc} 
& \multicolumn{5}{c}{ Process } \\
\cline { 2 - 5 } & MEMB & PSA & HYB-1 & HYB-2 & HYB-3 \\
Thermodynamic extent of & 1.0 & 0.0 & 0.550 & 0.311 & 0.076 \\
$\quad \begin{array}{l}\text { separation, } \phi \mathrm{m} \\
\text { Electricity (1000 Btu/Mcf gas) }\end{array}$ & 0.0 & 39.4 & 39.2 & 24.8 & 39.9 \\
Autil (1000 Btu/Mct gas) & 0.0 & 38.8 & 38.6 & 24.3 & -39.3 \\
$\begin{array}{l}\text { Thermal energy equivalent* (1000 } \\
\text { Btu/Mcf gas) }\end{array}$ & 0.0 & 118 & 118 & 74.5 & 120
\end{tabular}

* Thermal energy equivalents are based on an electric power generation efficiency of $33 \%$. 


\section{PSA System}

The base case NH-PSA system is shown in Figure V-2; stream conditions are given in Table V-6. The feed stream pressure is reduced to 275 psia before entering the PSA unit. The waste stream leaves the PSA unit at 275 psia, and the product stream is recompressed to the original feed pressure of 800 psia. The economics for the PSA system are summarized in Table V-4. The PC is $\$ 2.03 / \mathrm{Mcf}$ of which $54 \%$ is a result of operating costs. Because the PSA system has a relatively high product recovery ( $85 \%$ ), the expense caused by lost methane is only $\$ 0.16 / \mathrm{Mcf}$. Electricity is the major operating expense at $\$ 0.58 / \mathrm{Mcf}$. The total capital cost for the PSA system is almost $\$ 7$ million, about half of which is because of the compressor.

The thermodynamic results for the PSA system are shown in Table V-5. Electricity usage is $39,400 \mathrm{Btu} / \mathrm{Mcf} ; \mathrm{A}_{u t i l}$ resulting from electricity and cooling water streams is $38,800 \mathrm{Btu} / \mathrm{Mcf}$. The PSA process has a relatively small volume of waste gas (because of a high product recovery) which exits at moderate pressure ( $275 \mathrm{psia})$. Complete details of this evaluation are given in Appendix B.

\section{HYB - 1}

This hybrid system is shown in Figure V-2; stream conditions are given in Table V-7. The feed stream enters the membrane unit which, for optimum economic performance with these base case conditions, consists of only the first membrane. The membrane residue is then fed to the PSA unit, and the $\mathrm{N}_{2}$-rich permeate exits as a waste stream. The residue stream can have any value between the feed concentration of $20 \% \mathrm{~N}_{2}$ (in which case the system is reduced to NH-PSA and $\phi_{\mathrm{m}}$ is 0.0 ) and the product concentration of $3 \%$ (in which case the system is reduced to NH-MEMB and $\phi_{\mathrm{m}}$ is 1.0 ). For the base case example, we chose a residue stream compositicn of $10 \% \mathrm{~N}_{2}$, which gives a $\phi_{\mathrm{m}}$ of 0.55 . The membrane removes $70 \%$ of the nitrogen, but also accounts for $63 \%$ of the unrecovered methane; the overall methane recovery is $69 \%$.

The economics for this system are summarized in Table V-4. The PC is $\$ 2.47 / \mathrm{Mcf}$ and the total capital cost is $\$ 6$ million, of which over $90 \%$ is caused by the PSA section. Operating expenses contribute $\$ 1.40 / \mathrm{Mcf} ; \$ 0.44 / \mathrm{Mcf}$ is a result of unrecovered methane and $\$ 0.58 / \mathrm{Mcf}$ a result of electricity. 
Table V.6

STREAM CONDITIONS FOR N2 REMOVAL

WITH PSA TECHNOLOGY ALONE

(basis: 8 MMcfd feed rate)

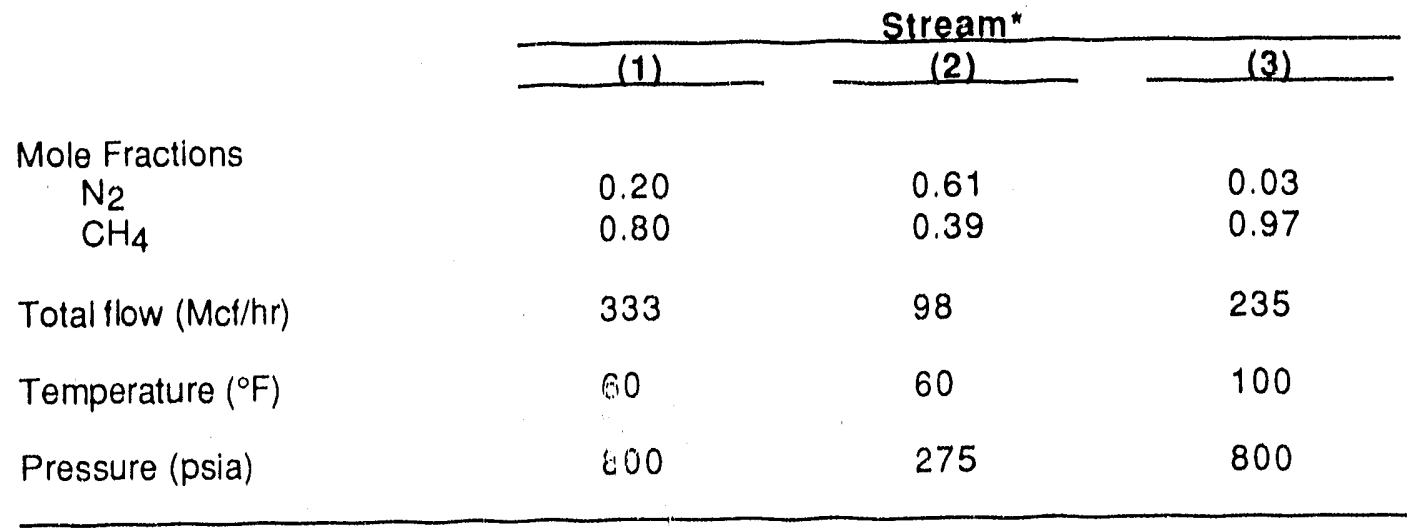

* Stream numbers refer to Figure V-2b. 


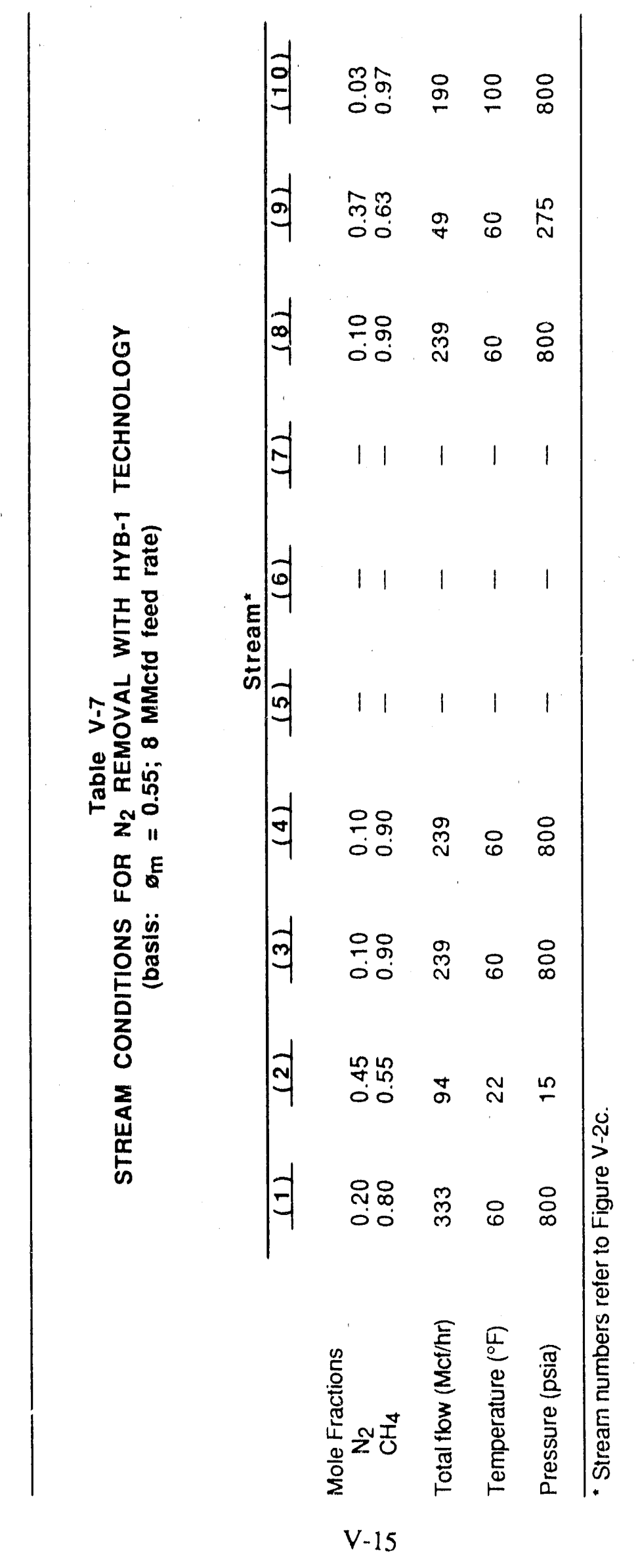


The thermodynamic results are shown in Table V-5. The electricity requirement of 39,200 $\mathrm{Btu} / \mathrm{Mcf}$ is because of product recompression in the PSA section, and $\mathrm{A}_{u t i l}$ is $38,600 \mathrm{Btu} / \mathrm{Mcf}$. Complete details of this evaluation are given in Appendix $\mathrm{P}$.

\section{HYB - 2}

This system combines the membrane and PSA units in a way that takes advantage of the low cost of the membrane unit and the high recovery of the PSA unit (Figure V-2). It also takes advantage of the pressure reduction on the PSA feed stream by using it as the pressure drop acrors the membrane. The stream conditions are given in Table V-8; feed enters a single membrane which produces a residue stream containing $3 \% \mathrm{~N}_{2}$ at 800 psia which is sent straight to the pineline. The permeate stream, however, contains a large amount of methane (47\% of the totai metha. . entering the separation system` and is sent to the PSA unit where most of this methane is recovered. Process optimization results in the optimum permeate pressure of $41 \mathrm{psia}$; this must be recompressed, but only to 275 psia, taking advantage of the pressure reduction which is necessary before entering the PSA unit.

The methane recovery resulting from this system is high, ove: $93 \% ; 53 \%$ in the membrane residue and $40 \%$ in the PSA product stream. The PC for this system is $\$ 1.55 / \mathrm{Mcf}$ (Table V-4) and the capital cost is $\$ 6.3$ million. The membrane sysiem accounts for $40 \%$ of the capital costs (twothirds due to the compressor), and PSA accounts for the remaining 60\% (one-half because of the compressor). The operating cost is $\$ 0.73 / \mathrm{Mcf}$; because of the high methane recovery, only $\$ 0.07 / \mathrm{Mcf}$ is due to unrecovered methane. Electricity accounts for $\$ 0.37 / \mathrm{Mcf}$ ( $30 \%$ for permeate compression and $70 \%$ for PSA product recompression).

The thermodynamic results are given in Table V-5; the electricity requirement is 24,800 Btu/Mcf. The high methane recovery resuits in a low waste gas volume : hich is at moderate pressure. Complete details of this evaluation are given in Appendix B.

\section{HYB - 3}

In this configuration, the fact that the membrane process selectively removes $\mathrm{N}_{2}$ is taken advantage of to increase the recovery of the PSA system (Figure V-2). Stream conditions are given in Table V-9. Feed enters the PSA system first; the prodict stream leaving the PSA system is recompressed to the feed pressure, and the $\mathrm{N}_{2}$-enriched waste stream is fed to the membrane unit. The PSA waste stream pressure is high enough that there is no need to compress it to a 
Table $V-8$

STREAM CONDITIONS FOR N2 REMOVAL WITH HYB-2 TECHNOLOG

(basis: 8 MMcfd feed rate)

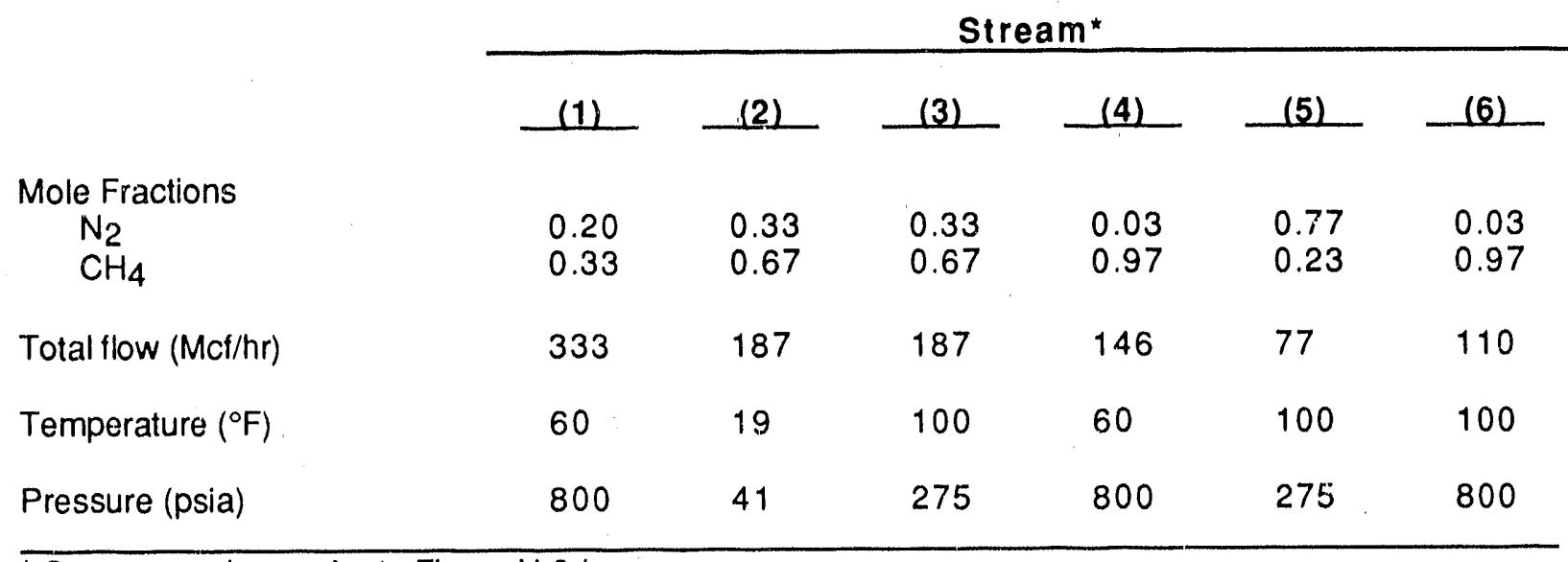

"Stream numbers refer to Figure V-2d.

Table $V-9$

STREAM CONDITIONS FOR N2 REMOVAL WITH HYB-3 TECHNOLOGY

(basis: 8 MMcfd feed rate)

\begin{tabular}{|c|c|c|c|c|c|c|}
\hline & & & St & & & \\
\hline & (1) & (2) & (3) & (4) & $(5)$ & $-(6)$ \\
\hline $\begin{array}{l}\text { Mole Fractions } \\
\mathrm{N}_{2} \\
\mathrm{CH}_{4}\end{array}$ & $\begin{array}{l}0.20 \\
0.80\end{array}$ & $\begin{array}{l}0.32 \\
0.68\end{array}$ & $\begin{array}{l}0.75 \\
0.25\end{array}$ & $\begin{array}{l}0.03 \\
0.97\end{array}$ & $\begin{array}{l}0.92 \\
0.08\end{array}$ & $\begin{array}{l}0.66 \\
0.34\end{array}$ \\
\hline Total flow (Mcf/hr) & 333 & 447 & 177 & 270 & 64 & 113 \\
\hline Temperature $\left({ }^{\circ} \mathrm{F}\right)$ & 60 & 60 & 60 & 100 & 51 & 60 \\
\hline Pressure (psia) & 800 & 275 & 275 & 800 & 15 & 275 \\
\hline
\end{tabular}

Stream numbers refer to Figure V-2e. 
higher pressure before feeding it to the membrane. Since this waste stream is available at 275 psia, but the overall waste stream needs only be at atmospheric pressure, this pressure differential can be used as the driving force for the membrane unit. The membrane produces an $\mathrm{N}_{2}$-rich permeate containing very little $\mathrm{CH}_{4}$ (only $8 \mathrm{~mol} \%$ ) and a $\mathrm{CH}_{4}$-enriched residue stream that is recycled to the PSA feed. Because the waste streari (the membrane permeate) contains little methane, the product recovery for this system is very high $(>98 \%)$.

The economics for this configuration are summarized in Table V-4. The PC is $\$ 1.92 / \mathrm{Mcf}$ and the capital cost is $\$ 8$ million; the membrane unit accounts for less than $5 \%$ of the capital cost. Operating costs are $\$ 0.96 / \mathrm{Mcf} ; \$ 0.02 / \mathrm{Mcf}$ for unrecovered methane, and $\$ 0.59 / \mathrm{Mcf}$ for electricity expenses.

The thermodynamic results are given in Table V-5; the electricity requirement is $39,900 \mathrm{Btu} / \mathrm{Mcf}$. The high methane recovery results in a low waste gas volume which is at low pressure, producing a small, negative $\mathrm{A}_{\text {util }}-(15,000 \mathrm{Btu} / \mathrm{Mcf})$. Complete details of this evaluation are given in Appendix B.

\section{Comparison of Base Case Systems}

Both the membrane and PSA technologies use pressure difference as the diving force for separation of $\mathrm{N}_{2}$ and $\mathrm{CH}_{4}$ by means of a separation agent (membrane material or PSA adsorbent). However, a major difference between the technologies is that membranes use a separating agent that is selective for $\mathrm{N}_{2}$ and, thus, removes $\mathrm{N}_{2}$ as a low pressu:e waste stream from the high pressure feed. PSA, on the other hand, uses a separating agent that is selective for $\mathrm{CH}_{4}$ and, thus, removes $\mathrm{CH}_{4}$ as a low pressure product stream from the high pressure feed.

This difference has two major effects on the design of a separation syste: .. The first is that, in either case, the quantity of separating agent needed is roughly proportional to the amount of materi2l removed by the separating agent; i.e., the membrane area needed is roughly proportional to the amount of $\mathrm{N}_{2}$ to be removed, and the amount of adsorbent required for the PSA system is roughly proportional to the amount of $\mathrm{CH}_{4}$ to be removec. The implication of this is that membranes will be favored when $\mathrm{N}_{2}$ is present in small quantities and PSA will be favored when $\mathrm{CH}_{4}$ is present in small quantities.

The second effect of using separating agents selective for different components is that the membrane system results in a high pressure $\left(800\right.$ psia) $\mathrm{CH}_{4}$-rich stream and a low pressure $(\sim 1 \mathrm{~atm}) \mathrm{N}_{2}$-rich stream. With PSA, the opposite is true; the $\mathrm{N}_{2}$-rich stream exits at the higher 
pressure (275 psia) and the $\mathrm{CH}_{4}$ stream exits at low pressure ( $\left.<1 \mathrm{~atm}\right)$. The implication of this difference is that, because the $\mathrm{CH}_{4}$ prot stream is usually required at a high pressure (typically between 300 and 1000 psia), recompression is required with the PSA system but not with the membrane system; thus, membranes are favored if the required product pressure is greater than atmospheric.

With these ideas in mind, it is obvious that the membrane system should be superior provided the performance of the PSA separating agent (adsorbent) is not greatly superior to the membrane separating agent. (This conclusion is not an intrinsic difference between membrane and PSA systems; there are PSA adsorbents that are $\mathrm{N}_{2}$ selective, just as there are membrane materials that are $\mathrm{CH}_{4}$ selective.) The results of the base case evaluations (summarized in Tables V-4 and V-5) can be rationalized in terms of the differences discussed above. The feed natural gas contains primarily $\mathrm{CH}_{4}\left(20 \% \mathrm{~N}_{2}\right)$, and the desired product pressure is high. These characteristics suggest a separation process using a separating agent selective for $\mathrm{N}_{2}$ should be superior; and for the base case conditions, the PC with the membrane process is approximately one-half that of the PSA system.

Of the hybrid systems, HYB-1 does not combine the two technologies in a synergistic manner. The membrane is used to treat a stream with a higher $\mathrm{N}_{2}$ content than the PSA unit treats. The fact that the membrane produces a high pressure $\mathrm{CH}_{4}$ stream is also wasted because the $\mathrm{CH}_{4}$ rich stream leaving the membrane must have its pressure reduced before entering the PSA unit. Thus HYB-1 combines the membrane and PSA technologies in a manner that brings out the worst properties of each, and the resulting PC is higher than with either the membrane or PSA technologies on their own.

The two remaining hybrid systems, HYB-2 and HYB-3, do take advantage of each technology's best properties; however, because the membrane technology is superic $r$ for the base case applicatiuns, the PCs resulting from HYB-2 and HYB-3 lie between the PCs for NH-MEMB and NH-PSA. (As will be seen later, under different conditions where the membrane does not have such a clearcut superiority over the PSA system, the hybrid systems can result in PCs lower than that with either of the two individual technologies.) HYB-2 reduces the cost of the PSA unit by drawing off a large portion of the methane so the PSA system can be reduced in size. The amount of product gas to be compressed is also reduced because the pipeline quality gas produced by the membrane does not require recompression. The product recovery is also high with HYB-2, 93\%; however, the capital costs are high, resulting in a PC somewhat higher than that with NH-MEMB. 
The final hybrid configuration, HYB-3, resulted in very high product recovery (98\%) but also had the highest capital and electricity costs of any of the five systems. This system resulted in a PC only slightly lower than that with NH-PSA.

\section{EFFECT OF KEY PROCESS PARAMETERS}

Many process- and application-specific parameters affect the outcome of the economic and thermodynamic evaluations. Some of these parameters affect the different systems in such varied ways that a change in one parameter will result in a reduced PC with one system, while the same change will result in an increased PC with another system. We examined six of these parameters that have a significant effect on the evaluations: feed composition, feed/product pressure, membrane selectivity, membrane cost, electricity cost, and product recovery.

\section{Feed Composition}

Variations in feed composition affect the two technologies, membrane and PSA, in different ways. With membrane technology, the amount of material that must be selectively removed $\left(\mathrm{N}_{2}\right)$ increases as the $\mathrm{N}_{2}$ content of the feed increases; however, the amount of methane that can potentially be recovered is reduced. Thus, the equipment cost for the separation is increased while the amount of product to be recovered is reduced, resulting in an increase in PC as the $\mathrm{N}_{2}$ content of the feed increases. For the PSA process, however, the equipment size is determined by the quantity of methane removed; thus, as the $\mathrm{N}_{2}$ content of the feed increases, the total equipment and operating costs are reduced, but so is the amount of product that can be produced to pay for these costs. Thus, the overall effect of increasing the $\mathrm{N}_{2}$ content in the feed to the PSA process may be either an increase or a decrease in PC.

Figure V-3a shows the effect of feed composition on the PCs for the five separation systems. For feed $\mathrm{N}_{2}$ contents between $10 \%$ and $40 \%$, NH-MEMB has the lowest PC of all systems and HYB- 1 has the highest. As expected from the above discussion, the $\mathrm{PC}$ resulting from $\mathrm{NH}$ MEMB increases as the $\mathrm{N}_{2}$ content increases; for NH-PSA, the PC also increases, but only gradually compared with NH-MEMB. NH-PSA would have a lower PC than NH-MEMB if the feed $\mathrm{N}_{2}$ content was above approximately $50 \%$. Thus, membrane technology is favored for low $\mathrm{N}_{2}$ feed contents, while PSA is favored for high $\mathrm{N}_{2}$ contents. 


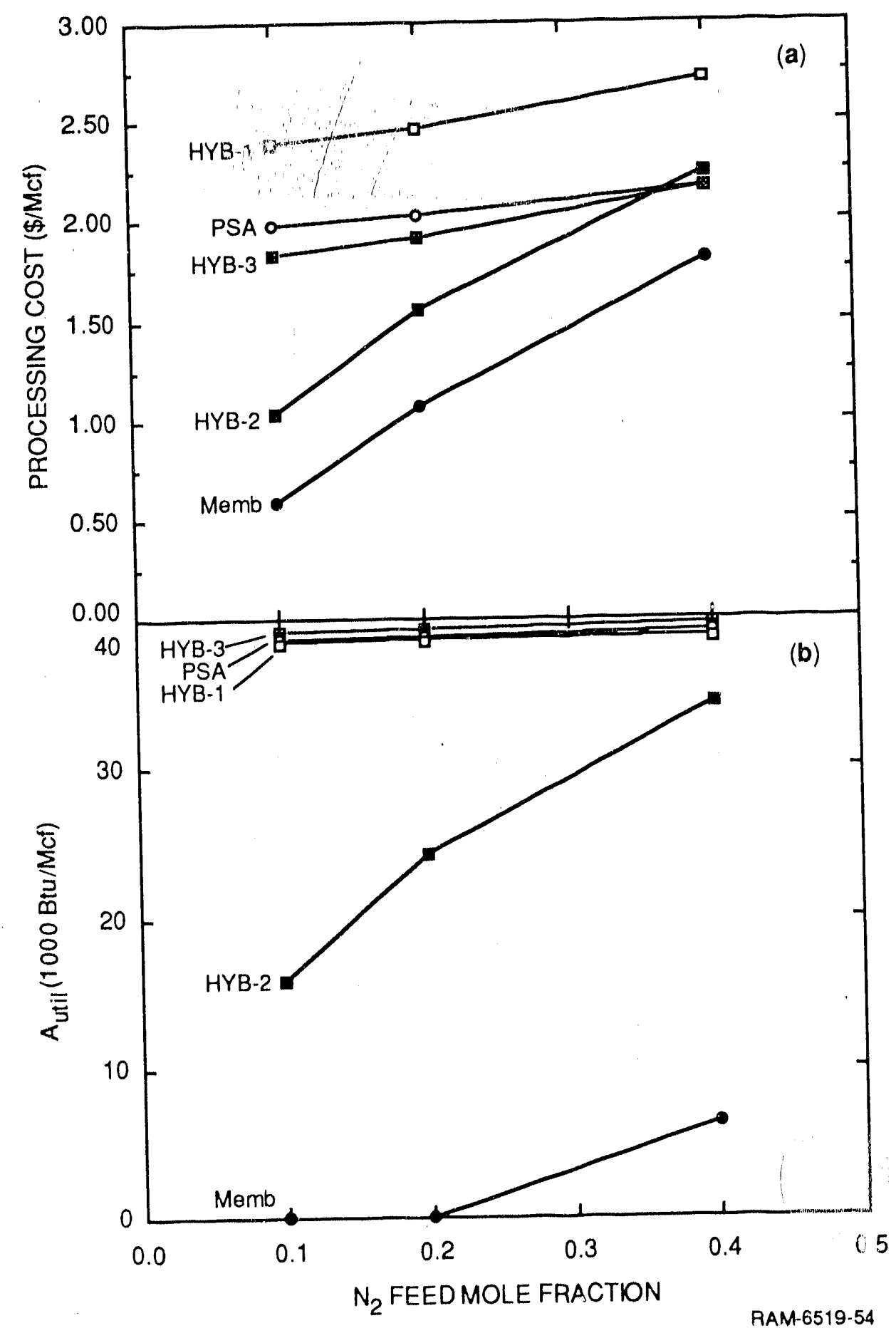

Figure V-3. Effect of feed composition on $P C$ and $A_{u t i l}$ for $N_{2}$ recovery. 
The PC for the three hybrid systems also increase as $\mathrm{N}_{2}$ content increases. HYB-3 has a PC about $10 \%$ less than NH-PSA with $10 \% \mathrm{~N}_{2}$ in the feed, but has the same PC when the feed $\mathrm{N}_{2}$ content is $40 \%$. PC with HYB-2 is about $\$ 0.50 / \mathrm{Mcf}$ more expensive than NH-MEMB for all feed concentrations.

Figure V-3b shows the effect of feed composition on $A_{u t i l}$ for the five separation systems. The results for NH-PSA, HYB-1, and HYB-3 are practically identical because in these systems the entire product steam must be recompressed. For HYB-2, some of the product stream is produced $a_{i}$ high pressure and does not require recompression; the fraction of product produced without needing compression is a function of the $\mathrm{N}_{2}$ content in the feed. For NH-MEMB, no electricity is required for $\mathrm{N}_{2}$ feed contents of $10 \%$ and $20 \%$ because only the first membrane is used. If the feed contains $40 \% \mathrm{~N}_{2}$, however, the full three membrane configuration is used and $A_{u t i l}$ is greater than zero. This graph shows that, in general, the PSA process uses much more energy than the membrane process. The energy needed by the PSA process is essentially independent of the feed composition, whereas the membrane process requires more energy as the $\mathrm{N}_{2}$ content of the feed increases.

\section{Feed/Product Pressure}

The feed and product pressures also have a great effect on the performance of both membrane and PSA processes. Although the feed and product pressure need not always be the same (in reality, many gas wells have a higher pressure than is needed for the pipeline, while many other wells have a pressure lower than the pipeline pressure), for simplicity we have assumed them to be equal. A high feed pressure reduces the membrane capital cost (because membrane area is approximately proportional to feed pressure), but the feed pressure does not affect the PSA costs because the feed pressure must be lowered to 275 psia no matter what the gas well pressure (unless the well pressure is below 275 psia, which requires compression of the feed to $275 \mathrm{psia}$ ). Changing the product pressure does not have any effect on the membrane system (because the product is always produced at ihe feed/product pressure), but it increases the PSA process costs (because the product gas requires recompression from 275 psia to the desired product pressure).

Figure V-4a shows the effect of feed/product pressure on PC for the five separation systems. NH-MEMB has the lowest PC for pressures above $\sim 300 \mathrm{psia}$; as the pressure increases the $\mathrm{PC}$ for NH-MEMB drops. In contrast to NH-MEMB, PC with NH-PSA increases as the pressure 
increases; this is also the case with HYB-3, which is dominated by its PSA section. In general, NH-MEMB has the lowest cost for high and moderate pressures, while HYB-3 has the lowest PC at low pressures.

Figure V-4b shows the effect of feed/product pressure on $A_{u t i l}$ for the five separation systems. Again, NH-PSA, HYB-1, and HYB-3 have practically identical results. The energy usage by these three systeris increases as the feed/product pressure increases due to the greater recompression requirements associated with the higher product pressures. For all pressures, NH-MEMB uses only a single membrane and, thus, does not use any energy. HYB-2 uses some energy for product recompression (from the PSA section only) and some for permeate recompression. Thus, with low feed pressures, the permeate pressure used by HYB-2 is also low, and the energy needed for permeate compression (the feed to the PSA section must be 275 psia) is greater than with high feed pressures.

\section{Membrane Selectivity}

The membrane selectivity is very important to the performance of the membrane system; increasing the selectivity will increase the product recovery and reduce the membrane capital costs. (As selectivity changes, we assume that the $\mathrm{N}_{2}$ permeability changes while the $\mathrm{CH}_{4}$ permeability remains constant.) Figure V-5a shows the effect of membrane selectivity on PC for four separation systems. (HYB-1 is not considered here or in later evaluations because it is always more expensive than any of the other systems.) NH-PSA is, of course, unaffected by the membrane selectivity and HYB-3, which is predominantly a PSA system, is only slightly affected. HYB-2 and particularly NH-MEMB, however, are strongly affected by selectivity.

For NH-MEMB, the PC is reduced from $\$ 1.07 / \mathrm{Mcf}$ (for the base case) to $\$ 0.28 / \mathrm{Mcf}$ as the selectivity is increased from 5 to 15 . Although this reduction in PC is due in part to a reduction in membrane capital cost, the primary cause is that the product recovery increases from $57 \%$ to $84 \%$ reducing the unrecovered methane expense from $\$ 0.73 / \mathrm{Mcf}$ to $\$ 0.18 / \mathrm{Mcf}$. If the selectivity is reduced, however, the PC for NH-MEMB is greatly increased - to $\$ 3.82 / \mathrm{Mcf}$ with a selectivity of 2.5. For selectivities below $\sim 4$, the full NH-MEMB configuration using all three membranes is required to achieve the minimum PC. Thus, reducing the selectivity greatly increases the capital cust for the system as well as reducing the product recovery (to $39 \%$ for a selectivity of 2.5 ). 


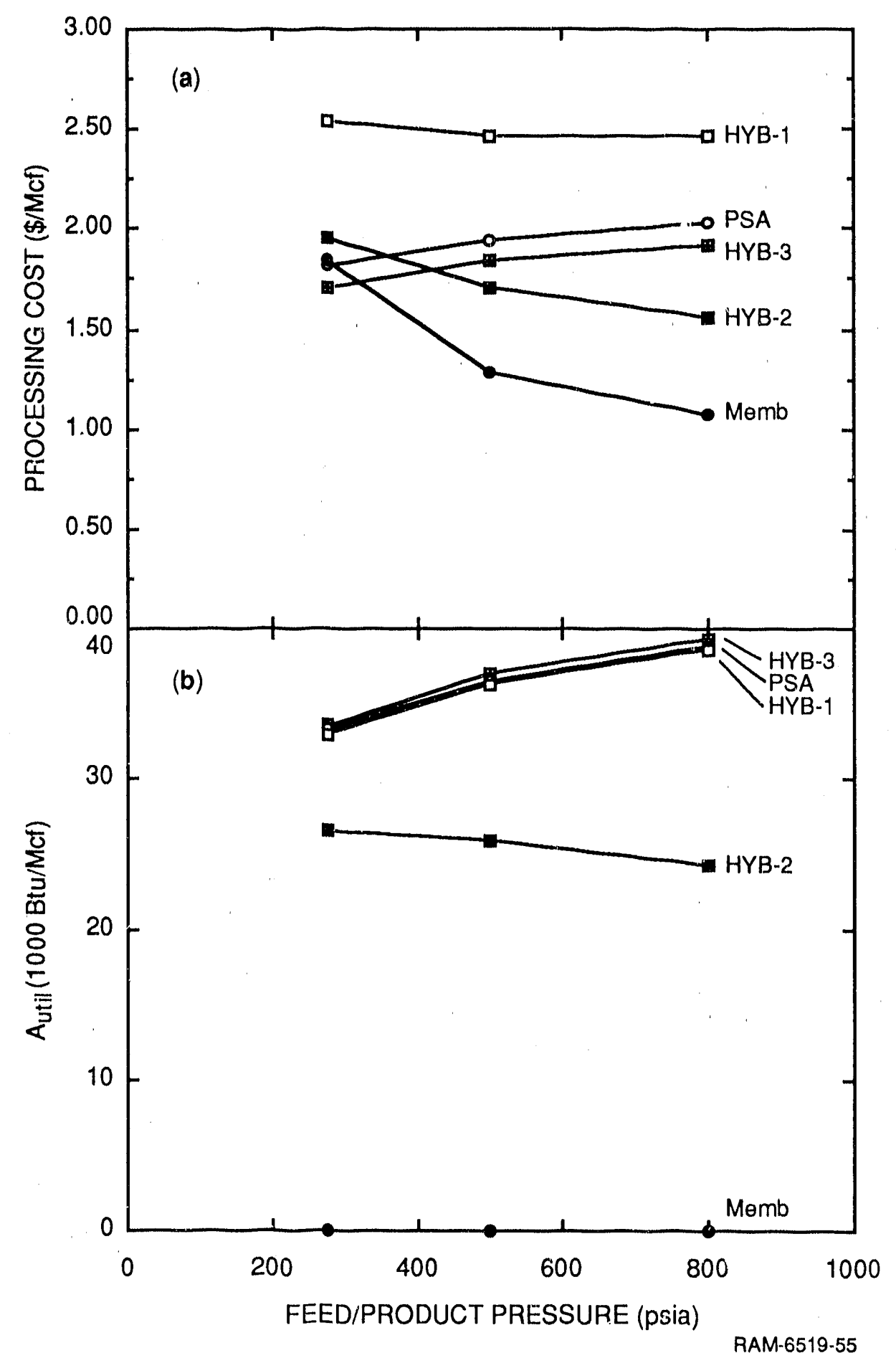

Figure V-4. Effect of feed/product pressure on $\mathrm{PC}$ and $\mathrm{A}_{\text {util }}$ for $\mathrm{N}_{2}$ recovery. 


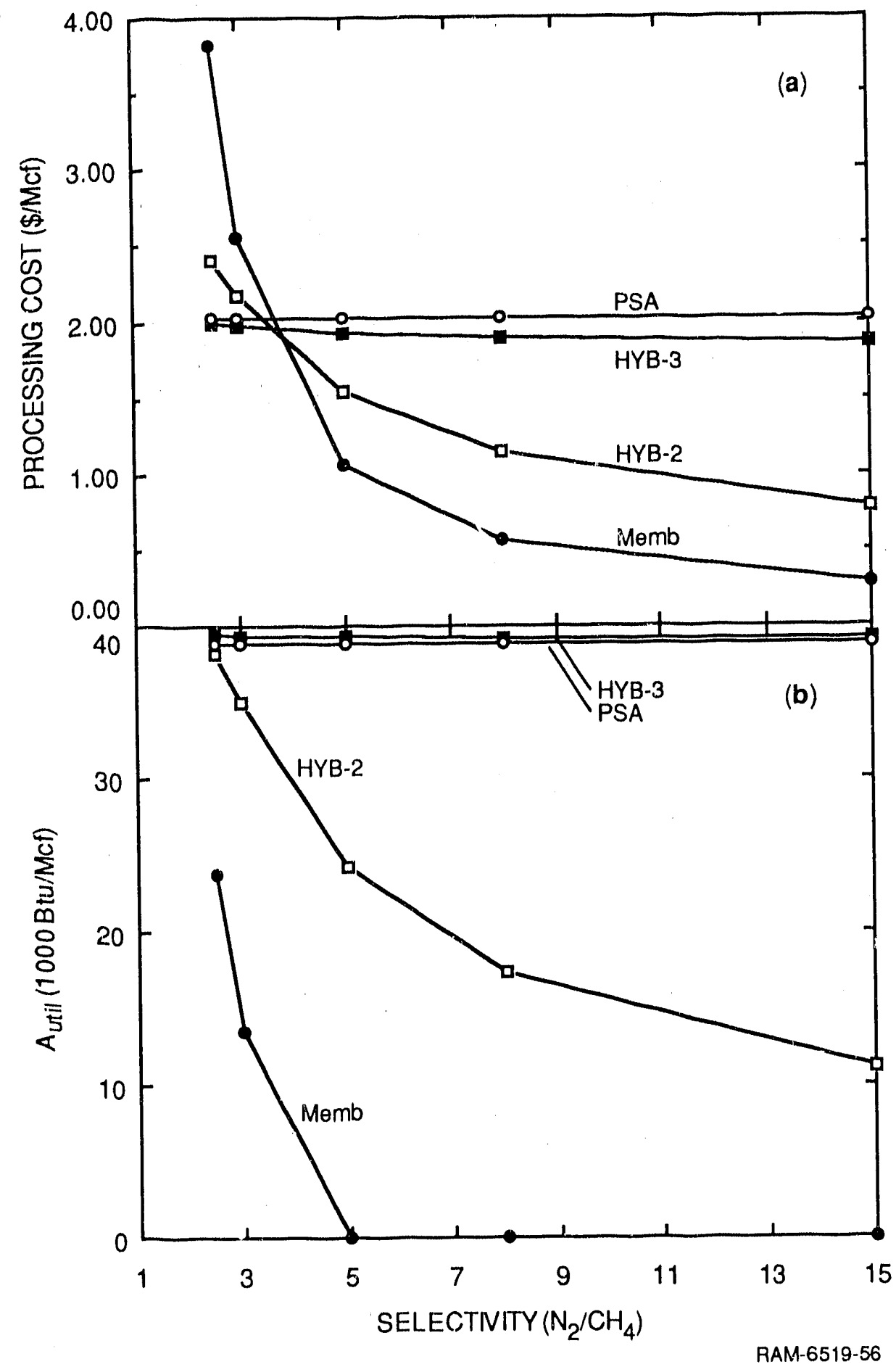

Figure V-5. Effect of membrane selectivity on $P C$ and $A_{\text {util }}$ for $\mathrm{N}_{2}$ recovery. 
With HYB-2, the PC does not vary as much as with NH-MEMB, although qualitatively they are affected similarly by changing the membrane selectivity. The difference between HYB-2 and NH-MEMB is that this configuration results in a high product recovery for all selectivities ( $88 \%$ to $98 \%$ for selectivities from 2.5 to 15 ). Thus, the increase in PC with reduced selectivity is due primarily to the increase in capital and operating costs of the PSA section (which performs a larger portion of the separation at low selectivities). In general, NH-MEMB is best when the membrane selectivity is above 4 and HYB-3 is best for selectivities below 4 .

Figure V-5b shows the effect of selectivity on $A_{u t i l}$. NH-PSA and HYB-3 have similar energy requirements which are independent of membrane selectivity. At low selectivities, NH-MEMB uses the full three membrane configuration and $\mathrm{A}_{\mathrm{util}}$ increases rapidly as selectivity drops below 5; for selectivities of 5 and above, the single membrane configuration is used and $A_{u t i l}$ is zero. HYB- 2 has an $A_{u t i l}$ value between that of NH-PSA and NH-MEMB systems and increases as selectivity drops.

\section{Membrane Cost}

Two other membrine properties have a significant influence on separation system performance: $\mathrm{CH}_{4}$ permeability and membrane cost. These factors affect the membrane in the same way and, therefore, only membrane cost will be discussed. (The effect of $\mathrm{N}_{2}$ permeability can be obtained from the results from varying membrane cost; i.e., a two fold increase in membrane cost or a two-fold decrease in $\mathrm{CH}_{4}$ permeability increases the membrane capital cost by a factor of two.)

Figure V-6a shows the effect of membrane cost on PC for the four separation systems. NHMEMB is affected the greatest of the four systems; a $\$ 1 / \mathrm{ft}^{2}$ change in membrane cost results in a $\$ 0.24 /$ Mcf change in PC. For membrane costs greater than $\$ 5 / \mathrm{ft}^{2}, \mathrm{NH}-\mathrm{PSA}$ results in the lewest PC of all systems, while with lower membrane costs, NH-MEMB gives the lowest PC. Thus, for membranes costing greater than $\$ 5 / \mathrm{ft}^{2}$, the PSA adsorbent material has properties sufficiently superior to the membrane material that PSA is preferred even though a process using a $\mathrm{N}_{2}$ selective separating agent should be favored.

For high membrane costs, the operating conditions of the systems using membranes are adjusted so that less membrane area is used at the expense of slightly greater energy use; membrane cost has no effect on energy use with NH-PSA. These results are shown in terms of $A_{u t i l}$ in Figure V-6b. 


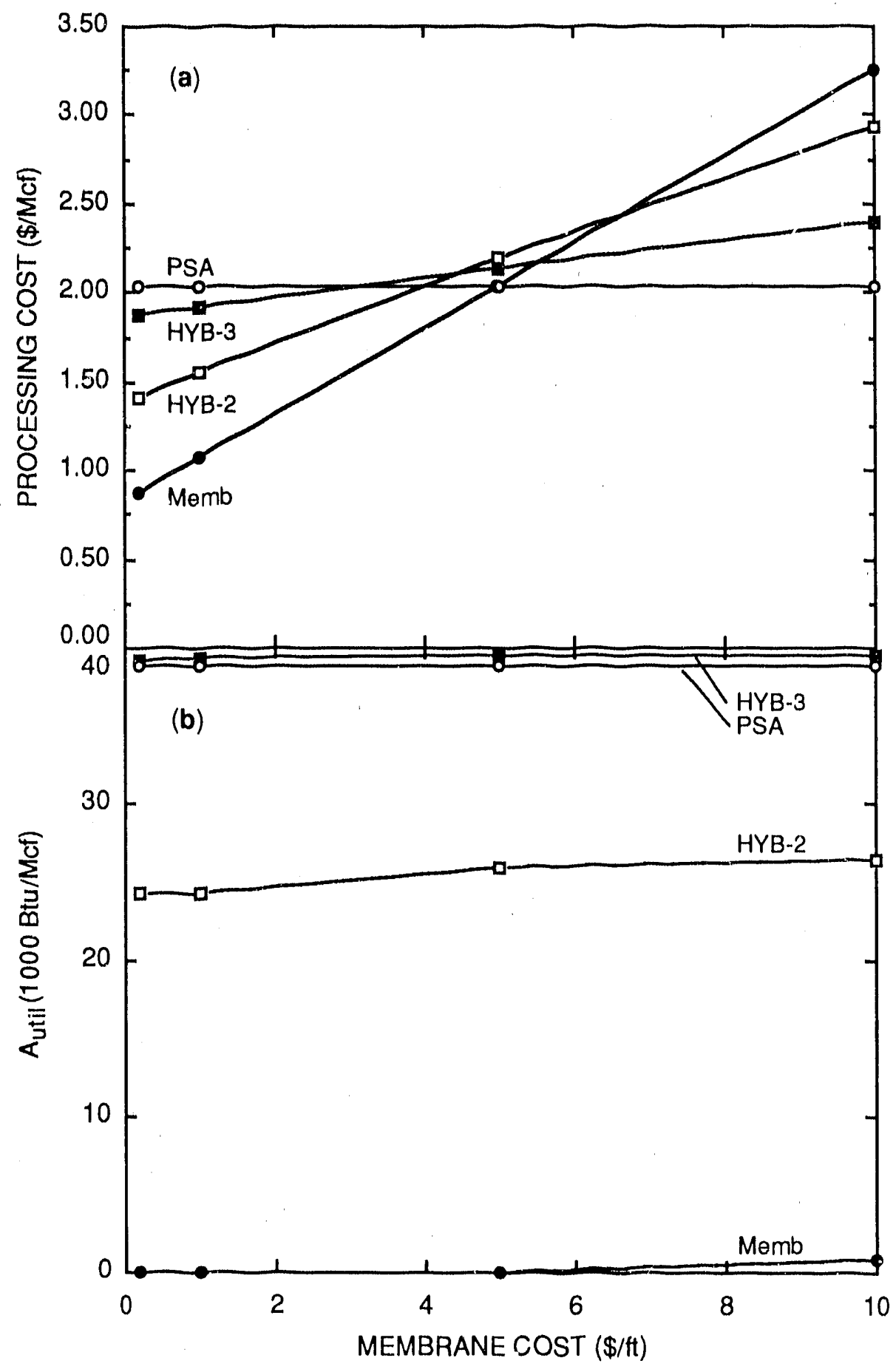

RAM-6519-57

Figure $V-6$. Effect of membrane cost on $P C$ and $A_{u t i !}$ for $N_{2}$ recovery. 


\section{Electricity Cost}

Figure V-7 shows that electricity cost has a significant effect on NH-PSA but no effect on NH-MEMB; doubling the cost of electricity increases the PC for NH-PSA by $30 \%$ over the base case value. The two hybrid configurations fall between the two single-technology systems. If conditions were such that NH-MEMB used the full three-membrane configuration, then electricity cost would also have an effect on NH-MEMB. The cost of electricity has no effect on $A_{u t i l}$ for any of the separation systems.

\section{Product Recovery}

The amount of methane recovered from the subquality feed is a process variable whose optimum value gives the best overall economic performance. Thus, the optimum value for product recovery will depend on how the economic performance is evaluated. We chose to use PC as the measure of economic performance; $\mathrm{PC}$ accounts for product recovery by charging an operating cost for any unrecovered methane. Thus, the value charged for this unrecovered methane will greatly influence both the optimum design of the separation system and the optimum product recovery that gives the lowest PC.

Figure V-8a shows PC for the four systems with unrecovered methane values of $\$ 1 / \mathrm{Mcf}$ (base case) and \$2/Mcf. NH-MEMB has the lowest product recovery of any of the base case systems and is affected most by increasing the unrecovered methane value. PC with NH-MEMB increases to $\$ 1.53 / \mathrm{Mcf}$ for an unrecovered methane value of $\$ 2 / \mathrm{Mcf}$ (from $\$ 1.07 / \mathrm{Mcf}$ for an unrecovered methane value of $\$ 1 / \mathrm{Mcf}$ ); the product rucovery also increases from $57 \%$ to $80 \%$. To achieve this higher recovery, the full three-membrane configuration is used in NH-MEMB.

NH-PSA is affected to a lesser extent than NH-MEMB because of its higher base case product recovery. PC with NH-PSA increases from $\$ 2.03 / \mathrm{Mcf}$ to $\$ 2.21 / \mathrm{Mcf}$ when the unrecovered methane value rises from $\$ 1 / \mathrm{Mcf}$ to $\$ 2 / \mathrm{Mcf}$. The two hybrid processes which have high product recoveries are not significantly affected by a change in the unrecovered methane value.

Changing the unrecovered methane value does not affect the operating conditions of any of the separation systems except NH-MEMB; thus, the unrecovered methane cost affects only $A_{u t i l}$ for NH-MEMB. When unrecovered methane is valued at $\$ 1 / \mathrm{ft}^{2}$, NH-MEMB uses only one membrane and $\mathrm{A}_{\mathrm{util}}$ is zero. However, at $\$ 2 / \mathrm{ft}^{2}$, NH-MEMB uses the three-membrane configuration requiring compression and resulting in $A_{u t i l}$ greater than zero. These results are shown in Figure V-8b. 


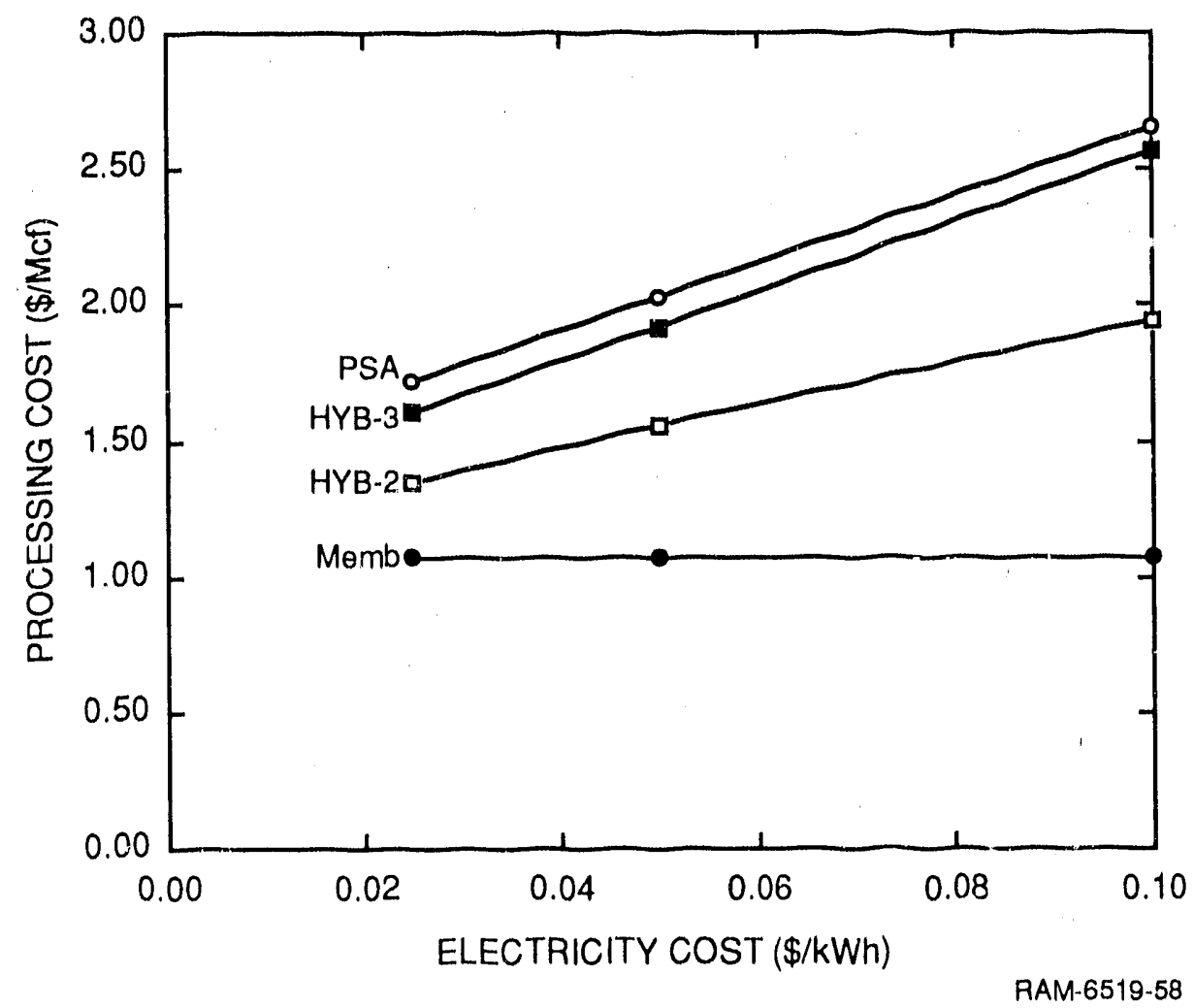

Figure V-7. Effect of electricity cost on $\mathrm{PC}$ for $\mathrm{N}_{2}$ recovery. 


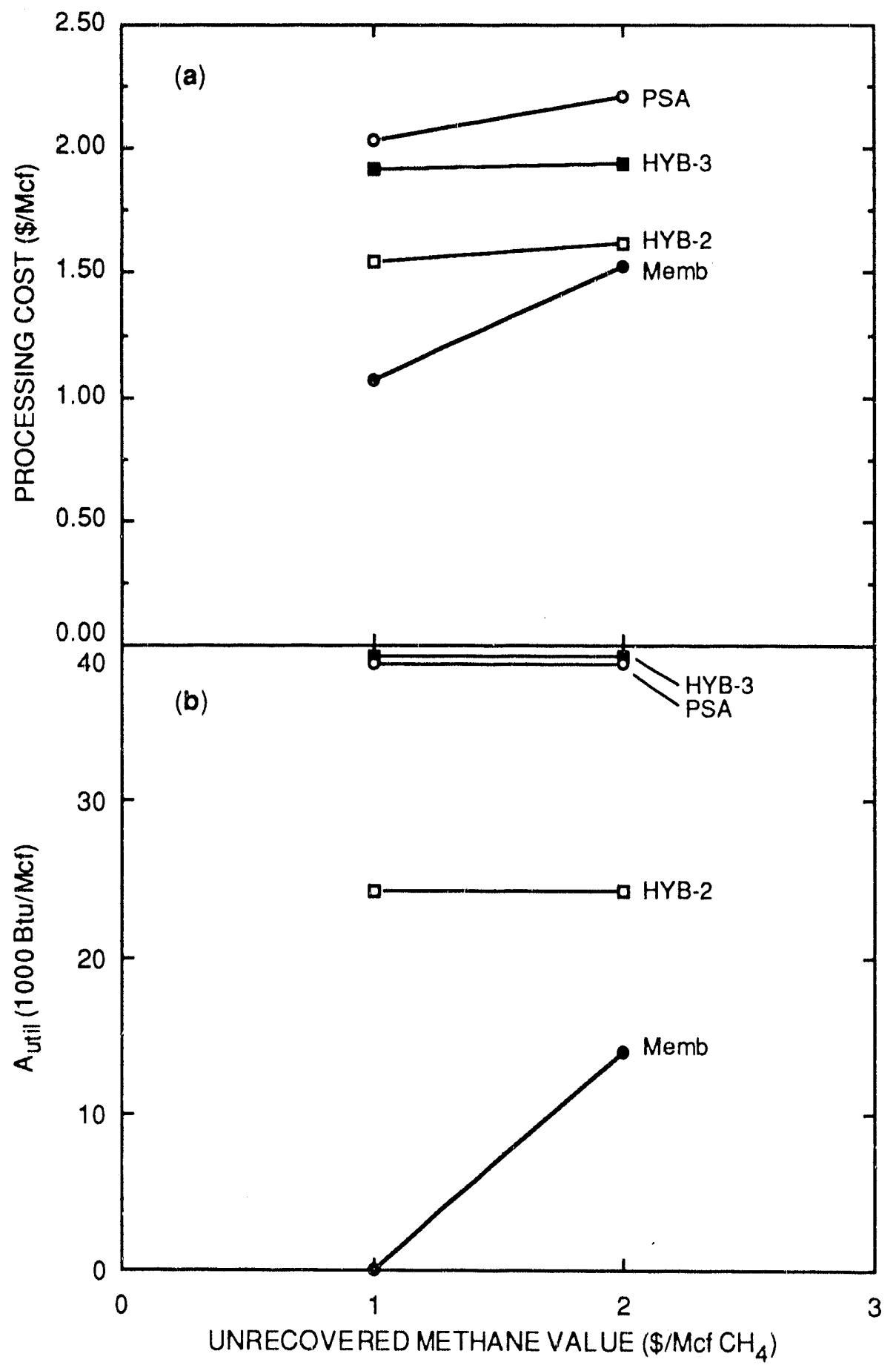

RAM- $6519-59$

Figure V-8. Effect of unrecovered methane value on $P C$ and $A_{u t i l}$ for $N_{2}$ recovery. 


\section{Summary of Process Parameter Results}

In general, these evaluations have shown that several parameters can significantly affect the performance of the hybrid and nonhybrid separation systems in various ways. Thus, to determine which system is best, we must know the conditions for the application of interest. In general, NH-MEMB is favored for feeds with low $\mathrm{N}_{2}$ content and when the feed/product pressure is high; what is meant by "low $\mathrm{N}_{2}$ content" or "high pressure" depends on the available membrane properties. When NH-MEMB is not the best system, HYB-3 usually gives slightly better performance than NH-PSA (except when membrane cost is high). HYB-2 is more expensive than NH-MEMB except under a few conditions (low selectivity, high membrane cost) where another system usually has the lowest PC of all.

In terms of energy use, NH-PSA, HYB-1, and HYB-3 have the largest $A_{u t i l}$, and of the parameters studied here, only feed/product pressure affects the resulting $A_{\text {util. }} . A_{\text {util }}$ resulting from NH-MEMB is lowest and is affected by all parameters (except feed/product pressure), but most strongly by membrane selectivity. HYB-2 has an $\mathrm{A}_{u t i l}$ between that of NH-MEMB and NH-PSA and is most strongly affected by membrane selectivity.

\section{CONCLUSIONS}

The separation system using membrane technology alone gives the best economic performance for many of the cases studied here, primarily because of its simple operation; only a single membrane is needed without recycle or compression, and the product stream is produced at pressure. However, if the membrane properties are not as good as those used in the base case assumptions, a more complicated membrane configuration is required, including recycle streams and compression. This change significantly raises the membrane system's PC, and NH-PSA or one of the hybrid systems had the best economic performance. Conditions such as high $\mathrm{N}_{2}$ content or low feed pressure also result in NH-MEMB having a higher PC than one of the other configurations.

Using membranes always reduces the energy requirement because miembranes produce a high pressure product and, therefore, require no energy input (unless the three membrane configuration is required, in which case, some energy is needed). In contrast, the PSA process produces the product at low pressure and requires a high energy input for recompression. Qualitatively, the 
$A_{u t i l}$ and $P C$ results behave in a similar manner. MEMB usually has both lowest $A_{u t i l}$ and PC; when $A_{u t i l}$ increases, PC also increases. Neither $A_{u t i l}$ nor PC changes greatly for PSA, although feed/product pressure has the greatest effect on both these results.

By examining how the separating agent of each technology performs the separation, we have been able to identify which technology, PSA or membrane, should be "favored" to give the best performance. However, if the favored process uses a separating agent with marginal properties, the unfavored process may give better system performance. It is in these situations, when the favored process has marginal properties, that a hybrid system has the greatest chance of creating a synergistic combination with better performance than either technology alone. This idea of a favored process may be generalized to include other systems besides membrane/PSA. 


\section{CHAPTER VI}

\section{CASE STUDY 3 - CONCENTRATION OF KRAFT BLACK LIQUOR}

Production of paper and paper products is one of the largest industries in the United States. The pulp and paper industry is consistently one of the four largest energy purchasers in the United States (along with chemicals, petroleum, and primary metals; Barron et al., 1987). A large portion of this energy is used for separation processes. The Kraft pulping process was invented in the late 1800s and now is the major pulping process used in the United States. In 1983 over 50 million tons of pulp were produced, of which more than $75 \%$ was produced by the Kraft process. In the Kraft process, pulping solution (known as white liquor consisting of inorganic chemicals such as sodium sulfide and sodium hydroxide) is used to break down the wood. The resulting solution contains primarily cellulose and lignin, plus the components from the pulping solution. The pulp (primarily cellulose) is removed, keaving a solution known as kraft black liquor (KBL). The KBL, for both environmental and econmic reasons, cannot be discarded, but must be recovered. The lignin is burned and provides a considerable amount of energy for use in the pulp plant; the inorganic chemicals remaining are too costly to replace and must be used to generate fresh pulping solution.

Figure VI-1 shows the major steps in the recovery of KBL. After pulping, the weak black liquor is concentrated, typically by multieffect evaporation, and then burnt in the recovery furnace. In the recovery furnace the remaining water is evaporated, lignin is combusted (providing energy for steam production), and sulfur compounds that were oxidized during the pulping step are reduced. Make-up chemicals (termed salt cake; primarily sodium sulfate) are added to the furnace, and the molten chemicals are removed from the furnace where further processing produces the white liquor used in the pulping step. In this study we examined the concentration step of this process. Although this step is typically carried out by evaporation, we considered several alternatives including freeze concentration and reverse osmosis.

$\mathrm{KBL}$ concentration is only one energy consumer in the overall paper making process; the pulping step (which is performed at elevated temperatures), the paper production process, and miscellaneous other uses (various heating and electrical requirements) also require considerable amounts of energy. The pulp and paper mill also has a variety of energy sources available to it such as the lignin in KBL, various wood scraps that can be used for energy production, and 


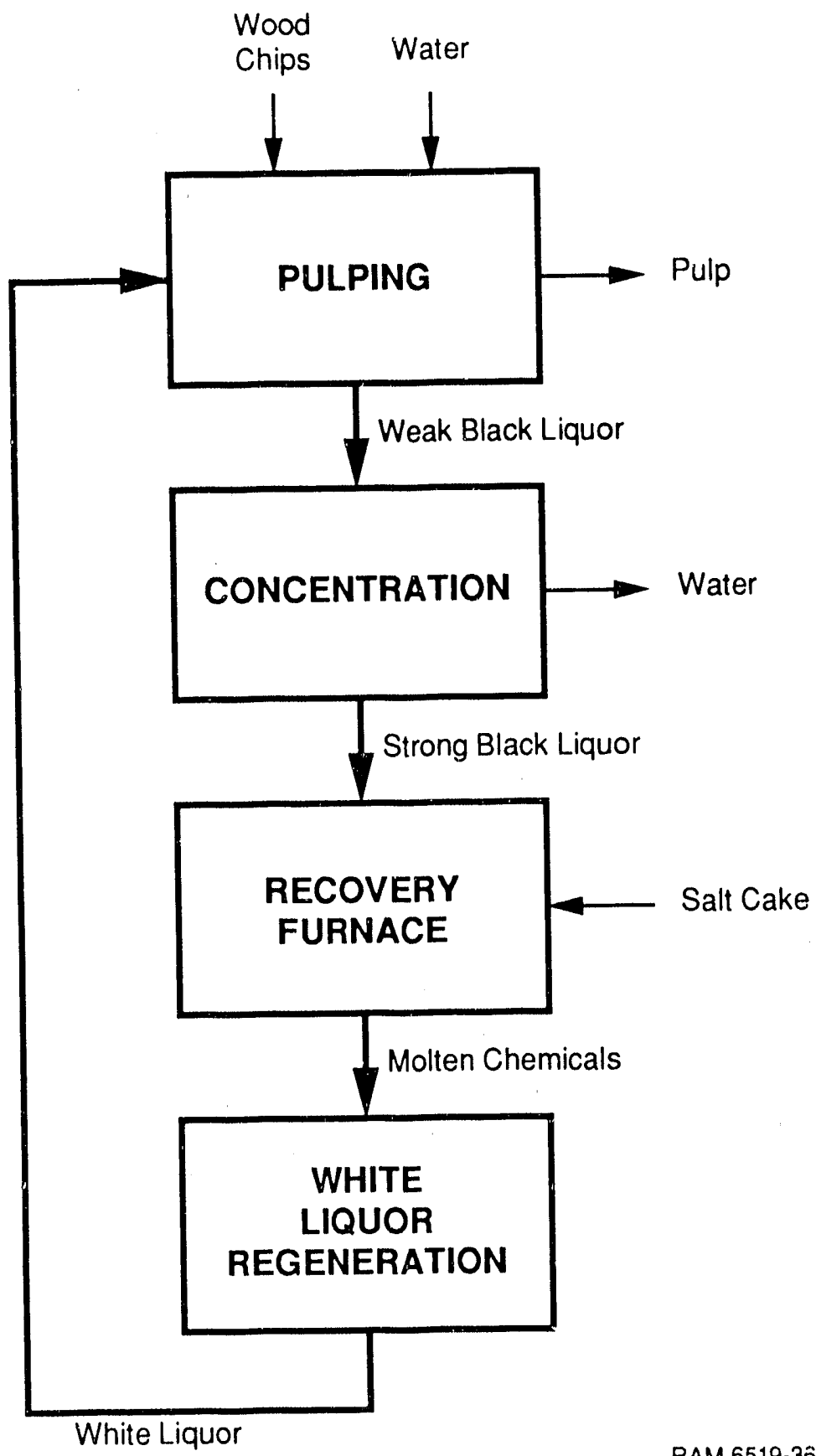

RAM-6519-30

Figure VI-1. Kraft pulping process. 
conventional fuels. Because the steam requirements of the plant are mostly low pressure (60 and $160 \mathrm{psig}$ ), high pressure steam produced in the recovery furnace and primary power boiler is used to generate electricity and the low pressure steam leaving the turbine-generator supplies the plant requircments. A typical heat balance is shown for a pulp and paper mill in Figure VI-2. The electricity generated is used in the plant, and any surplus or deficiency is made up by importing or exporting electricity.

The high degree of energy integration in the plant requires us to consider the effect of reducing the steam requirement of evaporation. Coleman (1986) performed such an analysis and stated that a reduction of the steam needed in the KBL concentration reducted the required steam output from the power boiler. This results in a savings in the purchased fuel needed for the primary power boiler but also a reduced electricity output. Whether the net effect on overall plant economics is favorable depends on the price of fuel and the price of imported or exported electricity. A complete analysis of this type is very site-specific and beyond the scope of this study. We assumed that the steam has a set value and did not include economic effects due to changes in electricity production.

We examined the use of two alternate technologies to evaporation for the concentration of KBL. Evaporation is inherently energy intensive because of the high heat of raporization of water. Use of multieffect evaporators minimizes the energy consumption, but it is still considerable. Freeze concentration still requires a phase change; however, the heat of fusion of water is about one-seventh that for vaporization; thus, considerable energy savings are possible. Reverse osmosis requires no phase change at all; however, the feed liquid must be pumped to a high pressure for the separation to take place and the energy needed in pumping reduces the energy savings potential of this process.

Three hybrid systems using some or all of these three technologies were compared with conventional evaporation for KBL concentration: reverse osmosis followed by evaporation, freeze concentration followed by evaporation, and reverse osmosis followed by freeze concentration followed by evaporation. The results indicate that evaporation is the most energy intensive of the three technologies; however, it uses the most economical power source (steam as opposed to electricity). Evaporation also has the lowest capital costs of the three technologies, and the overall cost for $\mathrm{KBL}$ concentration is less with conventional evaporation than with any of the hybrid systems. 


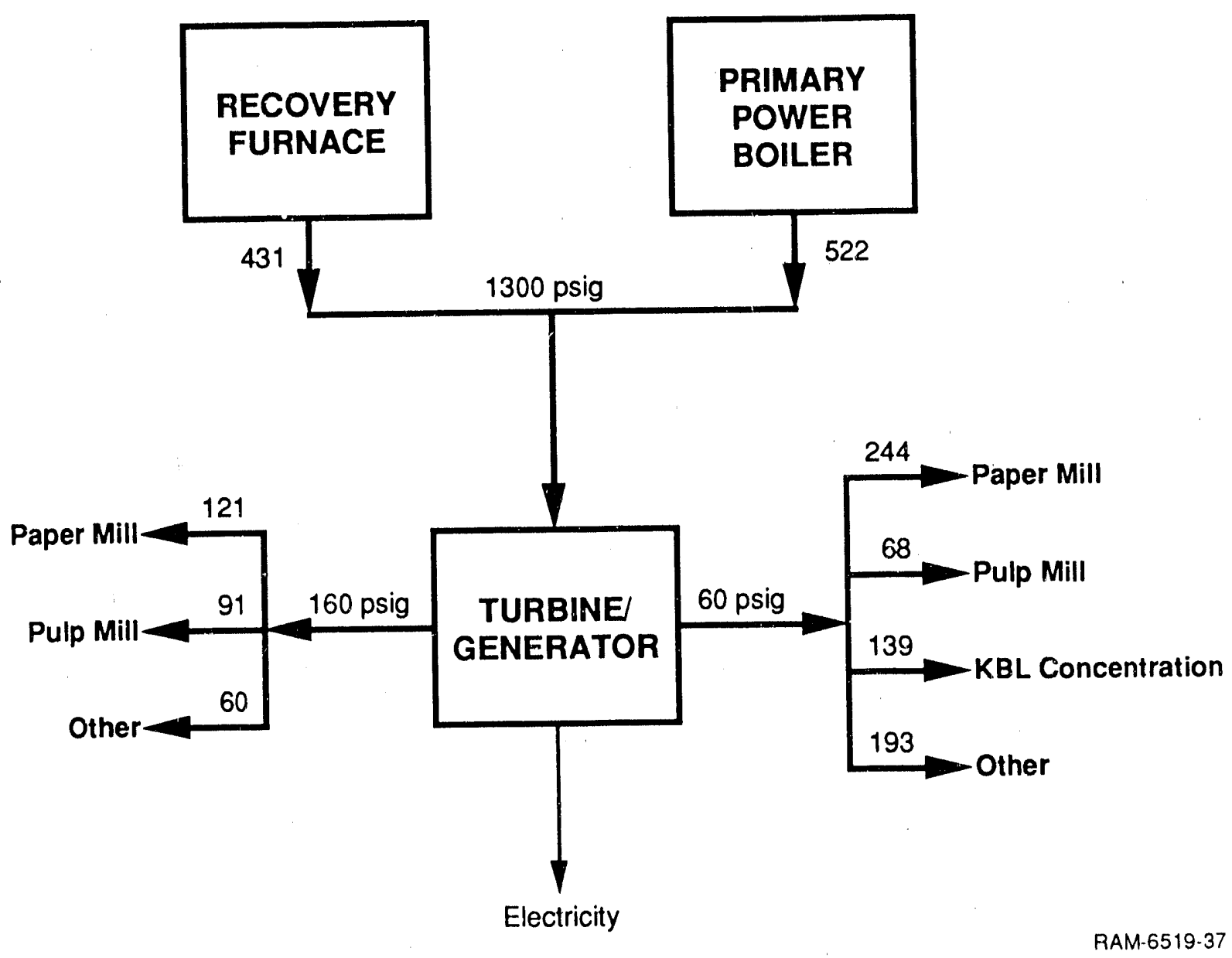

Figure VI-2. Steam balance for an integrated pulp and paper plant.

Numbers refer to stream flowrates in thousand ib per hour for production of 750 tons per day (TPD) of pulp. 


\section{PROCESS DESCRIPTION AND MODELING}

In the liquor recovery process, the weak black liquor from the pulp mill contains $12 \%$ to $18 \%$ solids and must be concentrated to $45 \%$ to $70 \%$ solids. We assumed that the weak liquor contains $15 \%$ solids and must be concentrated to $65 \%$ before combustion in the recovery furnace. The temperature of the liquor exiting the pulp mill is typically between 160 and $180^{\circ} \mathrm{F}$; we used $160^{\circ} \mathrm{F} . \mathrm{KBL}$ is a mixture of many organic and inorganic compounds whose exact composition varies depending on the feed materials and pulping conditions. A typical composition is given in Table VI-1. The physical properies of KBL, such as viscosity, specific gravity, vapor pressure, and osmotic pr.ssure can vary greatly depending on the temperature and composition of the liquor and can present different problems for each separation technology. For this reason it may be better to combine the technologies in a hybrid system to benefit from their individual advantages. A description of these technologies follows.

\section{Evaporation (EV)}

For KBL concentration multieffect, indirect-contact evaporators are typically used (MacDonald and Franklin, 1971; Wenzl, 1967). A multieffect evaporator increases energy efficiency by using the vapor evaporated from the KBL to vaporize more KBL in a downstream effect. A six-effect evaporator is illustrated in Figure VI-3. Steam enters the first effect, vaporizing a portion of the $\mathrm{KBL}$. This vapor goes to the second stage and vaporizes more $\mathrm{KBL}$ (which is at lower pressure and temperature than the previous effect). Thus one pound of steam can vaporize more than one pound of water. The approximate amount of water vaporized per pound of steam is given below for evaporators with one to seven effects:

\section{Number of Effects}

1

2

3

4

5

6

7

\section{Pounds Water \\ Vaporized \\ Per Pound Steam}

0.8

1.6

2.3

3.1

3.8

4.7

5.5
Btu (feed steam)
per Pound of
Water Vaporized

1,250

625

435

320

260

210

180 
Table VI-1

MAJOR COMPONENTS OF KRAFT BLACK LIQUOR

(Grace et al., 1977; Barron et al., 1987; Fricke, 1987)

Typical Concentrations

Welght Percent
of Total Sollds

Electrolytes

Sodium

Potassium

Carbonate

Sulfur

Other

\begin{tabular}{cc}
$12-25$ & $1.8-3.8$ \\
$0.1-2$ & $.02-.3$ \\
$4-6$ & $0.6-0.9$ \\
$2-5$ & $0.3-0.8$ \\
1 & 0.2 \\
\hline $25-35$ & $3.8-5.4$
\end{tabular}

Organic acids

Formic

$3-6$

$0.4-0.6$

Acetic

$3-4$

$0,{ }^{\prime}-0.9$

Lactic/glycolic

3. 5

$0.4-0.8$

Iso-saccharinic

10. 11

$1.5 \cdot 17$

$20-30$

$3.1-4.6$

Lignin

$33-45$

$5.0-6.9$

Other

$\frac{6}{100}$

0.9

Total

100

15.3 


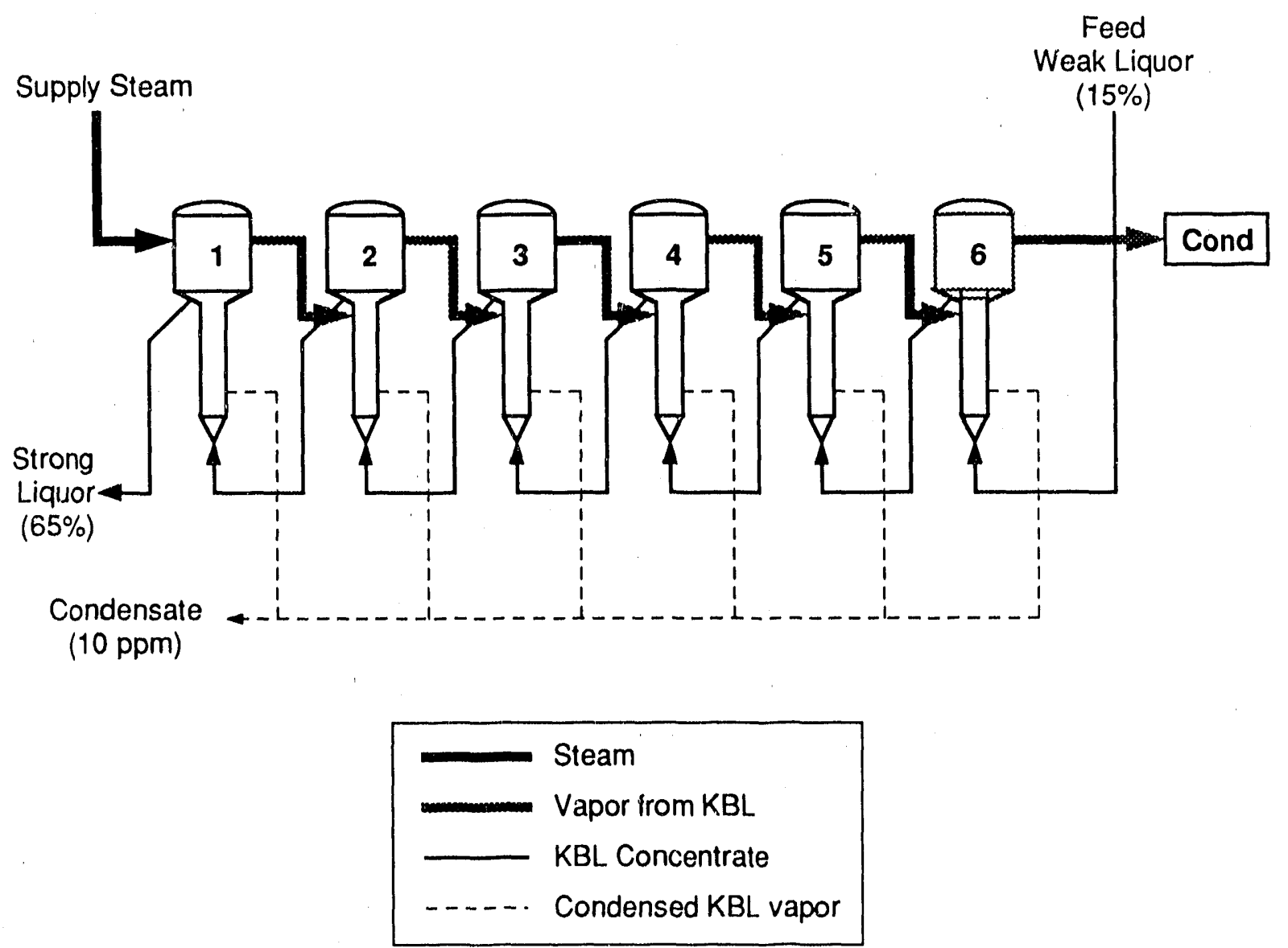

RAM- $6519-38$

Figure VI-3. Six-effect evaporator for KBL concentration. 
The steam consumption and installed capital costs used in this report were determined using the curves given by Coleman (1986). For feed solids concentrations between 15 and $20 \%$ solids, six effects were assumed; for feeds greater than $20 \%$ but less than $30 \%$, five effects were used, and for feeds greater than $30 \%$, four effects were assumed. We assumed a labor requirement of 0.3 worker/shift independent of evaporator capacity.

The KBL can be concentrated to as high as $70 \%$ solids; however, the increased viscosity presents difficulties for achievement of higher concentrations. The condensed vapor is very pure ( $10 \mathrm{ppm}$ impurities) and can be used as boiler feed water.

\section{Reverse Osmosis}

Reverse osmosis (RO) has been used for a variety of water concentration/purificatior applications including applications in the pulp and paper industry (Bansal and Wiley, 1977; Wiley et al., 1978; Maples and Lang, 1980; Olsen, 1980; Pepper and Tingle, 1983; Jönsson and Wimmerstedt, 1985; Sunavala, 1986). The concentration of KBL, however, has not been performed commercially by $\mathrm{RO}$ and is considered one of the most difficult $\mathrm{RO}$ applications in the pulp and paper industry. The difficulty lies in the high solids concentrations desired in the product. A high solids concentration means that the osmotic pressure will be high and therefore the feed must be pumped to a very high pressure. Several authors have suggested the upper bound for concentration of KBL to be 20 to 25\% solids (Pepper and Tingle, 1983; Sunavala, 1986).

The osmotic pressure of a solution can be estimated from its freezing point depression (the difference in freezing temperature between the solution and the pure solvent; Denbigh, 1971):

$$
\pi=\frac{T\left(T_{f}^{*}-T_{f}\right) h}{V T_{f}^{*} T_{f}}
$$

where

$$
\begin{aligned}
& \pi=\text { osmotic pressure (atm) } \\
& T=\text { actual solution temperature }(\mathrm{K}) \\
& \mathrm{T}_{\mathrm{f}}^{*}=\text { freezing temperature of pure solvent }(\mathrm{K}) \\
& \mathrm{T}_{\mathrm{f}}=\text { freezing temperature of solution }(\mathrm{K}) \\
& \mathrm{h}=\text { heat of fusion of solvent }(\mathrm{J} / \mathrm{mole}) \\
& \mathrm{V}=\text { molar volume of pure solvent }(\mathrm{cc} / \text { mole) }
\end{aligned}
$$


We used freezing point depression data (Johnson and Rhodes, 1985) to give the following relationship between percent solids (PS) content of $\mathrm{KBL}$ and its osmotic pressure:

$$
\pi=\frac{0.2963 \mathrm{~T} \cdot \mathrm{PS}}{273.15-0.2963 \mathrm{PS}}
$$

where $\pi$ is in atmospheres and $\mathrm{T}$ is in Kelvin. From Eqn. VI-2, a KBL solution containing $25 \%$ solids at $160^{\circ} \mathrm{F}$ will have an osmotic pressure of almost 1700 psia. This pressure is very high for membrane operation, and special modules may be necessary. (Most high pressure RO modules are designed for seawater desalination and have a maximum operating pressure of 1,000 psia.) We assumed that the maximum solids concentration achievable with a membrane is $25 \%$. Aside from operating at high pressures, the membranes must work at moderately high temperatures and at high $\mathrm{pH}$ (KBL typically has a pH of 12 to 13 ). These are very tough conditions for a membrane, but it is reasonable to believe such membranes could be produced if an effort was made.

Because few literature data are available dcscribing the performance of $\mathrm{RO}$ membranes for concentrating $\mathrm{KBL}$, we must estimate the rejection and flux characteristics of a membrane in this application from data available from similar applications. The flux across the RO membrane was calculated by:

$$
\begin{gathered}
\mathrm{Q}=\mathrm{K}(\Delta \mathrm{P}-\Delta \pi) \\
\Delta \pi=\left(\pi_{\mathrm{F}}+\pi_{\mathrm{R}}\right) / 2-\pi_{\mathrm{P}}
\end{gathered}
$$

where

$$
\begin{aligned}
& \mathrm{Q}=\text { flux }\left(\mathrm{lb} / \mathrm{hr}-\mathrm{ft}^{2}\right) \\
& \mathrm{K} \quad=\text { permeability coefficient }\left(\mathrm{lb} / \mathrm{ft}^{2}-\mathrm{hr}-\mathrm{psi}\right) \\
& \Delta \mathrm{P}=\text { average pressure differential across the membrane (psi) } \\
& \Delta \pi=\text { average osmotic pressure differential across the membrane (psi) } \\
& \pi_{\mathrm{F}}=\text { osmotic pressure of feed solution (psia) } \\
& \pi_{\mathrm{R}}=\text { osmotic pressure of residue stream (psia) } \\
& \pi_{\mathrm{P}}=\text { osmotic pressure of permeate stream (psia). }
\end{aligned}
$$


The value for $\mathrm{K}$ is a typical value taken from seawater desalination literature (Larson et al., 1982), $0.0134 \mathrm{lb} / \mathrm{ft}^{2} / \mathrm{hr} / \mathrm{psi}$. We have specified a feed pressure sufficient to give a $\Delta \mathrm{P}$ of $400 \mathrm{psi}$. The other important parameter used to describe mernbrane performance is the solute rejection $\left(S_{r}\right)$, defined as:

$$
\mathrm{S}_{\mathrm{r}}=1-\frac{\text { permeate-side solids concentration }}{\text { feed-side solids concentration }}
$$

To simplify mass balance calculations, we made the approximation that $S_{r}$ is equal to the ratio of feed-side to permeate-side percent solids. Although this approximation neglects changes in solution specific gravity, because our solute values of $S_{r}$ are only estimates, use of this approximation is acceptable. To obtain an estimate for $S_{t}$, we reviewed $\mathrm{RO}$ data from a wide range of solutions. Seawater membranes, for which the most work has been aimed, achieve reje ' ns as high as $99.8 \%$ for $\mathrm{NaCl}$. Although sodium is one of the major components of KBL (see Table VI-1) there are many other components, each having a different rejection characteristic. Lignin, for example, can be removed by ultrafiltration (Hill, 1987; $\mathrm{K} \cdot \mathrm{kman}$ et al., 1986) and therefore should be completely rejected by an RO membrane. On the other hand, organic acids, another major component of $\mathrm{KBL}$, can have rejections as low as $34 \%$ (for the smallest acid, formic) to over $90 \%$ (for acetic acid) from the same membrane (Toray). We chose to use a value of $98 \%$ for $S_{r}$; this value reflects the high values that can be achieved with RO membranes, but is not at the very high end because of the very broad range of compounds contained in KBL and because of the harsh conditions under which the membrane must operate.

The minimum permeate concentration that can be achieved while producing a $25 \%$ solids stream is $0.4 \%$ (with an $S_{r}$ of $98 \%$ ). This quantity of unrecovered solid is too great for an economic process. Because the solids are regenerated to produce the pulping solution, any loss of solids increases the amount and cost of make-upi salt cake that must be added to the recovery furnace (see Figure VI-1). The lost energy sources (lignin) and disposal costs also contribute to making a permeate stream containing $0.4 \%$ solids uneconomical. Thus, a second RO stage is needed to produce a final permeate stream that does not contain too much solid. We chose $300 \mathrm{ppm}$ as our maximum allowable solids content in the purified water stream leaving the membrane process; the cost of replacing this amount of solid is small, and the purity requirement is not too difficult for the membrane. 
The two-stage membrane process is shown in Figure VI-4. The KBL stream is concentrated from $15 \%$ to a maximum of $25 \%$ in the first stage, and the solids content of the water stream is reduced to $300 \mathrm{ppm}$ in the second stage. The residue stream leaving the second stage (which has a solids concentration somewhere between the first stage feed and permeate values) is recycled to the first stage. The pressure in tite concentrated stream is dropped to $1 \mathrm{~atm}$ after leaving the membrane.

Fouling is a potential problem in any RO application and would require careful design and probably pretreatment to prevent complete incapacitation of the membrane. The maximum solids concentration in the system of only $25 \%$ is a favorable factor. Proper pretreatment of the feed, a high feed velocity, and regular cleaning should minimize fouling problems.

The membrane costs were calculated using the flux given by Eqn. VI-3 and a installed membrane cost of $\$ 12 / \mathrm{ft}^{2}$. A membrane life of two years was used with a replacement cost of $\$ 5 / \mathrm{ft}^{2}$. These membrane costs were estimated from the January 1990 "components and services" catalog of Applied Membranes, Inc., San Marcos, CA (Filmtec Model M-S8040-F). Capital and operating costs of pumps were calculated by costing routines built into a commercial process simulator (ASPEN/SP; Simulation Sciences, Denver, CO). We assumed a labor requirement of 0.2 worker/shift, independent of capacity.

The increased loss of sodium compounds over that lost in evaporation, although small, was included by estimating the expense of purchasing salt cake to r ake up this loss. To estimate the amount of salt cake needed to balance that lost in the membrane permeate, we assumed that the smaller molecules are lost preferentially; thus we assumed that half the lost solids consists of sodium. The cost of an equivalent weight of salt cake $\left(\mathrm{Na}_{2} \mathrm{SO}_{4}\right)$ can then be determined. The energy potential lost in the unrecovered lignin is assumed to be insignificant as are any disposal costs.

\section{Freeze Concentration}

The concentration of KBL with freeze concentration (FC) has been studied by several groups over the past 15 years (Wiley et al., 1978; Johnson and Rhodes, 1985; Coleman, 1986; Barron et al., 1987). Freeze concentration is based on the phenomenon that as an aqueous solution cools to its freezing point, virtually pure ice crystals form while the remaining solution becomes more concentrated. Removal of the ice from the concentrated solution completes the separation. The basic freeze concentration process is shown in Figure VI-5. Feed is precooled before entering the crystallizer. After formation of ice in the crystallizer, the ice and concentrate are separated and melted. The concentrate and melt are then used to precool the feed. 


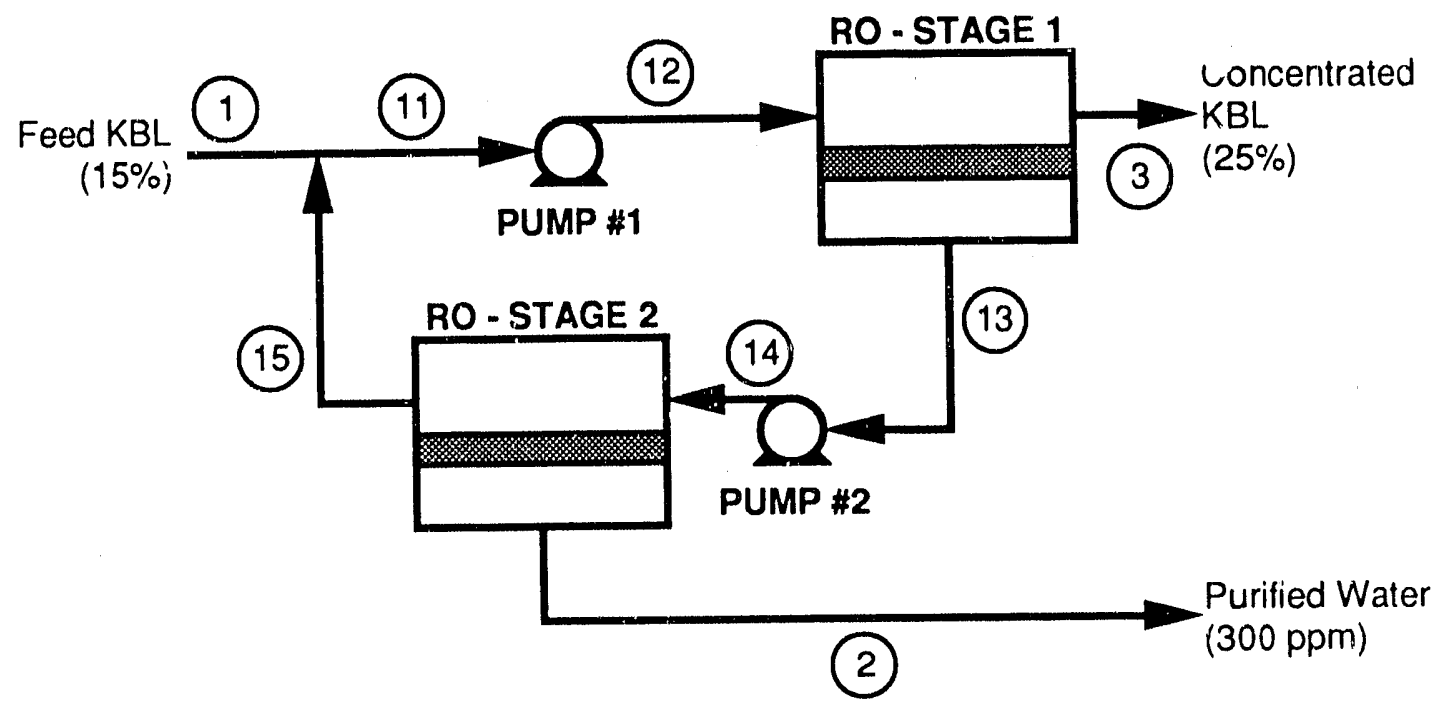

RAM-6519-39

Figure VI-4. Two-stage reverse osmosis system for KBL concentration.

Stream conditions are given in Tables VI-6 and VI-8. 


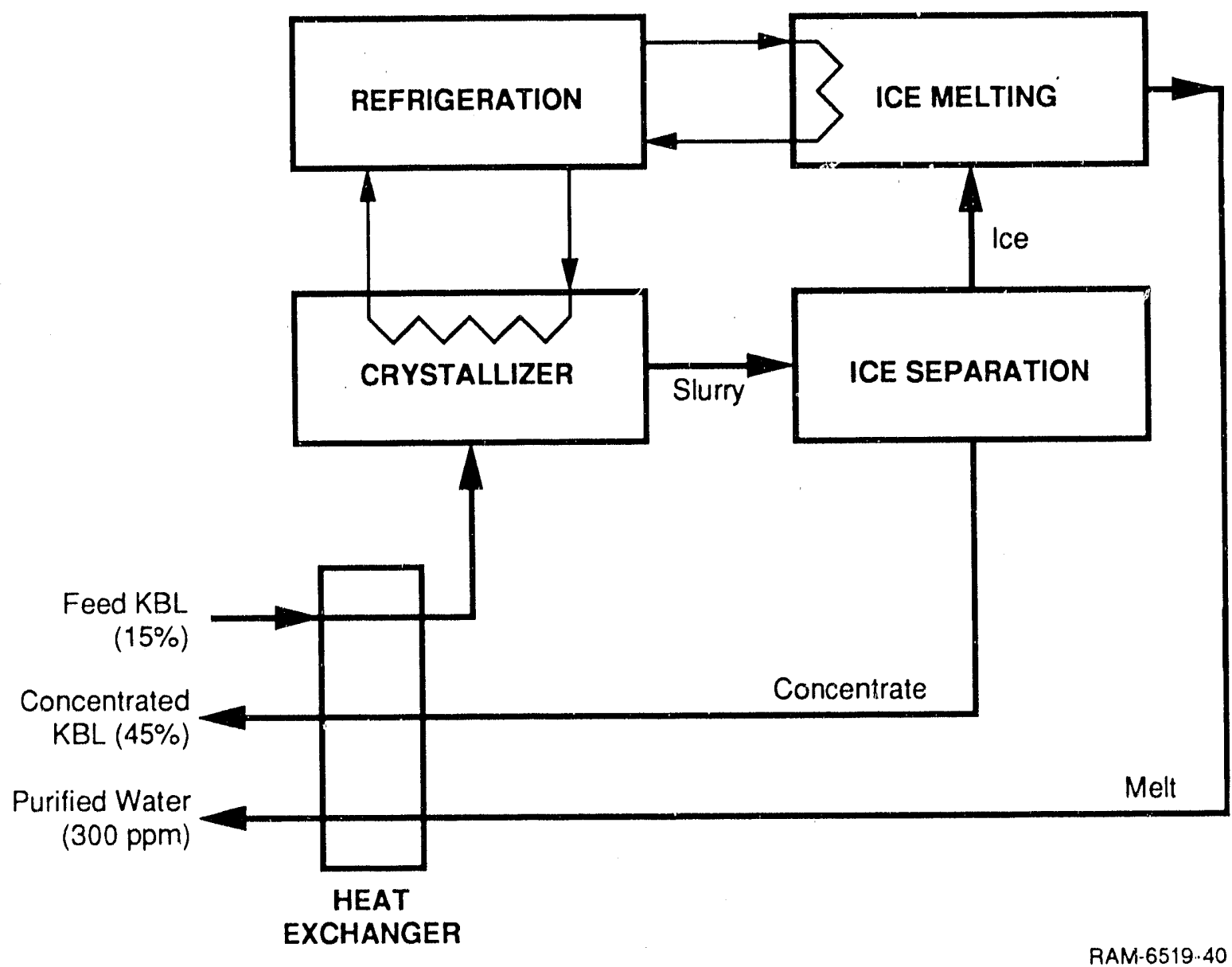

Figure VI-5. Freeze concentration system for concentration of KBL. 
As more water is removed through formation of ice, the freezing temperature drops. Because of the increased concentration and lowered temperature, the viscosity of the solution increases to a point where it is no longer possible to separate the ice from the concentrated solution and further concentration of the KBL by freeze concentration is not possible. Thus, the maximum achievable concentration is 40 to $45 \%$ solids. We assumed that the maximum value is $45 \%$.

Although in theory the ice melt should contain no impurities, in practice it contains about $300 \mathrm{ppm}$ solids. This solids loss must be considered in light of both a waste disposal problem and a resource (lignin and sulfur compounds) loss. Because the impurity level is quite low, we assumed that the water does not incur a disposal charge. The increased loss of lignin and sulfur compounds over that lost in evaporation is accounted for in the same manner as for reverse osmosis.

The electrical power requirements and installed capital costs were taken from the curves given by Coleman (1986). We assumed a labor requirement of 0.5 worker/shift, independent of capacity.

\section{Hybrid Processes}

Although either RO or FC may have an advantage over EV in terms of energy use or cost, neither is suitable on its own because the desired solids content (65\%) cannot be obtained. Thus, a hybrid system might be used to obtain the advantages of the membrane or the freeze concentrator, while still achieving the desired concentration. Several possible hybrid systems use some or all of the three technologies; these hybrids are shown in Figure VI-6. To determine the thermodynamic and economic performance of these hybrids, we combined the methods used above to describe each technology individually.

\section{THERMODYNAMIC EVALUATION}

The thermodynamic result reported here is the change in availability of the utility streams, $A_{u t i l}$. The results are reported with respect to the dimensionless "thermodynamic extent of separation," $\phi$, defined as the change in availability (evaluated at a single value for temperature and pressure) of the product and feed streams surrounding a section of the process. Because three technologies are considered, we define $\phi_{R O}, \phi_{F C}$, and $\phi_{E V}$, which refer to the reverse osmosis membrane, freeze concentration, and evaporation sections of the process.

Because $\mathrm{KBL}$ is a complex mixture, we calculated availability changes using the simplified equation for an ideal solution, assuming that KBL consists of only two components, solids and water. Thus, $\phi$ is determined by 

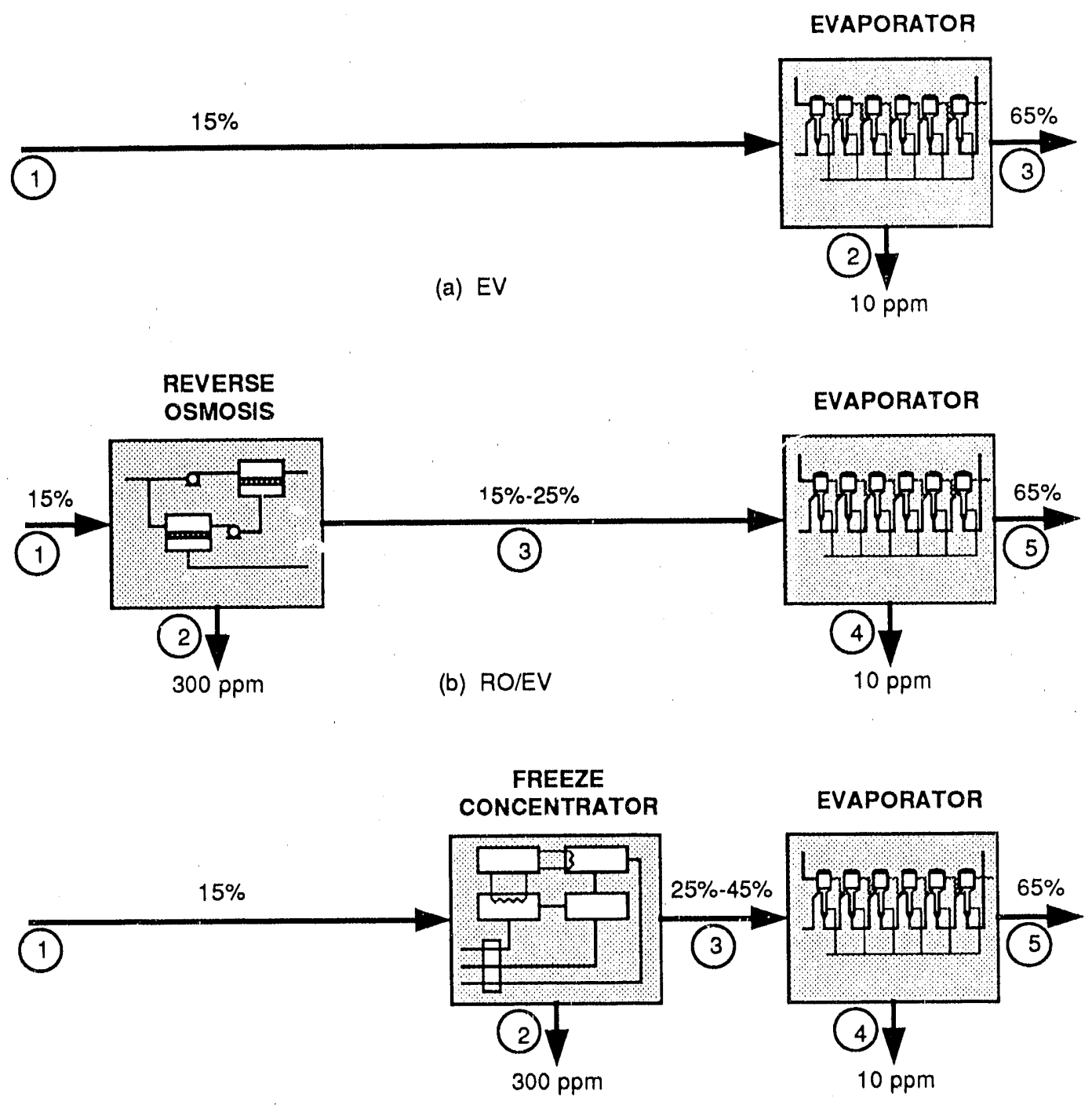

(c) FC/EV

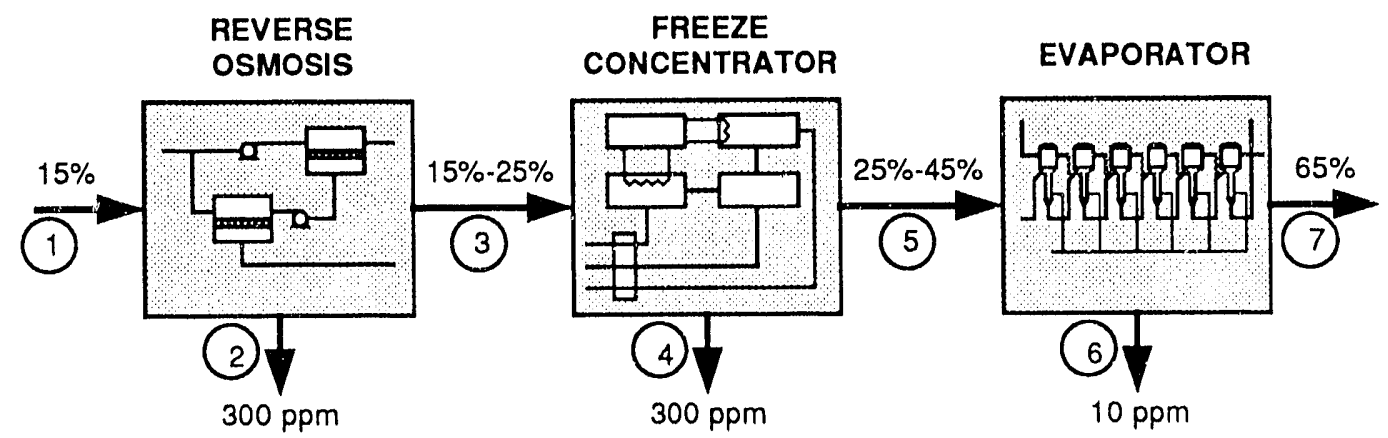

(d) RO/FC/EV

RAM-6519-41

Figure VI-6. Hybrid processes for concentration of KBL.

EV must always be used to achieve the desired concentration level. 


$$
\phi_{\mathrm{i}}=\sum_{\mathrm{PRODS}}\left[\mathrm{Y}_{\mathrm{S}} \cdot \ln \left(\mathrm{Y}_{\mathrm{S}}\right)+\mathrm{Y}_{\mathrm{W}} \cdot \ln \left(\mathrm{Y}_{\mathrm{W}}\right)\right] \cdot \sum_{\mathrm{FEEDS}}\left[\mathrm{Y}_{\mathrm{S}} \cdot \ln \left(\mathrm{Y}_{\mathrm{S}}\right)+\mathrm{Y}_{\mathrm{W}} \cdot \ln \left(\mathrm{Y}_{\mathrm{W}}\right)\right]
$$

where FEEDS and PRODS refer to the entering and exiting streams of section $\mathrm{i}$ (RO, FC, or EV) of the separation process, and $\mathrm{Y}_{S}$ and $\mathrm{Y}_{\mathrm{W}}$ refer to the mole fractions of solid and water, respectively. To determine mole fractions from mass fractions, we used a molecular weight for the solids of 75 . This molecular weight was calculated from freezing point depression data using the following approximation for ideal solutions to obtain the mole fraction corresponding to each mass fraction:

$$
\begin{gathered}
\ln \left(Y_{i}\right)=h\left(1 / T_{f}-1 / T_{f}^{*}\right) / R \\
M W_{S}=\left(Y_{W} M W_{W} / Z_{W}-Y_{W} M W_{W}\right) /\left(1-Y_{W}\right)
\end{gathered}
$$

where $\mathrm{R}$ is the gas constant, $\mathrm{MW}$ is a molecular weight, and $\mathrm{Z}$ is a mass fraction. The relationship between $\phi$ and PS is shown in Figure VI-7.

\section{ECONOMIC EVALUATION}

The processing cost (PC) is defined as dollars per 1,000 pounds of feed KBL processed. Membrane costs were calculated using a membrane cost of $\$ 5.00 / \mathrm{ft}^{2}$. An installation factor of 2.4 was used for the initial installation only; a membrane lifetime of two years was used. The remaining equipment costs were calculated by standard methods. Utility expenses are based on a steam cost of $\$ 2.00 / 1,000 \mathrm{lb}$ (at $60 \mathrm{psig}$ ), an electricity cost of 5 cents $/ \mathrm{kWh}$, and a cooling water cost of 5.7 cents $/ 1,000$ gal. Table VI-2 lists the specific parameters used in the economic evaluation.

\section{BASE CASE EVALUATIONS}

For each of the four configurations, we specified a number of process parameters to define a base case system. For all configurations, the base case feed and concentrate streams are essentially identical, while the purified water streams are slightly different ( 10 ppm solid in water stream from RO and FC, but only $10 \mathrm{ppm}$ from EV). For the base case RO/EV system, the membrane concentrates the $\mathrm{KBL}$ to $25 \%$ solids and evaporation completes the concentration. For the 


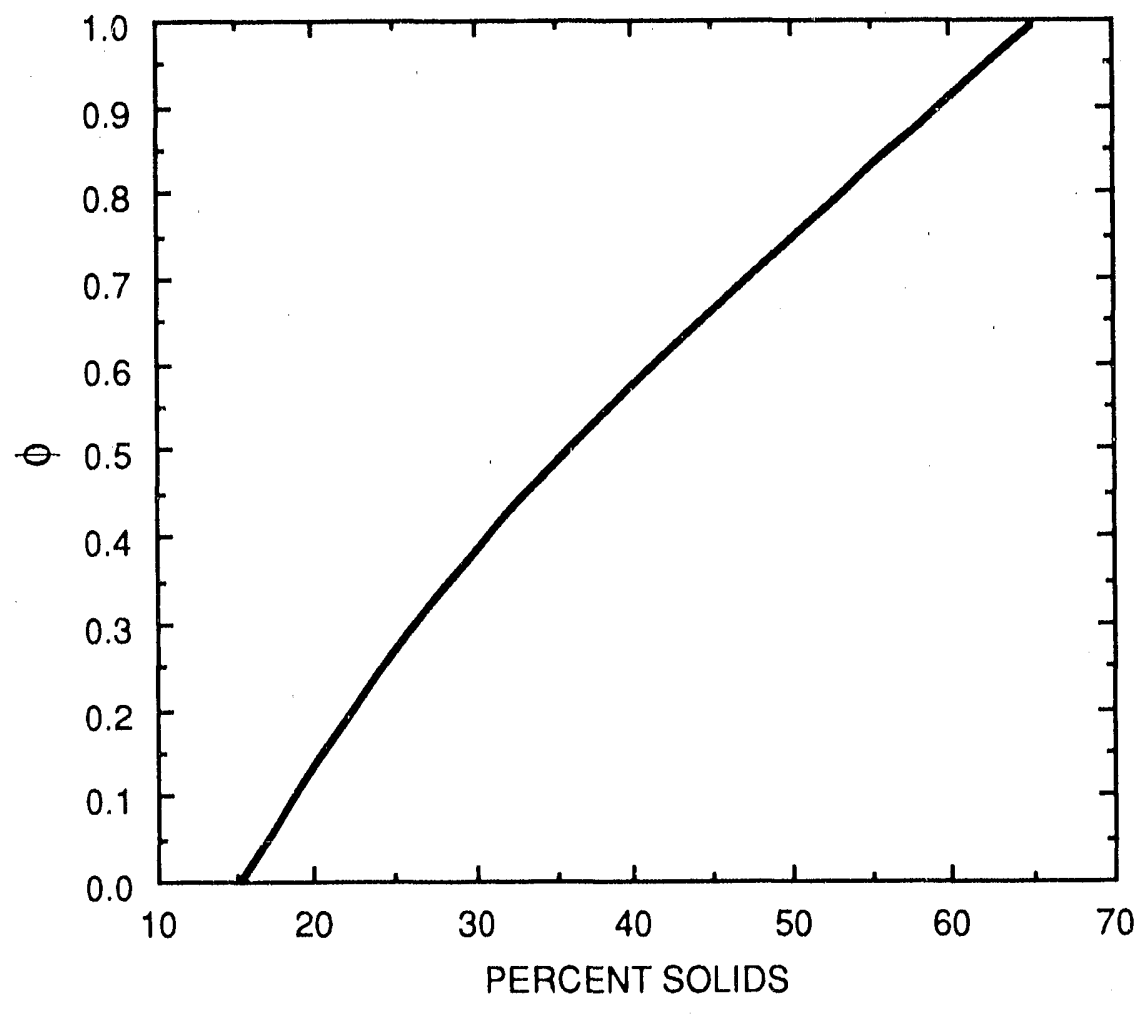

RAM-6519-42

Figure VI-7. Relationship between percent solids in the concentrated KBL stream and thermodynamic extent of separation. 


\section{Table VI-2 \\ ASSUMPTIONS USED IN ECONOMIC EVALUATIONS FOR KBL CONCENTRATION (Basls: 990,000 lb weak KBL/hr; 750 TPD pulp)}

Plant facilities investnient (PFI)

Installed membrane system cost

Replacement membrane cost

$\$ 12.00 / \mathrm{ft}^{2}$

Membrane life

$\$ 5 / \mathrm{ft}^{2}$

2 years

Utllity and operating costs

Steam (75 psia)

$\$ 2.00 / 1,000 \mathrm{lb}$

Electricity

$5 \notin / \mathrm{kWh}$

Cooling water

i $\quad 5.7 \notin / 1,000 \mathrm{gal}$

base case FC/EV system, the FC concentrates the KBL to $45 \%$ solids and EV completes the concentration. For the base case RO/FC/EV system, the membrane concentrates the KBL to $25 \%$ solids, FC to $45 \%$ solids, and EV completes the concentration. The weak KBL feed rate is $990,000 \mathrm{lb} / \mathrm{hr}$, typical of a pulp mill with a pulp capacity of 750 tons per day (TPD).

\section{Evaporation}

The stream compositions and conditions for the base case EV configuration are given in Table VI-3. The concentrate contains $65 \%$ solids while the purified water contains 10 ppm solids. The energy requirements for this configuration are shown in Table VI-4; 147 MBtu per 1,000 pounds of weak KBL feed ( 44.3 on availability basis) must be supplied from steam. The economics of this configuration are summarized in Table VI-5. The PC is $\$ 0.54 / 1,000 \mathrm{lb}$, over $60 \%$ of which is due to steam expenses. Capital costs for the evaporator are $\$ 3.6$ million. Details of this evaluation are included in Appendix C. 


\section{Table VI-3 \\ STREAM CONDITIONS FOR KBL CONCENTRATION WITH \\ EVAPORATION TECHNOLOGY ALONE \\ (Basls: $990,000 \mathrm{lb} / \mathrm{hr}$ weak KBL; $750 \mathrm{TPD}$ pulp)}

\begin{tabular}{c} 
Stream* $^{*}$ \\
\hline$(1) \quad \frac{(2)}{(3)}$
\end{tabular}

Mass fractions

Solids

Water

Total flow

Temperature $\left({ }^{\circ} \mathrm{F}\right)$

Pressure (psia)
0.15

0.85

990

180

15
$10 \mathrm{ppm}$

1.00

762

180

15
0.65

0.35

$(1,000 \mathrm{lb} / \mathrm{hr})$

228

180

15

"Stream numbers refer to Figure VI-6. 


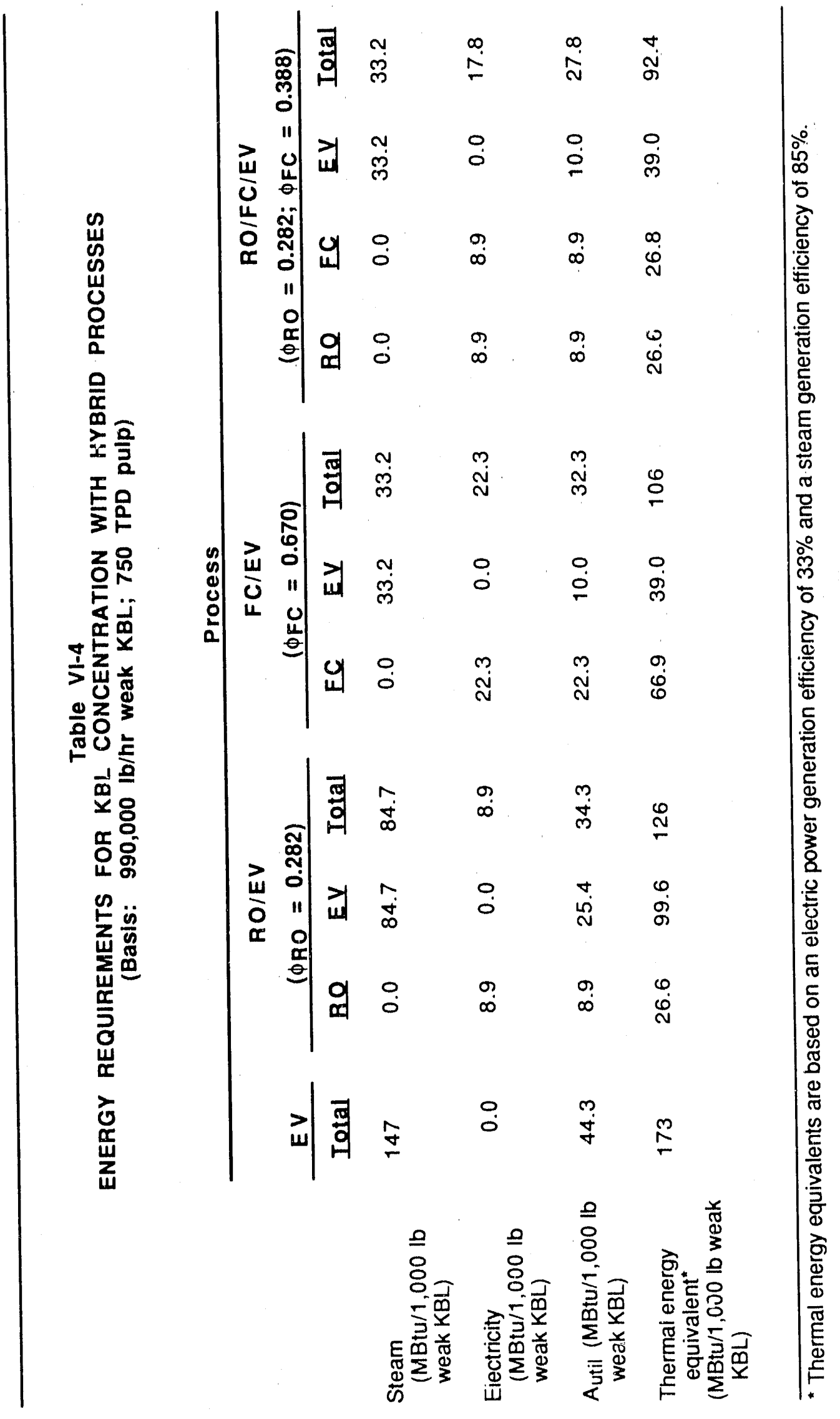

VI-20 


\section{Table VI-5}

ECONOMIC RESULTS FOR KBL CONCENTRATION WITH HYBRID PROCESSES

(Basis: $990,000 \mathrm{lb} / \mathrm{hr}$ weak KBL; $750 \mathrm{TPD}$ pulp)

\section{Process}

\begin{tabular}{cccc} 
& RO/EV & RC/EV & $\left(\phi_{\text {RO }}=0.282 ;\right.$ \\
EV & $\left(\phi_{R O}=0.282\right)$ & $(\phi F C=0.67)$ & $\left.\phi_{F C}=0.388\right)$ \\
\hline
\end{tabular}

Capital costs (\$U.S. millions)

RO unit

Freeze concentrator

Evaporator

0.0

2.45

0.0

0.0

360

2.31

General services

$\underline{0.54}$

0.71

0.0

16.8

1.21

$-2.70$

2.45

7.65

1.21

Total

4.14

5.47

$20.7 \%$

13.01

Operating costs $(\$ / 1,000 \mathrm{lb}$ weak KBL)

$\begin{array}{lllll}\text { Labor cost } & 0.028 & 0.040 & 0.124 & 0.091 \\ \text { Steam cost } & 0.326 & 0.187 & 0.073 & 0.073 \\ \text { Electricity cost } & 0.000 & 0.130 & 0.328 & 0.262 \\ \text { Other } & 0.029 & 0.044 & \underline{0.146} & 0.098 \\ \quad & 0.383 & 0.401 & 0.671 & 0.523 \\ \quad \text { Total } & & 0.65 & 1.34 & 1.01\end{array}$




\section{Reverse Osmosis/Evaporation}

The stream compositions and conditions for the base case RO/EV configuration are given in Table VI-6. The first stage n. smbrane feed must be pumped to a high pressure (1756 psia) to overcome the osmotic pressure of the solution. The first stage produces the $25 \%$ concentrate; however, the resulting permeate contains $0.4 \%$ solids and is sent to the second stage for final purification. The second stage feed requires compression to only 518 psia because the osmotic pressure it must overcome is small. The second stage produces a purified water stream containing $300 \mathrm{ppm}$ solids and a residue stream containing $2.6 \%$ solids; the residue stream is recycled to the first stage. The concentrate leaving the membrane section is concentrated to its final value by evaporation. The RO secion accounts for $52 \%$ of the water removed during concentration.

In terms of energy requirements (Table VI-4) this configuration is superior to the evaporation-only configuration; the $\mathrm{RO} / \mathrm{EV}$ configuration requires $8.9 \mathrm{MBtu}$ electricity (RO section) and 84.6 MBtu steam (EV section) per 1,000 lb of feed KBL. A reduction in steam requirement of $63 \mathrm{MBtu} / 1,000 \mathrm{lb}$ over evaporation alone is gained by adding the membrane at a cost of only $9 \mathrm{MBtu} / 1,000 \mathrm{lb}$ electricity. (The totai energy required in terms of availability is $34.3 \mathrm{MBtu} /$ $1,000 \mathrm{lb}, 10.0 \mathrm{MBtu} / 1,000 \mathrm{lb}$ less than the eva',oration alone.)

The economics of RO/EV are summarized in Table VI-5. Although the evaporator capital cost is less than for evaporation alone, the total capital cost is increased by $32 \%$. The energy requirements are reduced, but the total energy costs are almost the same and total operating costs are slightly greater than $\mathrm{EV}$ alone. The resulting $\mathrm{PC}$ is $\$ 0.65 / 1,000 \mathrm{lb}, 21 \%$ greater than for $\mathrm{EV}$ alone. Details of this evaluation are included in Appendix C.

\section{Freeze Concentration/Evaporation}

The stream compositions and conditions for the base case FC/EV configuration are given in Table VI-7. The feed stream is first sent to the FC unit where it is concentrated to $45 \%$ solids producing a purified water stream containing $300 \mathrm{ppm}$ solids. Evaporation is used to achieve the final KBL concentrate. The FC section accounts $\mathrm{fc} r 87 \%$ of the water removed during concentration.

In terms of energy requirements (Table VI-4) this configuration is superior to either of the previous configurations; FC/EV requires $22.3 \mathrm{MBtu}$ electricity (FC section) and 33.2 MBtu steam (EV section) per 1,000 lb of feed KBL. A reduction in steam requirement of $114 \mathrm{MBtu} / 1,000 \mathrm{lb}$ 


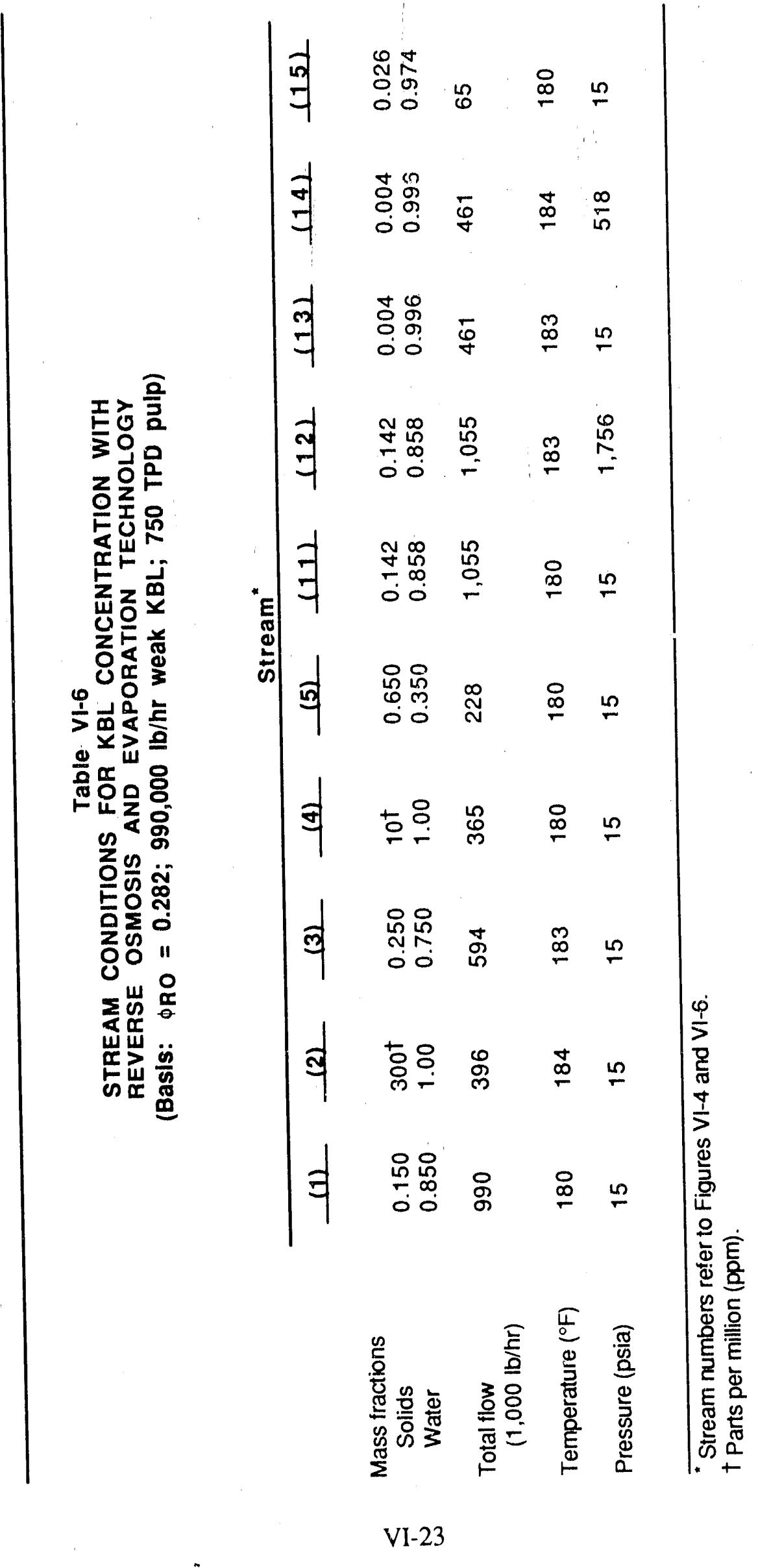


Stream"

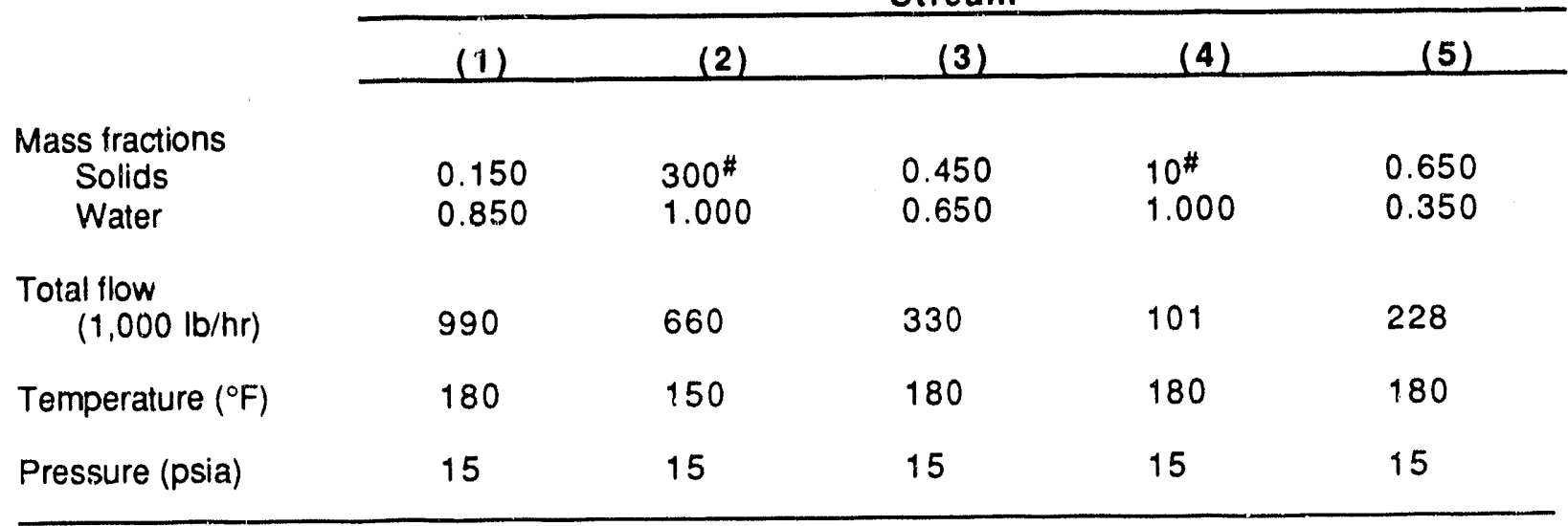

Stream numbers refer to Figure VI-6.

\# Parts per million (ppm).

over evaporation alone is gained by adding the FC section at a cost of only $22 \mathrm{MBtu} / 1000 \mathrm{Ib}$ electricity. (The total energy required in terms of availability is $32.3 \mathrm{MBtu} / 1,000 \mathrm{lb}, 12.0 \mathrm{MBtu} /$ $1,000 \mathrm{lb}$ less than the evaporation alone.)

The economics of FC/EV are summarized in Table VI-5. Although the evaporator capital cost is reduced by two-thirds, the FC is very expensive ( $\$ 17$ million) and the total capital cost is increased by a factor of five over evaporation alone. The energy requirements are less than those for evaporation alone, but using the more expensive electricity results in a $25 \%$ increase in total energy costs, and total operating costs are almost doubled. The resulting PC is $\$ 1.34 / 1,000 \mathrm{lb}$, more than double that of either EV or RO/EV. Details of this evaluation are included in Appendix C.

\section{Reverse Osmosis/Freeze Concentration/Evaporation}

The stream compositions and conditions for the base case RO/FC/EV configuration are given in Table VI-8. The membrane system is identical to that described for RO/EV: a $25 \%$ concentrate stream and a purified water stream containing $300 \mathrm{ppm}$ solids. The concentrate leaving the membrane section is further concentrated by FC to $45 \%$ solids (also producing water containing 


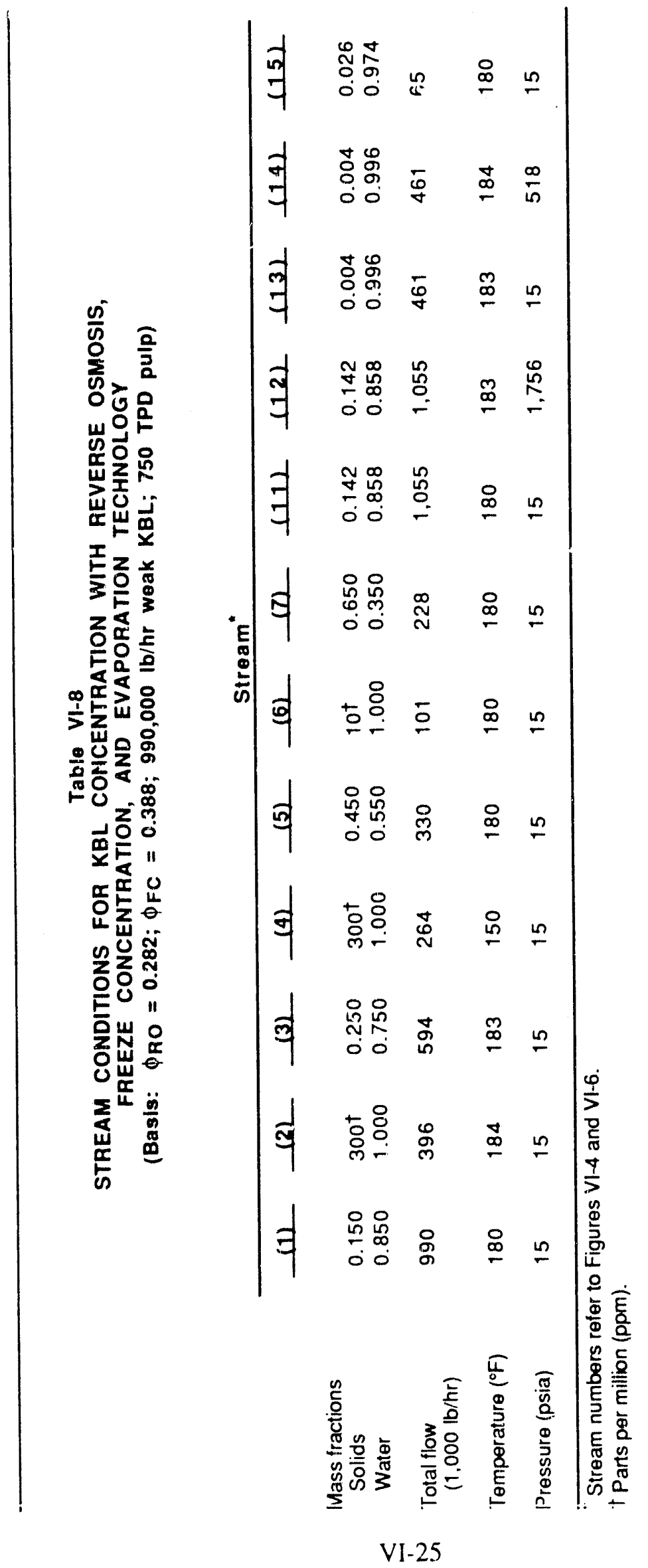


$300 \mathrm{ppm}$ solids). Evaporation is used to achieve the final KBL concentrate and is identical to that described for FC/EV. The RO and FC sections account for $52 \%$ and $35 \%$, respectively, of the water removed during concentration.

In terms of energy requirements (Table VI-4), this configuration is superior to any of the three configurations discussed above; it requires $17.8 \mathrm{MBtu}$ electricity (RO and FC sections) and 33.2 MBtu steam (EV section) per $1,000 \mathrm{lb}$ of feed $\mathrm{KBL}$. A reduction in steam requirement of $114 \mathrm{MBtu} / 1,000 \mathrm{lb}$ over evaporation alone is gained by adding the $\mathrm{RO}$ and FC sections at a cost of only $18 \mathrm{MBtu} / 1,000 \mathrm{lb}$ electricity. (The total energy required in terms of availability is $27.8 \mathrm{MBtu} /$ $1,000 \mathrm{lb}, 16.5 \mathrm{MBtu} / 1,000 \mathrm{lb}$ less than the evaporation alone.) Comparison of these results with those of FC/EV indicates that RO uses less energy per unit of water removed and results in greater overall energy savings than FC.

The economics of RO/FC/EV are summarized in Table VI-5. The FC capital costs are still the major portion of the total capital cost (\$13 million). Although the energy requirements are lowest of all configurations, the total energy costs are higher than all but FC/EV. The resulting PC is $\$ 1.01 / 1000$ lb which is less than FC/EV but still much greater than either EV or RO/EV.

\section{Comparison of Base Case Systems}

In comparing these four base case configurations, it is obvious that EV is superior economically to the other configurations, even though it consumes the most energy. This is the result of two factors. First, electricity is more expensive per Btu than steam. Thus, reducing overall energy consumption by replacing steam with electricity will not necessarily result in a decrease in total energy expenses. Second, although energy consumption is reduced by addition of RO or FC, the increased capital expenses more than offset any savings in energy expenses, particularly when FC is used. Details of this evaluation are included in Appendix C.

\section{EFFECT OF THERMODYNAMIC EXTENT OF SEPARATION}

Although it was shown in the previous section that $\mathrm{EV}$ is economically best of the base case configurations, there may be other conditions where one of the hybrid systems is superior. To examine these conditions, we varied the amount of separation performed by each technology within allowable limits. The PCs resulting from these calculations are shown in FigureVI- 8 for various values of solids concentration (weight percent) leaving the RO section (PSRO) and FC section ( $\mathrm{PS}$ FC). 


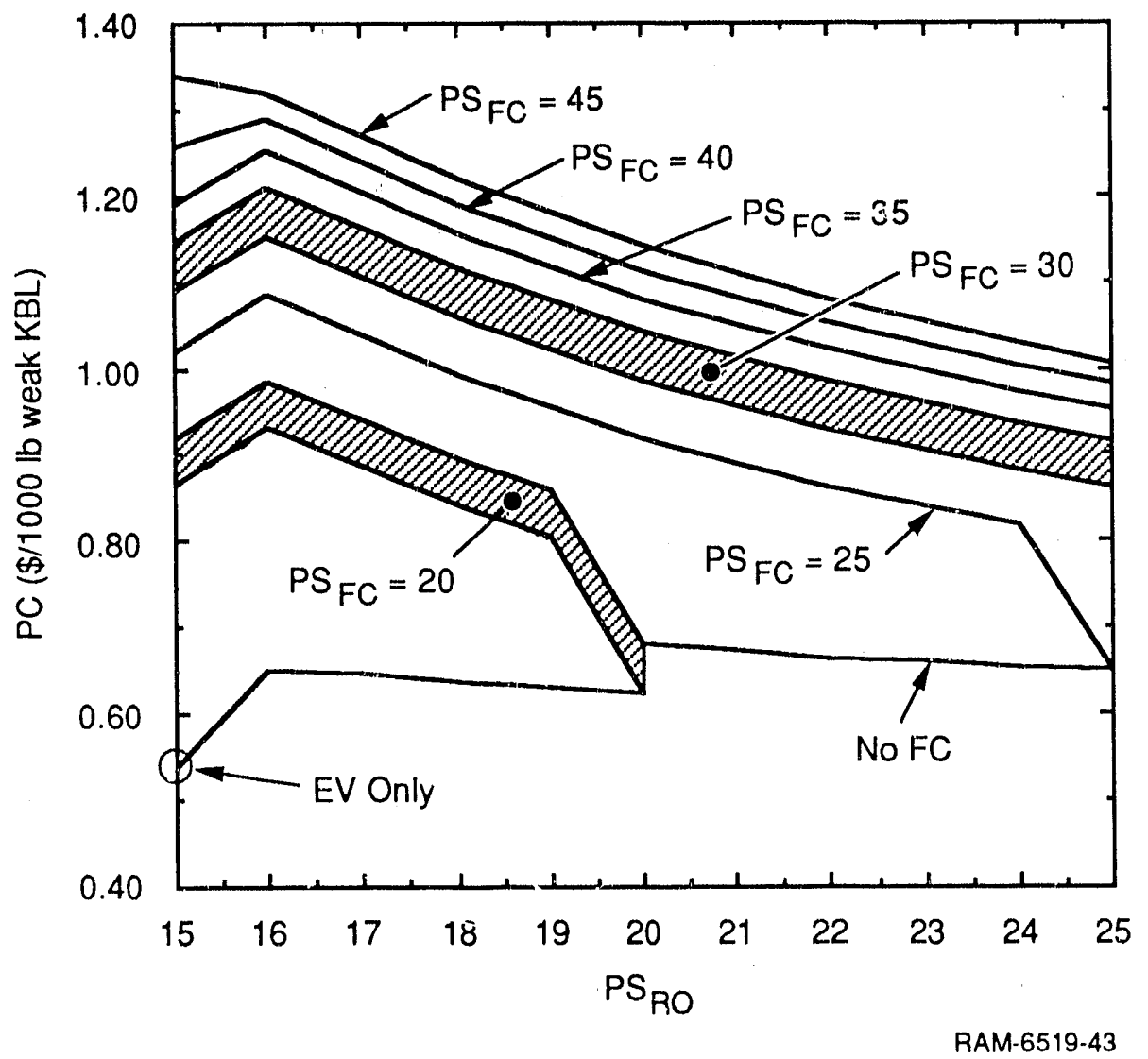

Figure VI-8. Processing cost for KBL concentration using various hybrid systems. 
In this figure, the lowest curve represents $\mathrm{PC}$ when RO/EV is used (no FC), the vertical axis represents $\mathrm{FC} / \mathrm{EV}$, and the remaining curves represent $\mathrm{RO} / \mathrm{FC} / \mathrm{EV}$. Evaporation is represented by the point where the RO/EV curve meets the verticle axis. (The broad bands representing PSFC equal to 20 and 30 reflect the discontinuity in costs that occurs because the number of effects used in the evaporator is changed at these points.) The graph shows a sharp cost increase between $\mathrm{PS}_{\mathrm{RO}}$ of 15 (no membrane) and 16 because no matter what amount of water is removed by the RO section, the sizes of the pumps are relatively constant; therefore, as soon as any membrane is used (even if to remove an infinitely small amount of water), the PC increases sharply because of the capital and operating cost of the purnps. (The same reasoning explains the sharp decrease in PC as PSRO approaches $\mathrm{PS}_{\mathrm{FC}}$ on two of the rurves.)

Figure VI-8 shows that increasing the separation due to FC at the expense of either EV or $\mathrm{RO}$ results in an increase in PC. The initial addition of RO results in a sharp increase due to pump costs; however, further increases in the amount of separation due to RO result in significant reductions in PC when FC is replaced, but only slight reductions when EV is replaced. Thus, if a membrane is to be used at all, it should be used to remove the maximum amount of water possible. Figure VI-8 shows that evaporation alone has the lowest PC of all possible configurations.

Figure VI-8 was drawn using $\mathrm{PS}_{\mathrm{RO}}$ as the independent variable; however, there are three possible independent variables: one to indicate the amount of the separation performed by each of the three technologies. These values are $\phi_{\mathrm{RO}}, \phi_{\mathrm{FC}}$, and $\phi_{\mathrm{EV}}$ described previously. (Actually only two of these are independent since the sum of the three must equal one. $\phi_{\mathrm{RO}}$ and $\phi_{\mathrm{FC}}$ are transformations of $\mathrm{PS}_{\mathrm{RO}}$ and $\mathrm{PS} \mathrm{FC}_{\mathrm{FC}}$ ) Thus, for every set of $\phi_{\mathrm{RO}}, \phi_{\mathrm{FC}}$, and $\phi_{\mathrm{EV}}$, there is a single value of $P C$ and $A_{\text {util }}$ associated with it.

To display the complete set of independent variables, we have used a triangular diagram, as shown in Figure VI-9. Each vertex represents a single technology, while each side represents a two-technology hybrid using the technologies represented by the adjoining vertices. The region inside the boundaries represents hybrids using all three technologies. Results ( $\mathrm{PC}$ and $\mathrm{A}_{\mathrm{util}}$ ) are represented as contours on the diagram (not shown here). The shaded region represents combinations that are not allowed ( $\phi_{\mathrm{RO}}$ cannot be greater than $0.282\left[\mathrm{PS}_{\mathrm{P} O}=0.25\right]$ and the sum of $\phi_{\mathrm{RO}}$ and $\phi_{\mathrm{FC}}$ cannot be greater than $0.670\left[\mathrm{PS}_{\mathrm{FC}}=45\right]$ ). The shaded lines at $\phi_{\mathrm{EV}}$ equal to 0.845 and 0.608 are where discontinuities in the curves occur because the number of effects used in the evaporator is changed at these points. 


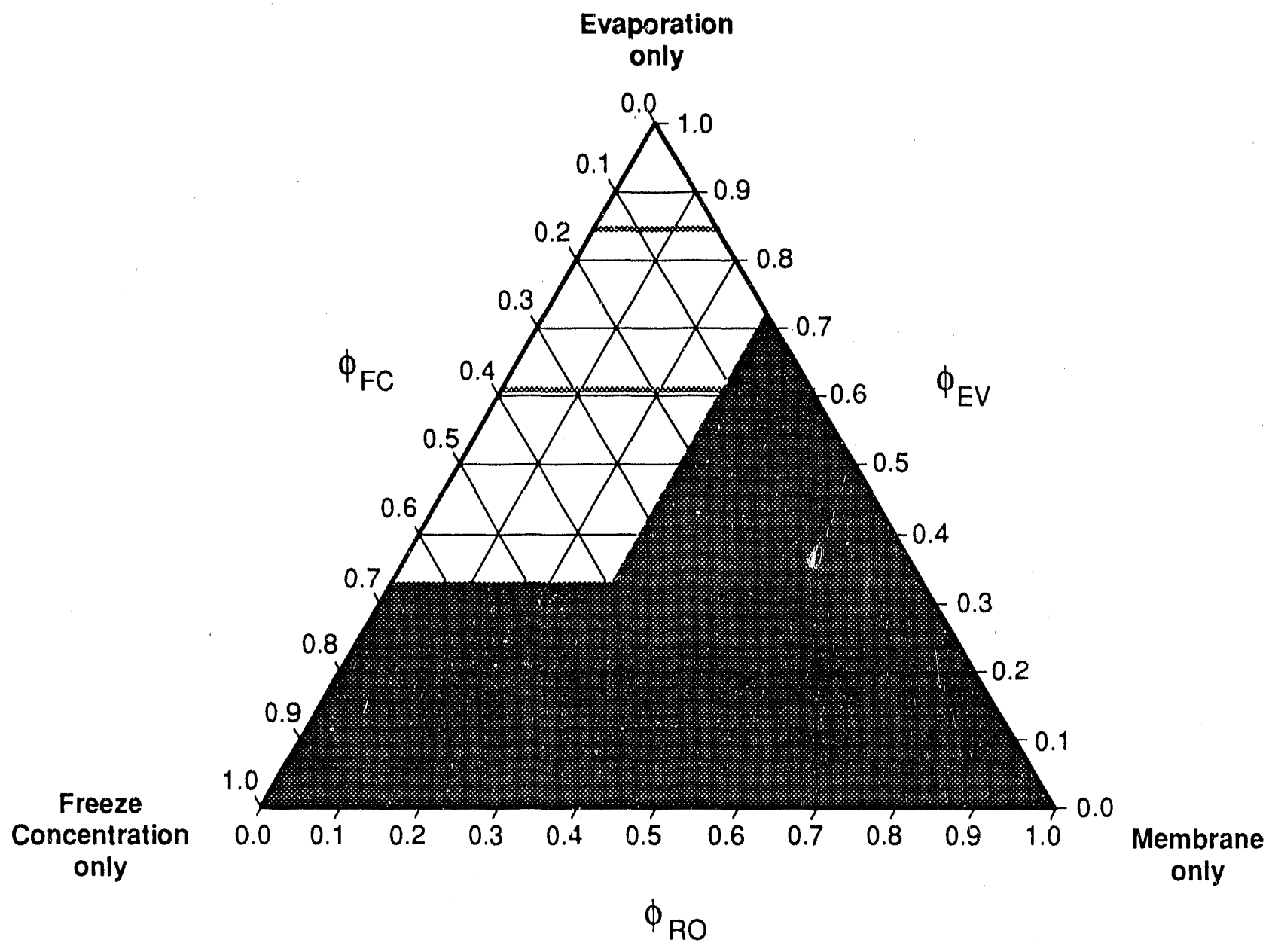

RAM-6519-44

Figure VI-9. Triangular diagram for display of thermodynamic and economic results.

Shaded region represents hybrid combinations that are not allowed. 
Figure VI-10 shows PC for the four systems on the triangular diagram (only the allowable region is shown). Again, the sharp increase in $\mathrm{PC}$ can be seen when a $\phi_{\mathrm{RO}}$ becomes greater than zero. The triangular diagram shows that the fastest way to reduce $\mathrm{PC}$, at least at the bottom of the diagram, is to increase $\phi_{\mathrm{EV}}$ while reducing $\phi_{\mathrm{FC}}\left(\phi_{\mathrm{EV}}\right.$ is constant); this is more effective than increasing $\phi_{\mathrm{EV}}$ and holding $\phi_{\mathrm{RO}}$ constant. Towards the top of the diagram, $\mathrm{PC}$ can be changed most quickly by increasing both $\phi_{\mathrm{EV}}$ and $\phi_{\mathrm{RO}}$ together.

Figure VI-11 shows $A_{u t i l}$ as a function of $\phi_{R O}, \phi_{F C}$, and $\phi_{E V}$. This figure shows that the fastest changes in $A_{u t i l}$ can be obtained by increasing $\phi_{R O}$ while reducing $\phi E V$ ( $\phi F C$ is constant). This means that, as was shown for the base case, RO uses the least energy, and evaporation uses the most. (Actually, the most energy is used by an RO/EV hybrid with $\phi_{\mathrm{RO}}$ just greater than zero because of pump expenses, as explained above.)

\section{EFFECT OF KEY PROCESS PARAMETERS}

The results so far indicate that although EV uses more energy than any of the three hybrid processes, it results in a PC $20 \%$ less than the next best system (RO/EV). However, several process and economic parameters will have an effect on these results, possibly to such an extent that a hybrid would be cheaper and more energy efficient than EV. The most important of these variables are the membrane solute rejection and membrane cost and the energy costs (steam and electricity). The effect of varying these parameters on the thermodynamic and economic evaluations is examined in the following sections.

\section{Solids Rejection}

The effect of varying the solids rejection $S_{r}$ on PC and $A_{u t i l}$ is shown in Figures VI-12 and VI-13; the base value for $S_{r}$ that we used previously was 0.98 . Reducing this value to 0.96 has a significant effect; the $\mathrm{PC}$ is increased by $\sim 50 \%$ and $\mathrm{A}_{\mathrm{util}} \mathrm{i}$ ieases by $25 \%$ when the maximum permissible amount of water is removed by $\mathrm{RO}\left(\phi_{\mathrm{RO}}=0.282\right)$. However, increasing $\mathrm{S}_{\mathrm{r}}$ to 0.99 does not result in a corresponding decrease in PC and $A_{u t i l}$. In fact, these results are essentially unchanged by increasing $S_{r}$ to 0.99 . This outcome occurs because the primary effect of $S_{r}$ is to vary the flow rate of the recycled residue stream. The recycle stream flow is $7 \%$ of the feed value when $\mathrm{S}_{\mathrm{r}}$ has the base case value of 0.98 . Increasing $\mathrm{S}_{\mathrm{r}}$ to 0.99 reduces the recycle flow rate to $1 \%$ of the reed value. Although this is a seven-fold decrease, it does not produce a large change in the 


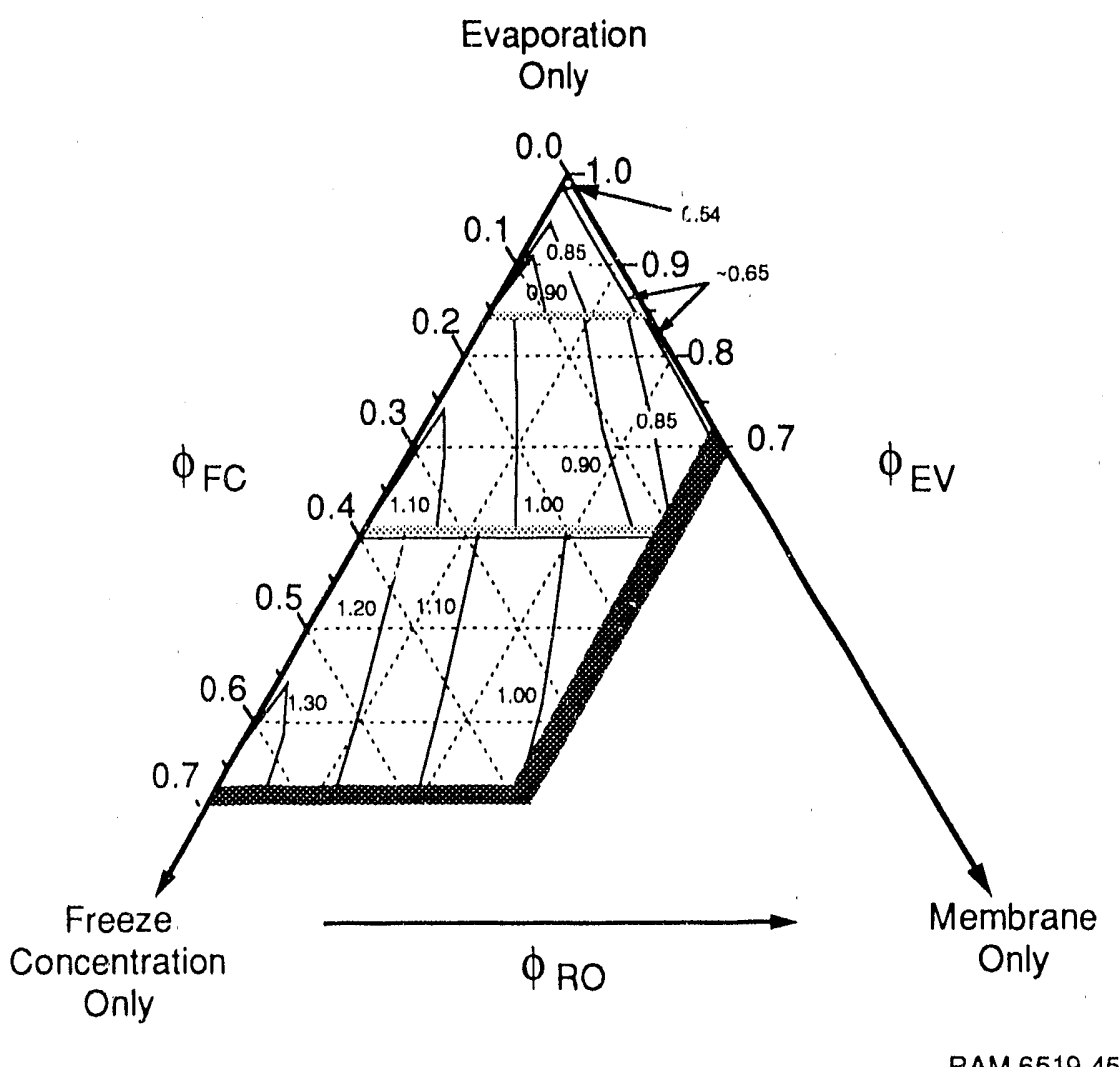

Figure VI-10. Processing cost for KBL concentration systems.

Contours represent PC in $\$ / 1000 \mathrm{lb}$ weak KBL. 


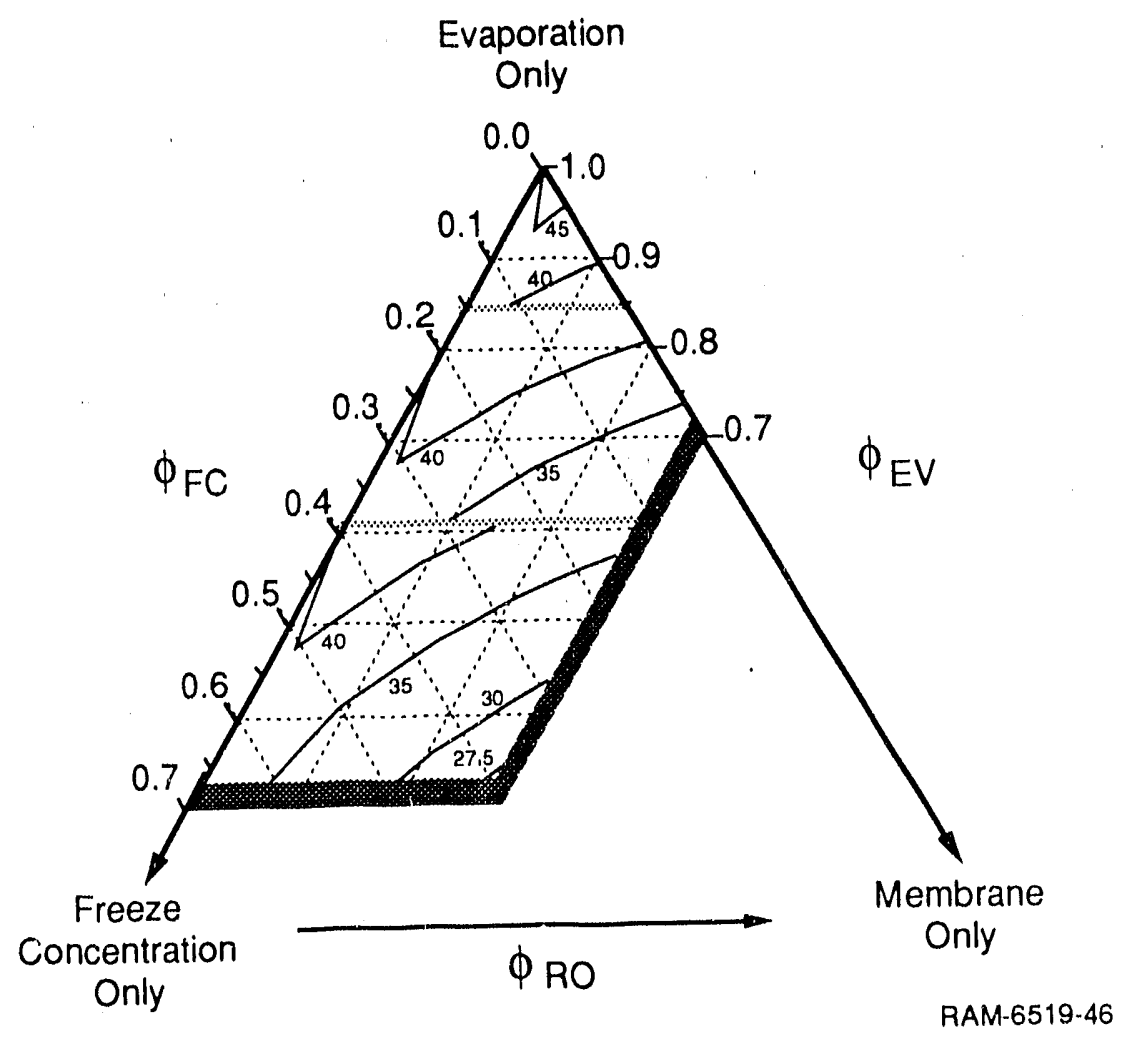

Figure VI-11. Availability consumption by utilities for KBL concentration systems.

Contours represent $A_{u t i l}$ in Btu/lb weak KBL. 


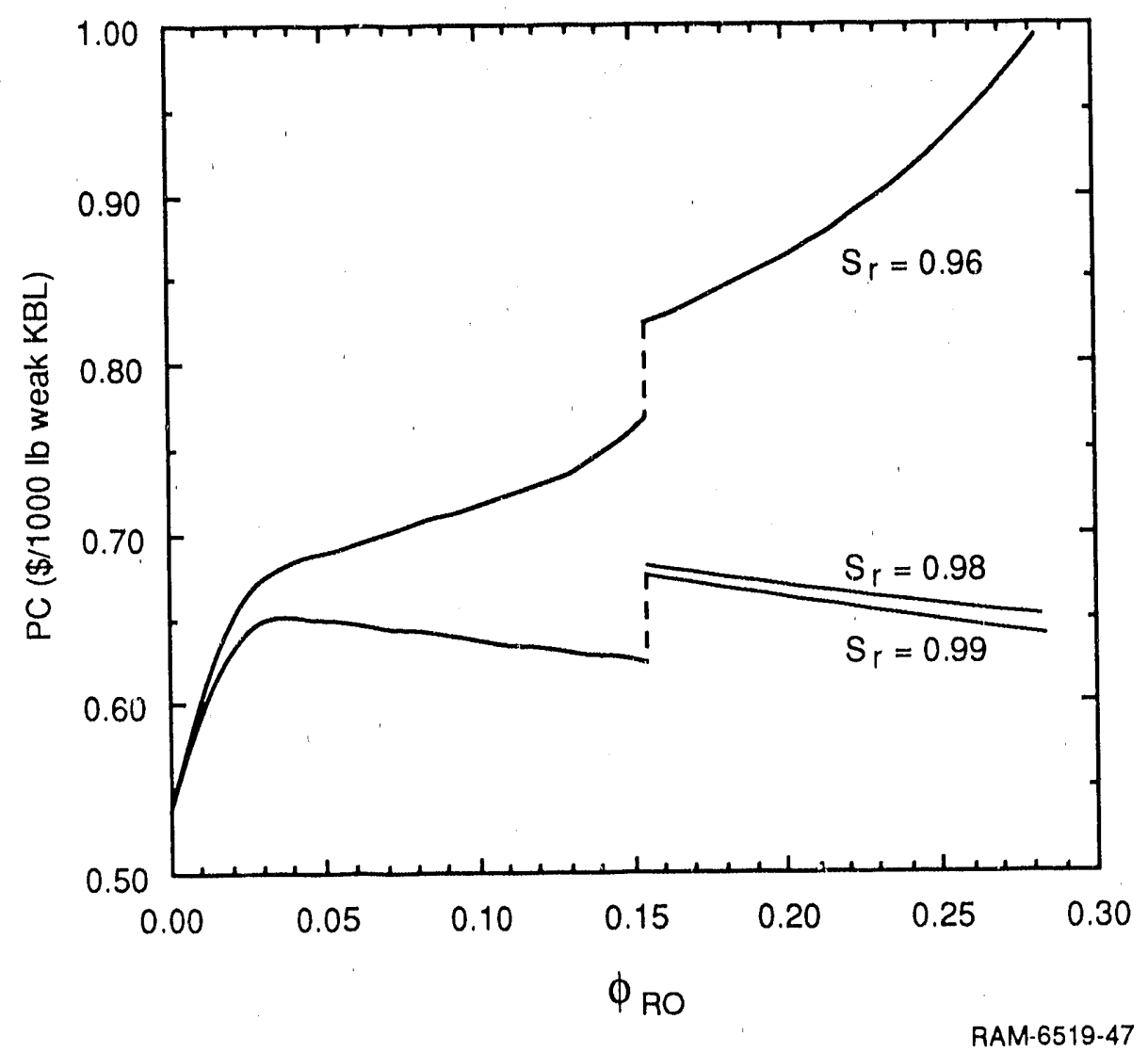

Figure VI-12. Effect of solute rejection on $\mathrm{PC}$ for $\mathrm{KBL}$ concentration (RO/EV). 


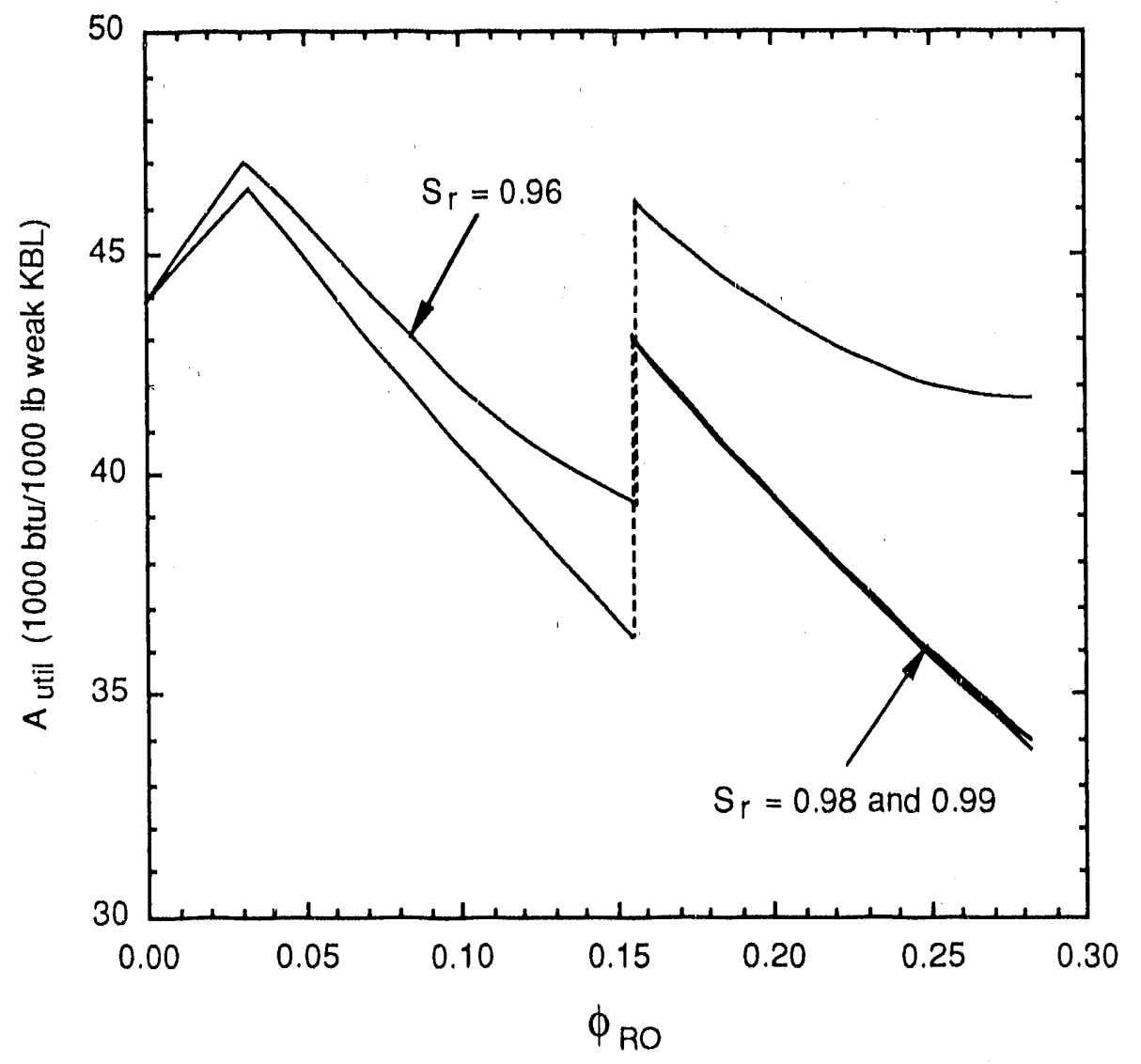

RAM- $6519-48$

Figure VI-13. Effect of solute rejection on $\mathrm{A}_{\mathrm{util}}$ for $\mathrm{KBL}$ concentration (RO/EV). 
flow rates of the other streams in the system. If $S_{r}$ is reduced to 0.96 , however, the recycle flow rate increases to $119 \%$ of the feed stream value, and all other streams in the system have correspondingly greater flow rates; thus, a large increase in PC results.

Although these results indicate there is no advantage to increasing $S_{r}$, if the increase were enough that the separation could be accomplished in a single stage and consumption of electricity could be reduced by about $10 \%$ (for $\phi_{\mathrm{RO}}=0.282$ ), the $\mathrm{PC}$ would be reduced to about the same value as resulted from $E V$. However, to achieve the separation in one stage would require a $S_{r}$ of 0.9985. Membranes with properties similar to this have been developed for seawater desalination, however, it is unlikely that this $\mathrm{S}_{\mathrm{r}}$ could be achieved under the difficult conditions of KBL concentration.

\section{Membrane Cost}

Figure VI-14 shows the effect of membrane cost on PC for costs of 2.50, 5.00 (base case value), and $10.00 \$ / \mathrm{ft}^{2}$. Doubling the membrane cost increases PC by $25 \%$, while halving the cost results in a $10 \%$ reduction in $\mathrm{PC}$ (for $\phi_{\mathrm{RO}}=0.282$ ). This figure suggests that membrane costs of $\sim \$ 1.00 / \mathrm{ft}^{2}$ would be required for RO/EV to be economically competitive with EV. ( $\mathrm{A}_{\text {util }}$ is unaffected by membrarie cost and, therefore, is not shown.)

\section{Steam Cost}

The value of steam can vary considerably in integrated pulp and paper mills. The internal energy balance of the plant may be such that an excess of the low pressure $(60 \mathrm{psig})$ steam is already available and no savings would be gained by reducing steam consumption. Other factors affecting the steam value are fuel cost and electricity cost (for import to or export from the plant), which are specific to each plant.

Figure VI-15 shows the reduction or increase in PC for steam costs different from the base value of $\$ 2 / 1000 \mathrm{lb}$ ( $\mathrm{A}_{\text {util }}$ is unaffected and, therefore, not shown). If steam has no value PC for EV is reduced by two thirds to $\$ 0.18 / 1,000 \mathrm{lb}$. Since steam cost does not affect either RO or FC, the greatest savings from a steam cost reduction occur when only $\mathrm{EV}$ is used; on the other hand, if steam costs are increased, the greatest increase in PC also occurs with EV. However, if steam costs are increased to $\$ 5 / 1,000 \mathrm{lb}$, EV results in a PC of $\$ 1.06 / 1,000 \mathrm{lb}$ while $\mathrm{RO} / \mathrm{EV}\left(\phi_{\mathrm{RO}}=0.282\right)$ results in a PC of $\$ 0.95 / 1,000 \mathrm{lb}$. To summarize, a decrease in steam cost will make EV even more favorable, while an increase will make EV less favorable; if steam cost is $\$ 5 / 1,000) \mathrm{lb}, \mathrm{RO} / \mathrm{EV}$ has a PC $10 \%$ less than EV. 


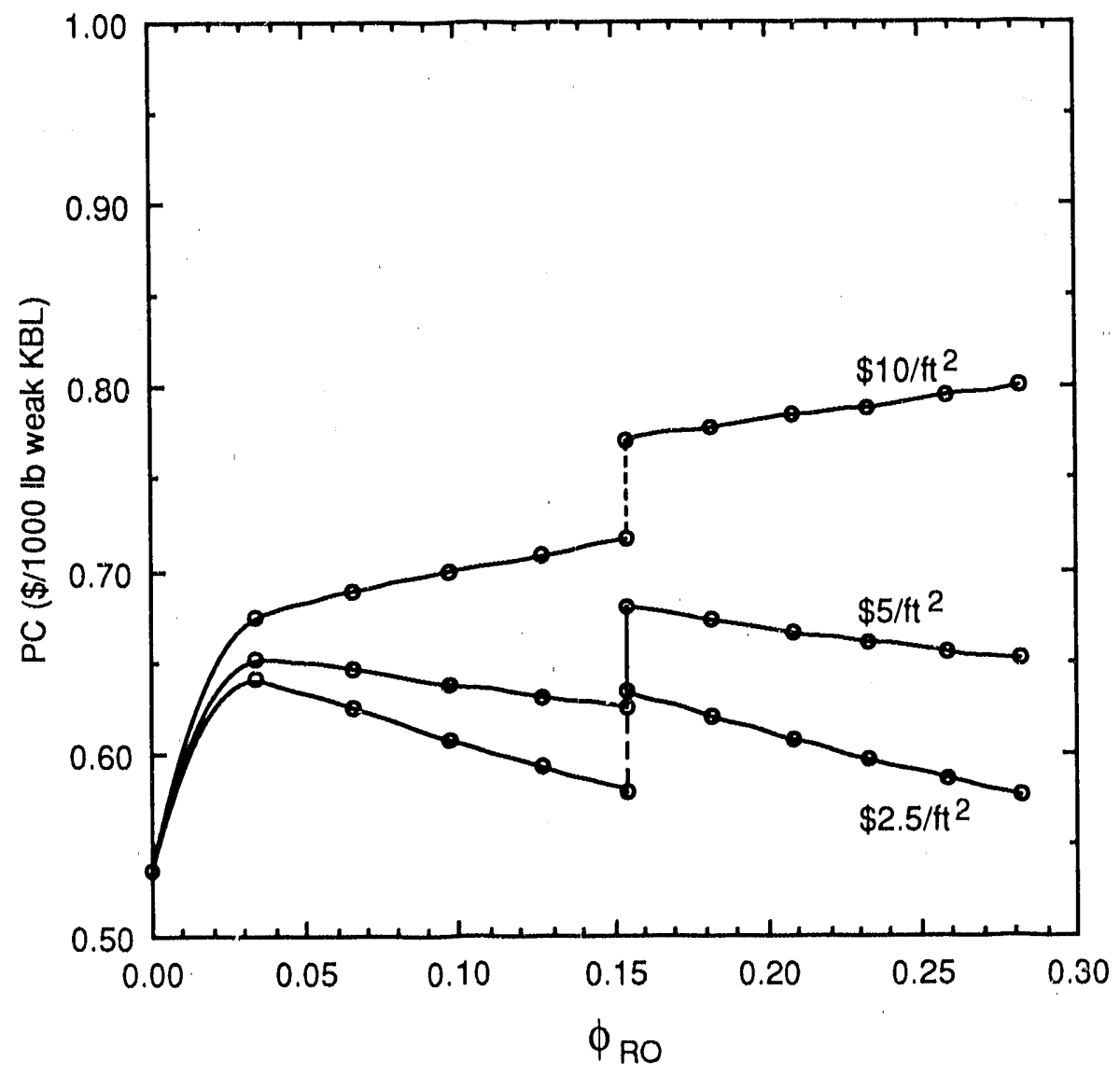

RAM- $6519-49$

Figure VI-14. Effect of membrane cost on PC for KBL concentration (RO/EV). 


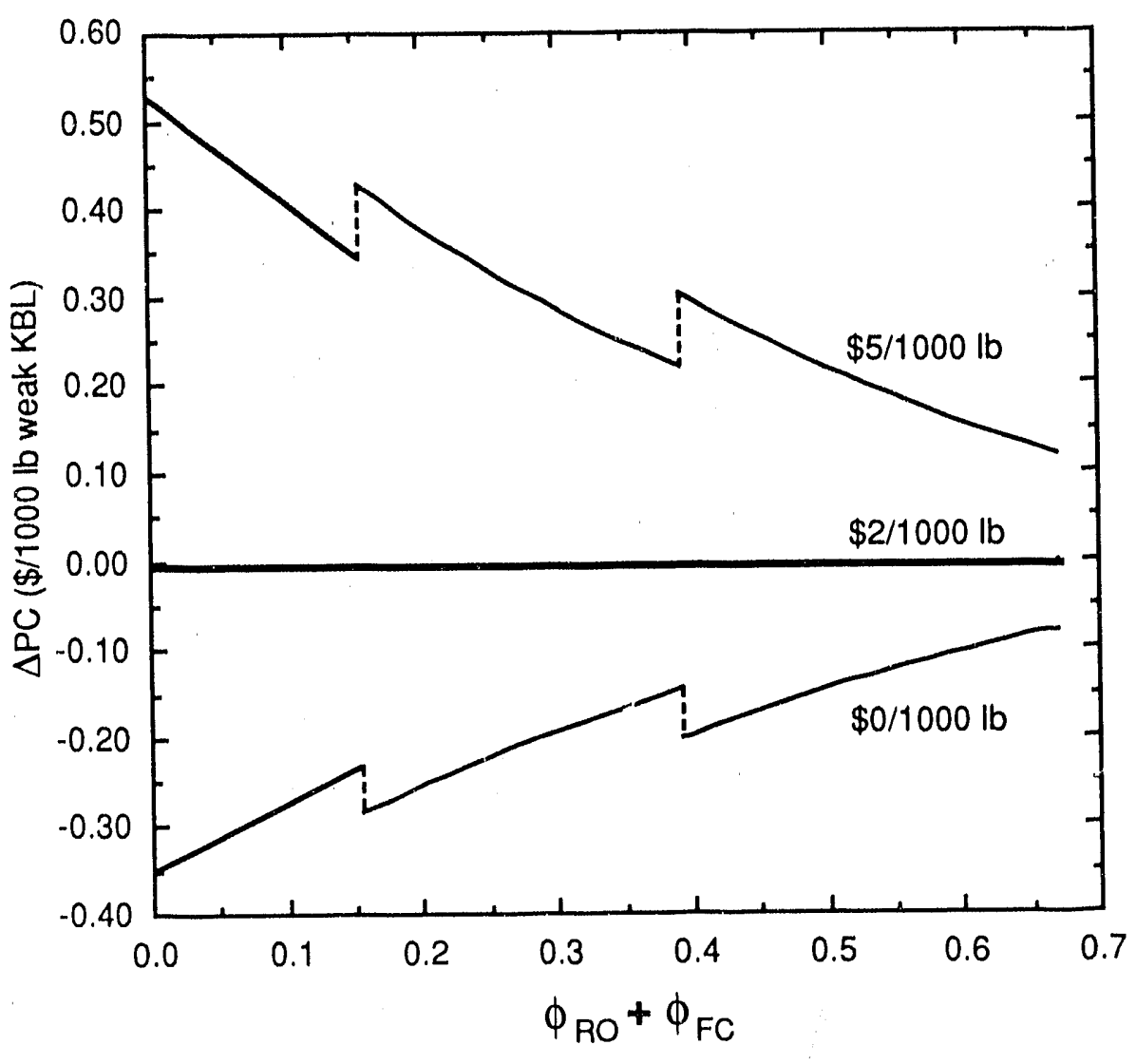

RAM- $6519-50$

Figure VI-15. Effect of steam cost on PC for KBL concentration.

$\triangle \mathrm{PC}$ represents the difference betwien $\mathrm{PC}$ at the steam cost indicated and that at $\$ 2 / 1000 \mathrm{lb}$. 


\section{Electricity Cost}

Figure VI-16 shows the effect of electricity cost on PC for RO/EV and FC/EV ( $A_{\text {util }}$ is unaffected and, therefore, not shown); electricity costs of 2.5, 5.0 (the base value), and $10.0 \mathrm{cents} / \mathrm{kWh}$ were used. Since EV does not use electricity, changes in electricity cost have the greatest effect when $\phi_{\mathrm{FC}}$ is least. Even with the low electricity cost, FC/EV was always more expensive than either $\mathrm{EV}$ or RO/EV. Although the difference is lessened, EV still has a lower $\mathrm{PC}$ than RO/EV even with the low electricity cost; for RO/EV to have the lower PC, the electricity cost would need to be less than $1.0 \mathrm{cent} / \mathrm{kWh}$.

\section{CONCLUSIONS}

In this case study, kraft black liquor (KBL) is concentrated by one or more of three technologies: evaporation (EV), reverse osmosis (RO), and freeze concentration (FC). The economic evaluations show that $\mathrm{EV}$ alone has a lower processing cost (PC) than any of the hybrid systems, $\mathrm{RO} / \mathrm{EV}, \mathrm{FC} / \mathrm{EV}$, or RO/FC/EV. In terms of thermodynamics, however, EV has the highest energy and availability consumption. Evaporation has the lowest PC despite the greatest energy consumption is because of its low capital cost and cheap energy source (low pressure steam as opposed to electricity) compared with FC or RO. This is the first case study in which the lowest PC resulted from use of the highest energy consuming technology. It is important to understand why this result occurs in terms of thermodynamic and economic interactions if useful guidelines concerning the use of hybrid systems are to be developed.

The evaluations of the four base case KBL concentration systems show that EV has the lowest PC, $\$ 0.54$ per $1,000 \mathrm{lb}$ weak KBL. Of the hybrid processes, RO/EV has the lowest PC $(\$ 0.65$ per $1,000 \mathrm{lb}$ weak KBL) followed by RO/FC/EV and FC/EV (1.34 and $\$ 1.01$ per 1,000 lb weak $\mathrm{KBL}$, respectively). In terms of energy, EV has the greatest availability consumption (44.3 MBtu per $1,000 \mathrm{lb}$ weak $\mathrm{KRL}$ ); the hybrid processes consume $27.8,32.3$, and $34.3 \mathrm{MBtu}$ per $1,000 \mathrm{lb}$ weak $\mathrm{KBL}$ for $\mathrm{RO} / \mathrm{FC} / \mathrm{EV}, \mathrm{FC} / \mathrm{EV}$, and $\mathrm{RO} / \mathrm{EV}$, respectively. In terms of individual technologies, the order of availability consumption is $\mathrm{RO}<\mathrm{FC}<\mathrm{EV}$. The thermodynamic and economic results for the base case evaluations are summarized in Tables VI-4 and VI-5.

Varying the extent of separation performed by FC, $\phi_{F C}$, showed no surprises: as $\phi_{F C}$ increases, both $\mathrm{PC}$ and $\mathrm{A}_{\mathrm{util}}$ also increase. When $\mathrm{KO}$ is added to a separation process, however, there is a sharp increase in cost and energy consumption even if the RO unit performs a very small fraction of the total separation $\left(\phi_{\mathrm{RO}} \sim 0\right)$. This sharp increase occurs because the entire feed 


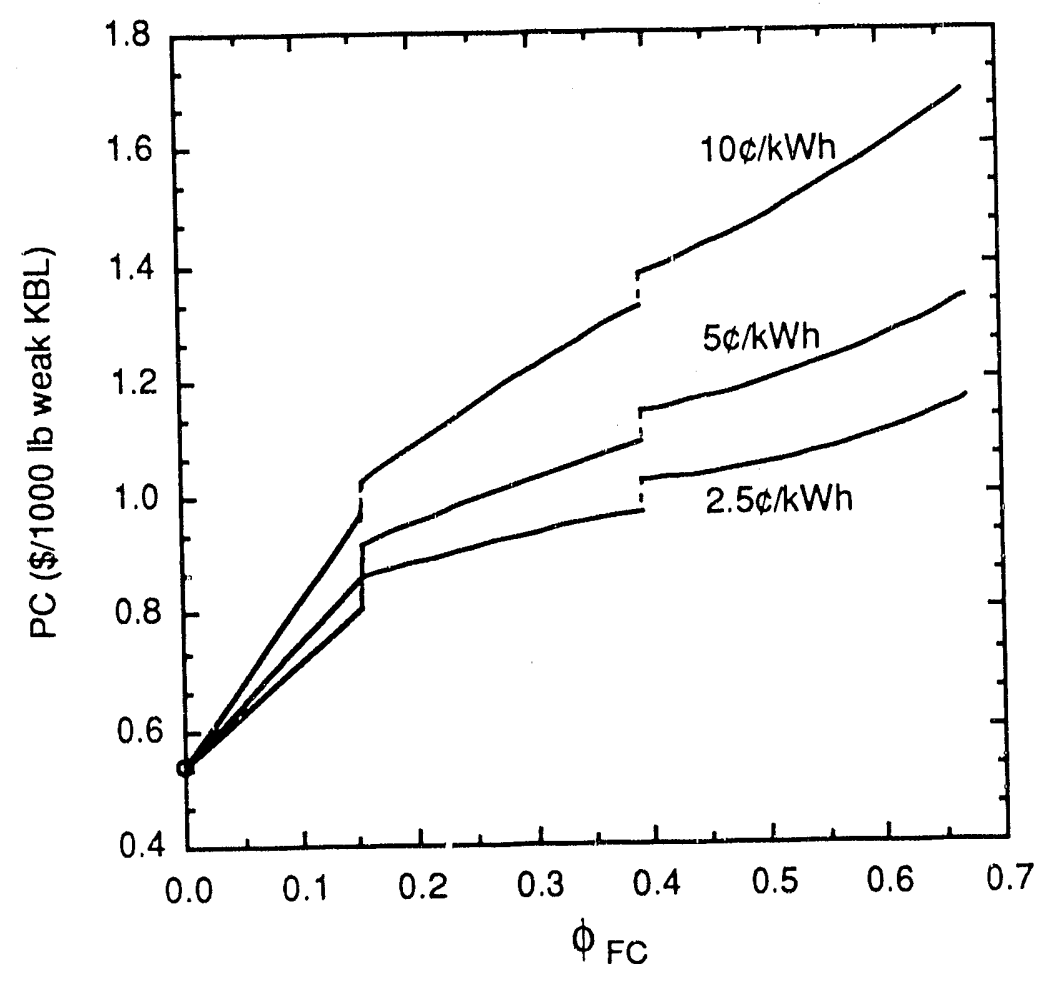

(a) FC/EV

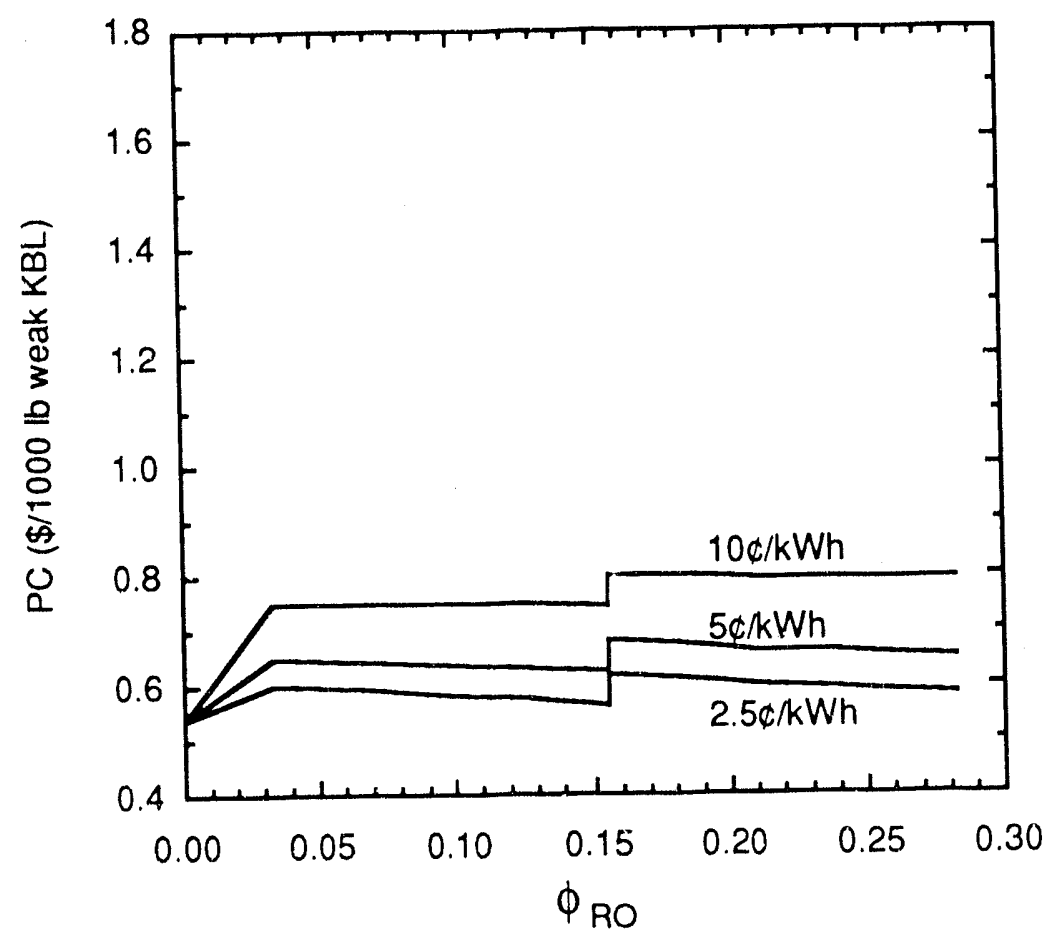

(b) $\mathrm{RO} / \mathrm{EV}$

RAM-6519-51

Figure VI-16. Effect of electricity cost on PC for KBL concentration. 
to the membrane must be pumped to a high pressure no matter what fraction of the feed is actually removed by the membrane; the pumping requirements can be a significant portion of the capital and operating costs for the RO section. Thus, after an initial sharp increase in cost and energy consumption, the cost for removing additional water by $\mathrm{RO}$ is comparatively low and the PC of hybrid systems drops; however, PC never drops to the level of EV alone.

Several other process parameters were examined for their effect on the economic and thermodynamic evaluations: membrane solids rejection $\left(S_{r}\right)$, membrane cost, steam cost, and electricity cost. For EV/RO, a reduction in $S_{r}$ from 0.98 to 0.96 results in significant increases in both PC and $A_{u t i l}$; conversely, an increase in $S_{r}$ to 0.99 had a negligible effect on both PC and $A_{u t i l}$. (However, if $S_{r}$ can be increased above 0.998 , the number of RO stages can be reduced from two to one and $\mathrm{FC}$ would be reduced to approximately that of $\mathrm{EV}$ alone.)

The membrane cost has a significant effect on PC, but no effect on $\mathrm{A}_{\mathrm{util}}$. Doubling the membrane cost (from 5 to $\$ 10 / \mathrm{ft}^{2}$ ) increased $\mathrm{PC}$ for RO/EV from $\$ 0.65$ to $\$ 0.79$ per $1,000 \mathrm{lb}$ weak KBL; to reduce the $\mathrm{PC}$ to the level attained with $\mathrm{EV}$ alone, a membrane cost of $\sim \$ 1 / \mathrm{ft}^{2}$ would be required.

The cost of steam $h$ a major influence on the cost for EV whether as a stand alone system or combined with either RO or FC as a hybrid system. For EV alone, steam represents the major operating expense and accounts for over $60 \%$ of the total PC. If steam cost were increased to $\$ 5 / 1,000 \mathrm{lb}$ (from a base case value of $\$ 2 / 1,000 \mathrm{lb}$ ), the PC for EV alone would be doubled to $\$ 1.07$ per $1,000 \mathrm{lb}$ weak KBL, while RO/EV would be increased to $\$ 0.95$ per $1,000 \mathrm{lb}$ weak KBL. Thus, at a site where steam has significantly more value than we assumed in this evaluation, the RO/EV hybrid system could be less expensive than EV. (Hybrid systems involving FC would not be less expensive unless steam costs approached $\$ 7 / 1,000 \mathrm{lb}$.) On the other hand, at sites where steam has less value than we assumed, the PC advantage of EV alone over the hybrid systems will be even greater than that of the base case.

Since EV does not require electricity, variations in electricity cost affect only systems that include RO and FC technologies. Electricity costs would have to be reduced to $\sim 1 \mathrm{cent} / \mathrm{kWh}$ before $\mathrm{RO} / \mathrm{EV}$ would have a lower $\mathrm{PC}$ than $\mathrm{EV}$ alone, while even with free electricity, FC/EV would still be more expensive than EV due to the high capital costs of FC.

To summarize, EV alone, although the greatest energy consumer, has the lowest $\mathrm{PC}$ because of its low capital cost and inexpensive energy source. Although RO/EV does have lower energy consumption and expenses, the PC is higher than EV alone because of RO's higher capital costs. 
certain conditions, the RO/EV system might be the preferred system; these conditions include high membrane performance or low membrane cost, high steam cost, and low electricity cost. Addition of FC to EV will also lower energy use, but greatly increases capital costs; FC/EV would be preferred only if the capital costs of FC could be reduced by a factor of five or ten. 


\section{CHAPTER VII}

\section{CASE STUDY 4 - SOLVENT DEASPHALTING}

In petroleum refining the primary method for separating the crude petroleum into its various fractions is distillation. Distillation at atmospheric pressure is used for the initial separation, and the various fractions are either further processed or sold as finished products. The heavy stream leaving the bottom of the atmospheric column is further distilled under vacuum in the vacuum still. The bottoms stream leaving the vacuum still (the vacuum resid) consists of asphalts and lighter oil components. To separate these two components, this stream can be further treated by a process known as solvent deasphalting (Berridge, 1973; Billon et al., 1977; Penning et al., 1982; Sherwood, 1978). In this process the vacuum resid is mixed with a light paraffin solvent (such as propane, butane, pentane) in a contacting column. The mixture separates into two phases, one containing asphalt components and the other containing deasphalted oil (DAO). The solvent is recovered from both phases and recycled, resulting in two products: asphalt and deasphalted oil.

The solvent deasphalting process is shown schematically in Figure VII-1. The deasphalted stream leaves the top of the columin and enters the primary solvent recovery section where most of the solvent is removed. Traditionally, this solvent recovery is accomplished by evaporation, either by heating the feed or lowering the pressure or a combination of both. The oil stream leaving this section still contains a small fraction of solvent that is removed by steam stripping. The asphalt stream leaving the bottom of the extraction tower undergoes a similar purification process.

We examined one section of this process: the primary solvent recovery from the oil stream leaving the top of the column. As an alternative to evaporation, which can be very energy intensive, ultrafiltration membranes have been suggested for separation of the solvent from the oil. Because no phase change occurs, there is a great potential for reduction in energy consumption and overall cost over evaporative techniques.

The results for the base case system show that the lowest overall cost occurs when a portion of the separation is performed by the membrane and the remainder by evaporation. However, if some form of heat recovery is used in the evaporation section, less membrane is needed to achieve the lowest cost; conversely, if the membrane properties are improved, more membrane is 


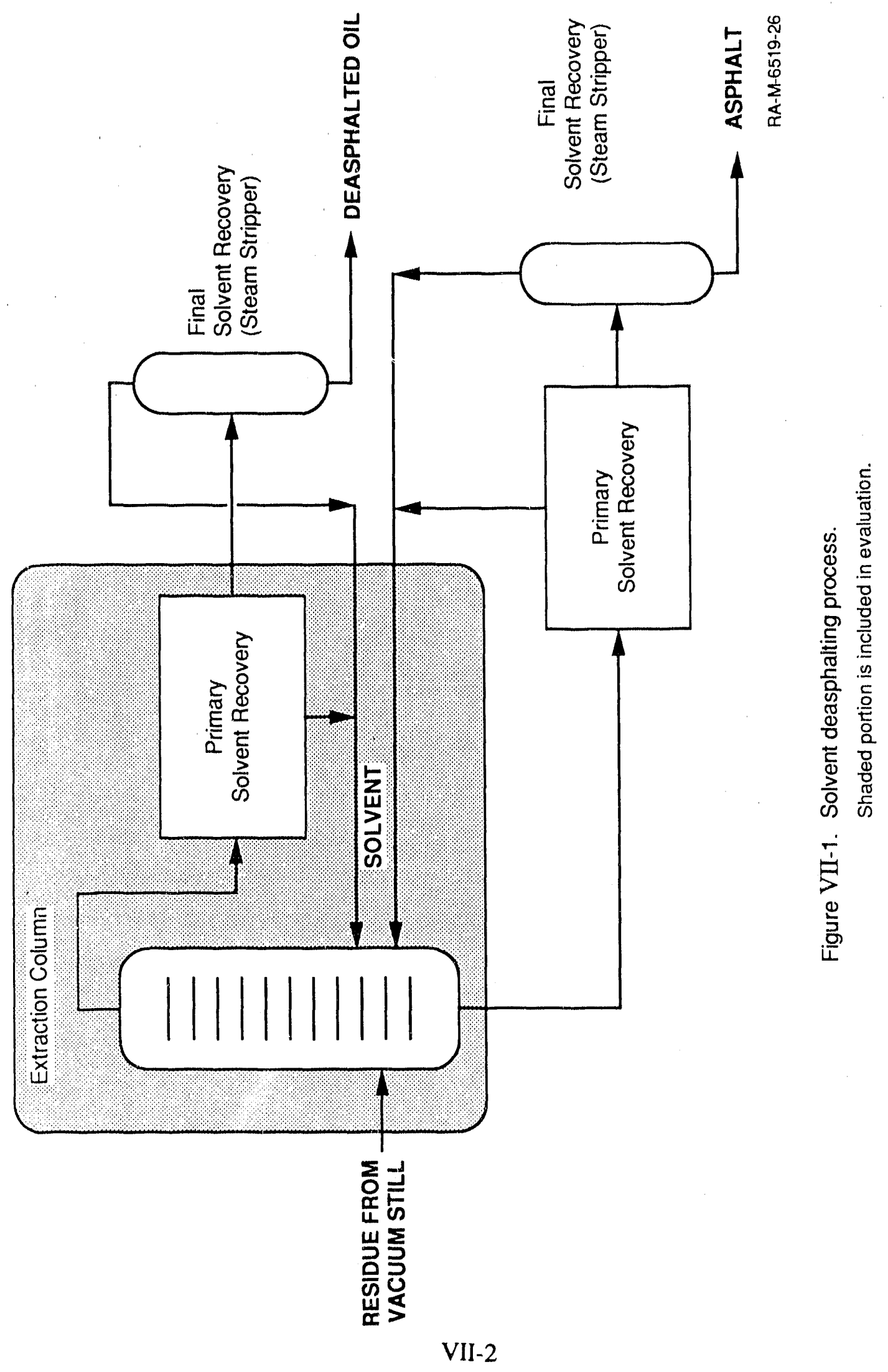


needed. In all cases the lowest energy use occurs by using the maximum amount of membrane technically possible. The capital costs of the membrane, however, more than make up for the energy savings if too much membrane is used.

\section{PROCESS DESCRIPTION AND MODELING}

Many commercial processes use evaporation for solvent recovery including Demex (UOP, Inc.), ROSE (Kerr-McGee), and others (Hydrocarbon Processing, 1986). The solvents used vary from process to process and from application to application. Three- to seven-carbon paraffins, as pure solvents or as mixtures, are typically used. The use of different solvents will result in different DAO recoveries and qualities, as well as different process operating conditions and economics (Sprague, 1986).

Although the various available processes differ in some respects, the basic idea behind all of them is to remove the solvent from the DAO by vaporizing the solvent. The solvent is condensed and recycled back to the extraction tower. Because the energy for evaporation of the solvent is a major expense, many processes use some form of heat recovery (i.e., the condensing stream is used to heat the vaporizing stream). Heat recovery can be achieved through vapor recompression, by vaporization at high temperature, and by other methods.

Because of the high energy requirements of vaporization, membrane separation (ultrafiltration) looks attractive for this process. Membranes typically have a lower energy consumption because they do not require a phase change. Previous laboratory studies, however, have shown that membranes can make only a partial separation of the oil/solvent mixture (Kulkarni et al., 1985; $\mathrm{Li}$ et al., 1984; Li et al., 1985; Li et al., 1987). If the solvent content of the mixture falls below $60 \%$ (by weight), the fluid viscosity becomes too great to allow flow through the membrane module. (This value for the limiting solvent content, although in reality a function of the particular vacuum resid and solvent used, was used throughout our evaluations.) Thus, a membrane alone is not a practical option for this separation but must be combined with evaporation as a hybrid process. Not only does the membrane produce a partially concentrated oil stream, but also some of the oil permeates across the membrane along with the solvent, producing an impure solvent stream. This stream is recycled to the extraction column with the result that a larger tower is needed to get the same product purities. Thus, inclusion of the membrane requires changes to the size of the extraction tower, and thus the extraction tower must be included in the analysis. 
The shaded portion in Figure VII-1 contains those units included in our analysis of solvent deasphalting. The other units, primary solvent recovery on the asphalt stream and the final solvent recovery units, are unaffected by inclusion of the membrane and were not included in the analysis. The base case feed will be a stream entering the recovery section (leaving the top of the extraction tower) containing $15 \% \mathrm{DAO}$ with propane as the solvent. The stream temperature is $160^{\circ} \mathrm{F}$ and the pressure is $435 \mathrm{psia}$, conditions typical of solvent deasphalting processes. We also specify that the DAO stream leaving the primary recovery section has the same flow rate and composition $(105,300 \mathrm{lb} / \mathrm{hr} ; 95 \%$ by weight $\mathrm{DAO})$ for all processes. The temperature and pressure, however, are free to vary depending on the operating conditions that result in the lowest overall cost.

\section{Evaporation Process}

The evaporation process is shown in Figure VII-2. The stream leaving the top of the extraction column is heated (optionally by a heat recovery unit) and flashed, producing a liquid stream enriched in DAO and a vapor stream containing almost pure solvent. The temperature of the heated stream is adjusted to give a $95 \%$ DAO liquid. The flash pressure is varied to give the lowest overall cost, but must be high enough that the solvent condensation temperature is greater than the cooling water outlet temperature $\left(115^{\circ} \mathrm{F}\right)$. The condensed vapor is then recycled to the extraction tower.

The process was modeled with a commercial process simulator (ASPEN/SP, JSD Simulation Service, Denver, $\mathrm{CO}$ ) using the Peng-Robinson equation of state. Properties of the DAO were estimated using a proprietary method (Oleson and Assoc.) based on distillation data provided by an industrial petroleum refiner. (The distillation data are given in Appendix D.)

The stream compositions and conditions for the base case process are given in Table VII-1. The system is designed to produce $100,000 \mathrm{lb}$ DAO per hour ( 8700 barrels per stream day). The solvent/DAO stream is heated to $274^{\circ} \mathrm{F}$ and flashed to $250 \mathrm{psia}$, producing a vapor that is almost pure solvent ( $>99.99 \%$ propane).

\section{Membrane/Evaporation Hybrid Process}

The membrane/evaporation hybrid system is shown in Figure VII-3. The process is the same as the evaporation process except that a membrane and pump are added upstream of the heater. The average transmembrane pressure is $200 \mathrm{psi}$, and the pressure along th $\mathrm{feed}$ side of the membrane varies depending on the amount of solvent removed. 


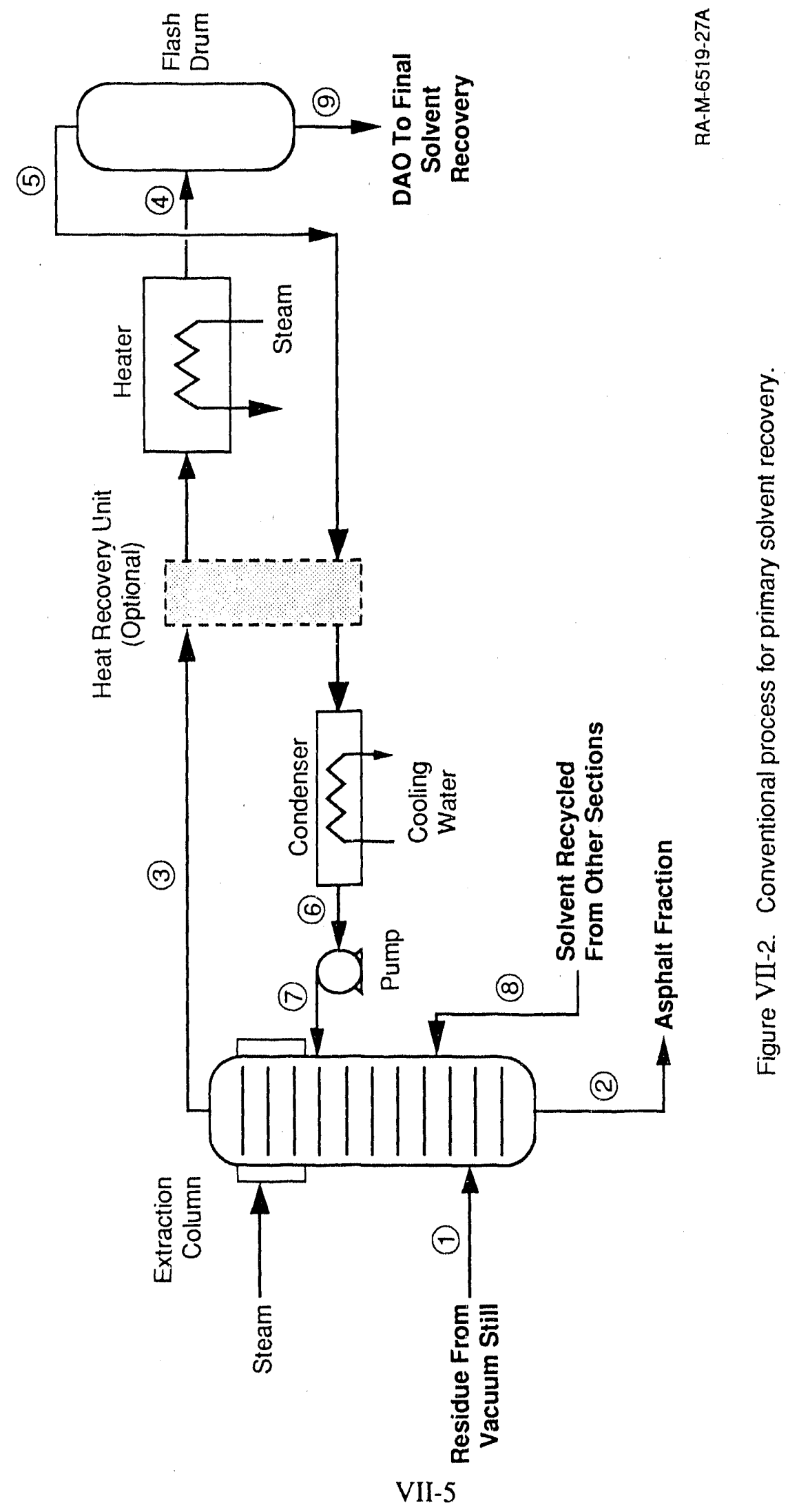




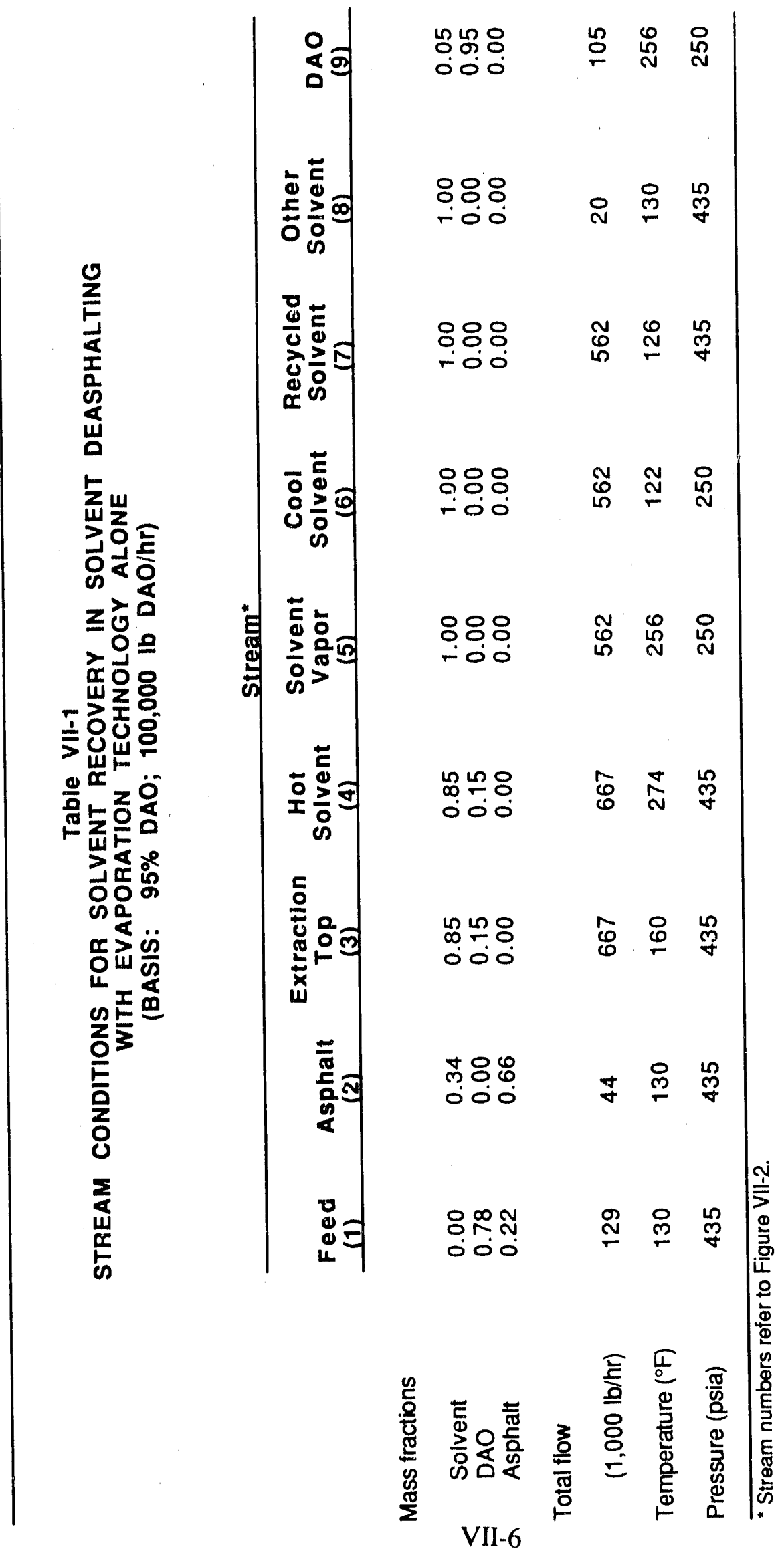




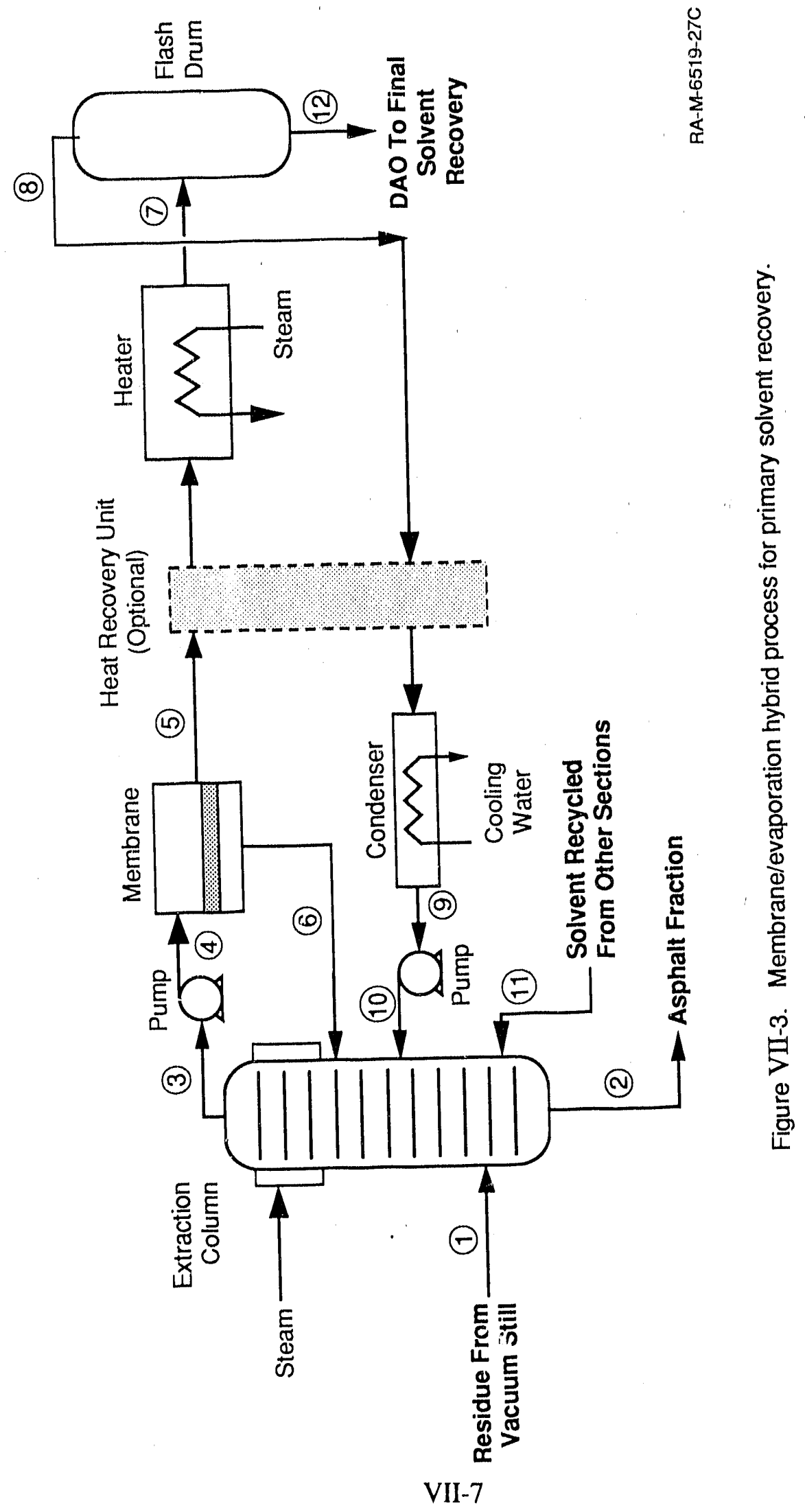


As in all membrane processes, the properties of the membrane determine the performance of the separation system. A membrane with a high separation factor $(\alpha)$ will produce a very pure solvent stream for recycle to the extraction column. A membrane with a low separation factor, however, will result in losses of DAO to the permeate stream. DAC impurities in the recycled solvent result in higher recycle flow rates and increase the size of the tower and membrane equipment.

The membrane properties used in our evaluations are based on results of $\mathrm{Li}$ et al. (1984); separation factors obtained under various conditions were between 2 and 6 . We chose to use a separation factor of 5 because we believe that further work on membrane development could produce membranes with $\alpha$ 's at least near the high end of Li's results. Li's results also indicated that the seplaration factor is independent of feed stream composition up to a DAO mass fraction of $40 \%$. At higher DAO concentrations, the DAO/solvent mixture is too viscous for further membrane processing, and evaporation must be used.

The overall permeate quality that can be obtained from a membrane module (for which the feed-side concentration changes along the membrane) is given by $\mathrm{Li}$ as

$$
Y=\frac{1+\alpha \cdot \ln \frac{\alpha-X_{\mathrm{r}}(\alpha-1)}{\alpha-\mathrm{X}_{\mathrm{f}}(\alpha-1)}}{(1-\alpha)}
$$

where

$$
\begin{aligned}
& Y=\text { DAO mass fraction in permeate } \\
& \alpha=\text { separation factor } \\
& X_{\mathrm{r}}=\text { DAO mass fraction in residue } \\
& X_{\mathrm{f}}=\text { DAO mass fraction in feed. }
\end{aligned}
$$

The required membrane area is calculated by dividing the permeate flow rate by the membrane flux. Thus, the flux is an important parameter in determining the cost of the membrane system. The membrane flux used was $3 \mathrm{lb} / \mathrm{hr} / \mathrm{ft}^{2}$, a value that is at the high end of Li's results but one that we believe is achievable with further membrane development.

The stream compositions and conditions for the base case process are given in Table VII-2 for a membrane/evaporation hybrid system where the membrane concentrates the DAO to $40 \%$ before final separation by evaporation. Like the evaporation system, the hybrid produces

\footnotetext{
* The separation factor is defined as $\alpha=[(1-\mathrm{Y}) / \mathrm{Y}] /\left[\left(1-\mathrm{X}_{\mathrm{f}}\right) / \mathrm{X}_{\mathrm{f}}\right]$ where symbols are given in nomenclature following Eqn. VII-1.
} 


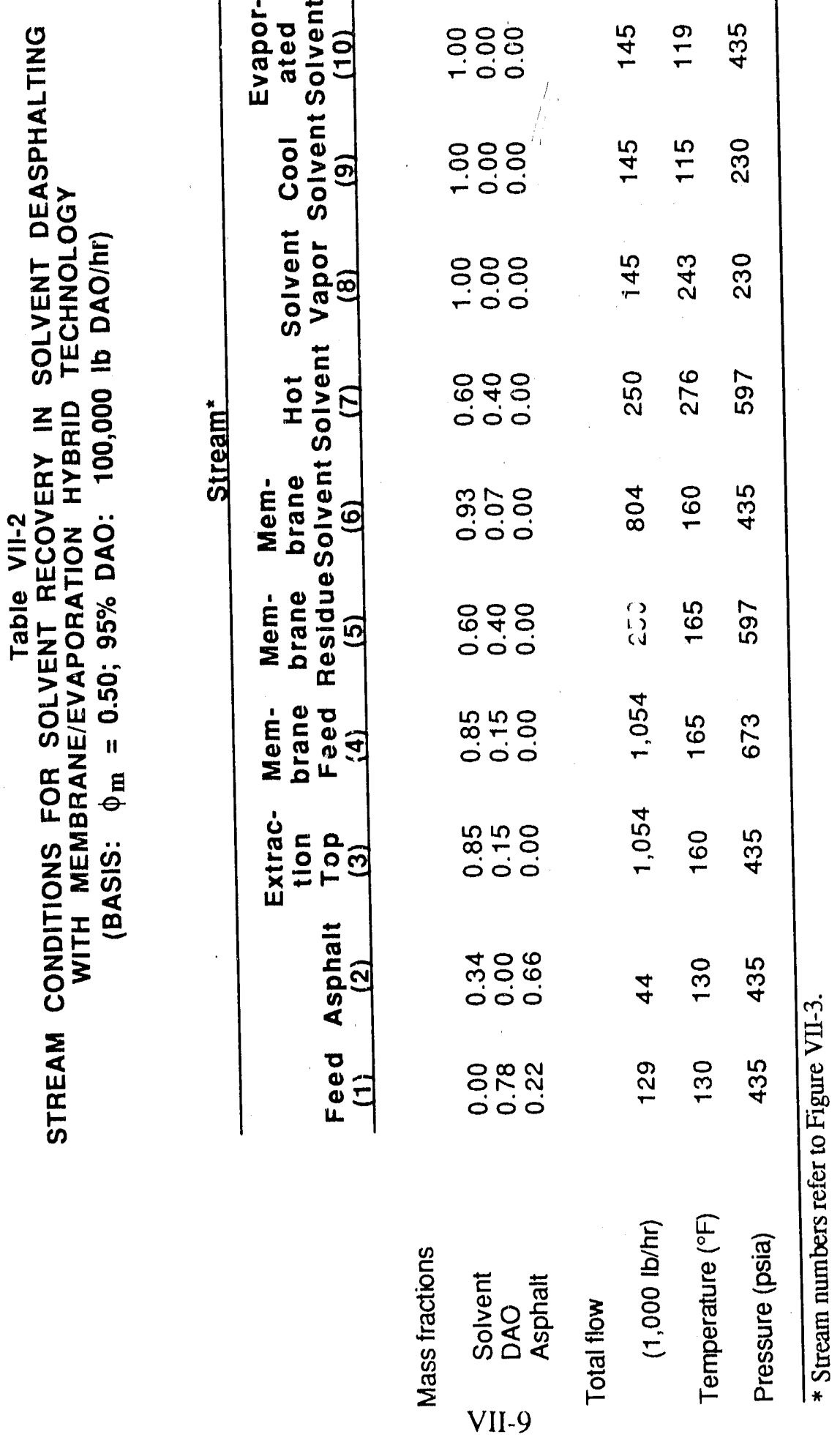


$100,000 \mathrm{lb}$ DAO per hour. The solvent/DAO stream is pressurized to $673 \mathrm{psia}$ before being fed to the membrane. The membrane permeate contains most of the solvent but also contains a significant portion of the DAO fed to the membrane. Thus, to produce the sarne amount of DAO as the evaporation system, the hybrid system must recycle a greater quantity of solvent $(70 \%$ more). The residue stream leaving the membrane is heated to $276^{\circ} \mathrm{F}$ and flashed to 230 psia. The resulting vapor is condensed and recycled to the extraction column. Vapor condensation is achieved by heat exchange with cooling water, or optionally, as part of a heat recovery system as described for the evaporation process above.

\section{THERMODYNAMIC EVALUATION}

In the case of solvent deasphalting, the reference temperature and pressure used in determining $\phi$ are that of the stream leaving the extraction tower: $160^{\circ} \mathrm{F}$ and $435 \mathrm{psia}$. The relationship between $\phi_{\mathrm{m}}$ and the mass fraction of DAO in the membrane residue is shown in Figure VII-4. $\phi_{\mathrm{m}}$ is zero when the DAO fraction leaving the membrane is the same as that entering the membrane (i.e., no membrane) and equal to one when the DAO fraction equals 0.95 (no evaporation). In this study the maximum value of $\phi_{\mathrm{m}}$ used was 0.5 , corresponding to $40 \% \mathrm{DAO}$ in the membrane residue.

\section{ECONOMIC EVALUATION}

The processing cost $(\mathrm{PC})$ is given in dollars per pound of DAO in the product stream. Membrane costs were calculated using the membrane area calculated as described above and a membrane cost of $\$ 6.00 / \mathrm{ft}^{2}$. An installation factor of 2.4 was used for the initial installation only; a membrane lifetime of one year was used. The remaining equipment costs were calculated by standard methods. Utility expenses are based on a steam cost of $\$ 5.00 / 1,000 \mathrm{lb}$ (at $250 \mathrm{psia}$ ), an electricity cost of 5 cents $/ \mathrm{kWh}$, and a cooling water cost of 5.7 cents $/ 1,000$ gal. Table VII-3 lists the application-specific parameters used in the economic evaluation.

\section{BASE CASE EVALUATIONS}

The base case systems for the evaporation and hybrid configurations both have the same feed conditions and product specifications. The stream compositions and conditions are given in Tables VII- 1 and VII-2 for these configurations. The product DAO specification is for a DAO stream containing $5 \%$ solvent; temperature and pressure are determined by the operating conditions 


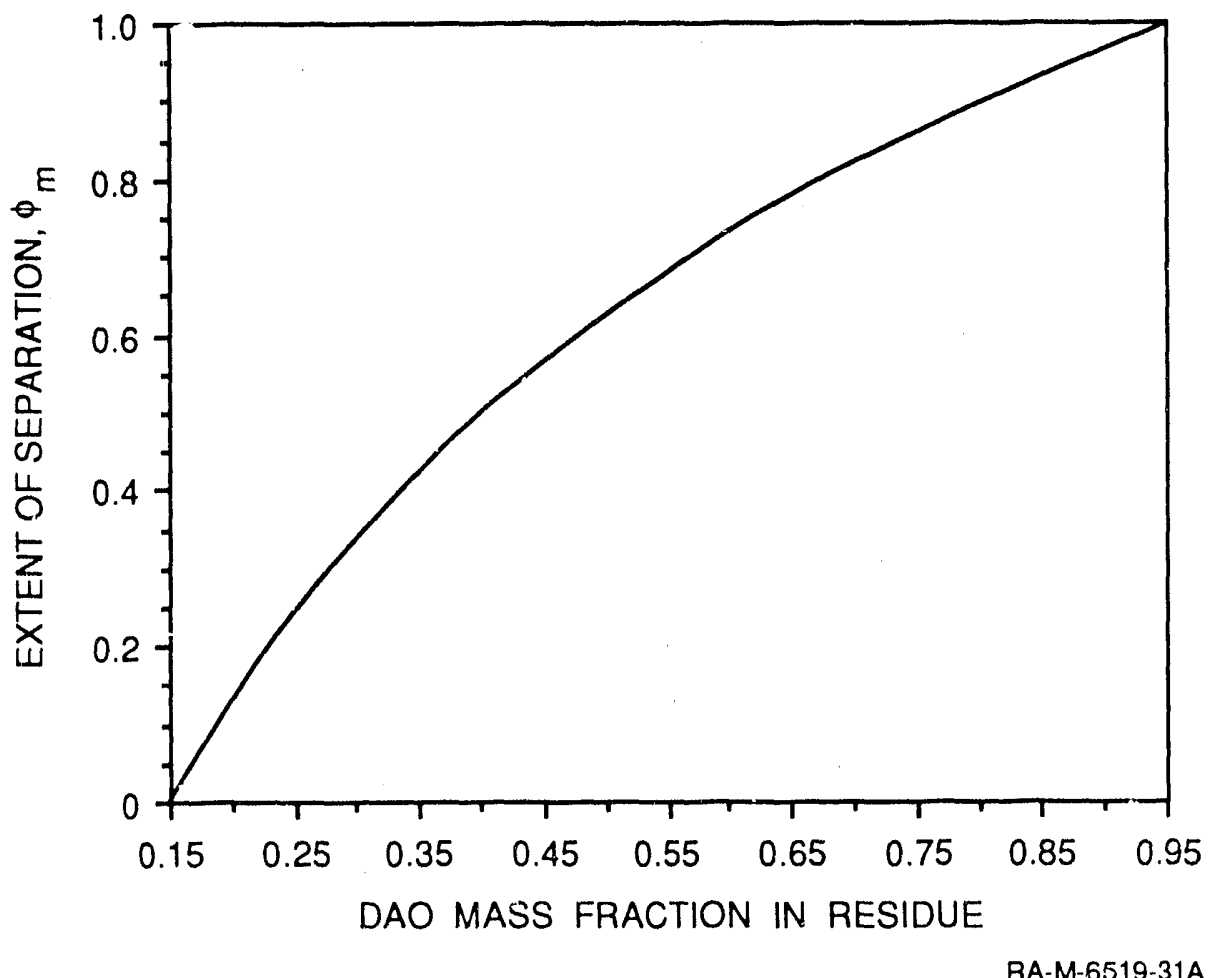

Figure VII-4. Relationship between DAO mass fraction in membrane residue and $\phi_{m}$ for propane. 


\section{Table VII-3 \\ ASSUMPTIONS USED IN ECONOMIC EVALUATIONS \\ FOR SOLVENT DEASPHALTING \\ (basis: $100,000 \mathrm{lb} \mathrm{DAO} / \mathrm{hr}$ )}

$\begin{array}{ll}\text { Plant facilities Investment (PFI) } & \\ \text { Installed membrane system cost } & \$ 14.40 / \mathrm{ft}^{2} \\ \text { Replacement membrane cost } & \$ 6 / \mathrm{ft}^{2} \\ \text { Membrane life } & 1 \text { year }\end{array}$

\section{Utility costs}

$\begin{array}{ll}\text { Steam (250 psia) } & \$ 5.00 / 1,000 \mathrm{lb} \\ \text { Electricity } & 5.0 \mathrm{kWh} \\ \text { Cooling water } & 5.7 \varnothing / 1,000 \mathrm{gal}\end{array}$

resulting in the lowest PC. In the case of the evaporation system, the DAO stream leaves the flash drum at $256^{\circ} \mathrm{F}$ and 250 psia, whereas, in the hybrid system, the DAO stream is at $243^{\circ} \mathrm{F}$ and 230 psia. The base case hybrid system has the maximum permissible value for $\phi_{\mathrm{m}}$ of 0.5 .

Table VII-4 shows the energy requirements for both evaporation and hybrid systems. The heating requirement of evaporation is the main energy consumer for either system. Addition of the membrane reduces the evaporator energy requirement by over $70 \%$ while requiring only a small energy input to run the aduied pump. The thermal energy equivalent for the hybrid system is onethird that of the evaporation system.

Table VII-5 summarizes the economic evaluation for the two base case systems. Alth iugh the energy requirements of the hybrid system are much lower than those of the evaporation system, the capital costs of the hybrid system are twice that of the evaporation system, resulting in a PC only slightly lower with the hybrid system ( $\$ 0.88 / \mathrm{lb}$ DAO compared with $\$ 1.00 / \mathrm{lb} \mathrm{DAO})$ ). The capital costs account for less than $20 \%$ of the evaporator system PC but account for over 6()$\%$ of PC for the hybrid system. Energy costs for the evaporator system are over $70 \%$ of total PC but are only $23 \%$ of the hybrid system PC. These results demonstrate the capital/energy trade-off that often occurs when replacing a traditional separation technology with a membrane unit. 


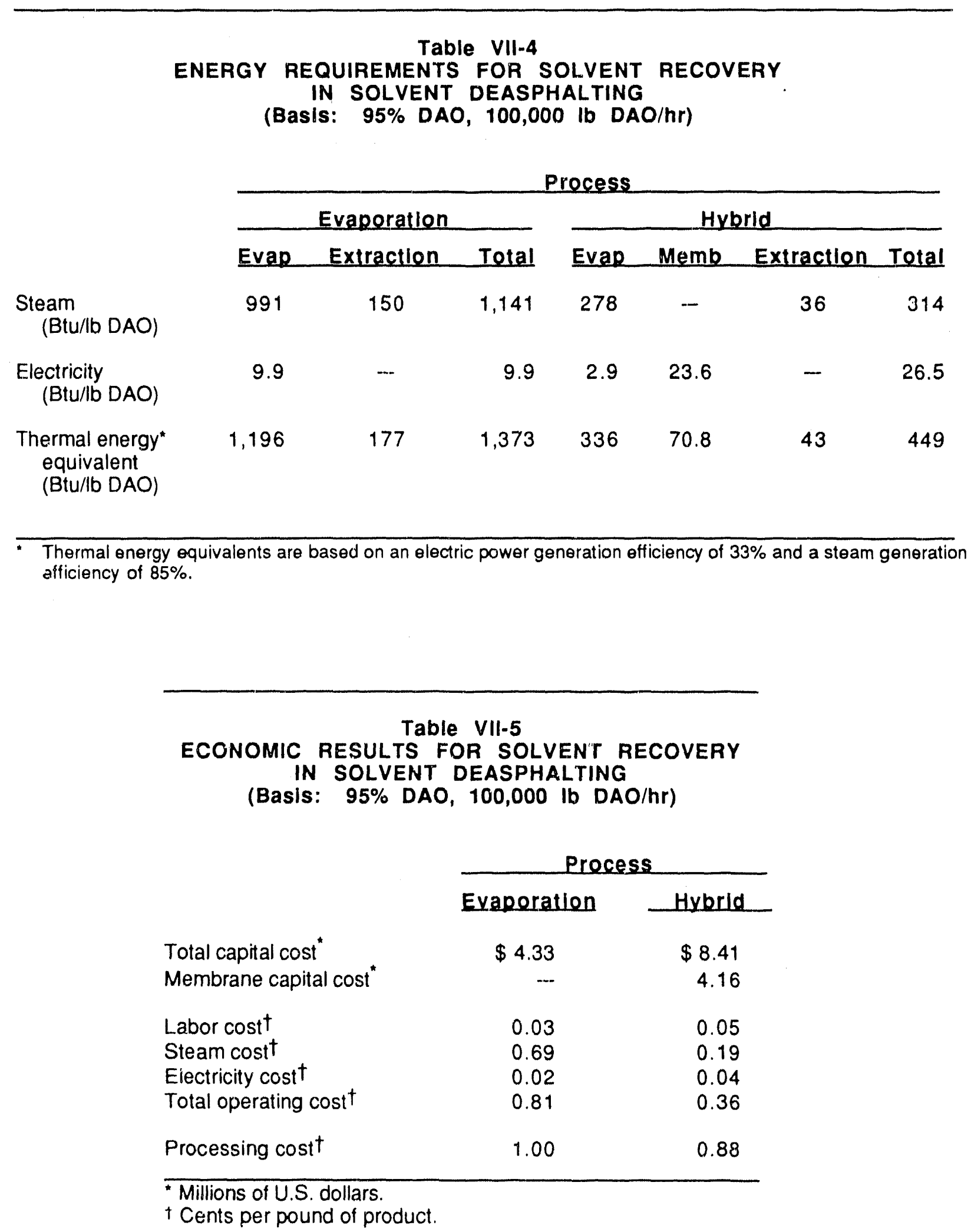


Complete details of the base case evaluations, including breakdowns of utility requirements, capital costs, and total processing cost are given in Appendix D for both evaporation and hybrid systems.

\section{EFFECT OF THERMODYNAMIC EXTENT OF SEPARATION}

The effect of varying the thermodynamic extent of separation $\left(\phi_{m}\right)$, that is, varying the separation work done by each of the two technologies, is illustrated in Figure VII-5 in terms of PC and the availability consumed in utility streams, Autil. The left side of the graph $\left(\phi_{\mathrm{m}}=0\right)$ corresponds to the evaporation only system, and the right side $\left(\phi_{\mathrm{m}}=0.5\right)$ corresponds to the maximum degree of concentration that can be performed by the membrane before the fluid becomes too viscous for processing by the membrane. The two extremes of the graph represent the two base case systems described in the previous section.

Figure VII-5a shows a minimum in PC of 0.83 cents $/ \mathrm{lb}$ DAO at $\phi_{\mathrm{m}}$ equal to $\sim 0.35$; this corresponds to a DAO mass fraction in the membrane residue of 0.31 . To simplify what is happening to the $\mathrm{PC}$ as $\phi_{\mathrm{m}}$ increases, it is useful to think of an increase in $\phi_{\mathrm{m}}$ as having two significant effects: a reduction in steam use in evaporation and an increase in the total capital cost for the system. Figure VII-6a shows that the amount of solvent to be evaporated by the evaporation section (and therefore the steam needed for evaporation) with $\phi_{m}=0.25$ is about half that with $\phi_{m}=0.0$. However, a further increase in $\phi_{m}$ to 0.50 results in an evaporation rate one-fourth that of the $\phi_{\mathrm{m}}=0.0$ case; thus there is a diminishing advantage to increasing $\phi_{\mathrm{m}}$ at higher values of $\phi_{\mathrm{m}}$. On the other hand, the capital costs (Figure VII-6b) increase by $40 \%$ of the $\phi_{\mathrm{m}}=0.0$ value when $\phi_{\mathrm{m}}$ is increased from 0.0 to 0.25 , while a change from 0.25 to 0.50 results in a capital cost increase of $54 \%$ of the $\phi_{\mathrm{m}}=0.0$ value; thus there is an increasing disadvantage to increasing $\phi_{\mathrm{m}}$ at higher values of $\phi_{\mathrm{m}}$.

Whether the net result of these two effects is a decrease or increase in PC as $\phi_{\mathrm{m}}$ increases depends on the magnitude of each effect; however, from the above discussion, it is obvious that the advantageous effect of increasing $\phi_{m}$ is greatest at low values of $\phi_{m}$; therefore, if a calculation at a low value of $\phi_{m}$ shows that adding membrane increases the overall costs, we know that the lowest PC for any system will be at $\phi_{\mathrm{m}}=0.0$ and further evaluations of hybrid systems are not necessary. However, if a calculation shows that an addition of membrane at $\phi_{\mathrm{m}}=0$ results in a lowering in the PC, we know that this does not necessarily mean that we should use as much membrane as technologically possible, but that there is a minimum in the PC curve at some point other than $\phi_{\mathrm{m}}=0.0$. 

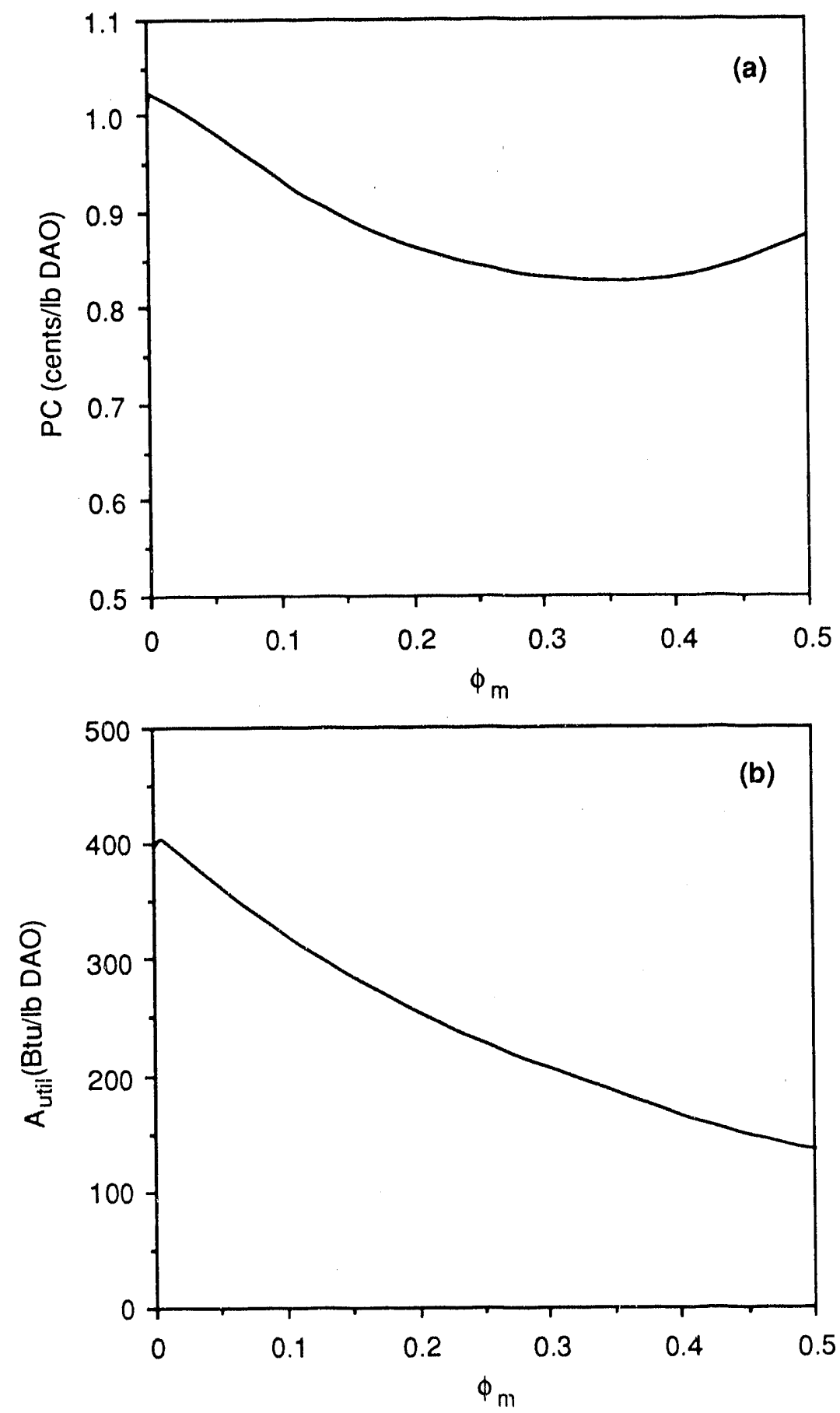

RA-M- $6519-28 C$

Figure VII-5. Effect of $\phi_{\mathrm{m}}$ on PC and utility availability consumption for solvent deasphalting. 

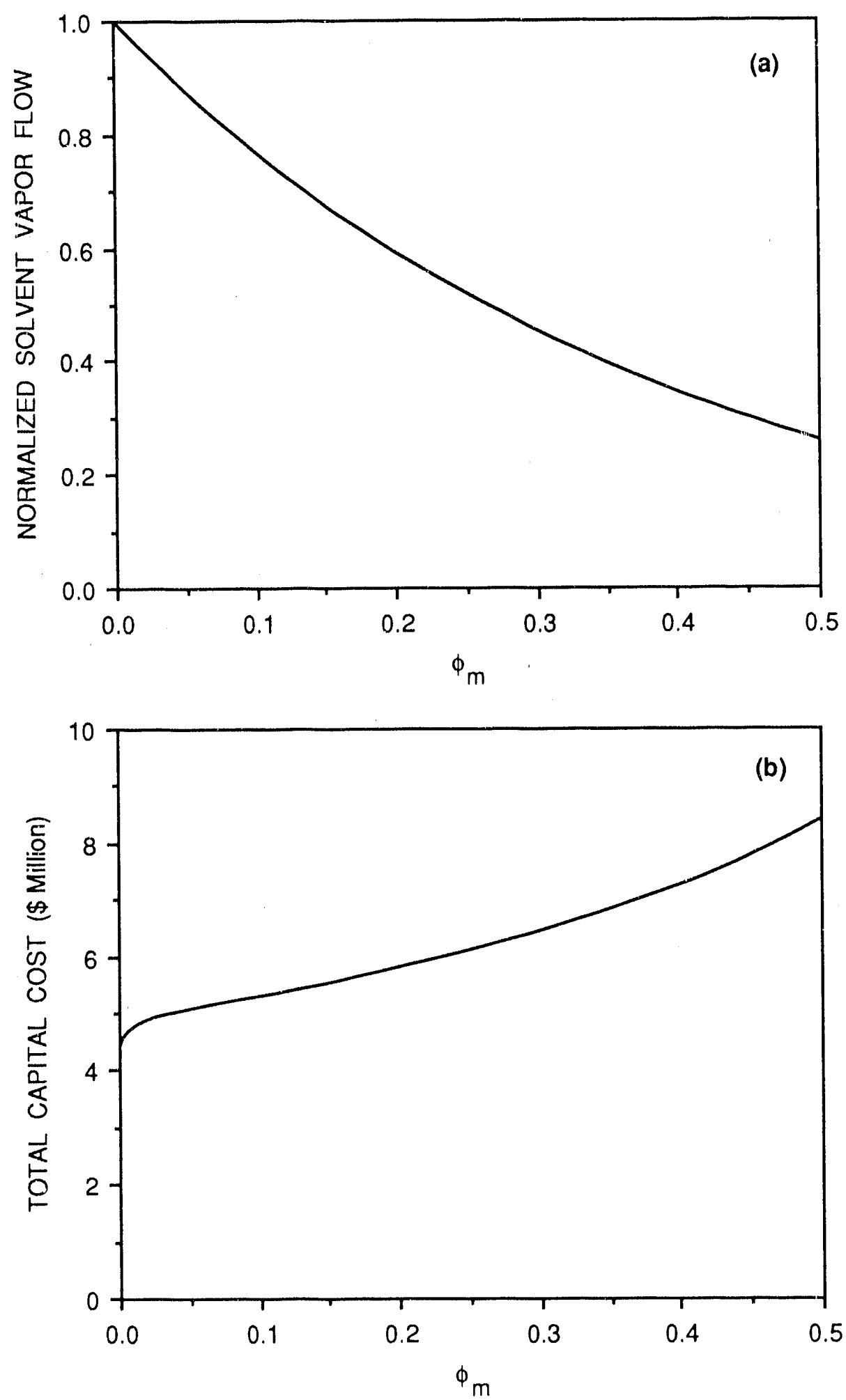

Figure VII-6. Capital cost and solvent vapor flow as a function of $\phi_{\mathrm{m}}$ for solvent deasphalting. 
In essence, we have determined that the second derivative of the $\mathrm{PC}$ versus $\phi_{\mathrm{m}}$ curve is positive, and we were able to determine this fact without performing anything other than "back-ofthe-envelope" calculations. The evaporation rate was calculated by a simple mass balance calculation, without the need for information about membrane performance. (The cost of energy required by the membrane can be assumed insignificant for ultrafiltration; this may not be the case for a gas separation membrane, however.) The shape of the capital cost curve is determined primarily by the membrane unit; the cost of the membrane should have a positive second derivative with respect to $\phi_{\mathrm{m}}$ since it is well known that membranes perform most efficiently when the feed-side concentration of the more permeable component is greatest. Combining these two effects, we can predict that the membrane will have the greatest benefit in terms of PC close to $\phi_{\mathrm{m}}$ equal to zero.

Figure VII-5b shows that the utility consumption curve qualitatively is very similar to the solvent vapor flow curve (Figure VII-6a). This similarity is not surprising because the major utility use in this separation is the steam used for evaporation.

To summarize these evaluations, the optimum system is a membrane/evaporation hybrid with $\phi_{\mathrm{m}}$ of $\sim 0.35$ (corresponding to a mass fraction DAO in membrane residue of $\sim 0.31$ ). The benefit of addiıg a membrane to the evaporation system is that the steam required can be reduced considerably by using membranes; the savings in steam cost is greater than the added capital costs of the membrane and results in a net decrease in PC from $\$ 1.00 / \mathrm{lb}$ DAO for evaporation alone to $\$ 0.83 / \mathrm{lb}$ DAO for the optimum hybrid system. Increasing the membrane area beyond the optimum point produces further steam savings, but at the cost of even greater increases in capital expenses, and results in an increase in $\mathrm{PC}$.

\section{EFFECT OF HEAT RECOVERY}

In the previous section we demonstrated that the major advantage in using a membrane was that the steam expenses were reduced considerably. However, as described previously, many evaporation systems include some type of heat recovery; thus, some of the heating energy can be supplied by the condensing flash vapor. If some type of heat recovery system is used, the steam requirements of the evaporation section can be greatly reduced without the addition of membranes. To examine the effect of heat recovery on the overall economics and thermodynamics of the separation system, we included an optional heat recovery unit (Figures VII-2 and VII-3). 
Heat can be recovered from the condensing solvent vapor in many ways; however, in all cases, the condensation temperature must be greater than the feed vaporization temperature if heat is to be transferred from the condensing to the feed stream. This can be arranged in several ways such as flashing at high pressure and therefore high temperature or recompression of the vapor stream after flashing at low temperature. The configuration of the heat recovery system depends on many factors: solvent species, feed composition, feed temperature and pressure, and economic factors. To allow us to perform a range of calculations without doing complex redesign and optimization of our system, we assumed that the specified amount of heat is recovered by heat exchange without regard to the temperature gradient between condensing and vaporizing streams.

We define the efficiency of the heat recovery unit, $Q$, as the fraction of the heat released by condensation of the solvent vapor stream that is transferred to the feed stream. Thus, a $\mathrm{Q}$ of 0.0 corresponds to no heat recovery as in the base case systems above. A Q of 1.0 corresponds to recovering all the heat released during condensation.

The effect of $Q$ on $P C$ is shown in Figure VII-7a for values of $Q$ from 0.0 to 1.0. This figure shows that the value of $\phi_{m}$ for the optimum system becomes smaller as $Q$ is increased; that is, as $Q$ increases, the size of the membrane unit used to give the lowest PC goes down. At a $Q$ of 0.5 and above, the optimum system is evaporation alone; addition of any membrane results in an increase in $\mathrm{PC}$.

Figure VII-7b shows that the system $A_{u t i l}$ is at a minimum by using as much membrane as possible for all values of $Q$; however, the steam requirement for systems with $Q$ greater than 0.5 is already reduced enough that further steam expense reductions by addition of the membrane do not offset the added capital cost of the membrane unit.

\section{EFFECT OF SEPARATION FACTOR}

Another important system variable is the membrane separation factor, $\alpha$. As $\alpha$ increases the permeate DAO fraction decreases, and the extraction tower size is reduced. Figure VII-8a shows the PC for separation systems with membrane separation factors of 3, 5 (base case), 10, and 100 . At $\phi_{\mathrm{m}}$ equal to 0.0 , all curves converge since no membrane is used. As $\phi_{\mathrm{m}}$ increases, the amount of membrane increases, and the differences between the curves also increase.

Even with a separation factor as low as 3, there are benefits to using a hybrid system; for this separation factor, the optimum $\phi_{\mathrm{m}}$ value is $\sim 0.2$ giving a PC of $\$ 0.95 / \mathrm{lb}$ DAO. As the separation factor of the membrane increases, the optimum $\phi_{m}$ also increases. The optimum $\phi_{m}$ is 0.45 

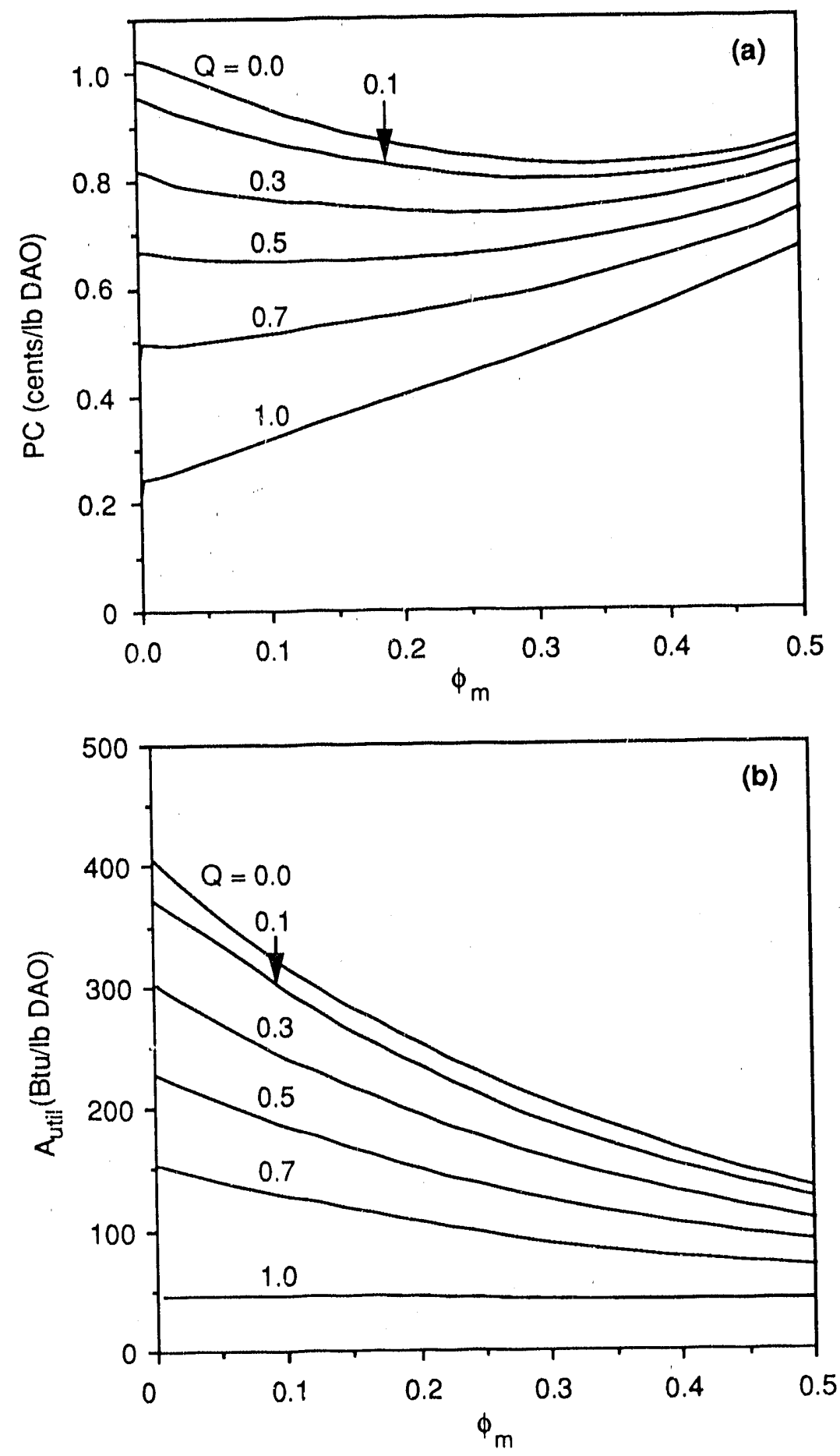

Figure VII-7. Effect of $\phi_{m}$ on PC and availability consumption with various heat recoveries, $Q$, for solvent deasphalting. 

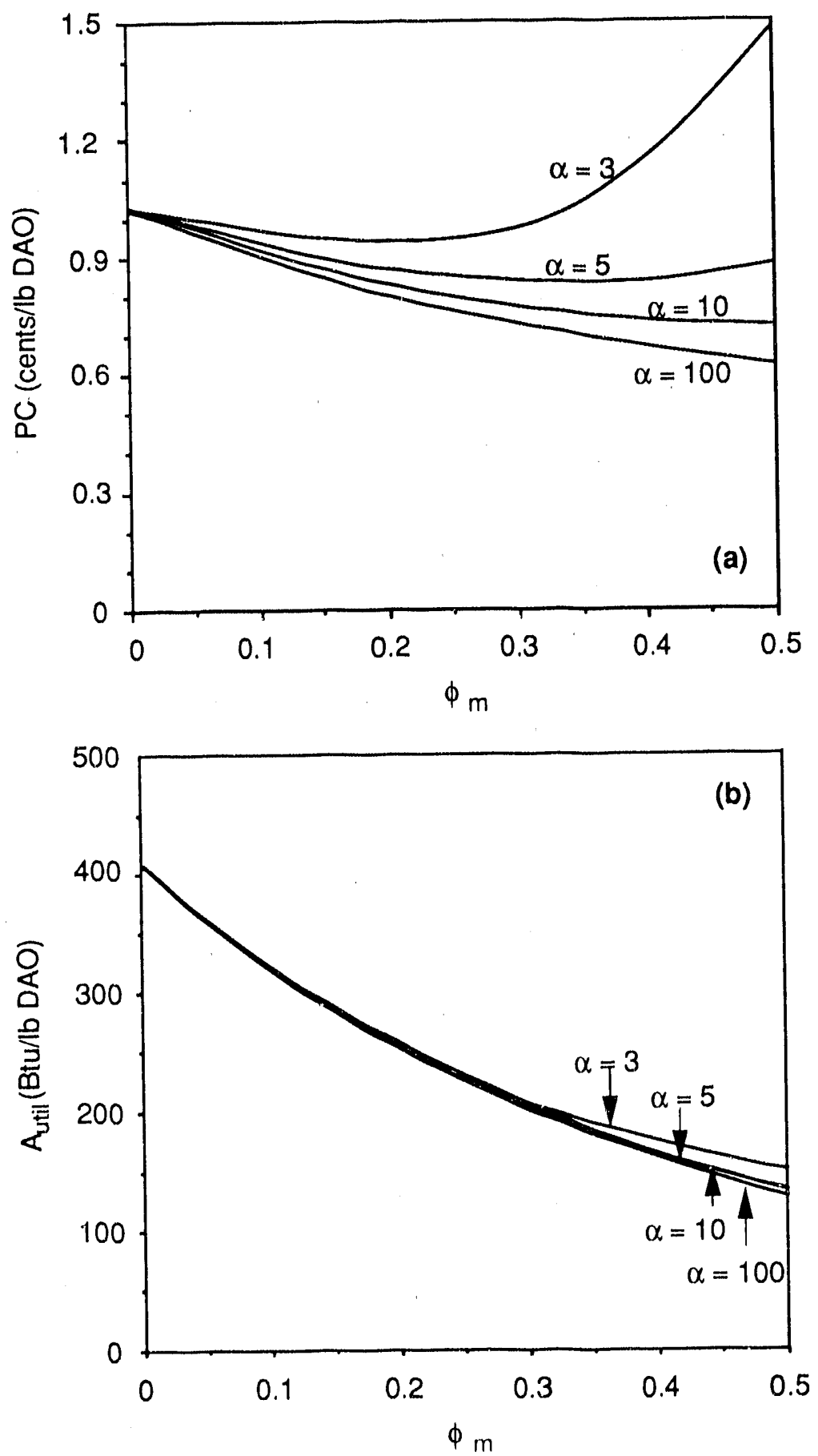

RA-M-6519-29D

Figure VII-8. Effect of $\phi_{m}$ and separation factor( $\alpha$ ) on PC and availability consumption for solvent deasphalting.

(No heat recovery.) 
and $>0.5$ for separation factors of 10 and 100 , respectively; the optimum PC also decreases to $\$ 0.72 / \mathrm{lb}$ DAO and $\$ 0.58 / \mathrm{lb} \mathrm{DAO}$. Considering that the base case value of 5 is optimistic for current membranes, a separation factor of 100 is not likely to be achieved in the near future. However, a value of 10 is reasonable in the next decade if continuing research is performed.

Figure VII-8b shows $A_{u t i l}$ for systems with different membrane properties. There is very little difference between the curves for different membrane properties because, for a given $\phi_{\mathrm{m}}$, any separation factor will result in an identical membrane residue stream and thus the steam requirement of the evaporator will be unaffected. A higher $\alpha$ will reduce the energy requirements of the membrane section, but this energy requirement is hardly noticeable compared with the steam used in evaporation.

The benefit of increasing membrane properties is not in a reduction of energy use, but in a reduction in the capital costs of the extraction and membrane sections because less DAO is recycled in the membrane permeate. It is interesting that separation factors even as low as 3 will be beneficial to the overall PC and that increasing the separation factor to even as high as 100 will still have increased benefits.

\section{EFFECT OF SOLVENT COMPOSITION}

Up to this point, we have assumed that propane is the solvent used in the extraction process. Although this solvent is a common one for this type of separation, many other solvents are also used, typically, butane or pentane. Using a lighter solvent results in a higher quality DAO product; however, the maximum DAO yield is reduced (Sprague, 1986). Thus the choice of the solvent used in the extraction process depends on the product DAO specifications and on the availability and cost of the various candidate solvents.

To examine the effect of the solvent species on the economic and thermodynamic performancis, we performed evaluations for the base case system using pentane in place of propane. We assumed that the membrane properties are the same for pentane as for propane (in reality, we expect the separation factor to be slightly lower for the heavier solvent, pentane); however, the thermodynamic properties are different for the two solvents. The major difference in operating conditions is that the DAO/solvent mixture must be heated to a higher temperature and is flashed at a lower pressure when using the heavier solvent. 
Figure VII-9 shows results of evaluations using pentane as the solvent for evaporation and hybrid systems with heat recovery efficiencies of 0.0 and 0.5 . Qualitatively they are similar to the results obtained with propane. The major difference is that the maximum value of $\phi_{m}$ is 0.38 . This difference occurs because the thermodynamic properties of the two solvents are different; the relationship between $\phi_{m}$ and the residue stream composition is different for the two solvents. Figure VII-10 shows $\phi_{m}$ as a function of the residue DAO mass fraction for both pentane and propane.

Although the difference between the two curves in Figure VII-10 is not great, a comparison of PC and $A_{u t i l}$ for systems using different solvents must be shown on the basis of DAO mass fraction because a single value of $\phi_{m}$ corresponds to different compositions with different solvents. In Figure VII-11, PC and $A_{u t i l}$ are shown for systems using either pentane or propane as a function of the residue composition. These figures show that there is very little difference either qualitatively or quantitatively between systems using propane and systems using pentane.

\section{CONCLUSIONS}

The main energy consumer and main operating expense in both the evaporation and hybrid systems is the steam used for evaporation. Using membranes can lower the steam expense from $\$ 0.69$ to $\$ 0.19 / \mathrm{lb}$ DAO and reduce the energy consumption by two-thirds (in terms of both availability and thermal energy equivalent). However, this reduction in steam use results in greater capital cost for the hybrid system: the evaporation capital cost is half that of the base case hybrid system. Because of this trade-off between steam costs and capital costs, the minimum PC occurs between the two base case systems at a value of $\phi_{\mathrm{m}}$ of approximately 0.35 .

By breaking the processing cost into two principal factors, steam expense and membrane capital cost, we are able to understand how the PC is affected by varying $\phi_{m}$. By examination of the system mass balance, we know that the greatest reduction in steam use per unit change in $\phi_{\mathrm{m}}$ occurs at $\phi_{\mathrm{m}}$ equal to zero. It is also general knowledge that, for membranes, the initial portion of the separation (near $\phi_{\mathrm{m}}$ equal to zero) is the easiest and cheapest. Knowing these two facts we can see that the membrane will be most beneficial at values of $\phi_{m}$ close to zero. Thus, if an evaluation shows that a hybrid system using only a small amount of membrane does not reduce PC, we know that increases in membrane area (increased $\phi_{m}$ ) will be even less beneficial. If, however, the PC is reduced by addition of a small amount of membrane, we still do not know if the lowest PC will occur by using the most membrane technically feasible or by using some smaller amount of membrane; this issue can be decided only by further calculations. 

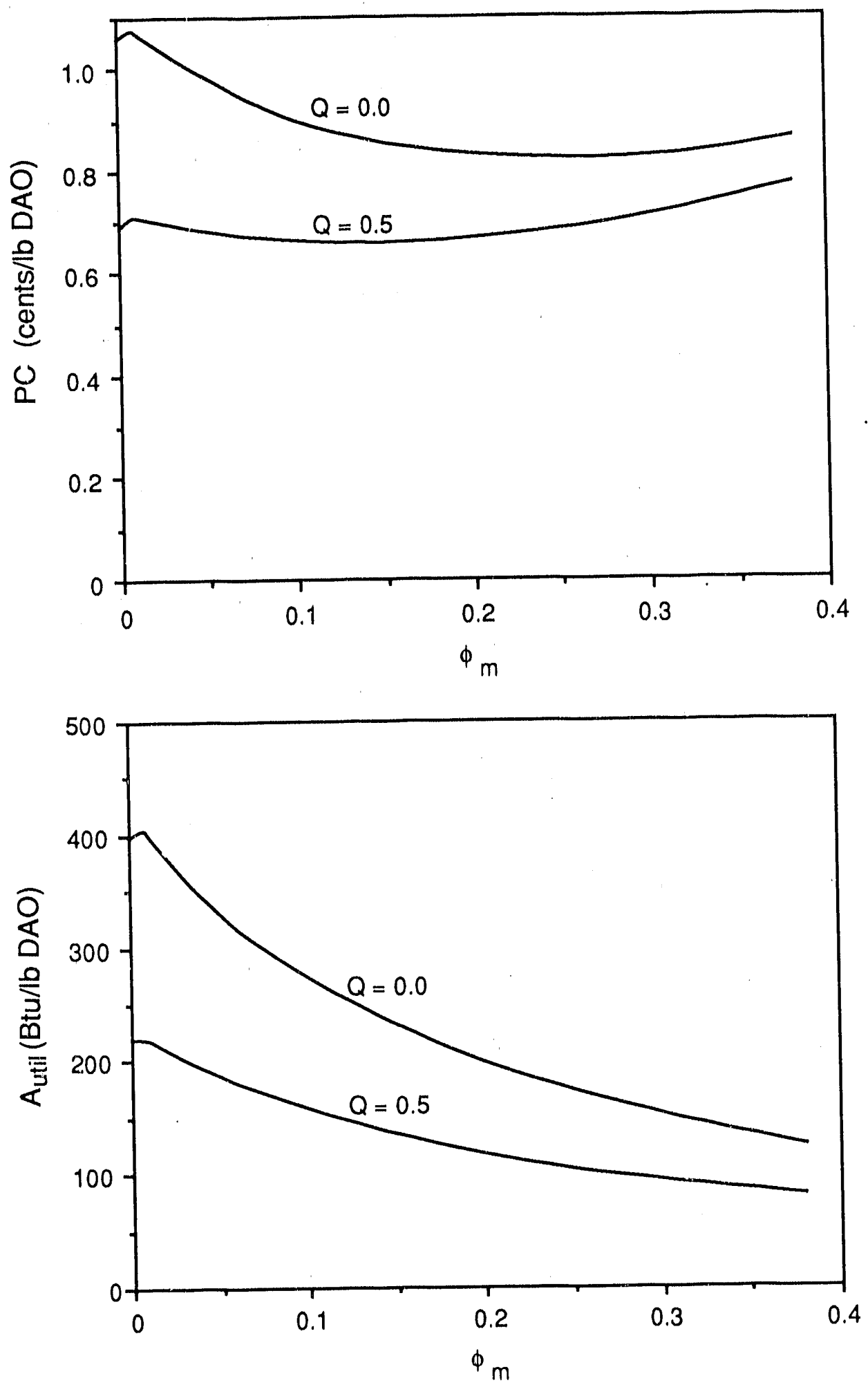

RA-M-6519-33A

Figure VII-9. Effect of $\phi_{m}$ on PC and availability consumption with and without heat recovery using pentane as solvent in solvent deasphalting $(\alpha=3)$. 


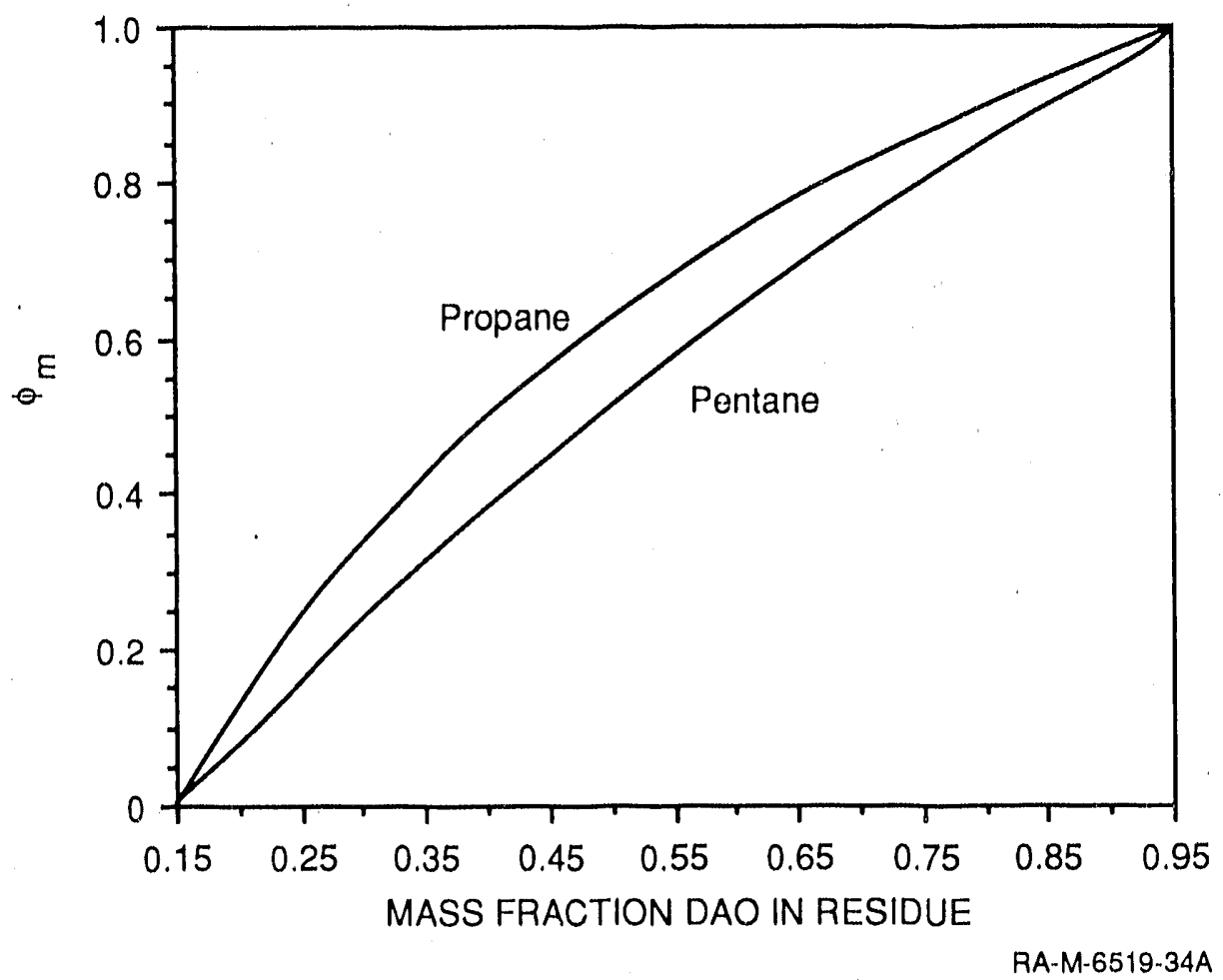

Figure VII-10. Relationship between DAO mass fraction and $\phi_{m}$ for propane and pentane. 

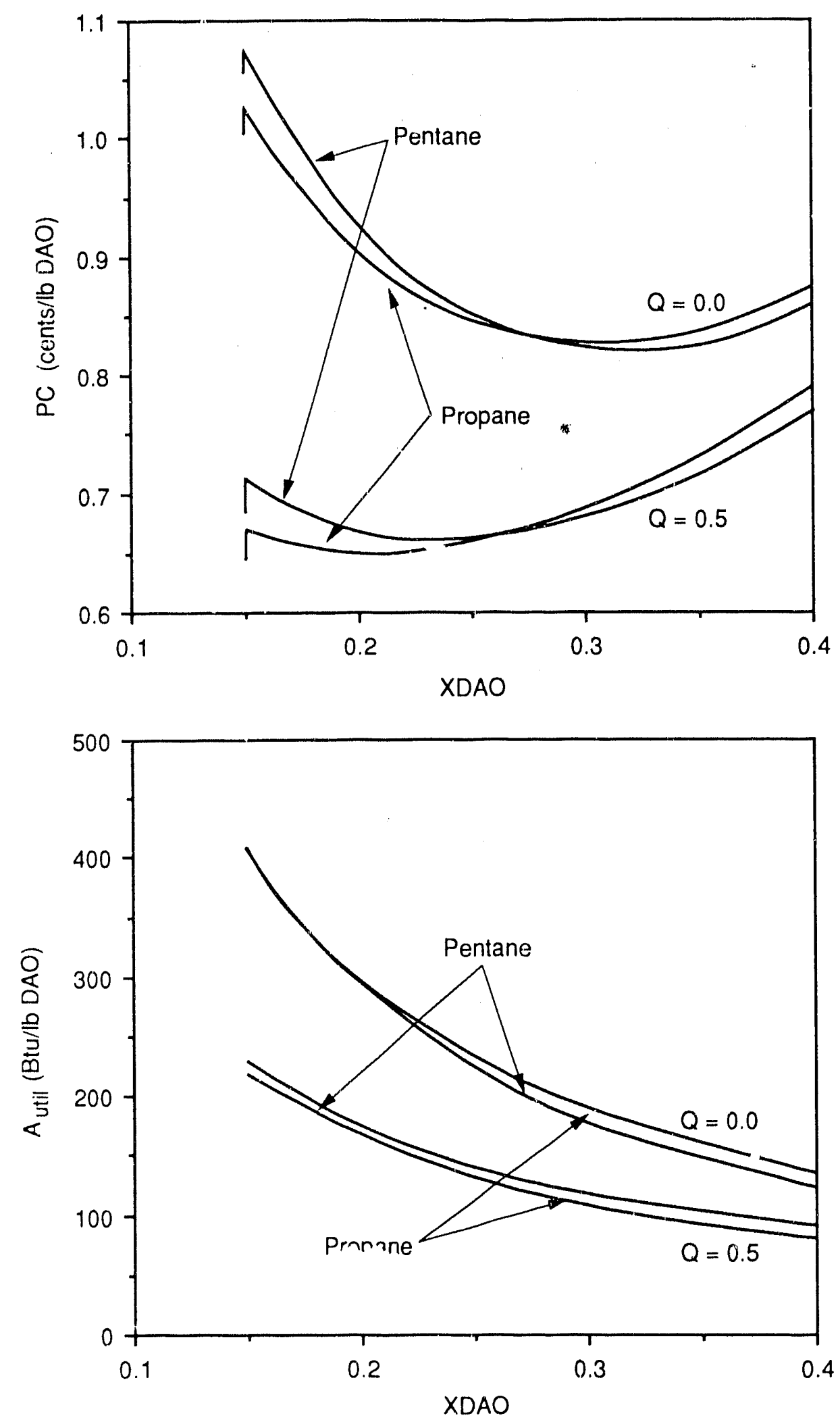

RA-M-6519-35A

Figure VII-11. Comparison of propane and pentane based solvent deasphalting systems with and without heat recovery $(\alpha=3)$. 
The fact that energy (steam for evaporation) is the greatest operating expense indicates that the advantage of using a membrane is greatly reduced by use of a heat recovery system. Our analysis has shown that, for heat recoveries greater than $50 \%$, addition of a membrane will result in an increase in PC for our base case system.

Another important operating parameter is the separation factor. Although the highest value for separation factor is the most desirable, our calculations have shown that values as low as 3 will still be beneficial. If the separation factor is doubled above the base case value to 10 , the optimum value for $\phi_{\mathrm{m}}$ is very close to the maximum value of 0.5 . Higher values of the separation factor give further benefits, even to values as high as 100 .

We also examined the effect of using different solvents to perform the separation. Aside from propane (the base case solvent), pentane was evaluated and shown to have results similar to those with propane. 


\section{CHAPTER VIII \\ GUIDELINES FOR ASSESSING LIKELIHOOD OF SUCCESS OF HYBRID SYSTEMS}

The objective of this task was to develop guidelines for identifying situations in which a hybrid membrane system is likely to give superior performance (economics and energy consumption) over systems consisting of a single technology alone. To arrive at these guidelines, we spent time thinking about why certain process schemes examined in the case studies (Chapters IV through VII) were better than others, what the membranes did best, how efficiently energy was utilized by the various unit operations, and similar questions. Some of the guidelines have been hinted at in the previous chapters. Here, we seek to provide qualitative and quantitative guidelines to help the practicing engineer answer one "simple" question, namely, "Is there a good chance that a hybrid process would be the process of choice at practical operating conditions?"

The value of answering this question is quite high since it is possible to expend substantial manpower trying to optimize a processing scheme only to find that a whole new family of options exist if a new unit operation is included in the scheme. Conversely, complex processing schemes, for example, schemes including hybrid systems, are not necessarily superior economically despite the many options for optimizing such schemes. In the current era of high-speed process simulators, deciding what to simulate is more important than doing the simulation.

It is worthwhile to say what we do not expect from our guidelines, We do not expect our guidelines to replace those established for generally assessing the applicability of a separation unit operation (e.g., King, 1980, pg. 688). Rather, we expect that engineers using the guidelines for hybrid systems will have already identified at least one membrane and one nonmembrane technology that they believe has a good chance of solving the separation problem at hand. Our guidelines are also not meant to identify when membranes themselves are superior. Rather, our guidelines will lead the way to assessing when hybrid systems are superior.

Our quantitative guidelines use the availability, efficiency, and extent of separation terms defined in Chapter III. The reader may wish to refresh his memory before proceeding.

\section{STATEMENT OF GUIDELINES}

Table VIII-1 lists the qualitative and quantitative guidelines for answering the question "Is there a good chance that a hybrid process would be the process of choice at practical operating conditions?" The following sections explain the concepts from which these guidelines derived and 


\section{Table VIII-1 \\ GUIDELINES FOR ASSESSING \\ LIKELIHOOD OF SUCCESS OF HYBRID SYSTEMS}

\section{Qualitatlve Guidellnes}

(1) A hybrid is likely to be successful when there are driving force limitations in one or both membrane/nonmembrane technologies.

(2) A hybrid is likely to be successful when there is a point-wise variation in the separation factor (e.g., relative volatility, distribution coefficient, membrane selectivity).

(3) A hybrid is likely to be successful when a reversal of the minor component is possible and the two technologies act on different components.

(4) A hybrid is likely to be successful when the membrane fails to produce the required product purity on its own but has some of the following advantages:
(a) The membrane better utilizes energy contained in the feed.
(b) The membrane transfers less material.
(c) The membrane accomplishes its portion of the separation in a single stage.
(d) The membrane avoids a phase change associated with the nonmembrane technology.
(e) The traditional technology does not involve energy recovery schemes.
(f) The membrane reduces the total residence time of the process.
(g) The membrane allows process streams to exist as liquids.
(h) The membrane decreases capital investment needed to supply the driving force for the separation process.
(i) The membrane reduces the size of downstream equipment.

(5) A hybrid is not likely to be successful when the membrane does not make the desired final purity in at least one of its outlet streams.

\section{Quantitative Guidelines}

(1) A hybrid is favored when

$A_{\text {sep }}($ memb $)<1 / 3^{*} A_{\text {sep }}$ (nonmemb) and $C C_{\text {sep }}$ (memb) $>C C_{\text {sep }}$ (nonmemb).

(2) A hybrid is favored when

$G>1$. 
define the terms used in our quantitative guidelines. In Chapter IX, these guidelines are part of the criteria leading to recommendations for experimental work.

\section{RATIONALE OF QUALITATIVE GUIDELINES}

It is logical to postulate that concepts leading to guidelines would derive from consideration of energy and capital costs since the notion of "successful" is an economic one. Beyond this basic near-tautology, it is difficult to lay out a rationale that would lead all reasonable thinkers to the same set of guidelines. Nevertheless, we wish to explain the reasoning behind our guidelines and how our case studies (Chapters IV through VII) support our guidelines.

The major underlying theme of all hybrid systems is that there is something "strong" and something "weak" about each process that is part of the hybrid system under the conditions of interest. Further, the strengths and weaknesses of the individual processes must be complementary in some sense. It is not enough, therefore, to identify when one technology (e.g., membranes) might be favored. Rather, there must also be something that one technology falls short of accomplishing so that there is a need for a complementary technology.

\section{Direct Strength/Weakness Guidelines}

Our qualitative guideline Number 4 (a to i) most directly exemplifies the major underlying theme. It is a common notion among process designers that membranes often fail to produce the required purity. It was natural, therefore, for us to ask when this weakness can be combined with strengths to make a hybrid system. To answer this question, we asked "What is good about a membrane?" T'o answer this question, we examined the energy and capital cost issues that typify membrane processes.

Energy. With respect to energy consumption, we devised five key questions that indicate when a membrane process is likely to have an energy advantage over a nonmembrane process:

(1) Does the membrane better use energy contained in the feed?

(2) Does the membrane transfer less material?

(3) Can the membrane accomplish the desired portion of the total separation in a single stage?

(4) Does the membrane avoid a phase change that occurs when the nonmembrane technology is used?

(5) Does the nonmembrane technology not use energy recovery schemes? 
These five questions transferred directly to guideline items $4 \mathrm{a}$ to $4 \mathrm{e}$. Our case studies indicate that a "yes" answer to these makes a hybrid system likely when the membrane fails to make the desired purity.

Guideline $4 \mathrm{a}$ is illustrated by Case Study 2 (removal of $\mathrm{N}_{2}$ from natural gas) where the feed stream was available to 800 psia. The membrane utilized this energy to drive the separation maintaining the product at pressure. In the PSA process, however, the product methane is at low pressure and must be recompressed. Hence, the membrane uses the feed pressure (energy) well, and the PSA process does not. Guideline $4 \mathrm{~b}$ is illustrated by Case Study 1 (propylene/propane). Here, the membrane is very selective for propylene (>100), and distillation is only slightly selective for propylene (relative volatility $\leqslant 1.2$ ). Hence, the membrane transfers little materi: 1 other than propylene, whereas, distillation moves significant quantities of propane along with the propylene.

Guideline $4 \mathrm{c}$ is illustrated by Case Study $2\left(\mathrm{~N}_{2}\right.$ from natural gas) and 3 (KBL concentration). In Case Study 2, one stage was required with $20 \% \mathrm{~N}_{2}$ in the feed, no energy input was required, and the membrane was significantly favored (economically) over PSA. When the $\mathrm{N}_{2}$ content in the feed was $40 \%$, however, the membrane system consisted of two stages, including additional energy and capital for recompression for the second stage. Although the membrane was still favored over PSA, it was only marginally favored. In Case Study 3, the membrane section of the hybrid consisted of two stages, and the hybrid was not competitive with evaporation technology alone. However, if the membrane properties were improved so that only one stage was necessary, the separation costs with evaporation and with the hybrid were the same.

Guideline $4 \mathrm{~d}$ is commonly associated with membrane processes and is illustrated directly in Case Studies 3 and 4. Guideline $4 \mathrm{e}$ is illustrated by Case Study 4 . Here, the membrane hybrid had a lower cost (PC) than flasin expansion alone, primarily because of energy savings. However, if energy was recovered in the flash expansion process, the energy savings were reduced. Finally, with greater than $50 \%$ energy recovery, flash expansion alone had the lowest cost.

Capital. With respect to capital cost, we devised four key questions that indicate when a membrane process is likely to have a capital cost advantage over a nonmembrane process:

(1) Does use of the membrane reduce total residence time in the process?

(2) Does use of the membrane allow process streams to be in the liquid phase?

(3) Does use of the membrane decrease the capital investment needed to supply the driving force for separation?

(4) Does the membrane reduce size of downstream equipment? 
These four questions transferred directly to guideline items $4 \mathrm{f}$ to $4 \mathrm{i}$. Guideline $4 \mathrm{f}$ is illustrated by Case Study 1. Here, high reflux and reboil rates are required by the distillation column, increasing the average residence time in the distillation column. The residence time in the membrane unit is quite short, and when the membrane is added to the distillation column, the column needs less reflux and reboil. The size and capital cost of the distillation column is therefore substantially reduced.

Guideline $4 \mathrm{~g}$ (keeping streams in liquid phase) is not illustrated by one of our case studies, but we included it because it can be important in membrane hybrids in general. Keeping streams in the liquid phase lowers capital cost because the piping and pumps are smaller to move liquids than to move gases. Guideline $4 \mathrm{~h}$ is illustrated by Case Study $2\left(\mathrm{~N}_{2}\right.$ from natural gas). The addition of a membrane section to the PSA reduced the capital cost for compression equipment. Guideline $4 i$ is logical but is only indirectly inferred from Case Study 4 wherein the recycle of solvent causes a large increase in capital cost.

\section{Implicit Strength/Weakness Guidelines}

Several of our qualitative guidelines $(1,2,3$, and 5$)$ come about by considering that a given technology might be "strong" in one part of the process and "weak" in some other part. We call this an "implicit" strength/weakness issue because the character exhibited by a process is not particularly clear at first glance nor necessarily constant. Driving force limitations (Guideline 1), for example, come about after a certain extent of separation has taken place. It is not so much a matter of the process itself as it is the objective of the processing. Guideline 1 is illustrated in Case Study 1 with the 1-mol carrier concentration. Here, the membrane does a fine job until the very end of the separation where there is virtually no driving force left, and capital costs sky rocket. In combination with the distillation column, however, the driving force limitation is removed. Also, in Case Study 3, the reverse osmosis membrane is used as far as it can go, given the osmotic pressure of the solution, and evaporation comes in to finish the separation.

Guidelines 2 and 3 draw attention to possibilities for change inside the process scheme. In Guideline 2, we point out that changes in selectivity will affect dramatically the choice of technology. Any azeotropic distillation is an example of this situation, and a membrane hybrid is likely, as has been demonstrated commercially for ethanol/water and isopropanol/water separations. In Case Study 1, we use a facilizated transport membrane with an effective selectiviîy of 60 at the distillation feed conditions and 250 with $5 \%$ propylene product (actual base case hybrid calculation). The membrane selectivity increased with decreasing propylene concentration, showing that the membrane is likely to perform well at the bottom of the distillation column. 
Guideline 3 is an appeal always to so the least work and that doing the least work may mean working on one component at the beginning of a separation and another component at the end. For example, in Case Study 2, the best hybrid system relied on this principle (HYB-2). The feed gas with $20 \% \mathrm{~N}_{2}$ was fed first to the nitrogen-selective membrane. The permeate was nitrogen-rich, and this stream was fed to a PSA unit that acted on the new minor component, $\mathrm{CH}_{4}$.

Finally, Guideline 5 brings out the point that a hybrid is not likely to be successful when further processing is required on both the residue and the permeate streams coming from the membrane. We include this guideline in the "implicit" category because, going back to the strength and weakness theme, the strength and weakness exists in the one technology, namely, the membrane. Here, if the membrane is totally weak (no final purity in either stream), a nonmembrane technology by itself is required. If the membrane is totally strong (final purity in both streams), the membrane by itself will do. If the membrane makes only one satisfactory stream, a hybrid is likely. Case Study 1 is an example where propane product is made by the membrane, and a hybrid is superior. However, one recycle stream is required (the permeate purity was not product quality). Case Study 4 is an example where the incomplete membrane separation gives a permeate and a residue that must both be processed further, and it is difficult to justify a hybrid.

\section{RATIONALE OF QUANTITATIVE GUIDELINES}

Quantitative guideline 1 is a direct strength/weakness comparison; the other is probably the most subtle of all our guidelines but summarizes the essence of our implicit strength/weakness comparisons in a very neat package.

The terms we have used in quantitative guideline 1 are defined below:

$$
\begin{gathered}
\mathrm{A}_{\text {sep }}=\mathrm{A}_{\text {util }} / \mathrm{A}_{\text {proc }} \\
\mathrm{CC}_{\text {sep }}=\frac{\text { Capital cost }}{\mathrm{A}_{\text {proc }}}\left(\frac{\$}{\mathrm{Btu} / \mathrm{hr}}\right)
\end{gathered}
$$

These terms are a measure of the energy required and the capital investment required to accomplish a given separation. The term $A_{\text {sep }}$ is like the inverse of thermodynamic efficiency, and we therefore expect it to be greater than 1 (no utilities are used for some membrane processes, however, and $\mathrm{A}_{\text {sep }}$ is zero in such cases). The te $\mathrm{m} \mathrm{CC}_{\text {sep }}$ gives an intuitive feel for the capital required for a given amount of separative work. 
Table VIII-2 gives the values of $\mathrm{A}_{\mathrm{scp}}$ and $\mathrm{CC}_{\mathrm{sep}}$ for all membrane and traditional unit operations studied in Chapters IV through VII. Also listed in this table is whether, in the base case, a membrane, hybrid, or nonmembrane process was the process of choice. The analysis of just the base cases tells us that (1) membranes do not generally overcome a capital penalty with an energy advantage and (2) the energy advantage of a membrane must be substantial to overcome a capital cost penalty. Our study of all of our sensitivity calculations led us to conclude that the membrane must conserve only about one-third of the energy of the traditional process for the hybrid process to be superior. This conclusion gives us the criterion $A_{\text {sep }}$ (membrane) $<1 / 3 A_{\text {sep }}$ (nonmembrane) in quantitative guideline 1. If at the same time, we had a less expensive membrane capital cost, the membrane alone would be the process wice (as in Case Studies 1 and 2). For a hybrid, we need $\mathrm{CC}_{\text {sep }}$ (membrane) $>\mathrm{CC}_{\text {sep }}$ (nonmembrane); hence, quantitative guideline 1 .

To understand quantitative guideline 2 , we return to the concept of "thermodynamic extent of separation," $\phi$. This term can help us quantify when there is a shift from strength to weakness during a separation and, therefore, when it is likely that a hybrid will be the process of choice.

It is valuable to perfor:n the thought experiment of conducting a separation and stopping at any number of points along the way. At any point, the value of $\phi$ varies from zero to 1 . The efficiency of a process also varies along the way. It is sensible to speak of the efficiency, EFF, as being a function of $\phi(\operatorname{EFF}(\phi))$. We can imagine conducting the separation with any number of technologies, for example, membrane and nonmembrane technologies. In general, the efficiency of conducting a given extent of separation will vary with the technologies chosen. Hence

$$
\operatorname{EFF}_{\mathrm{m}}(\phi) \neq \operatorname{EFF}_{\mathrm{T}}(\phi)
$$

where the subscript $m$ denotes a membrane process and the subscript $T$ denotes a traditional process.

We are interested in whether these two efficiencies, $\mathrm{EFF}_{\mathrm{m}}$ and $\mathrm{EFF}_{\mathrm{T}}$, are significantly different from each other. Hence we define

$$
g(\phi)=\left|\operatorname{EFF}_{\mathrm{m}}(\phi)-\operatorname{EFF}_{\mathrm{T}}(\phi)\right|
$$

where we have used the absolute value sign so that $g(\phi)$ is always positive. To illustrate this function, Figure VIII-1 shows two sets of EFF results from Case Study 1; Figure VIII-1a shows the results for distillation and the base case membrane containing $2 \mathrm{~mol} \mathrm{Ag}{ }^{+}$, and Figure VIII-1b shows 
Table VIII-2

ENERGY CONSUMPTION AND CAPITAL COSTS FOR MEMBRANE AND TRADITIONAL UNIT OPERATIONS

\begin{tabular}{|c|c|c|c|}
\hline Process & Asep & $\begin{array}{c}C_{8 \text { ep }} \\
\text { (s/BIU/hr) }\end{array}$ & $\begin{array}{l}\text { Process of } \\
\text { Cholce in } \\
\text { Base Case }\end{array}$ \\
\hline \multicolumn{4}{|l|}{$\mathrm{C}_{3}$ separation } \\
\hline Membrane & $4-5$ & $3-6$ & Membrane only \\
\hline Distillation & $15-60$ & $10-60$ & \\
\hline \multicolumn{4}{|l|}{$\mathrm{N}_{2} / \mathrm{CH}_{4}$ separation } \\
\hline Membrane & $0-30$ & $8-35$ & Membrane only \\
\hline PSA & $10-50$ & $15-40$ & \\
\hline \multicolumn{4}{|l|}{ KBL concentration } \\
\hline Membrane (RO) & $7 \cdot 19$ & $2 \cdot 5$ & Evaporation only \\
\hline Freeze concentration & $5-9$ & $4-8$ & \\
\hline Evaporation & $7-9$ & $0.5-1$ & \\
\hline \multicolumn{4}{|l|}{ Solvent deasphalting } \\
\hline Membrane (UF) & $3-6$ & $3-12$ & Hybrid \\
\hline Flash expansion & $15-50$ & $2 \cdot 5$ & \\
\hline
\end{tabular}



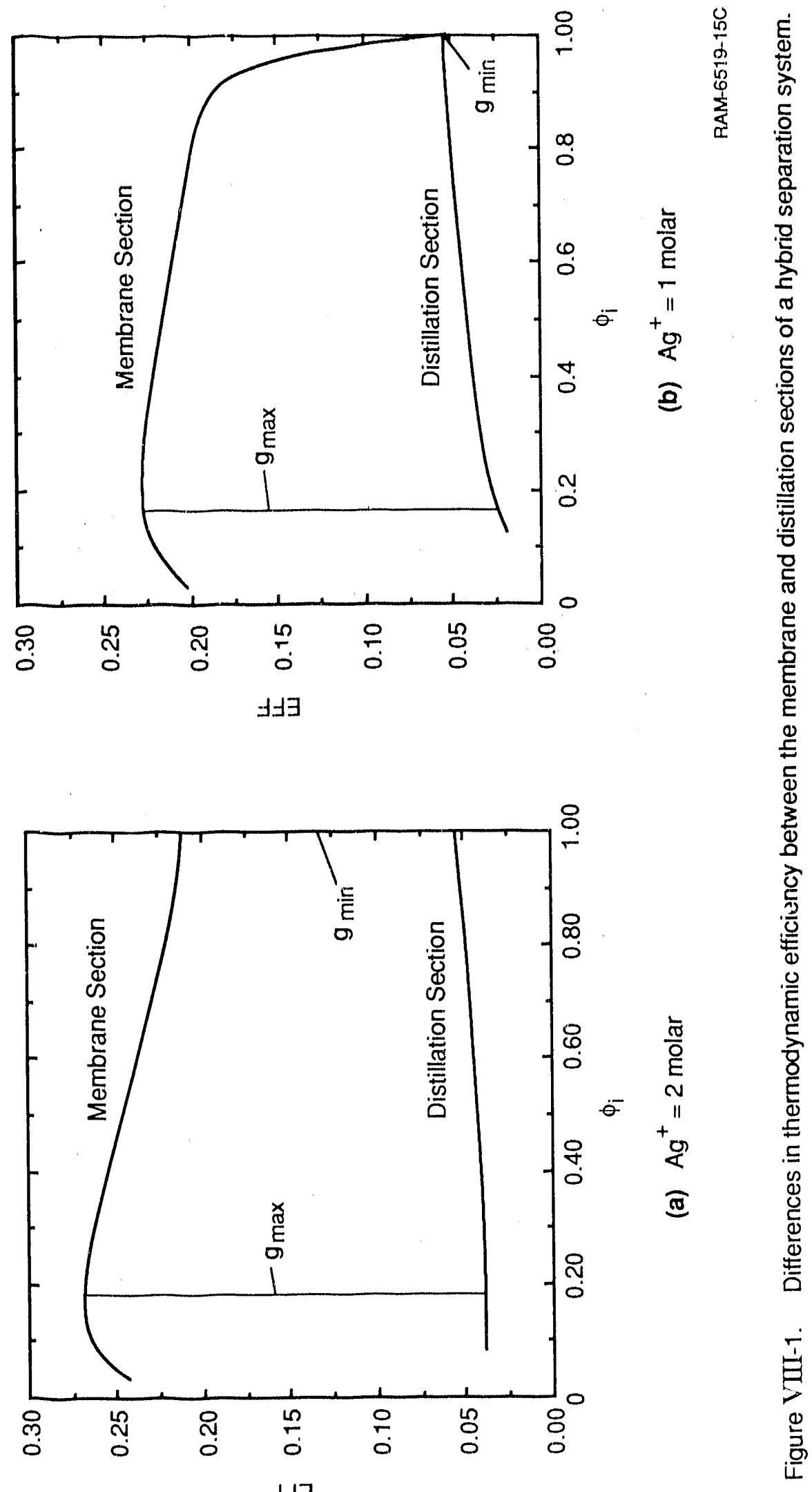

VIII-9 
results for distillation plus the more practical membrane containing $1 \mathrm{~mol} \mathrm{Ag}^{+}$. In Figure VIII-1a, $\mathrm{g}(\phi)$ ranges from a maximum of 0.23 at $\phi$ equal to 0.19 to a minimum of 0.16 at $\phi$ equal to 1.0 ; in Figure VIII-1b, $\mathrm{g}(\phi)$ ranges from 0.20 to 0.0 .

Some thought about this function $\mathrm{g}(\phi)$ is worthwhile. If $\mathrm{g}(\phi)$ is constant, it means that one process or the other is always more efficient. We would immediately conclude that a hybrid is not likely. Therefore, for a hybrid to be likely, we need some change in $g(\phi)$ over the course of the separation. To quantify "some change" we define

$$
\mathrm{G}=\frac{\mathrm{g}_{\max }-\mathrm{g}_{\min }}{\mathrm{EFF}_{\mathrm{avg}}}
$$

where $\mathrm{EFF}_{\mathrm{avg}}$ is the average value for $\mathrm{EFF}$ at $\phi$ equal to $1 / 2$ defined as

$$
\mathrm{EFF}_{\mathrm{avg}}=1 / 2\left[\mathrm{EFF}_{\mathrm{m}}(\phi=0.5)+\mathrm{EFF}_{\mathrm{T}}(\phi=0.5)\right]
$$

In Case Study 1, the values of $\mathrm{G}$ from Eqn. VIII-5 with $\mathrm{Ag}^{+}$concentrations of 1 and 2 mol are 1.54 and 0.54 , respectively. The hybrid process was the process of choice for $1 \mathrm{M} \mathrm{Ag}+$ concentration $(\mathrm{G}=1.54)$, and the membrane alone was the process of choice for $2 \mathrm{M} \mathrm{Ag}+$ concentration $(\mathrm{G}=0.54)$. Further, in Case 3B (reverse osmosis with evaporation), evaporation alone was the process of choice, and the computed value of $G$ is 0.8 . The quantity $G$ therefore captures our notion of "significant" change in efficiency over the course of a separation, and we conclude that $G$ $>1$ leads to a hybrid, whereas $\mathrm{G}<1$ leads to one technology alone as the process of choice. 


\section{CHAPTER IX}

\section{RECOMMENDATIONS FOR EXPERIMENTAL STUDIES}

The last part of this project was to recommend to the Department of Energy hybrid process applications for experimental investigation. These applications include the case studies evaluated as part of this project and any other separation applications that are likely to (1) be economically favored over alternative technologies, (2) be accepted by the commercial sector, (3) result in sizable energy savings (preferably $>10^{13} \mathrm{Btu} / \mathrm{yr}$ if implemented by $50 \%$ of the commercial sector), and (4) be in need of government research support. The decision process leading to our recommendations included answering four questions:

Is a hybrid process likely to be the process of choice under practical operating conditions? (Use guidelines from the previous chapter.)

Are $30 \times 10^{12} \mathrm{Btu} / \mathrm{yr}$ of energy consumed in the traditional process today?

Is the commercial sector likely to accept the hybrid system?

Is there a need for government support?

The second question, regarding the energy consumption hurdle, is based on the guideline that for a hybrid to be successful, the hybrid system must use less than one-third the energy of the corresponding traditional technology (quantitative guideline 1). Thus, if half the commercial sector implements the hybrid process, one-third of the energy consumed today by the traditional process will be saved. Thus, the traditional process must use at least $3 \cdot 10^{13} \mathrm{Btu} / \mathrm{yr}$ for the hybrid to result in an energy savings of $10^{13} \mathrm{Btu} / \mathrm{yr}$, the desired energy savings hurdle.

It is instructive to estimate the minimum amount of a material that must be produced domestically for the energy hurdle to be satisfied. The following relationship applies

$$
M_{a}=E_{h} / X / E_{c}
$$

where

$M_{a}=$ minimum quantity of product made to satisfy energy hurdle (lb/yr)

$\mathrm{E}_{\mathrm{h}}=$ energy hurdle (Btu/yr)

$\mathrm{X}=$ the fraction of energy consumed that would be saved by using a hybrid

$E_{C}=$ energy consumed per unit mass of product $(B t u / b)$ 
We will assume that $X$ has a value of $0.25, E_{c}$ is $4000 \mathrm{Btu} / \mathrm{lb}$, and $\mathrm{E}_{\mathrm{h}}$ is $10^{13} \mathrm{Btu} / \mathrm{yr}$ (realistic estimate for $\mathrm{X}$, high estimate for $\mathrm{E}_{\mathrm{c}}$ ). With these assurnptions, there must be at least 1 billion pounds of a product produced every year. Hence, only 50 to 100 products are worth considering (Table IX-1). We examined the top 50 chemicals produced in the United States and considered several generic processes that are used throughout the chemical industry (i.e., steam stripping of sour water). We put forward 10 systems that we recommend to DOE as worthy of more detailed studies; these systems are listed in Table IX-2 in order of highest to lowest priority. These applications are described in detail below.

\section{PROPANE/PROPYLENE SEPARATION}

Description. This application was described in detail in Chapter IV. The membrane is placed at the bottom of the column producing a propane stream of the desired purity plus a propylene-enriched stream which is recycled to the distillation column (Figure IX-1).

\section{Is the hybrid likely to be the process of choice?}

Yes. It is likely to be accepted because it results in a significant reduction in operating and capital costs.

It is probable, at least initially, that a membrane would be incorporated as a retrofit rather than as an original installation.

\section{Are $10^{13}$ Btu/yr of energy saved?}

Energy consumed

U.S. production

Total energy consumption

Reduction ic. energy consumption with hybrid

Portion of industry using hybrid

Total energy saved with hybrid
$2600 \mathrm{Btu} / \mathrm{lb}$ of propylene

20.2 billion pounds (1989)

$53 \times 10^{12} \mathrm{Btu} / \mathrm{yr}$

$50 \%$

$50 \%$

$1.3 \cdot 10^{13}$ Btu/yr

\section{Likelihood of acce tance by commercial sector?}

Very high. Alternatives to traditional distillation have been examined by a number of producers including Amoco, Union Carbide, Exxon, and Shell.

\section{Need for government research support?}

Yes. The existing processes are cash makers and, thus, there is a high risk to making any changes to the current process. A hybrid technology will need to be proved before industry will risk incorporating it. 
Table IX-1

TOP 50 CHEMICALS PRODUCED IN THE UNITED STATES IN 1989

\begin{tabular}{|c|c|c|c|}
\hline Chemical & Blllions of Pounds & Chemical & Blllions of Pounds \\
\hline Sulfuric acid & 88.80 & Ethylene glycol & 5.50 \\
\hline Nitrogen & 53.77 & p-Xylene & 5.49 \\
\hline Oxygen & 37.75 & Ethylene oxide & 5.32 \\
\hline Ethylene & 34.95 & Hydrochloric acid & 5.26 \\
\hline Ammonia & 33.76 & Methyl tert-butyl ether & 4.98 \\
\hline Lime & 32.99 & Ammonium sulfate & $4.7^{\circ}$ \\
\hline Phosphoric acid & 23.12 & Cumene & $4.5+$ \\
\hline Chlorine & 22.32 & Phenol & 3.89 \\
\hline Sotium hydioxide & 22.15 & Acetic acid & 3.83 \\
\hline Propylene & 20.23 & Potash & 3.35 \\
\hline Sodium carbrinate & 19.79 & Propylene oxide & 3.2 \\
\hline Nitric acid & 15.98 & Butadiene & 3.09 \\
\hline Urea & 15.47 & Carbon black & 2.91 \\
\hline Ammonium nitrate & 15.11 & Acrylonitrile & 2.61 \\
\hline Etinylene dichloride & 13.68 & Acetone & 2.50 \\
\hline Benzene & 11.67 & Vinyl acetate & 2.47 \\
\hline Carbon dioxide & 10.83 & Cyclohexane & 2.39 \\
\hline Vinyl chloride & 9.62 & Aluminum sulfate & 2.35 \\
\hline Ethylbenzene & 9.22 & Titanium dioxide & 2.22 \\
\hline Terephthalic acid & 8.31 & Calcium chloride & 1.92 \\
\hline Styrene & 8.13 & Sodium silicate & 1.75 \\
\hline Methanol & 7.14 & Adipic acid & 1.64 \\
\hline Formaldehyde & 6.37 & Sodium sulfate & 1.60 \\
\hline Toluene & 5.8 & Isopropyl alcohol & 1.43 \\
\hline \multirow[t]{2}{*}{ Xylene } & 5.80 & Caprolactam & 1.31 \\
\hline & $\begin{array}{l}\text { Total organics } \\
\text { Total Inorganics } \\
\text { Grand total }\end{array}$ & $\begin{array}{l}210.61 \\
400.44 \\
611.04\end{array}$ & \\
\hline
\end{tabular}


Table IX-2

SYSTEMS RECOMMENDED FOR EXPERIMENTAL STUDY

\section{System}

1) Propane/propylene separation

2) Ethane/ethylene separation

3) Sour water stripping

4) Inorganic acid dehydration

5) Natural gas dehydration

6) Deasphalting of oil

7) Acetic acid dehydration

8) Ammonia manufacturing

9) Methyl tertiary-butyl ether manufacture

10) Urea manufacture
Potentlal Energy Saving
$\left(10^{12}\right.$ Btu/yr $)$

13

6

6

5

$10-20$

10

3

2

$1-2$

$1-2$

IX -4 


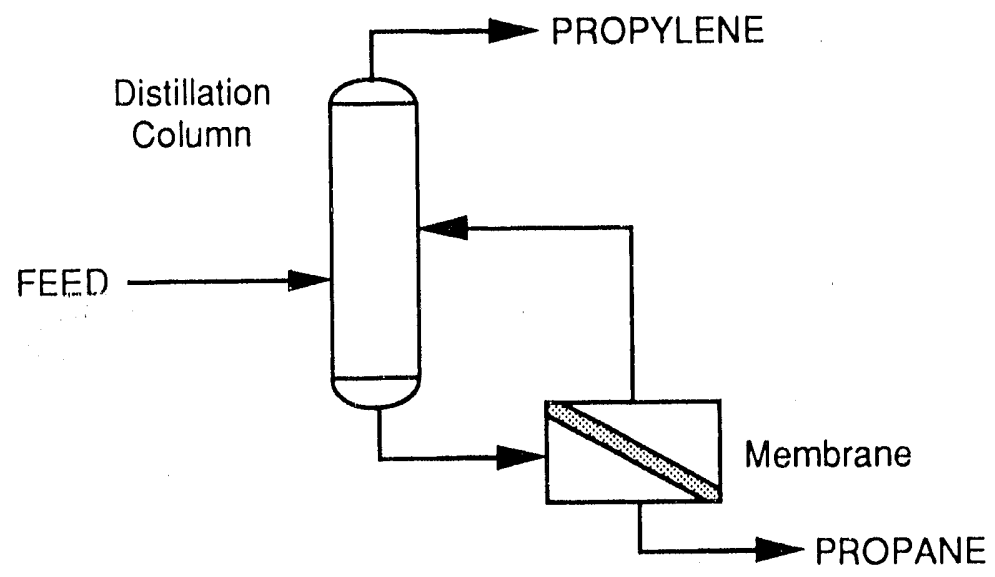

RAM-6519-12C

Figure IX-1. Hybrid configuration for propylene separation.

IX -5 


\section{ETHANE/ETHYLENE SEPARATION}

Description. This application is a variation of the propane/propylene application.

\section{Is the hybrid likely to be the process of choice?}

Yes: It is likely to be accepted because, like propylene/propane separation, the distillation is difficult and expensive. The distillation column is approximately 240 feet tall and 15 feet in diameter, the relative volatility is 1.75 .

\section{Are $10^{13}$ Btu/yr of energy saved?}

Energy consumed

U.S. production

Total energy consumption

Reduction in energy consumption with hybrid

Portion of industry using hybrid:

Total energy saved with hybrid
$700 \mathrm{Fiu} / \mathrm{ib}$ of ethylene 35.0 billion pounds (1989) $24 \times 10^{12} \mathrm{Btu} / \mathrm{yr}$ $50 \%$

$50 \%$

\section{Likelihood of acceptance by commercial sector?}

Very high. Alternatives to traditional distillation have been examined by a number of producers including Amoco, Union Carbide, Exxon, and Shell.

\section{Need for government research support?}

Yes. The existing processes are cash makers and, thus, there is a high risk to making any changes to the current process. Materials must be developed for low temperature operation. A hybrid technology will need to be proved before industry will risk incorporating it.

\section{SOUR WATER STRIPPING}

Description. Removal of $\mathrm{NH}_{3}$ and $\mathrm{H}_{2} \mathrm{~S}$ from stripping steam with membrane/stripper hybrid so steam can be reused (Figure IX-2).

\section{Is the hybrid likely to be the process of choice?}

Yes. The membrane is unlikely to be capable of performing separation on its own. Complete removal of $\mathrm{NH}_{3}$ and $\mathrm{H}_{2} \mathrm{~S}$ is not necessary if the steam is reused. This low purity specification is encouraging to the use of membranes. If different membranes selective for $\mathrm{NH}_{3}$ and $\mathrm{H}_{2} \mathrm{~S}$ individually are developed, the hybrid can be used to recover an $\mathrm{NH}_{3}$ byproduct. 


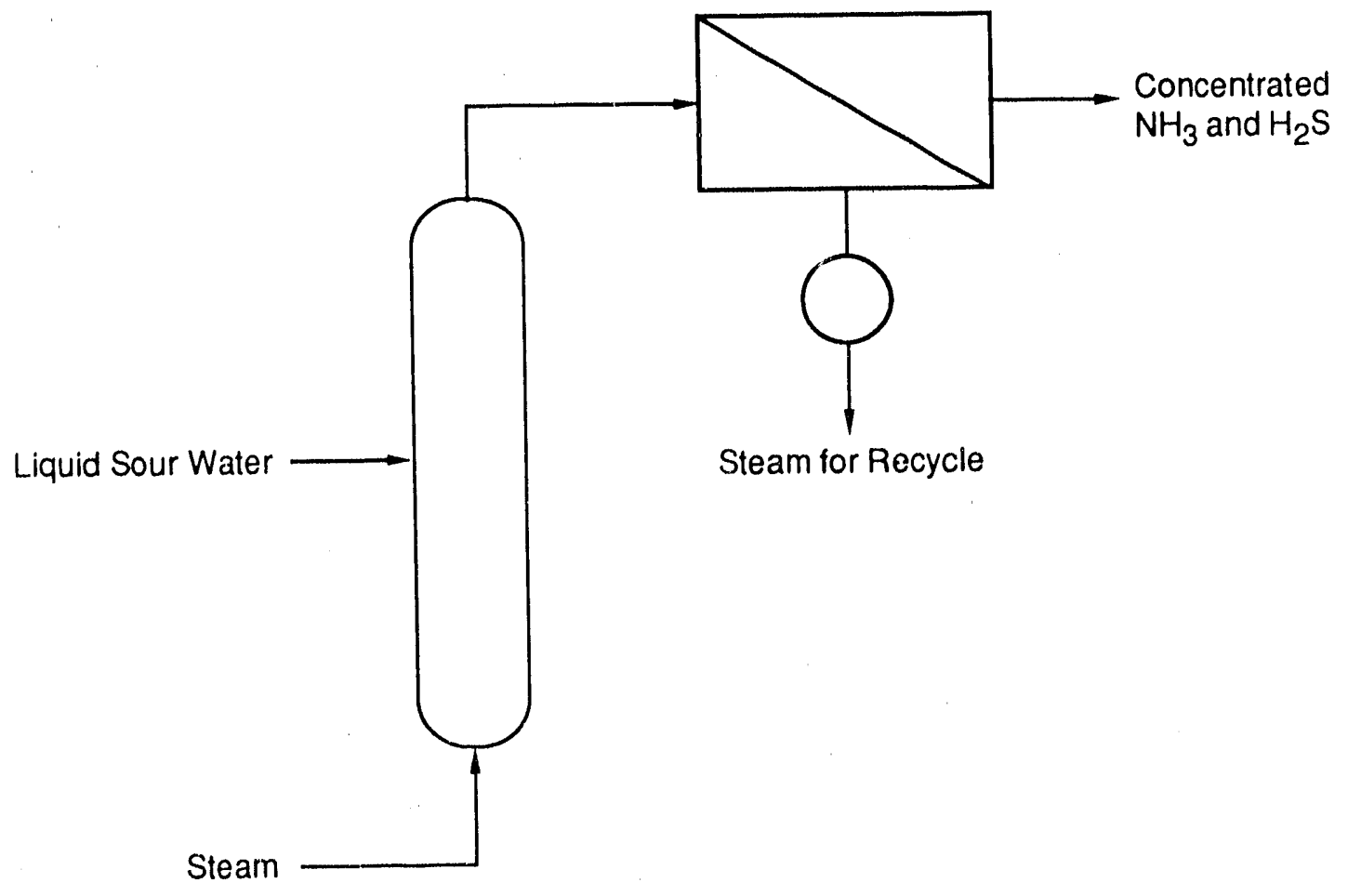

RA-M-5310-4A

Figure IX-2. Membrane-assisted recovery of $\mathrm{NH}_{3}$ and $\mathrm{H}_{2} \mathrm{~S}$ from sour water. 
Are $10^{13} \mathrm{Btu} / \mathrm{yr}$ of energy saved?

Energy consumed

U.S. production

Tota! energy contisisintion

Reduction in ertegy consumption with hybrid

Portion of indu try using hybrid:

Total energy saved with hybrid

NA

NA

$24 \times 10^{12} \mathrm{Btu} / \mathrm{yr}$

$50 \%$

$50 \%$

$6 \cdot 10^{12} \mathrm{Btu} / \mathrm{yr}$

\section{Likelihood of acceptance by commercial sector?}

Good.

Need for government research support?

Yes. Industry is very familiar with steam stripping technology, and a new technology will need to be proved for it to be accepted.

\section{INORGANIC ACID DEHYDRATION}

Description. Dehydration of acids (in phosphoric acid manufacture and regeneration of spent sulfuric acid in a variety of industries) by reverse osmosis/ evaporation hybrid. This system would be similar to that used in Chapter V for concentration of KBL; RO would be used for the initial concentration step followed by evaporation.

\section{Is the hybrid likely to be the process of choice?}

Yes. The membrane is unlikely to achieve high concentrations on its own (driving force limitations because of high osmotic pressure of concentrated solutions).

Membranes have the advantage of avoiding phase changes. (This reduces the amount of capital equipment constructed of expensive, acid-tolerant materials.)

\section{Are $10^{1 ?}$ Btu/yr of energy saved?}

Energy consumed

U.S. production

Total energy consumption

Reduction in energy consumption with hybrid

Portion of industry using hybrid

Total energy saved with hybrid
NA

NA

$20-25 \times 10^{12} \mathrm{Btu} / \mathrm{yr}$

$50 \%$

$50 \%$

$5 \cdot 10^{12} \mathrm{Btu} / \mathrm{yr}$ 


\section{Likelihood of acceptance by commercial sector?}

Good. These are cost-sensitive commodity chemicals; a small reduction in manufacturing costs can lead to an increased market share. However, suitable membrane materials must be found with high tolerance to acids.

\section{Need for government research support?}

Yes. The difficulty in finding $\mathrm{pH}-$, temperature-, and pressure-resistant membranes materials is great.

\section{NATURAL GAS DEHYDRATION}

Description. Removal of water vapor from natural gas by membrane/absorption or adsorption hybrid. The membrane can be used for the initial water removal, and either absorption or adsorption systems could be used for final dehydration. The membrane permeate can be either recompressed (condensing out water) and recycled or used as fuel for regeneration of the nonmembrane technology (Figures IX-3 and IX-4).

Is the hybrid likely to be the process of choice?

Yes. The membrane properties are good until the final stages of water removal (driving force limitations); thus, final dehydration by another technology is necessary.

\section{BAre there $10^{13} \mathrm{Btu} / \mathrm{yr}$ of energy saved?}

Energy consumed

U.S. production

Total energy consumption

Reduction in energy consumption with hybrid

Portion of industry using hybrid:

Total energy saved with hybrid

\author{
NA \\ $\mathrm{NA}$ \\ $80 \times 10^{12} \mathrm{Btu} / \mathrm{yr}$ \\ $50 \%$ \\ $50 \%$ \\ $1 \cdot 10^{13}-2 \cdot 10^{13} \mathrm{Btu} / \mathrm{yr}$
}

\section{Likelihood of acceptance by commercial sector?}

Moderate. Glycol absorption is a well developed, technically adequate technology. Addition of a second step may be considered undesirable, particularly at remote sites.

\section{Need for government research support?}

Moderate. This technology is being actively considered today. 


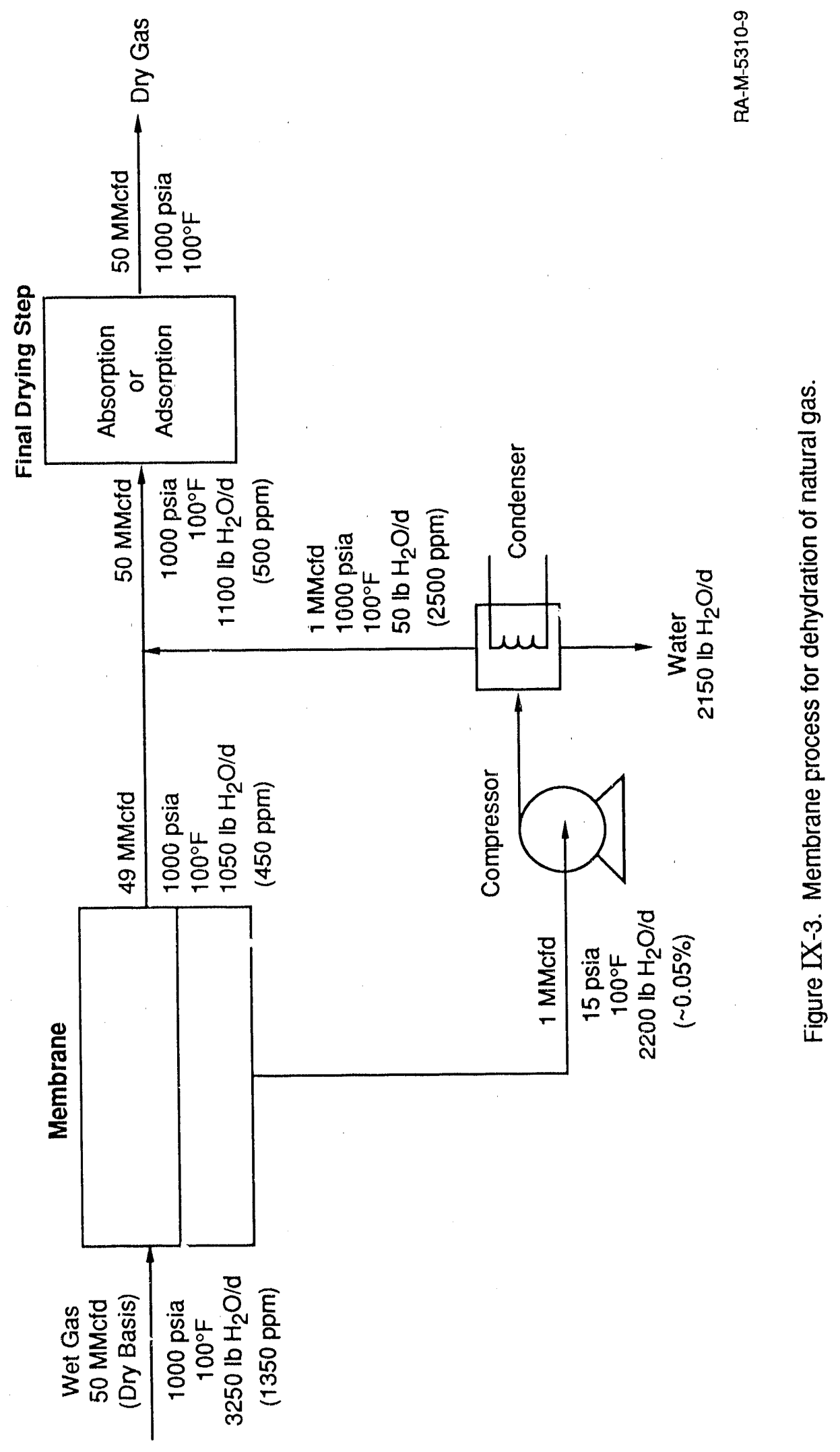




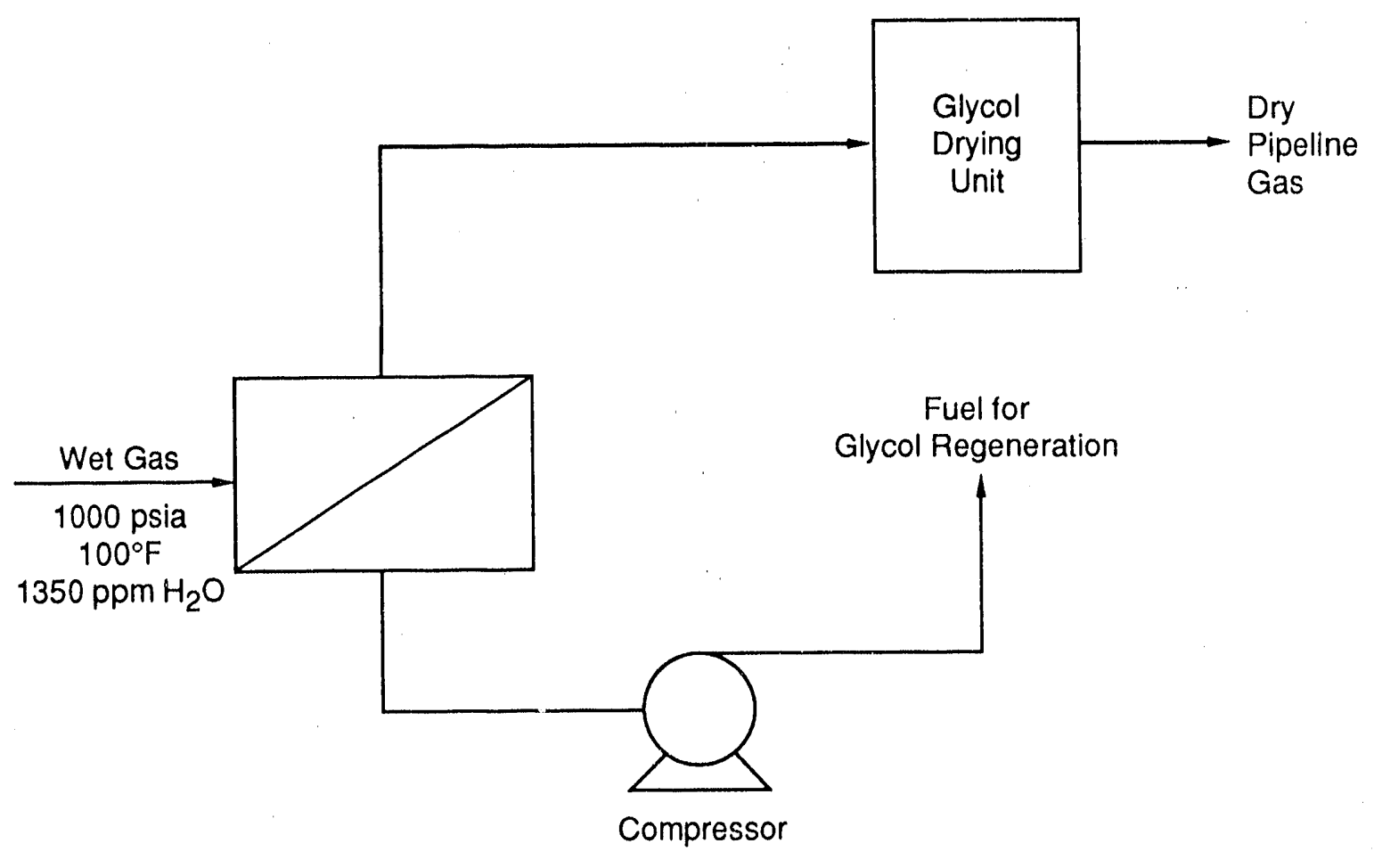

RA-M-5310-36

Figure IX-4. Membrane-assisted glycol dehydration plant.

The permeate stream could be used in fire the glycol regeneration section.

IX-11 


\section{SOLVENT DEASPHALTING}

Description. Uses UF/flash expansion hybrid to separate DAO from extraction solvent in petroleum residue refining. This process was discussed in detail in Chapter VII.

\section{Is the hybrid likely to be the process of choice?}

Yes. Hybrids show favorable energy savings (avoid phase change) and cost reductions over traditional technology. Membranes cannot do entire separation on their own because of the high viscosity of concentrated DAO.

\section{Are $10^{13}$ Btu/yr of energy saved?}

Energy consumed

U.S. production

Total energy consumption

Reduction in energy consumption with hybrid

Portion of industry using hybrid

Total energy saved with hybrid

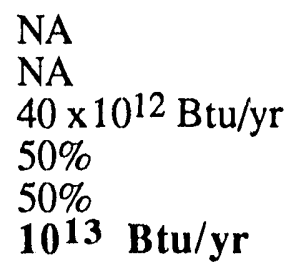

Likelihood of acceptance by commercial sector?

Moderate with present-day membranes, high with improved membranes.

\section{Need for government research support?}

High. Previous DOE research has not solved fouling issue; possible need for chemically resistant materials.

\section{ACETIC ACID DEHYDRATION}

Description. Uses pervaporation/distillation hybrid for dehydration in acetic acid manufacture. Distillation col be used to achieve $~ 90 \%$ acetic acid, and membranes would be used to achieve final purity ( igure IX-5).

\section{Is the hybrid likely to be the process of choice?}

Yes. Distillation works well until acetic acid concentration reaches $90 \%$ (variation in relative volatility.)

Membrane is unlikely to achieve desired separation on its own.

Distillation is capital and energy intensive. 


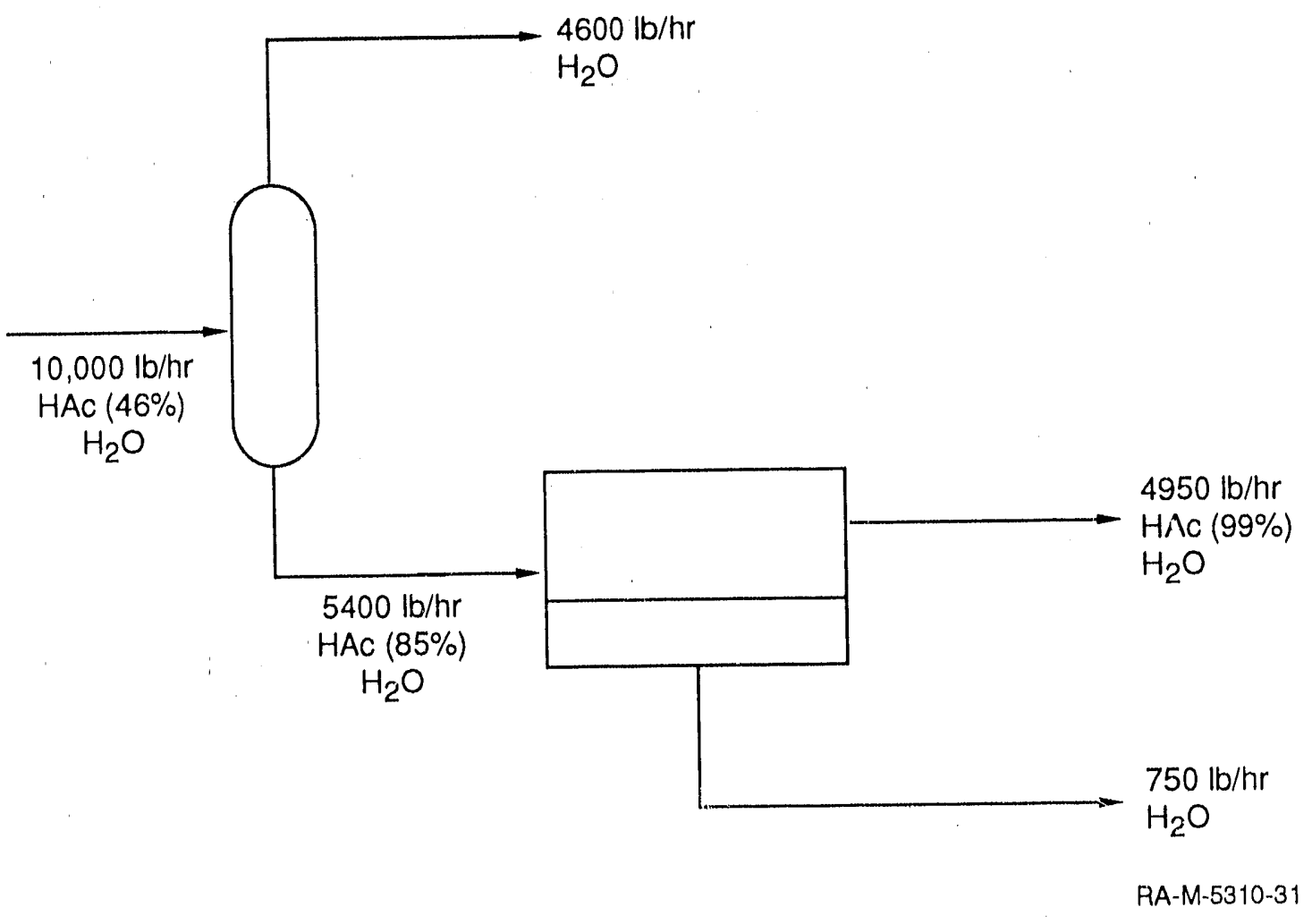

Figure IX-5. Hybrid process for dehydration of acetic acid.

IX-13 
Are $10^{13} \mathrm{Btu} / \mathrm{yr}$ of energy saved?

Energy consumed

U.S. production

Total energy consumption

Reduction in energy consumption with hybrid

Portion of industry using hybrid

Total energy saved with hybrid
NA

NA

$10 \times 10^{12} \mathrm{Btu} / \mathrm{yr}$

$50 \%$

$50 \%$

$3 \cdot 10^{12} \mathrm{Btu} / \mathrm{yr}$

Likelihood of acceptance by commercial sector?

Good.

Need for government research support?

High. Need membranes resistant to concentrated acetic acid.

\section{AMMONIA MANUFACTURE}

Description. Membrane/condensation hybrid could be used to remove impurities from high pressure raw ammonia stream.

Is the hybrid likely to be the process of choice?

Yes. Membrane efficiently makes use of energy in feed gas.

Are $10^{13}$ Btu/yr of energy saved?

Energy consumed

U.S. production

Total energy consumption

Reduction in energy consumption with hybrid

Portion of industry using hybrid

Total energy saved with hybrid

$$
350
$$

33.8 (1989)

$12 \times 10^{12} \mathrm{Btu} / \mathrm{yr}$

$33 \%$

$50 \%$

$2 \cdot 10^{12} \mathrm{Btu} / \mathrm{yr}$

\section{Likelihood of acceptance by commercial sector?}

Good. Ammonia is a cost-driven chemical, so reductions in manufacturing costs can lead to increased market share.

\section{Need for government research support?}

Yes. Existing processes are cash makers with a high reluctance to make risky changes; improved technologies need to be proved before industry is likely to accept them. 


\section{METHYL TERTIARY-BUTYL ETHER MANUFACTURE}

Description. The traditional process uses distillation to separate MTBE from methanol. Although high MTBE purity can be reached with distillation, the methanol leaving the top of the column contains substantial MTBE because of formation of an azeotrope. The methanol/MTBE stream is recycled to the reactor feed. If a membrane system (probably pervaporation) can be used to increase the purity of the methanol stream, the recycle flowrate would be reduced, decreasing the size and cost of the entire plant (Figure IX-6).

\section{Is the hybrid likely to be the process of choice?}

Yes. Distillation cannot perform a complete separation because of formation of an azeotrope (variation in relative volatility). separation.

Membrane reduces process recycle (and therefore equipment size) by completing

BAre $10^{13} \mathrm{Btu} / \mathrm{yr}$ of energy saved?

Energy consumed

U.S. production

Total energy consumption

Reduction in energy consumption with hybrid

Portion of industry using hybrid

Total energy saved with hybrid
NA

NA

$2-4 \times 10^{12} \mathrm{Btu} / \mathrm{yr}$

$33 \%$

$50 \%$

$10^{12}-2 \cdot 10^{12} \mathrm{Btu} / \mathrm{yr}$

\section{Likelihood of acceptance by commercial sector?}

Good.

\section{Need for government research support?}

Moderate. Hoechst/Celanese is developing membrane technology for this application; however, module design is difficult for pervaporation.

\section{UREA MANUFACTURE}

Description. Replace two-stage evaporation with RO/evaporation hybrid similar to KBL concentration case study.

\section{Is the hybrid likely to be the process of choice?}

Possibly. Membrane is likely to reduce energy requirement (avoid phase change). Membrane probably cannot do entire separation because of high osmotic pressure. 


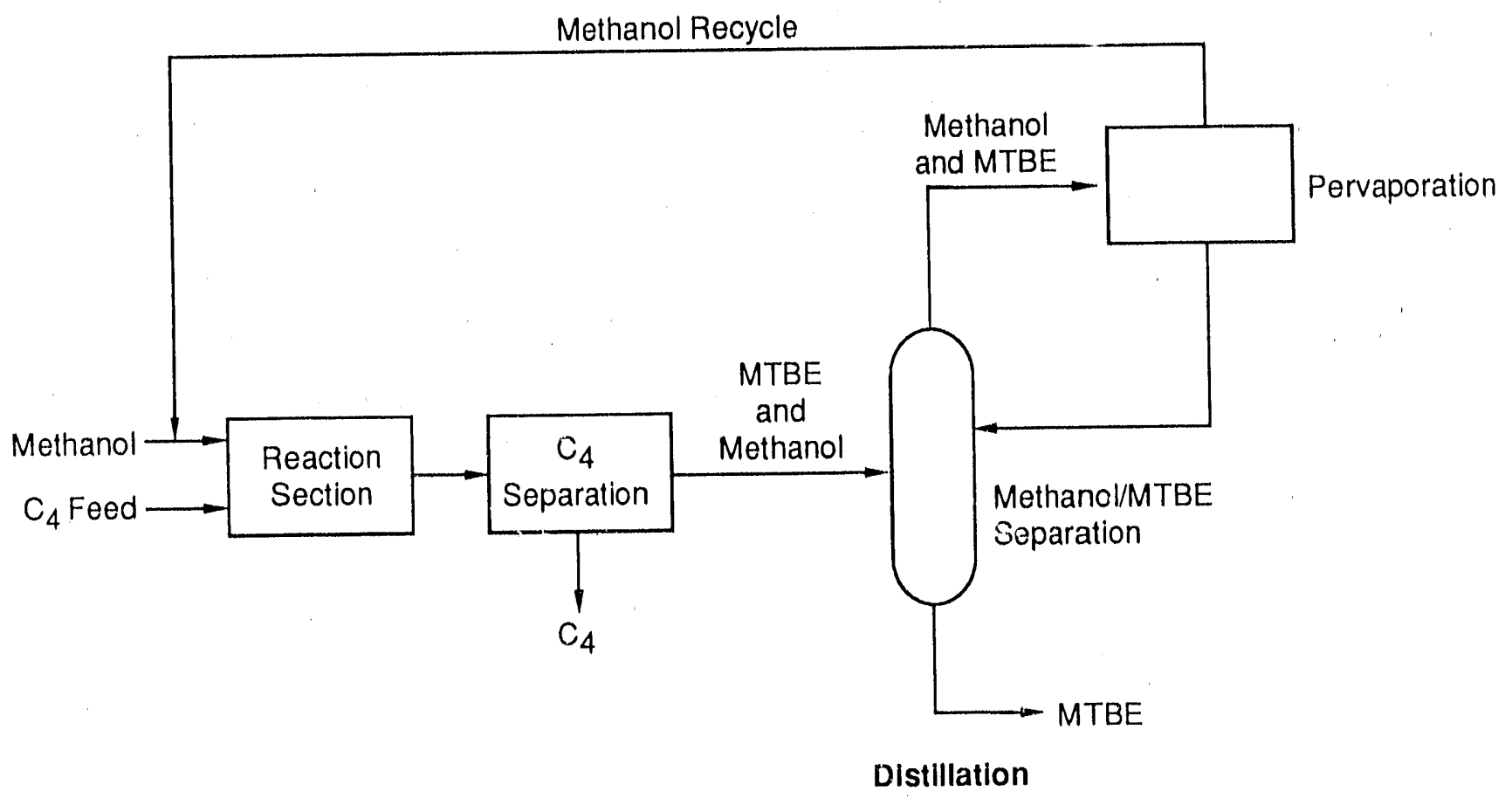

RM-6519-63

Figure IX-6. Pervaporation/distillation hybrid in the MTBE manufacturing process. 
Are $10^{13} \mathrm{Btu} / \mathrm{yr}$ of energy saved?

Energy consumed:

U.S. production:

Total energy consumption:

Reduction in energy consumption with hybrid:

Portion of industry using hybrid:

Total energy saved with hybrid:

NA

NA

$2-4 \times 10^{12} \mathrm{Btu} / \mathrm{yr}$

$33 \%$

$50 \%$

$10^{12}-2 \cdot 10^{12} \mathrm{Btu} / \mathrm{yr}$

Likelihood of acceptance by commercial sector?

Low.

Need for government research support?

Yes, if a promising membrane technology appears. 


\section{REFERENCES}

Bansal, I. K., and A. J. Wiley, "Application of Reverse Osmosis in the Pulp and Paper Industry," in Reverse Osmosis and Synthetic Membranes, National Research Council of Canada, Ottawa, Canada, (1977), pp. 459-79.

Baker, R. W., N. Yoshioka, J. M. Mohr, and A. J. Kahn, "Separation of Organic Vapors from Air," J. Membr. Sci. 31, 259-71 (1987).

Barron, T. S., J. A. Heist, K. M. Hunt, and P. J. Wrobel, "Industrial Applications of Freeze Concentration Technology," Final Report to Flectric Power Research Institute, EM-5232-1 (June 1987).

Berridge, S. A., in Modern Petroleum Technology, Fourth Edition, Hobson, G. D., and W. Pohl, Eds., (Applied Science Publishers, Ltd., Great Britain, 1973), pp. 422-423.

Billon, A., J. P. Peries, E. Fehr, and E. Lorenz, "SDA Key to Upgrading Heavy Crudes," Oil and Gas Journal, pp. 43-48 (January 24, 1977).

Bravo, J. L., J. R. Fair, J. L. Humphrey, C. L. Martin, A. F. Seibert, and S. Joshi, "Assessment of Potential Energy Savings in Fluid Separation Technologies: Technology Review and Recommended Research Area," U.S. Depariment of Energy Report No. DOE/LJ/12473-1 (DE85013839) (December 1984).

Coleman, T. C., "Economic Evaluation of Kraft Black Liquor Freeze Concentration for the Pulp and Paper Industry," Final Report to U.S. Department of Energy, Office of Industrial Programs, DOE/CE/40725-1 (September 1986).

Craig R. G., and D. C. Spence, "Production of Mono- and Diolefins by Catalytic

Dehydrogenation of LPG," Houdry Division Technical Report No. 100.2 available from Air Products and Chemicals, Inc., Allentown, PA (1988).

Denbigh, K., The Principles of Chemical Equilibrium with Applications in Ch.emistry and Chemical Engineering (Cambriage University Press, London, England, 1971).

Fricke, A. L., "Physical Properties of Kraft Black Liquor," Summary Raport on Phases I and II to U.S. Department of Energy, Office of Industrial Programs, DOE/CE/40606-T5 (September 1987).

Gaggioli, R. A., "Thermodynamics: Second Law Analysis," ACS Sympcsium Series No. 122, American Chemical Society, Washington, DC (1980).

Gottschlich, D. E., and D. L. Roberts, "The Use of Thermodynamics in Designing Membrane Systems for Gas Separation," Paper No. 78e presented at the March 1990 AIChE Meeting, Orlando, FL. 
Gottschlich, D. E., D. L. Roberts, and J. D. Way, "A Theoretical Comparison of Facilitated Transport and Solution-Diffusion Membrane Modules for Gas Separation," Gas Sep. Pur., 2, 65 71 (1988).

Gottschlich, D. E., D. L. Roberts, J. G. Wijmans, C.-M. Bell, and R. W. Baker, "Economic Comparison of Several Membrane Configurations for $\mathrm{H}_{2} / \mathrm{N}_{2}$ Separation," Gas Separation And Purification, 3, 170-9 (1989).

Grace, T. M., D. G. Sachs, and H. J. Grady, "Determination of the Inorganic Composition of Alkaline Black Liquors," Tappi, 60(4), 122-5 (1977).

Hayes, R. A., "Polyimide Gas Separation Membranes," U.S. Patent 4717393, January 5, 1988; assignee E.I. du Pont de Nemours and Company.

Hill, M. K., "Ultrafiltration of Kraft Black Liquor," Final Report, Phase II to U.S. Department of Energy, Office of Industrial Programs, DOE/CE/40606-T4 (September 1987).

Hughes, R. D., J. A. Mahoney, and E. F. Steigelmann, "Olefin Separation by Facilitated Transport Membranes," in Recent Developments in Separation Science, N. N. Li, J. Calo, Eds., Volume IX (CRC Press, Cleveland, OH, 1982).

Hydrocarbon Processing, "1986 Refining. Process Handbook," pp. 83-114 (September 1986).

Johnson, W. E., and C. R. Rhodes, "Freeze Crystallization Technology for Kraft Black Liquor," DOE/CS/40034-T4 (April 1985).

Jönsson, A.-S. and R. Wimmerstedt, "The Application of Membrane Technology in the Pulp and Paper Industry," Desalination, 53, 181-196 (1985).

Kim, T. H., W. J. Koros, and G. R. Husk, "Temperature Effects on Gas Permselection Properties in Hexafluoro Aromatic Polyimides," J. Memb. Sci., 46, 43-56 (1989).

King, C. J., Separation Processes, McGraw-Hill, New York, NY, 1980.

Kirkman, A. G., J. S. Gratzl, and L. L. Edwards, "Kraft Lignin Recovery by Ultrafiltration: Economic Feasibility and Impact on the Kraft Recovery System," Tappi J., pg. 110-4 (May 1986).

Koval, C. A., and T. Spontarelli, "Condensed Phase Facilitated Transport of Olefins through an Ion Exchange Membrane," J. Am. Chem. Soc., 110, 293-5 (1988).

Kulkarni, S. S., E. W. Funk, and N. N. Li, "Hydrocarbon Separations with Polymeric Membranes," presented at the National Meeting of American Institute of Chemical Engineers, Seattle, WA, August 25-28, 1985.

Larson, R. E. et al.,"The FT-30 Reverse Osmosis Membrane - Three Years Experience in a Variety of Desalting Applications," presented at the WSIA 10th Annual Conference and Trade Fair, Honolulu, Hawaii, July 25-29, 1982. 
Li, N. N., E. W. Funk, A. Chang, M. E. Childs, S. S. Kulkarni, and S. Kulprathipanja, "Membrane Separation Processes in the Petrochemical Industry, Signal UOP Research Center, Phase I," DOE Report Ivo. DOE/ID/12422-T1, NTIS Order No. DE85017030, December 15, 1984.

Li, N. N., E. W. Funk, Y. A. Chang, S. S. Kulkarni, A. X. Swamikannu, and L. S. White, "Membrane Separation Processes in the Petrochemical Industry, Phase II," DOE Report No. DOE/ID/12422-1, NTIS Order No. DE87009326, December 30, 1985.

Li, N. N., E. W. Funk, Y. A. Chang, S. S. Kulkarni, A. X. Swamikannu, and L. S. White, "Membrane Separation Processes in the Petrochemical Industry, Phase II," DOE/ID/12422-2, NTIS Order No. 90001600, September 30, 1987.

MacDonald, R. G., and J. N. Franklin, Pulp and Paper Manufacture, 2nd edition, Vol. 1, Joint Textbook Committee of the Paper Industry of the United States and Canada, Eds. (McGraw-Hill, New York, 1971).

Maples, G., and E. W. Lang, "Studies of Membrane Processes for Pulp Mill Pollution Control," presented at the AIChE Meeting, Portland, Oregon, 1980.

Meyer, H. S., D. Leppin, and J. L. Savidge, "Gas Research Institute's Gas Processing Research and Development Program," presented at the 69th Meeting of the Gas Processors' Association, Phoenix, AZ (March 13-14, 1990).

Mohr, C. M., S. A. Leeper, D. E. Engelgau, and B. L. Charboneau, "Membrane Applications and Research in Food Processing: An Assessment," DOE Report No. DOE/ID-10210, NTIS Order No. DE88016250, August, 1988.

National Petroleum Council, Enhanced Oil Recovery (June 1984).

Oleson and Associates, Inc., P.O. Box 4318, Laguna Beach, CA 92652.

Olsen, O., "Membrane Technology in the Pulp and Paper Industry," Desalination, 35, 291-302 (1980).

Peinemann, K.-V., and S. K. Shukla, "Olefin Separation by Fixed Carrier Membranes," Presented at the Third Annual Meeting of the North American Membrane Society, Austin, Texas, May 1989.

Penning, R. T., A. G. Vickers, and B. R. Shah, "Extraction Upgrades Resid," Hydrocarbon Processing, pp. 145-150 (May 1982).

Pepper, D. and J. Tingle, "Reverse Osmosis and Ultrafiltration for Energy Conservation and Pcilition Control," Pulp \& Paper Canada, 84(10), 46-8 (1983).

Roberts, D. L., "Commercial Applications of Gas Separation Membranes," World Congress III of Chemical Engineering, Tokyo, Japan (September 1986).

Sherwood, H. D., "SDA Solvents Key to Cracking Stocks," Oil and Gas Journal, pp.148-58 (March 27, 1978). 
Shindo, Y., T. Habuta, H. Yoshitome, and H. Inoue, "Calculation Methods for Multicomponent Gas Separation by Perrneation," Sep. Sci. Tech. 20, 445-59 (1985).

Spillman, R. W., Barrett, T. Cooley, "Economics of Gas Separation Membranes," Chem. Eng. Prog., pp. 41-62 (January 1989).

Sprague, S. B., "How Solvent Selection Affects Extraction Performance," presented at the Annual Meeting of the National Petroleum Refiners Association, Los Angeles, CA, March 23-25, 1986.

SRI International, Chemical Economics Handbook (Ethanol) (1985).

Sunavala, P. D., "Alternatives to the Multiple Effect Evaporator for Concentrating Black Liquor," $J$. of Scientific and Industrial Research, 45, 142-145 (1986).

Teramoto, M., H. Matsuyama, T. Yamashiro, and Y. Katayama, "Separation of Ethylene from Ethane by Supported Liquid Membranc's Containing Silver Nitrate as a Carrier," J. Chem. Eng. Japan, 19(5), 419-424 (1986).

Thermodynamics: Second Law Analysis, Gaggioli, R. A., ed., ACS Symposium Series Number 122 (American Chemical Society, Washington, DC, 1980).

Toray Industries, Inc., "PEC-1000" Literature, Tokyo, Japan.

U.S. Department of Commerce, 1982 Census of Manufacturers. Wenzl, H.F.J., Kraft Pulping Theory and Practice (Lockwood Publishing Co., Inc., New York,
1967).

Wiley, A. J., L. E. Dambruch, P. E. Parker, and H. S. Dugal, "Treatment of Bleach Plant Effluents, A Combined Reverse Osmosis/Freeze Concentration Process," Tappi, 61(12), 77-80 (1978).

Yang, R. T., Gas Separation by Adsorption Processes, (Butterworths Publishers, Stoneham, MA, 1987), Chapter 7, pp. 237-74. 
Appendix A

DETAILED PROCESS FLOW CONDITIONS AND COST BREAKDOWNS FOR CASE STUDY 1 - PROPYLENE/PROPANE SPLITTING 


\section{Table A-1}

STREAM CONDITIONS FOR PROPYLENE/PROPANE SEPARATION WITH MEMBRANE TECHNOLOGY ALONE

(Basis: 95\% propylene; 500 million Ib product per year)

\begin{tabular}{llll}
\hline \multicolumn{3}{c}{ Stream* } \\
\hline Feed & Propane & Permeate & $\begin{array}{c}\text { Compressed } \\
\text { Permeate }\end{array}$ \\
(1) & (2) & (3) & (4)
\end{tabular}

Mole Fractions

$\begin{array}{llllll}\text { Propylene } & 0.439 & 0.038 & 0.950 & 0.950 & 0.950 \\ \text { Propane } & 0.543 & 0.930 & 0.049 & 0.049 & 0.049 \\ \mathrm{C}_{4+}{ }^{-} & 0.018 & 0.032 & 0.001 & 0.001 & 0.001\end{array}$

Total flow

$(1,000 \mathrm{lb} / \mathrm{hr})$

148.6

85.1

63.5

63.5

63.5

Temperature $\left({ }^{\circ} \mathrm{F}\right)$

115

124

253

108

Pressure (psia)

250

250

14.7

250

250

Stream numbers refer to Figure IV -4 in main text. 
Table A-2

UTILITY REQUIREMENTS FOR PROPYLENE/PROPANE SEPARATION WITH MEMBRANE TECHNOLOGY ALONE

(Basis: 95\% propylene; 500 million lb product per year)

\begin{tabular}{lrrrr} 
& \multicolumn{4}{c}{ Utillity } \\
\cline { 2 - 5 } & Steam & Water & Electricity & Iotal \\
Mass flow (lb/lb product) & 0.116 & 6.49 & - & - \\
Energy flow (Btu/lb product) & 110 & -198 & 110 & - \\
$\begin{array}{c}\text { Thermal energy equivalent } \\
\text { (Btu/lb product) }\end{array}$ & 129 & - & 331 & 460
\end{tabular}

Table A-3

CAPITAL INVESTMENT FOR PROPYLENE/PROPANE

SEPARATION WITH MEMBRANE TECHNOLOGY ALONE

(Basis: 95\% propylene; 500 million ib product per year)

\section{Process Unit}

Membrane unit

(Membrane replacement $=\$ 126,000)$

Heater

Condenser

Compressor

General services

TOTAL
Installed Cost

(S1.000)

$\$ 302$

44

103

3,014

478

$\$ 4,031$ 


\section{Table A-4}

PROPYLENE/PROPANE SEPARATION WITH MEMBRANE TECHNOLOGY ALONE: ESTIMATED ANNUAL OPERATING COSTS AND REVENUE REQUIREMENTS (Basis: 95\% propylene; 500 million lb product per year)

\begin{tabular}{|c|c|c|c|}
\hline . & $\begin{array}{l}\text { Thousands } \\
\text { of Dollars } \\
\text { Per year }\end{array}$ & $\begin{array}{l}\text { Cents per } \\
\text { Pound of } \\
\text { Propxlene }\end{array}$ & $\begin{array}{l}\text { Percent } \\
\text { of Total }\end{array}$ \\
\hline $\begin{array}{l}\text { Malntenance materlals } \\
\text { Labor }\end{array}$ & 81 & 0.016 & 3.0 \\
\hline $\begin{array}{l}\text { Operating } \\
\text { Supervision } \\
\text { Maintenance } \\
\text { Benefits }\end{array}$ & $\begin{array}{r}39 \\
21 \\
101 \\
56 \\
\end{array}$ & $\begin{array}{l}0.008 \\
0.004 \\
0.020 \\
0.011\end{array}$ & $\begin{array}{l}1.4 \\
0.8 \\
3.7 \\
2.1\end{array}$ \\
\hline Total labor & 217 & 0.043 & 8.0 \\
\hline \multicolumn{4}{|l|}{ Utilities } \\
\hline $\begin{array}{l}\text { Steam } \\
\text { Electric power } \\
\text { Cooling water }\end{array}$ & $\begin{array}{r}291 \\
818 \\
\quad 30 \\
\end{array}$ & $\begin{array}{l}0.058 \\
0163 \\
0.006 \\
\end{array}$ & $\begin{array}{r}10.7 \\
30.2 \\
1.1 \\
\end{array}$ \\
\hline Total utilines & 1,139 & 0.227 & 42.0 \\
\hline \multicolumn{4}{|l|}{ Fixed costs } \\
\hline $\begin{array}{l}\text { Corporate costs } \\
\text { General and administrative expenses } \\
\text { Property taxes and insurance }\end{array}$ & $\begin{array}{r}54 \\
32 \\
101 \\
\end{array}$ & $\begin{array}{l}0.011 \\
0.006 \\
0.020 \\
\end{array}$ & $\begin{array}{l}2.0 \\
1.2 \\
3.7\end{array}$ \\
\hline Total fixed cosis & 187 & 2.037 & 6.9 \\
\hline Total operating costs & 1.624 & 2.324 & 59.9 \\
\hline Capital-related charges and income tax & 1.087 & 0.217 & 40.1 \\
\hline Total processing cost & 2,711 & 0.542 & 100.0 \\
\hline
\end{tabular}


DETAILED PROCESS FLOW CONDITIONS AND COST BREAKDOWNS FOR STANDALONE DISTILLATION SYSTEM

A-6 


\section{Table A.5 \\ STREAM CONDITIONS FOR PROPYLENE/PROPANE SEPARATION WITH DISTILLATION TECHNOLOGY ALONE \\ (Basis: 95\% propylene; 500 million lb product per year)}

\begin{tabular}{lll}
\multicolumn{3}{c}{ Stream } \\
\hline Feed & Propane & Propylene \\
(1) & (2) & (3) \\
\hline
\end{tabular}

Mole Fractions

Propylene

Propane

$\mathrm{C}_{4+}$

Total Flow $(1,000 \mathrm{lb} / \mathrm{hr})$

Temperature $\left({ }^{\circ} \mathrm{F}\right)$

Pressure (psia)
0.439

0.543

0.018

148.6

115

250
0.038

0.930

0.032

85.1

127

260
0.950

0.050

0.000

63.5

105

240

"Stream numbers refer to Figure IV-5 in main text. 
Table A. $\mathbf{6}$

UTILITY REQUIREMENTS FOR PROPYLENE/PROPANE SEPARATION WITH DISTILLATION TECHNOLOGY ALONE

(Basis: 95\% propylene; 500 million ib product per year)

\begin{tabular}{lrrrr} 
& \multicolumn{4}{c}{ Uillity } \\
\cline { 2 - 5 } & Steam & Water & Electricity & Iotal \\
Mass flow (lb/lb product) & 2.30 & 71.3 & - & - \\
Energy flow (Btu/lb product) & 2,190 & $-2,190$ & 6.30 & - \\
$\begin{array}{l}\text { Thermal energy equivalent } \\
\text { (Btu/lb product) }\end{array}$ & 3,570 & - & 19.0 & 2,580
\end{tabular}

Table A-7

CAPITAL INVESTMENT FOR PROPYLENE/PROPANE SEPARATION WITH DISTILLATION TECHNOLOGY ALONE (Basis: $95 \%$ propylene; 500 million lb product per year)

\section{Process Unit}

Distillation Unit

(and associated equipment)

General services

TOTAL

\section{Installed Cost}

$(\$ 1.000)$

$\$ 18,000$

2.300

$\$ 20,300$ 
Table A.8

PROPYLENE/PROPANE SEPARATION WITH DISTILLATION TECHNOLOGY ALONE: ESTIMATED ANNUAL OPERATING COSTS AND REVENUE REQUIREMENTS

(Basis: 95\% propylene; 500 million lb product per year)

\begin{tabular}{|c|c|c|c|}
\hline & $\begin{array}{l}\text { Thousands } \\
\text { of Dollars } \\
\text { Per year }\end{array}$ & $\begin{array}{l}\text { Cents per } \\
\text { Pound of } \\
\text { Propylene }\end{array}$ & $\begin{array}{l}\text { Percent } \\
\text { of Total }\end{array}$ \\
\hline Maintenance materlals & 406 & 0.081 & 3.0 \\
\hline \multicolumn{4}{|l|}{ Labor } \\
\hline $\begin{array}{l}\text { Operating } \\
\text { Supervision } \\
\text { Mainteriance } \\
\text { Benefits }\end{array}$ & $\begin{array}{r}39 \\
82 \\
508 \\
220 \\
\end{array}$ & $\begin{array}{l}0.008 \\
0.016 \\
0.102 \\
0.044\end{array}$ & $\begin{array}{l}0.3 \\
0.6 \\
3.7 \\
1.6\end{array}$ \\
\hline Total labor & 849 & 0.170 & 6.2 \\
\hline \multicolumn{4}{|l|}{ Utillities } \\
\hline $\begin{array}{l}\text { Steam } \\
\text { Electric power } \\
\text { Cooling water }\end{array}$ & $\begin{array}{r}5,770 \\
47 \\
324 \\
\end{array}$ & $\begin{array}{l}1.154 \\
0.009 \\
0.065 \\
\end{array}$ & $\begin{array}{r}42.4 \\
0.3 \\
2.4 \\
\end{array}$ \\
\hline Total utilities & 6,141 & 1.228 & 45.1 \\
\hline \multicolumn{4}{|l|}{ Flxed costs } \\
\hline $\begin{array}{l}\text { Corporate costs } \\
\text { General and administrative expenses } \\
\text { Property taxes and insurance }\end{array}$ & $\begin{array}{l}273 \\
126 \\
508 \\
\end{array}$ & $\begin{array}{l}0.055 \\
0.025 \\
0.102 \\
\end{array}$ & $\begin{array}{l}2.0 \\
0.9 \\
3.7 \\
\end{array}$ \\
\hline Total fixed costs & 907 & 2.181 & 6.7 \\
\hline Total operating costs & 8.303 & 1.606 & $\underline{60.9}$ \\
\hline Capital-related charges and income tax & 5.320 & 1.064 & 39.1 \\
\hline Total processing cost & 13,623 & 2.724 & 100.0 \\
\hline
\end{tabular}


MEMBRANE/DISTILLATION HYBRID SYSTEM

$$
(\phi m=0.69)
$$




\section{Table A-9}

STREAM CONDITIONS FOR PROPYLENE/PROPANE SEPARATION WITH MEMBRANE/DISTILLATION HYBRID TECHNOLOGY (Basis: $95 \%$ propylene; 500 million lb product per year)

Stream*
Feed Propylene Bottoms Permeate $\begin{gathered}\text { Compressed } \\ \text { Permeate }\end{gathered}$
(1)
(2)

Mole fractions

$\begin{array}{llllllll}\text { Propylene } & 0.439 & 0.950 & 0.317 & 0.933 & 0.933 & 0.933 & 0.038 \\ \text { Propane } & 0.543 & 0.050 & 0.661 & 0.066 & 0.066 & 0.066 & 0.930 \\ \mathrm{C}_{4+} & 0.018 & 0.000 & 0.022 & 0.001 & 0.001 & 0.001 & 0.032\end{array}$

$\begin{array}{llllllll}\text { Total flow } & 148.6 & 63.5 & 121.9 & 36.7 & 36.7 & 36.7 & 85.1\end{array}$

$(1000 \mathrm{lb} / \mathrm{hr})$

$\begin{array}{llllclll}\begin{array}{c}\text { Temperature } \\ \left({ }^{\circ} \mathrm{F}\right)\end{array} & 115 & 105 & 121 & - & 307 & 108 & 127 \\ \begin{array}{c}\text { Pressure } \\ \text { (psia) }\end{array} & 250 & 240 & 260 & 14.7 & 250 & 250 & 260\end{array}$

"Stream numbers refer to Figure IV-7 in main text. 
Table A-10

UTILITY REQUIREMENTS FOR PROPYLENE/PROPANE

SEPARATION WITH MEMBRANE TECHNOLOGY ALONE

(Basis: 95\% propylene; 500 million lb product per year)

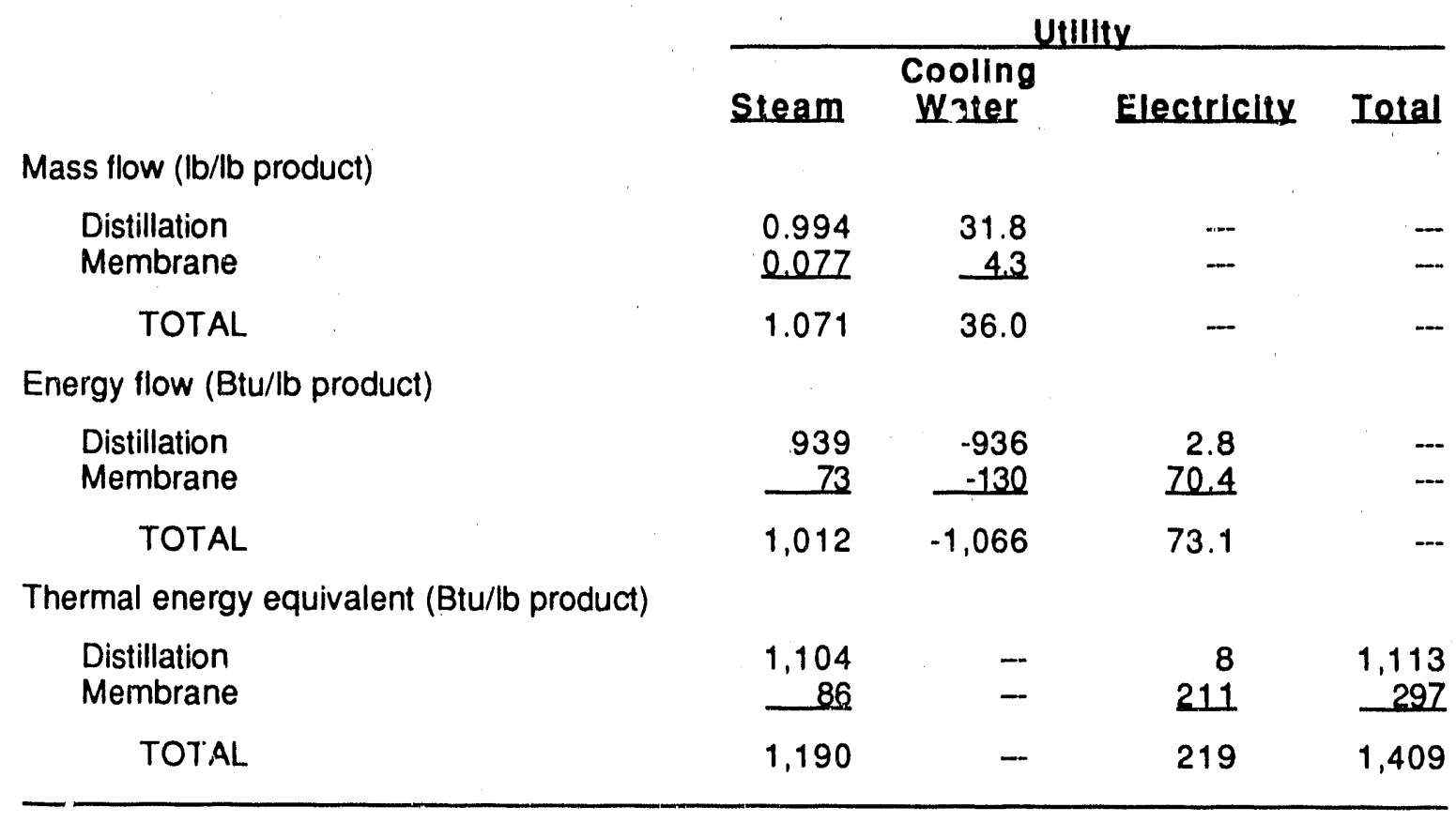




\section{Table A-11}

CAPITAL INVESTMENT FOR PROPYLENE/PROPANE SEPARATION WITH MEMBRANE/DISTILLATION HYBRID TECHNOLOGY ALONE

(Basis: 95\% propylene; 500 million lb product per year)

\section{Process Unit}

Membrane section

Membrane unit (membrane replacement $=86$ )

Heater

Condenser

Compressior

Total

Distillation column

(and associated equipment

General services

Total
Installed Cost

$(51,000)$

\$ $\quad 207$

76

2.733

$\$ 3,059$

7,712

1.394

$\$ 12,165$ 


\section{Table A-12}

PROPYLENE/PROPANE SEPARATION WITH MEMBRANE/DISTILLATION HYBRID TECHNOLOGY: ESTIMATED ANNUAL OPERATING COSTS AND REVENUE REQUIREMENTS (Basis: $95 \%$ propylene; 500 million lb product per year)

\begin{tabular}{|c|c|c|c|}
\hline & $\begin{array}{l}\text { Thousands } \\
\text { of Dollars } \\
\text { Per year }\end{array}$ & $\begin{array}{l}\text { Cents per } \\
\text { Pounc of } \\
\text { Propylene }\end{array}$ & $\begin{array}{l}\text { Percent } \\
\text { of Total }\end{array}$ \\
\hline Maintenarive materials & 243 & 0.049 & 3.1 \\
\hline \multicolumn{4}{|l|}{ Labor } \\
\hline $\begin{array}{l}\text { Operating } \\
\text { Supervision } \\
\text { Maintenance } \\
\text { Benefits }\end{array}$ & $\begin{array}{r}39 \\
52 \\
304 \\
138 \\
\end{array}$ & $\begin{array}{l}0.008 \\
0.010 \\
0.061 \\
0.028\end{array}$ & $\begin{array}{l}0.5 \\
0.7 \\
3.9 \\
1.7\end{array}$ \\
\hline Total labor & 533 & 0.107 & 6.8 \\
\hline \multicolumn{4}{|l|}{ Utilities } \\
\hline $\begin{array}{l}\text { Steam } \\
\text { Electric power } \\
\text { Cooling water }\end{array}$ & $\begin{array}{r}2,677 \\
542 \\
159 \\
\end{array}$ & $\begin{array}{l}0.535 \\
0.108 \\
0.032\end{array}$ & $\begin{array}{r}33.9 \\
6.9 \\
2.0 \\
\end{array}$ \\
\hline Total utilities & 3,378 & 0.675 & 42.8 \\
\hline \multicolumn{4}{|l|}{ Fixed costs } \\
\hline $\begin{array}{l}\text { Corporate costs } \\
\text { General and administrative expenses } \\
\text { Properly taxes and insurance }\end{array}$ & $\begin{array}{r}158 \\
79 \\
304 \\
\end{array}$ & $\begin{array}{l}0.032 \\
0.016 \\
0.061\end{array}$ & $\begin{array}{l}2.0 \\
1.0 \\
3.9\end{array}$ \\
\hline Total fixed costs & 541 & 0.108 & 6.9 \\
\hline Total operating costs & 4.694 & $\underline{0.934}$ & 59.5 \\
\hline Capital-related charges and income tax & 3.193 & 0.638 & 40.5 \\
\hline Total processing cost & 7,887 & 1.572 & 100.0 \\
\hline
\end{tabular}


Appendix B

UTILITY REQUIREMENTS AND COST BREAKDOWNS FOR CASE STUDY 2 - NITROG N REMOVAL FROM NATURAL GAS 
STAND-ALONE MEMBRANE SYSTEM 
Table B-1

UTILITY REQUIREMENTS FOR N2 REMOVAL WITH MEMBRANE TECHNOLOGY ALONE (basls: 8 MMcfd feed rate)

\begin{tabular}{|c|c|c|}
\hline & \multicolumn{2}{|c|}{ Utullty } \\
\hline & Water & Electrlalty \\
\hline $\begin{array}{l}\text { Mass flow } \\
\text { (Ib/Mct gas) }\end{array}$ & 0.0 & - \\
\hline $\begin{array}{l}\text { Energy flow } \\
\text { (1000 Btu/Mct gas) }\end{array}$ & - & 0.0 \\
\hline $\begin{array}{l}\text { Thermal energy equivalent* } \\
\text { (1000 Btu/Mcf gas) }\end{array}$ & - & 0.0 \\
\hline Autil (1000 Btu/Mcf gas) & 0.0 & 0.0 \\
\hline
\end{tabular}

Table B-2

CAPITAL INVESTMENT FOR $\mathrm{N}_{2}$ REMOVAL WITH MEMBRANE TECHNOLOGY ALONE (basis: 8 MMcid feed rate)

Process Unit

Membrane unit

General services

Total
Installed Cost (smillions)
$\$ 0.64$
0.09
$\$ 0.73$ 
Table B-3

N2 REMOVAL WITH MEMBRANE TECHNOLOGY:

ESTIMATED ANNUAL OPERATING COSTS AND PROCESSING COST

(basls: 8 MMcfd feed rate)

Unrecovered methane

Maintenance materials

\section{Labor}

Operating labor

Supervision

Maintenance labor

Benefits

Total labor

\section{Thousands \\ of Dollars \\ per Year}

903

15

13

5

18

13

49

Utilitles

Electric power

Cooling water

Total utilities \begin{tabular}{l}
0 \\
0 \\
\hline
\end{tabular}

0
s//Mcf qas

0.73

0.01

0.01

0.00

0.01

0.01

0.04

0.00

0.00

0.00

0.01

0.01

0.02

0.80

0.27

1.07
Percent

of Total

68.2

1.1

Fixed costs

General and administrative expenses

Property taxes and insurance

Total fixed costs

1324

1.0

0.4

1.4

1.0

3.7

Total operating costs

Capital-related charges and income tax

Total processing cost

991

333

18

25

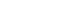

0.0

0.0

0.0 
STAND-ALONE PSA SYSTEM

B-5 


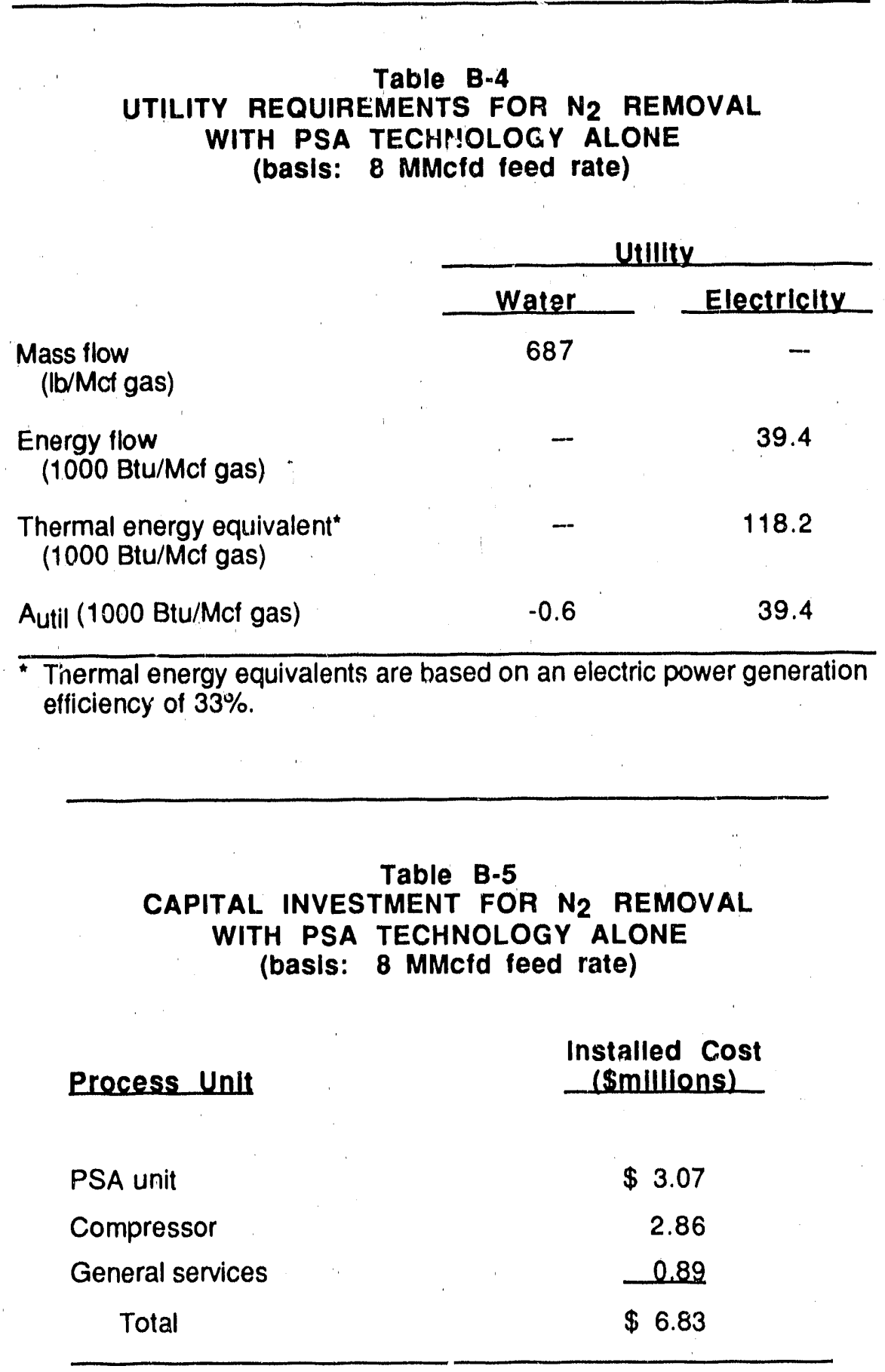

\section{B-6}




\section{Table B-6}

N2 REMOVAL WITH PSA TECHNOLOGY:

ESTIMATED ANNUAL OPERATING COSTS AND PROCESSING COST (basis: 8 MMcid feed rate)

Unrecovered methane

Malntenance materlals

Labor

Operating labor

Supervision

Maintenance labor

Benefits

Total labor

UtIIItles

Electric power

Cooling water

Total utilities
Thousands

of Dollars

per Year

303

137

13

28

171

74

285

1077

9

1085

\section{s/Mcf gas}

0.16

0.02

0.01

0.02

0.09

e.04

0.15

0.58

e.00

0.58

0.02

0.09

0.11

1.09

0.94

2.03
Percent

of Total

8.0

1.0

Fixed costs

General and administrative expenses

Property taxes and insurance

Total fixed costs

Total operating costs

Capital-related charges and income tax

Total processing cost $\begin{array}{r}42 \\ 171 \\ \hline\end{array}$

213

2023

1745

3768
0.3

0.7

4.5

2.0

7.6
28.6

l.2

28.8 
HY B - 1

B-8 


\section{Table $8-7$}

UTILITY REQUIREMENTS FOR N2 REMOVAL WITH HYB-1

(basis: 8 MMcfd feed ate)

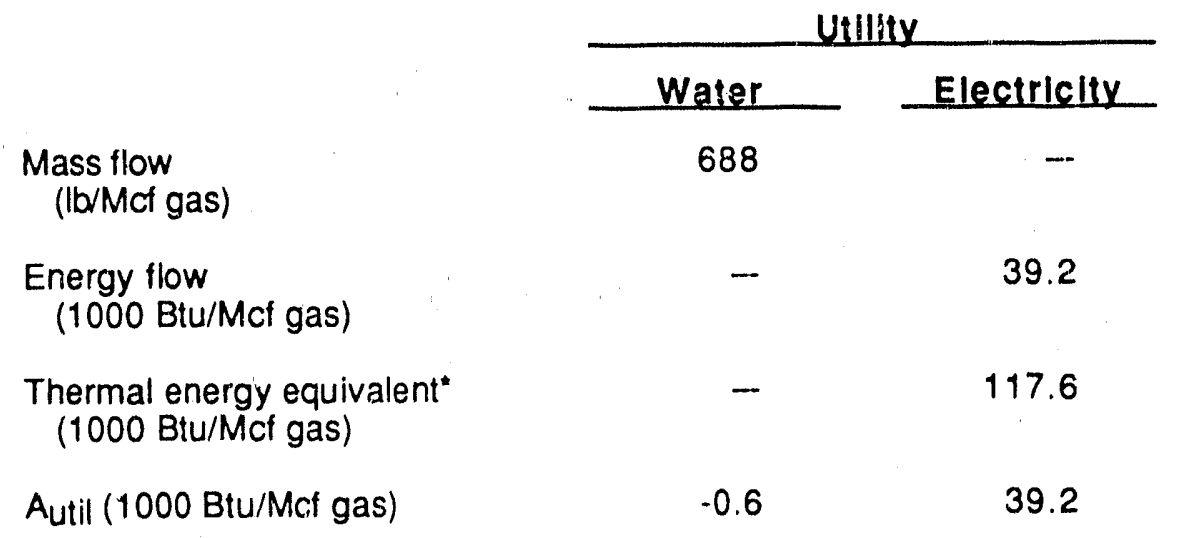

- Thermal energy equivalents are based on an electric power gentration efficiency of $33 \%$.

Table B-8

CAPITAL INVESTMENT FOR N2 REMOVAL WITH HYB-1

(basis: 8 MMcfd feed rate)

Process Unit

PSA unit

Compressor

Membrane unit

General services

Total
Installed Cost

(smlllons)
$\$ 2.52$
2.44
0.31
0.79
$\$ 6.07$ 


\section{Table B-9}

$\mathrm{N}_{2}$ REMOVAL WITH HYB-1:

ESTIMATED ANNUAL OPERATING COSTS AND PROCESSING COST (basis: 8 MMcfd feed rate)

\begin{tabular}{|c|c|c|c|}
\hline Unrecovered methane & 653 & 0.44 & 17.6 \\
\hline Malntenance materials & 121 & 0.08 & 3.3 \\
\hline \multicolumn{4}{|l|}{ Labor } \\
\hline $\begin{array}{l}\text { Operating labor } \\
\text { Supervision } \\
\text { Maintenance labor } \\
\text { Benefits }\end{array}$ & $\begin{array}{r}13 \\
25 \\
152 \\
66 \\
\end{array}$ & $\begin{array}{l}0.01 \\
0.02 \\
0.10 \\
0.04\end{array}$ & $\begin{array}{l}0.4 \\
0.7 \\
4.1 \\
1.8\end{array}$ \\
\hline Total & 256 & 0.17 & 6.9 \\
\hline \multicolumn{4}{|l|}{ Utilities. } \\
\hline $\begin{array}{l}\text { Electric power } \\
\text { Cooling water }\end{array}$ & $\begin{array}{r}863 \\
7 \\
\end{array}$ & $\begin{array}{l}0.58 \\
0.00 \\
\end{array}$ & $\begin{array}{r}23.3 \\
0.2 \\
\end{array}$ \\
\hline Total utilities & 870 & 0.58 & 23.5 \\
\hline \multicolumn{4}{|l|}{ Fixed costs } \\
\hline $\begin{array}{l}\text { General and administrative expenses } \\
\text { Property taxes and insurance }\end{array}$ & $\begin{array}{r}38 \\
152 \\
\end{array}$ & $\begin{array}{l}0.03 \\
0.10 \\
\end{array}$ & $\begin{array}{l}1.0 \\
4.1 \\
\end{array}$ \\
\hline Total fixed costs & 189 & 0.13 & 5.1 \\
\hline Total operating costs & 2090 & 1.39 & 56.4 \\
\hline Capital-reiated charges and income tax & 1614 & 1.08 & 43.6 \\
\hline Total processing cost & 3704 & 2.47 & 100.0 \\
\hline
\end{tabular}

Thousands

of Dollars

per Year

25

152

Maintenance labor

Total

Electric power

Total utilities

General and administrative expenses

Total fixed costs

Total operating costs

Capital-reiated charges and income tax

Total processing cost
S/Mct gas

Percent

of Total

7.6

0.7

4.1

6.9 
H Y B - 2

B-11 


\section{Table B-10 \\ UTILITY REQUIREMENTS FOR N2 REMOVAL WITH HYB-2 \\ (basls: 8 MMcfd feed rate)}

\begin{tabular}{|c|c|c|}
\hline & \multicolumn{2}{|c|}{ Utility } \\
\hline & Water & Electricity \\
\hline $\begin{array}{l}\text { Mass flow } \\
\quad \text { (lb/Mct gas) }\end{array}$ & 560 & -- \\
\hline $\begin{array}{l}\text { Energy flow } \\
(1000 \text { Btu/Mcf gas })\end{array}$ & - & 24.8 \\
\hline $\begin{array}{l}\text { Thermal energy equivalent } \\
\text { (1000 Btu/Mcf gas) }\end{array}$ & - & 74.5 \\
\hline Autil (1000 Btu/Mcf gas) & -0.5 & 74.5 \\
\hline
\end{tabular}

* Thermal energy equivalents are based on an electric power generation efficiency of $33 \%$.

Table B-11

CAPITAL INVESTMENT FOR N2 REMOVAL WITH HYB-2

(basis: 8 MMcfd feed rate)

Process: Unit

Membrane unit

Compressor \#1

PSA unit

Compressor \#2

General services

Total
Installed Cost

(smWlens) 


\section{Table $B-12$ \\ N2 REMOVAL WITH HYB-2: \\ ESTIMATED ANNUAL OPERATING COSTS AND PROCESSING COST (basis: 8 MMcfd feed rate)}

\section{Unrecovered methane \\ Maintenance materials \\ Labor \\ Operating labor \\ Supervision \\ Maintenance labor \\ Benefits}

Total labor

\section{Utilities}

Electric power

Cooling water

Total utilities

\section{Thousands \\ of Dollars \\ per Year}

140

126

13

26

158

69

265

740

7

747

39

158

197

Total fixed costs

Total operating costs

Capital-related charges and income tax

Total processing cost

\section{$\$$ s/Mcf gas}

0.07

0.06

0.01

0.01

0.08

0.03

0.13

0.37

0.00

0.37

0.02

e. 8

0.10

0.73

0.82

1.55
Percent

of Total

4.5

4.0

0.4

0.8

5.0

2.2

8.4
23.6

0.2

23.8
1.2

5.0

6.3

47.1

52.9

100.0 
H Y B -3

B-14 
Table B-13

UTILITY REQUIREMENTS FOR N2 REMOVAL WITH HYB-3

(basls: 8 MMcfd feed rate)

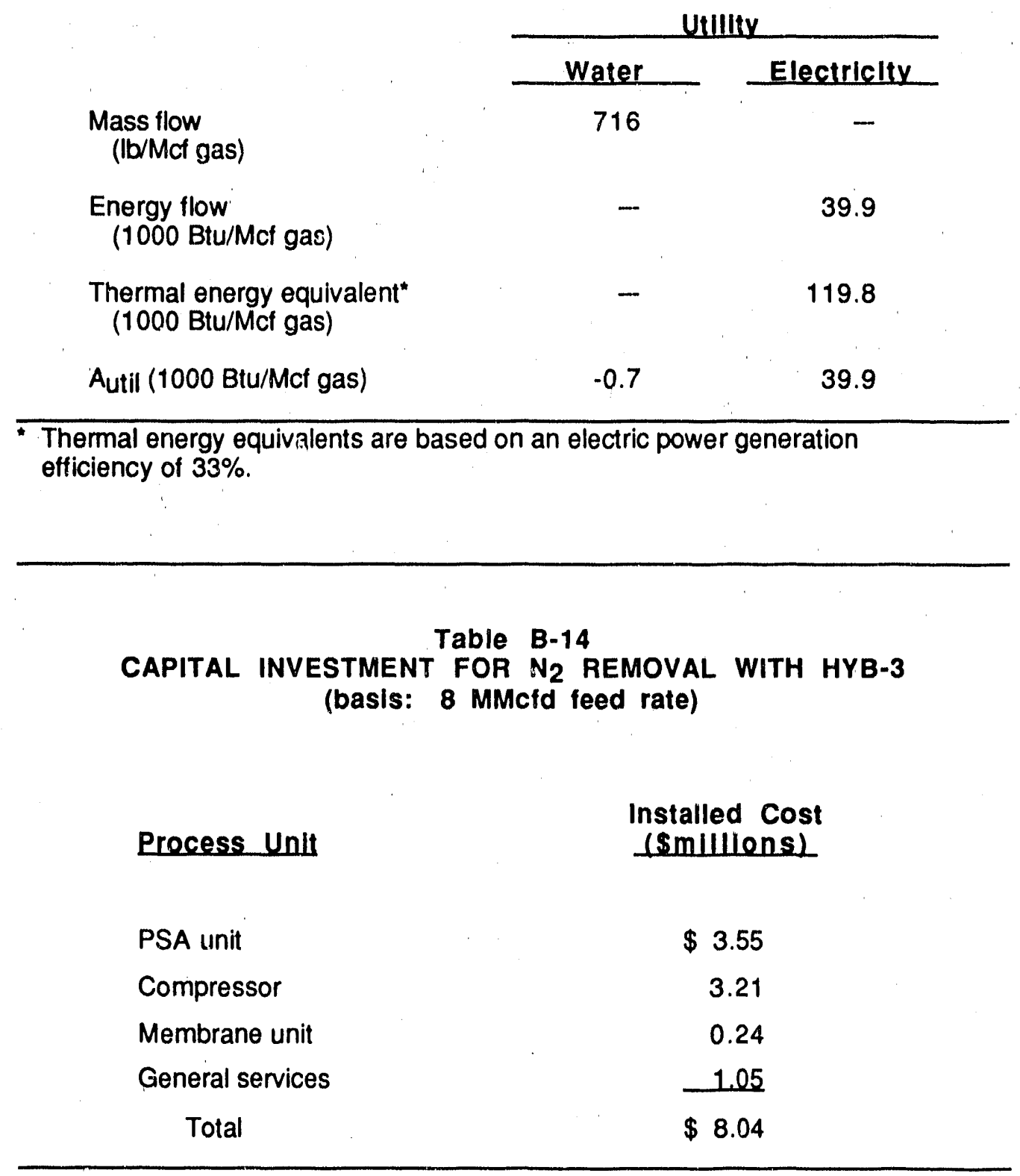


Table B-15

N2 REMOVAL WITH HYB-3:

ESTIMATED ANNUAL OPERATING COSTS AND PROCESSING COST (basis: 8 MMcfd feed rate)

\begin{tabular}{|c|c|c|c|}
\hline$\cdot$ & $\begin{array}{l}\text { Thousands } \\
\text { of Dollars } \\
\text { per Year }\end{array}$ & s//Mcf gas & $\begin{array}{l}\text { Percent } \\
\text { of Total }\end{array}$ \\
\hline Unrecovered methane & 40 & 0.02 & 1.0 \\
\hline Maintenance materials & 161 & 0.08 & 3.9 \\
\hline \multicolumn{4}{|l|}{ Labor } \\
\hline $\begin{array}{l}\text { Operating labor } \\
\text { Supervision } \\
\text { Maintenance labor } \\
\text { Benefits }\end{array}$ & $\begin{array}{r}13 \\
32 \\
201 \\
86 \\
\end{array}$ & $\begin{array}{l}0.01 \\
0.02 \\
0.09 \\
0.04 \\
\end{array}$ & $\begin{array}{l}0.3 \\
0.8 \\
4.9 \\
2.1\end{array}$ \\
\hline Total labor & 333 & 0.16 & 8.1 \\
\hline \multicolumn{4}{|l|}{ Utilities } \\
\hline $\begin{array}{l}\text { Electric power } \\
\text { Cooling water }\end{array}$ & $\begin{array}{r}1250 \\
10 \\
\end{array}$ & $\begin{array}{l}0.59 \\
e .00\end{array}$ & $\begin{array}{r}30.5 \\
0.2 \\
\end{array}$ \\
\hline Total utilities & 1261 & 0.59 & 30.8 \\
\hline \multicolumn{4}{|l|}{ Fixed costs } \\
\hline $\begin{array}{l}\text { General and administrative expenses } \\
\text { Property taxes and insurance }\end{array}$ & $\begin{array}{r}49 \\
201 \\
\end{array}$ & $\begin{array}{l}0.02 \\
0.09 \\
\end{array}$ & $\begin{array}{l}1.2 \\
4.9 \\
\end{array}$ \\
\hline Total fixed costs & 250 & 0.12 & 6.1 \\
\hline Total operating costs & 2044 & 0.96 & 49.9 \\
\hline Capital-related charges and income tax & 2054 & 0.96 & 50.1 \\
\hline Total processing cost & 4098 & 1.92 & 100.0 \\
\hline
\end{tabular}


Appendix C

UTILITY REQUIREMENTS AND COST BREAKDOWNS FOR CASE STUDY 3 CONCENTRATION OF KBL. 
STAND-ALONE EVAPORA'TION SYSTEM

C-2 


\section{Table C-1}

UTILITY REQUIREMENTS FOR KBL CONCENTRATION WITH EVAPORATION TECHNOLOGY ALONE

(BasIs: $990,000 \mathrm{lb} / \mathrm{hr}$ weak KBL; $750 \mathrm{TPD}$ pulp mill)

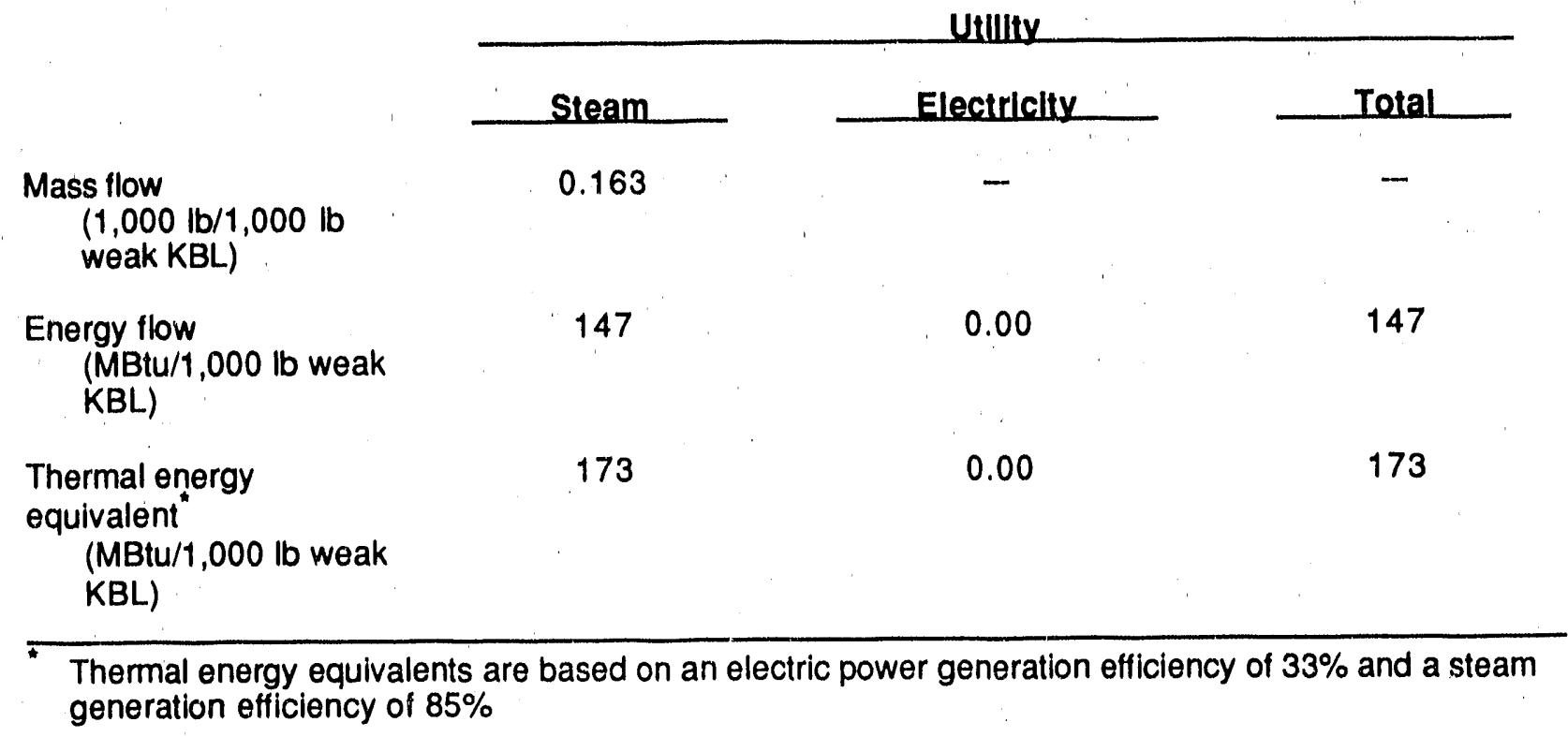

Table C.2

CAPITAL INVESTMENT FOR KBL CONCENTRATION WITH EVAPORATION TECHNOLOGY ALONE

(Basis: $990,000 \mathrm{lb} / \mathrm{hr}$ weak KBL; 750 TPD pulp mIII)

\section{Process Unlt}

Evaporator

General Services

Total
Installed Cost

(smillion)

$\$ 3.60$

0.54

$\$ 4.14$ 


\section{Table C-3}

KBL CONCENTRATION WITH EVAPORATION TECHNOLOGY:

ESTIMATED ANNUAL OPERATING COSTS AND PROCESSING COST

(Basls: $990,000 \mathrm{lb} / \mathrm{hr}$ weak KBL; 750 TPD pulp mill)

Salt cake

Malntenance Materials

Labor

Operating labor

Supervision

Maintenance labor

Benefits

Total labor

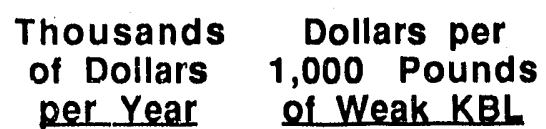

per Year

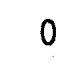

83

Utilities

Steam

Electric power

Total utilities

Fixed costs

General and administrative expenses

Property taxes and insurance

Total fixed costs

Total operating costs

Capital-related charges and income tax

Total processing cost

39

21

104

58

222

2,549

0

2,549

33

104

136

2,990

1,199

0.005

0.003

0.013

$\underline{0.007}$

0.028

0.326

0.000

0.326

0.004

$\underline{0.013}$

0.017

0.382

0.153

0.536

4,189
60.8

0.0

60.8
Percent

of Totai

0.0

2.0

0.9

0.5

2.5

1.4

5.3

100.0 
REVERSE OSMOSIS/EVAPORATION HYBRID SYSTEM $\left(\phi_{\mathrm{RO}}=\mathbf{0 . 2 8 2}\right)$ 


\section{Table C.4}

UTILITY REQUIREMENTS FOR KBL CONCENTRATION WITH

RO/EV HYBRID TECHNOLOGY

(Basis: $\phi R O=0.282 ; 990,000 \mathrm{lb} / \mathrm{hr}$ weak KBL; $750 \mathrm{TPD}$ pulp)

\begin{tabular}{lccc} 
& \multicolumn{3}{c}{ Utillty } \\
Mass flow (1,000 lb/ 1,000 lb weak KBL) & Steam & Electriclty & Total \\
Energy flow (MBtu/ 1,000 lb weak KBL) & 0.094 & - & - \\
Thermal energy equiva-lent ${ }^{*}$ (MBtu/ 1,000 lb weak KBL) & 99.6 & 26.6 & 126 \\
\hline
\end{tabular}

Thermal energy equivalents are based on an electric power generation efficiency of $33 \%$ and a steam generation efficiency of $85 \%$

Table C-5

CAPITAL INVESTMENT FOR KBL CONCENTRATION WITH

RO/EV HYBRID TECHNOLOGY

(Basis: $\phi R O=0.282 ; 990,000 \mathrm{lb} / \mathrm{hr}$ weak KBL; $750 \mathrm{TPD}$ pulp)

Process Unlt

Reverse osmosis unit

Membrane \#1

(replacement cost $=0.43$ )

Pump \#1

Membrane \#2

(replacement cost $=0.37$ )

Pump \#2

Total

Evaporator

General services

Total
Installed Cost

(\$million)

$\$ 1.04$

0.40

0.89

0.13

$\$ 2.45$

2.31

0.71

$\$ 5.47$

C-6 
Table C.6

SOLVENT DEASPHALTING WITH RO/EV HYBRID TECHNOLOGY:

ESTIMATED ANNUAL OPERATING COSTS AND PROCESSING COST

(Basis: $\phi R O=0.282 ; 990,000 \mathrm{lb} / \mathrm{hr}$ weak $\mathrm{KBL} ; 750 \mathrm{TPD}$ pulp)

Salt cake

Malntenance Materials

Labor

Supervision

Maintenance labor

Benefits

Total labor
Operating labor

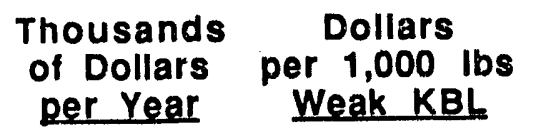

41

109

66

30

137

81

314

1,464

1.019

2,483

Total utilities

Flxed costs

General and administrative expenses

Property taxes and insurance

Total fixed costs

Total operating costs

Capital-related charges and income tax

Total processing cost

$\begin{array}{rll}46 & 0.006 & 0.9 \\ 137 & 0.018 & 2.7 \\ 183 & 0.023 & 3.6 \\ 3,131 & 0.401 & 61.5 \\ 1.958 & 0.250 & 38.5 \\ 5,089 & 0.651 & 100.0\end{array}$

Percent

of Total

0.8

2.1

1.3

0.6

2.7

1.6

6.2

0.040

28.8

20.0

48.8

0.187

$\underline{0.130}$

0.318

0.9

2.7

3.6

61.5

38.5

100.0 
FREEZE CONCENTRATION/EVAPORATION HYBRID SYSTEM

$\left(\phi_{\mathrm{FC}}=\mathbf{0 . 6 7 0}\right)$ 


\section{Table C.7}

UTILITY REQUIREMENTS FOR KBL CONCENTRATION WITH

FC/EV HYBRID TECHNOLOGY

(Basis: $\phi F C=0.670 ; 990,000 \mathrm{lb} / \mathrm{hr}$ weak $\mathrm{KBL} ; 750 \mathrm{TPD}$ pulp)

Mass flow $(1,000 \mathrm{lb} / 1,000 \mathrm{lb}$ weak $\mathrm{KBL})$

Energy flow (MBtu/ 1,000 lb weak KBL)

Thermal energy equivalent" (MBtu/ 1,000 lb weak KBL)
Utility

\begin{tabular}{cccc}
\hline Steam & Electricity & Total \\
\cline { 1 - 1 } 0.037 & & -- & \\
33.2 & & 22.3 & 55.5 \\
39.0 & & 66.9 & 106 \\
\hline
\end{tabular}

Table C.8

CAPITAL INVESTMENT FOR KBL CONCENTRATION WITH

FC/EV HYBRID TECHNOLOGY

(Basis: $\phi F C=0.670 ; 990,000 \mathrm{lb} / \mathrm{hr}$ weak $\mathrm{KBL} ; 750 \mathrm{TPD}$ pulp)

Process Unit

Freeze concentrator

Evaporator

General services

Total
Installed Cost

(smillion)

$\$ 16.80$

1.21

2.70

$\$ 20.72$

C-9 


\section{Table C.9}

KBL CONCENTRATION WITH FC/EV HYBRID TECHNOLOGY:

ESTIMATED ANNUAL OPERATING COSTS AND

PROCESSING COST

(Basis: $\phi F C=0.670 ; 990,000 \mathrm{lb} / \mathrm{hr}$ weak KBL; $750 \mathrm{TPD}$ pulp)

Salt cake

Maintenance Materials

Labor

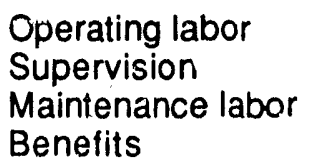

Total labor

$\begin{array}{cc}\text { Thousands } & \text { Dollars per } \\ \text { of Dollars } & 1,000 \text { Pounds } \\ \text { per Year } & \text { of Weak KBL }\end{array}$

68

414

105

93

518

251

968

574

2.564

3,137

143

$\underline{518}$

661

5,249

5.218

10,467

0.401

0.085

0.668

1.339
0.009

0.053

0.013

0.012

0.066

0.032

0.124

\section{Percent}

of Total

0.6

4.0

1.0

0.9

4.9

2.4

9.2

1.4

Total operating costs

50.1

Capital-related charges and income tax

49.9

Total processing cost

100.0 
REVERSE OSMOSIS/FREEZE CONCENTRATION/EVAPORATION HYBRID SYSTEM

$\left(\phi_{\mathrm{RO}}=0.282 ; \phi_{\mathrm{FC}}=\mathbf{0 . 3 8 8}\right)$ 
Table C-10

UTILITY REQUIREMENTS FOR KBL CONCENTRATION WITH RO/FC/EV HYBRID TECHNOLOGY

\begin{tabular}{|c|c|c|c|c|}
\hline & \multicolumn{4}{|c|}{ Utility } \\
\hline & \multirow[b]{2}{*}{ Steam } & \multicolumn{2}{|c|}{ Electricity } & \multirow[b]{2}{*}{ Total } \\
\hline & & Membrane & FC & \\
\hline $\begin{array}{l}\text { Mass flow }(1,000 \mathrm{lb} / 1,000 \mathrm{lb} \text { weak } \\
\text { KBL) }\end{array}$ & 0.037 & - & -- & - \\
\hline $\begin{array}{l}\text { Energy Flow (MBtu/1,000 lb weak } \\
\text { KBL) }\end{array}$ & 33.2 & 8.9 & 8.9 & 51.0 \\
\hline $\begin{array}{l}\text { Thermal energy equivalent } \\
(\mathrm{MBtu} / 1,000 \mathrm{lb} \text { weak } \mathrm{KBL})\end{array}$ & 39.0 & 26.6 & 26.8 & 92.4 \\
\hline
\end{tabular}

Table C.11

CAPITAL INVESTMENT FOR KBL CONCENTRATION WITH RO/FC/EV HYBRID TECHNOLOGY

\section{Process Unit}

Reverse osmosis unit

Membrane \#1

(replacement cost $=0.43$ )

Pump \#1

Membrane \#2

(replacement cost $=0.37$ )

Pump \#2

Total

Freeze concentrator

Evaporator

General services

Total
Installed Cost

(\$million)

$\$ 1.04$

0.40

0.89

0.13

$\$ 2.45$

7.65

1.21

1.70

$\$ 13.01$ 


\section{Table C.12}

KBL CONCENTRATION WITH RO/FCIEV HYBRID TECHNOLOGY: ESTIMATED ANNUAL OPERATING COSTS AND PROCESSING COST

\section{Salt cake}

Maintenance Materials

Labor

Operating labor

Supervision

Maintenance labor

Benefits

Total labor

\begin{tabular}{cc}
$\begin{array}{c}\text { Thousands } \\
\text { of Dollars }\end{array}$ & $\begin{array}{c}\text { Dollars per } \\
1,000 \text { Pounds } \\
\text { per Year }\end{array}$ \\
\hline
\end{tabular}

68

260

131

69

325

184

709

0.009

0.033

0.017

0.009

0.042

0.024

0.091
0.073

0.261

0.335

2,618

105

325

430

4,085

$\underline{3.787}$

7,872
0.013

0.042

0.055

0.523

2.484

1.007
Percent

of Total

0.9

3.3

1.7

0.9

4.1

2.3

$9: 0$

Total operating costs

Capital-related charges and income tax

Total processing cost 


\section{Appendix D}

DISTILLATION DATA, UTILITY REQUIREMENTS, AND

COST BREAKDOWNS FOR CASE STUDY 4 - SOLVENT DEASPHALTING

D-1 
Table D-1

DISTILLATION DATA FOR DEASPHALTED OIL FRACTION

USED IN DAO PROPERTY ESTIMATION

Volume \% Distllled

$$
\begin{aligned}
& 0.5 \\
& 5.0 \\
& 10 \\
& 20 \\
& 30 \\
& 40 \\
& 50
\end{aligned}
$$

\section{Iemperature ( $\left.{ }^{\circ} \mathrm{F}\right)$}

575

705

760

825

880

930

980

Distillation method: ASTM D1160

API gravity: 19.2 
EVAPORATION SYSTEM

D-4 
Table D.2

UTILITY REQUIREMENTS FOR SOLVENT RECOVERY IN SOLVENT DEASPHALTING WITH EVAPORATION TECHNOLOGY ALONE

(Basis: 95\% DAO, 100,000 lb DAO/hr)

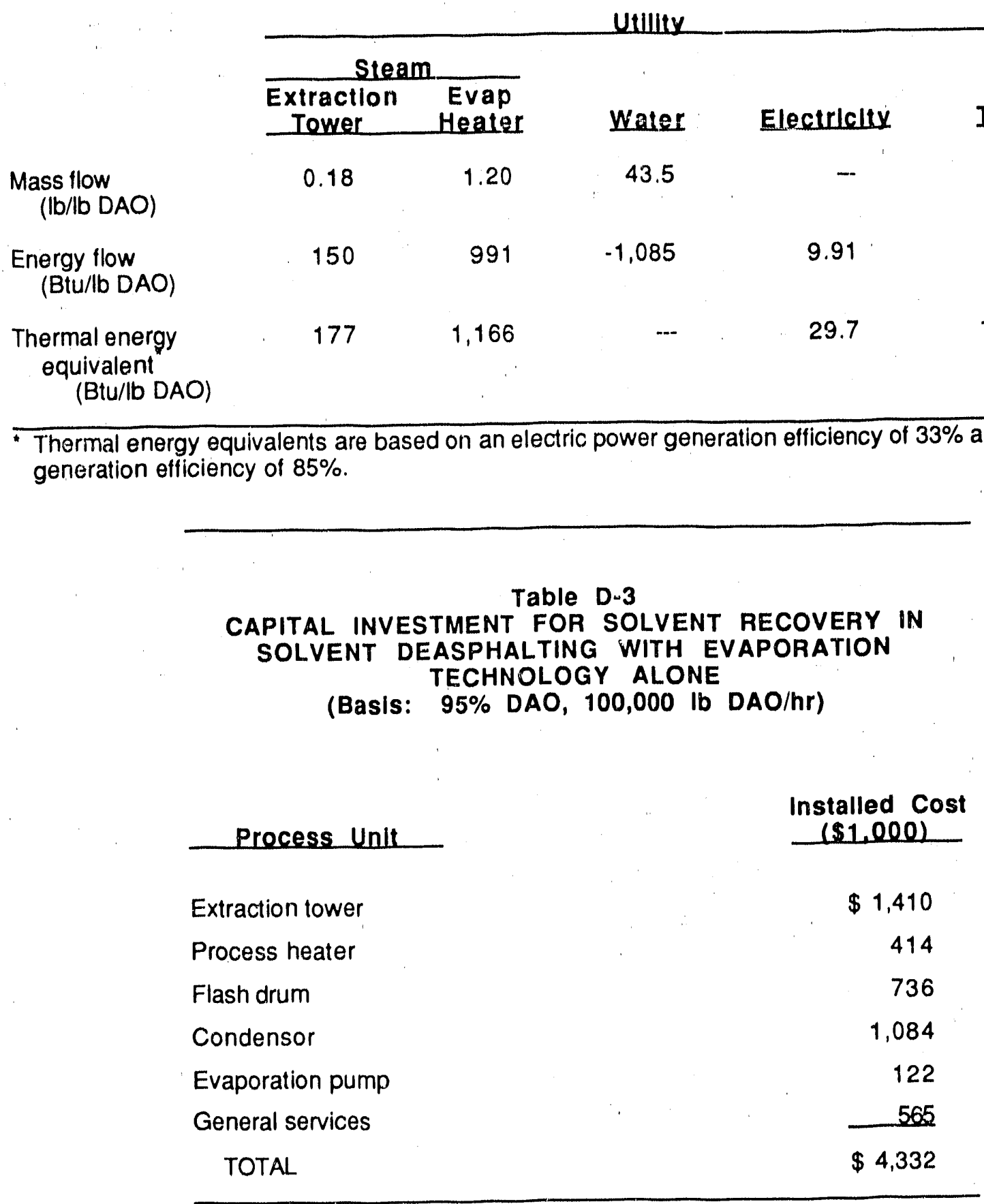

D-5 
Table D-4

SOLVENT DEASPHALTING WITH EVAPORATION TECHNOLOGY: ESTIMATED ANNUAL OPERATING COSTS AND PROCESSING COST (Basls: 95\% DAO, 100,000 lb DAO/hr)

\section{Malntenance materials}

Thousands

\section{of Dollars}

per Year

\section{Dollars per \\ Pound \\ of DAQ}

Percent

of Total

\section{Labor}

Operating labor

Supervision

Maintenance labor

Benefits

$$
\$ 87
$$

$\$ 0.011$

1.1

Total labor

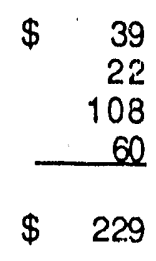

$\$ 0.005$

0.003

0.014

0.008

0.5

0.3

1.4

60

$\$ .029$

2.8

2.9

\section{Utilities}

Steam

Electric power

Cooling water

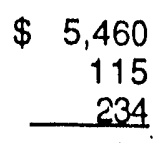

$\begin{array}{r}0.691 \\ 0.015 \\ 0.030 \\ \hline\end{array}$

68.9

1.5

3.0

Total utilities

$\$ 5,808$

$\$ 0.736$

73.3

Fixed costs

Corporate costs

General administrative expenses

Property taxes and insurance

Total fixed costs

Total annual operating costs

Capital-related charges and income tax

Total processing cost
$\$ \quad 159$

34

234

$\$ \quad 301$

$\$ 6,425$

$\$ 1.503$

$\$ 7,928$
$\$ \quad 0.020$ 0.004

0.014

$\$ \quad 0.038$

$\$ 0.814$

$\$ \quad 0.190$

\$. 1.004
2.0

0.4

14

3.8

81.0

19.0

100.0 
HYBRID SYSTEM

$\left(\phi_{m}=\mathbf{0 . 5 0}\right)$

D-7 


\section{Table D-5}

UTILITY REQUIREMENTS FOR SOLVENT RECOVERY IN SOLVENT DEASPHALTING WITH MEMBRANE/EVAPORATION HYBRID TECHNOLOGY

(Basis: $\phi_{m}=0.5 ; 95 \%$ DAO; 100,000 lb DAO/hr)

\begin{tabular}{|c|c|c|c|c|c|c|}
\hline & \multicolumn{6}{|c|}{ Utility } \\
\hline & \multicolumn{2}{|c|}{ Steam } & \multirow[b]{2}{*}{ Water } & \multicolumn{2}{|c|}{ Electriclty } & \multirow[b]{2}{*}{ Iotal } \\
\hline & $\begin{array}{l}\text { Extractlon } \\
\text { Tower }\end{array}$ & $\begin{array}{c}\text { Evap } \\
\text { Heater }\end{array}$ & & $\begin{array}{l}\text { Memb } \\
\text { Pump }\end{array}$ & $\begin{array}{l}\text { Evap } \\
\text { Pump }\end{array}$ & \\
\hline $\begin{array}{l}\text { Mass flow } \\
\text { (Ib/lb DAO) }\end{array}$ & 0.044 & 0.337 & 11.2 & -- & - & $\rightarrow$ \\
\hline $\begin{array}{l}\text { Energy flow } \\
\text { (Btu/lb DAO) }\end{array}$ & 36.4 & 278 & -279 & 23.6 & 2.86 & $\cdots$ \\
\hline $\begin{array}{l}\text { Thermal energy } \\
\text { equivalent } \\
\text { (Btu/lb DAO) }\end{array}$ & 42.8 & 327 & - & 70.8 & 8.58 & 449 \\
\hline
\end{tabular}

Table D-6

CAPITAL INVESTMENT FOR SOLVENT RECOVERY IN SOLVENT DEASPHALTING WITH MEMBRANE/EVAPORATION HYBRID TECHNOLOGY

(Basis: $\phi m=0.5,95 \%$ DAO: $1,000 \mathrm{lb} \mathrm{DAO} / \mathrm{hr}$ )

\begin{tabular}{lr}
\multicolumn{1}{c}{ Process Unit } & $\begin{array}{r}\text { Installed Cost } \\
(\$ 1.000)\end{array}$ \\
\hline Membrane unit & $\begin{array}{r}\$, 863 \\
\text { Membrane pump }\end{array}$ \\
Extraction tower & 296 \\
Process heater & 146 \\
Flash drum & 591 \\
Condensor & 344 \\
Evaporation pump & 38 \\
General services & 1,097 \\
TOTAL & $\$ 8,409$ \\
\hline Membrane replacement $=\$ 1,610,000$ &
\end{tabular}

D-8 
Table D-7

SOLVENT DEASPHALTING WITH MEMBRANE/EVAPORATION HYBRID

TECHNOLOSYY: ESTIMATED ANNUAL OPERATING COSTS AND REVENUE

REQUIREMENTS

(Basis: $\phi_{m}=0.5 ; 95 \%$ DAO, 100,000 lbs DAO/hr)

Malntenance materials

Labor

Operating labor

Supervision

Maintenance labor

Benefits

Total labor
Thousands of Dollars

per Year

$\$ 168$

$\$ 0.021$

$\$ 0.005$

0.005

0.027

0.013

$\$ 388$

$\$ 0.049$

$\$ 1,504$

307

60

$\$ 1,871$
Total utilities

Steam

Electric power

Cooling water

\section{costs}

Corporate costs

General administrative expenses

Property taxes and insurance

Total fixed costs

Total annual operating costs

Capital-related charges and income tax

Total processing cost
$\$ 138$

57

210

$\$ 0.020$

0.007

0.027

2.0

0.8

3.0

$\$ \quad 406$

$\$ 0.051$

$-5.9$

$\$ 2,833$

$\$ 0.359$

41.0

$\$ 4.082$

$\$ 0.517$

59.0

$\$ 6,914$

\$ 0.876

100.0

D-9 

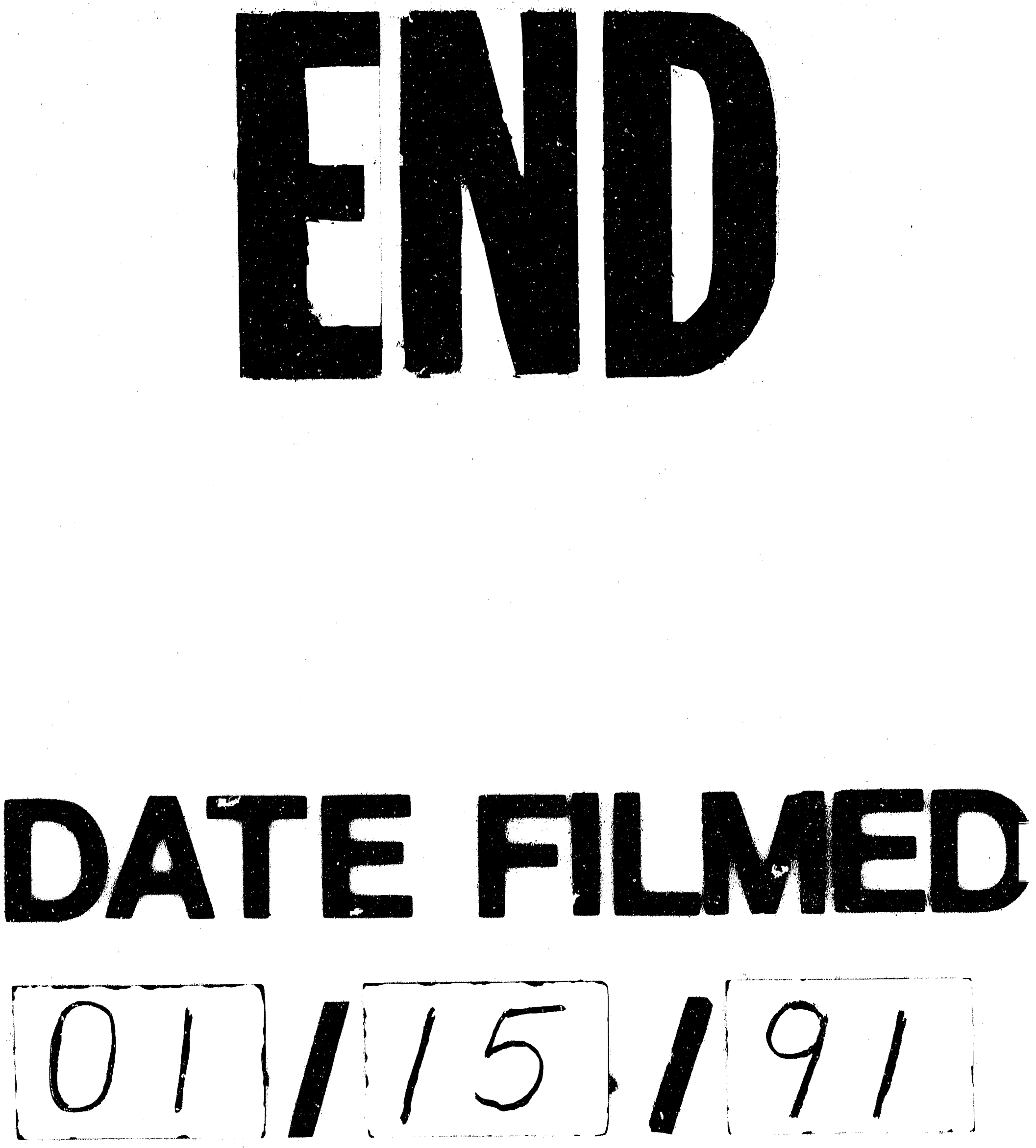
